\title{
THE DAIRY HERD HEALTH AND PRODUCTIVITY SERVICE
}

\author{
JAMES MILLER KELLY
}

\author{
DVM\&S \\ The University of Edinburgh
}

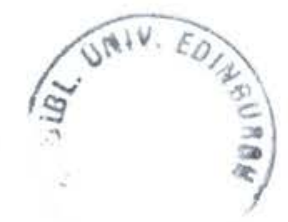




\section{DECLARATION}

I declare that this thesis and the work presented herein was done entirely by myself unless otherwise indicated.

James Miller Kelly

June 2001 


\section{Acknowledgements}

This work would not have been possible without the help and cooperation of a great many people. During my time in the Department of Veterinary Clinical Studies I was initially encouraged in the establishment of the Dairy Herd Health and Productivity Service by the late Professor Gordon Ferguson. During the past years the continuation and development of the service has always had the enthusiastic support of Professor Richard Halliwell and other colleagues.

David Whitaker has been involved with me in operating the DHHPS over twenty years and I have been fortunate in having such a committed and enthusiastic colleague. Grateful thanks are also due to Alex Dowell who has been in charge of the laboratory analysis over the entire length of the project and has diligently overseen the introduction of new equipment, new assays and has supervised the quality control. He has been ably assisted by a number of technical staff over this period.

Sandra Smith has been of invaluable help in providing assistance with the analysis, collation and presentation of a vast amount of data.

I am grateful to Kath Tracey for assistance with the final typing of this thesis.

Thanks are also due to many large animal veterinary practitioners who for many years have been staunch supporters of the project.

I gratefully acknowledge our sponsors, initially Spillers Agriculure and then for the greater part of the time Dalgety Agriculture. Without their financial backing and the involvement of their nutritional advisers and other support staff the operation of the DHHPS would not have been possible.

Most important of all the service could not have functioned without the key participants, the farmers, whose enthusiastic support I gratefully acknowledge.

On a personal basis I would like to thank my late wife Elizabeth who was a constant source of inspiration and encouragement to me in all I attempted to achieve. 


\begin{abstract}
Herd health and reproduction have been ranked as top priorities for improving the future productivity and profitability of dairy enterprises. There is a multitude of genetic, disease, nutritional, management and physiological issues that can dramatically alter health and reproduction. It is generally agreed that a multidisciplinary approach is necessary if improvement is to be achieved. Herd health schemes have evolved in the dairy industry throughout the world but the uptake of such schemes in the UK has been low. The veterinary input to many dairy farms is at best routine fertility visits confined to examination of the reproductive tract, and at worst occasional emergency calls. The Dairy Herd Health and Productivity Service (DHHPS) was established to provide the opportunity for veterinary surgeons to lead a multidisciplinary team which can monitor health, fertility and production and can plan remedial action, when necessary. Over a period of twenty years it has continued to identify infertility, mastitis and lameness as the main reasons for the involuntary disposal of dairy cows, although on some farms BSE has been a major factor. The trend in the last few years has been for an increase in culling for reasons of disease rather than for age or yield. The average disease rates have remained consistently high with over 100 treatments per 100 cows each year. Infertility, mastitis and lameness are the most common disease problems on DHHPS farms.
\end{abstract}

Blood profiling and condition scoring have demonstrated that at least a third of cows tested were mobilising excessive fat during the transition from the dry period to early lactation. The DHHPS found $34.3 \%$ of 9,235 dry cows, sampled 0 14 days before calving and 28 per cent of 20,502 cows between 5-40 days post calving, had raised BHB blood concentrations. 30.6 per cent of the same dry cows and 21.9 per cent of the early lactation animals had elevated NEFA results.

Blood urea was measured to reflect the current protein intake and the protein /energy balance of the ration. 14 per cent of 9325 dry cows and 9.5 per cent of 20502 of early lactation cows had low urea $\mathrm{N}(<1.7 \mathrm{mmol} / \mathrm{l}) .25$ per cent of the cows sampled between 5-40 days post partum had blood urea nitrogen concentrations above $3.3 \mathrm{mmol} / 1$. 
Low magnesium levels were detected throughout the year. 9.2 per cent of 9235 dry cows and 7 per cent of 19,738 early lactation cows between 5-40 days calved had blood magnesium concentration $<0.8 \mathrm{mmol} / \mathrm{l}$.

GSHPx was used as an indicator of selenium status. 16.3 per cent of 1,206 heifers and 4.9 per cent of 6,998 cows had low GSHPx results

Metabolic profiling can assist in identifying possible nutritional imbalances, but is likely to be most effective when it is carried out as part of a full, systematic investigation of the nutritional status of the herd.

A survey of farmers and veterinary surgeons who have been involved with DHHPS indicated that they are receiving considerable benefits from the service. The service, by combining techniques such as computerised data recording and preplanned blood analysis, provides regular information on disease occurrence, adequacy of nutrition and management in relation to productivity and economic performance. The main reason for its success was the team approach. The DHHPS has facilitated the solving of complex problems by encouraging multidisciplinary participation and affords the opportunity for the veterinary practitioner to become involved in giving positive advice on animal health. 


\section{TABLE OF CONTENTS}

Page

CHAPTER 1 Introduction 1

CHAPTER 2 5

$2.1 \quad$ Historical Aspects of Preventive Medicine 5

$2.2 \quad$ Phase Two in Development of Preventive Medicine 8

2.3 The Development of Herd Health and Productivity Schemes 10

$\begin{array}{lll}2.4 & \text { The Use of the Computer } & 13\end{array}$

2.5 The Principal Problems Identified by Health Schemes The Holistic Approach 15

$2.6 \quad$ Review of the Development of The Dairy Cow 16

2.7 The Criteria Which Influence the Ability of a Herd to Achieve Optimum Productivity 16

$\begin{array}{lll}2.7 .1 & \text { Genetic Potential } & 17\end{array}$

2.7.2 Digestion and Metabolism 19

$\begin{array}{lll}2.7 .3 & \text { Nutrient Requirements } & 21\end{array}$

$\begin{array}{lll}\text { 2.7.3.1 } & \text { Energy Requirements }\end{array}$

2.7.3.2 Protein Requirements 23

$\begin{array}{lll}\text { 2.7.3.3 } & \text { Fibre } & 24\end{array}$

2.7.3.4 Minerals 25

$\begin{array}{lll}\text { 2.7.3.5 Vitamins } & 25\end{array}$

$\begin{array}{lll}2.7 .3 .6 & \text { Water } & 26\end{array}$

2.7.3.7 Dry Matter Intake (DMI) 26

$\begin{array}{lll}\text { 2.7.3.8 } & \text { Feeds For Dairy Cows } & 27\end{array}$

2.7.3.8.1 Concentrate 28

$\begin{array}{lll}\text { 2.7.3.8.2 } & \text { Forages } & 28\end{array}$

$\begin{array}{lll}2.7 .3 .8 .2 .1 & \text { Grazing } & 28\end{array}$

$\begin{array}{llr}\text { 2.7.3.8.2.2 } & \text { Silage } & 29\end{array}$

2.7.3.8.2.3 Ensiled Whole Crop Cereals 30

$\begin{array}{lll}2.7 .3 .8 .2 .4 & \text { Hay } & 31\end{array}$

$\begin{array}{lll}2.7 .3 .8 .2 .5 & \text { Straw } & 31\end{array}$

2.7.3.8.2.6 Forage Legumes and Other Green Foods 31

2.7.3.9 Feed Management Strategies $\quad 32$

$\begin{array}{lll}\text { 2.7.3.9.1 } & \text { Feeding To Yield }\end{array}$

$\begin{array}{lll}\text { 2.7.3.9.2 Lead Feeding } & 33\end{array}$

$\begin{array}{lll}\text { 2.7.3.9.3 } & \text { Flat Rate Feeding } & 33\end{array}$

2.7.3.9.4 Complete Diets or Total Mixed Rations (TMR) 33

2.7.3.9.5 Buffer Feeding 34

$\begin{array}{lll}\text { 2.7.3.9.6 Dry Cow Feeding } & 34\end{array}$

2.7.4 Management and Environment 35

2.7.4.1 Housing systems $\quad 35$

$\begin{array}{lll}2.7 .5 & \text { Disease } & 38\end{array}$

2.7.5.1 Metabolic Disease $\quad 39$

$\begin{array}{lll}\text { 2.7.5.1.1 Ketosis } & 39\end{array}$ 
$\begin{array}{lll}\text { 2.7.5.1.2 } & \text { Milk Fever } & 40\end{array}$

2.7.5.1.3 Hypomagnesaemia (grass tetany) 41

2.7.5.1.4 Acidosis $\quad 42$

$\begin{array}{lll}\text { 2.7.5.2 Mastitis } & 42\end{array}$

2.7.5.3 Fertility 44

2.7.5.3.1. Energy Deficiency and Fertility 44

2.7.5.3.2 Protein and Fertility 45

2.7.5.3.3 Minerals and Reproductive Performance 46

2.7.5.3.4 Trace Elements 46

2.7.5.3.5 Vitamins and Reproductive Performance 47

$\begin{array}{lll}\text { 2.7.5.4 Lameness } & 47\end{array}$

2.7.5.4.1 Nutritional or Metabolic Factors 48

2.7.5.4.2 Environmental and Behavioural effects $\quad 49$

2.7.5.4.3 Infectious Causes of Lameness 49

$\begin{array}{lll}2.8 & \text { Assessing nutritional status } & 50\end{array}$

2.8.1 Dry Matter Intake $\quad 50$

2.8.2 Calculated Energy Balance $\quad 50$

$\begin{array}{ll}2.8 .3 & \text { Faecal Consistency }\end{array}$

2.8.4 Cud Chewing 51

2.8.5 Body Condition Scoring 51

2.8.6 Milk Yield 52

2.8.7 Milk Quality $\quad 52$

2.8.8 Metabolic Profiles $\quad 53$

2.8.8.1 Energy Status 56

2.8.8.1.1 Glucose 56

2.8.8.1.2 Ketone Bodies 57

2.8.8.1.3 Non-esterified Fatty Acids (NEFA's ) or Free Fatty

2.8.8.2 Protein Status 61

2.8.8.2.1 Urea $\quad 61$

$\begin{array}{lll}\text { 2.8.8.2.2 Albumin } & 62\end{array}$

$\begin{array}{lll}\text { 2.8.8.2.3 Globulin } & 63\end{array}$

$\begin{array}{lll}\text { 2.8.8.3 } & \text { Mineral Status } & 63\end{array}$

$\begin{array}{lll}\text { 2.8.8.3.1 Calcium } & 63\end{array}$

$\begin{array}{lll}\text { 2.8.8.3.2 } & \text { Magnesium } & 63\end{array}$

$\begin{array}{lll}\text { 2.8.8.3.3 Phosphorus } & 63\end{array}$

$\begin{array}{lll}\text { 2.8.8.3.4 } & \text { Trace elements } & 64\end{array}$

$\begin{array}{lll}\text { 2.8.8.3.4.1 Copper } & 64\end{array}$

2.8.8.3.4.2 Selenium (Glutathione peroxidase (GSHPx)) 64

2.8.8.3.4.4 Iodine (Thyroxine (T4)) 64

2.8.9 Milk Profiles $\quad 64$ 


\section{CHAPTER 3}

3.1

Fig 3.1

Establishment of the DHHPS

66

3.2

How the service operates

67

3.2 .1

Materials and Methods

68

3.2 .2

Farmers are recruited according to the following criteria

68

The veterinary surgeon's commitments are:

68

3.2 .3

The nutritional adviser

68

3.2 .4

Procedure for new DHHPS members

69

Fig 3.2 Sheet 1

70

3.2 .5

Statistics

71

Results $\quad 72$

3.3

Number of DHHPS members

72

3.3.1

Fig 3.3 Number of DHHPS members during each year

$\begin{array}{lll}\text { Fig 3.3 Number of DHHPS members during each year } & 72\end{array}$

Fig 3.4 Number of years current members have been on DHHPS

73

Cow breeds from DHHPS farms

74

Table 3.1 Cow breeds from 309 Sheet 1's to May $1998 \quad 74$

3.3.3

Herd Size at May 1998

74

Fig 3.5 Herd size range of DHHPS farms. Data collected from 316 DHHPS Sheet 1's

Milk yields in DHHPS herds

Fig 3.6 Varying milk yields of DHHPS farms, data collected from 305 DHHPS Sheet 1's

Forage feeding systems

Fig 3.7 Feeding systems used by DHHPS farmers, data collected from 294 Sheet 1's

Discussion

The Farmer

The Veterinary Practitioner

Reasons for Leaving the Service

\section{CHAPTER 4}

4.1

4.2

4.2.1

Fig 4.1

4.2.2

Fig 4.2

4.3.1

Table 4.1

Monthly Data Input

Materials and Methods

Sheet 2 (Fig 4.1)

81

Sheet 2

Quarterly Herd Health Report (Fig 4.2)

82

84

85

86

Results

86

Cull Rates

86

Fig 4.3 Changes in Voluntary and Involuntary Culling between 1980 and 1988, shown as percentages of total disposal 
$\begin{array}{lll}\text { 4.3.1.1 } & \text { Reasons for Culling } & 88\end{array}$

$\begin{array}{lll}\text { 4.3.1.2 } & \text { Voluntary Culling } & 88\end{array}$

4.3.1.3 Involuntary Culling 88

4.3.2 Treatment rates for all areas for 12 month periods 89

4.3.2.1 Fertility treatment $\quad 89$

4.3.2.2 Mastitis annual treatment rates $\quad 89$

$\begin{array}{lll}\text { 4.3.2.3 Digestive disease } & 89\end{array}$

4.3.2.4. Ketosis $\quad 89$

$\begin{array}{llr}\text { 4.3.2.5 Hypocalcaemia } & 89\end{array}$

$\begin{array}{lll}\text { 4.3.2.6 Hypomagnesaemia } & 90\end{array}$

$\begin{array}{lll}\text { 4.3.2.7 Lameness } & 90\end{array}$

$\begin{array}{lll}4.3 .2 .8 & \text { Other } & 90\end{array}$

$4.4 \quad$ Discussion 90

Table 4.2 Treatment rates between 1980 and 1998 shown as a
percentage of total treatments

$\begin{array}{ll}4.5 & \text { Reproductive Performance } \\ & 100\end{array}$

CHAPTER 5

5.1

5.1 .1

5.1 .2

5.1 .3

5.1 .4

5.1.5

Fig 5.1

5.1.6

Fig 5.2

5.1.7

5.1.7.1

5.1.7.2

5.1.8

5.1.8.1

5.1.8.2

5.1.8.3

5.1 .9

5.1 .10

5.2

Fig 5.4

5.2.1

Fig 5.5
Materials and Methods

104

Selection of Cows for Blood Sampling 104

Timing of blood tests

104

Some Suggested Blood Sampling Times 105

Blood Sampling Procedure 105

Biochemical Analysis

105

107 optimal values

107

108

109

109

109

110

111

111

111

112

113

113

114

115

115 1997 
Fig 5.6 Mean butterfat values per month with 95\% Confidence Intervals. Data taken from Friesian and Holstein herds blood sampled between January 1993 and May 2000. Ranges from 46-294 herds per month, average 159.

Fig 5.7 Mean Milk Protein values per month with 95\% Confidence Intervals. Data taken from Friesian and Holstein herds blood sampled between January 1993 and May 2000. Ranges from 46-294 herds per month, average 159.

Fig 5.8 Blood Test Results Sheet showing high globulins

Fig 5.9 Typical composition of grass and maize silages (Dalgety Agriculture)

Fig 5.11 Percentage of cows/heifers within various weight ranges. Mean cow weight $651 \mathrm{Kg}$, mean heifer weight $576 \mathrm{Kg}$. Data from 1580 heifers and 6843 cows blood tested between March '97 and March '98

\subsection{Condition Score}

Table 5.1 Body Condition Score (c.s.) from dairy cows blood sampled between March 1997 and March 1998

Fig 5.12 Percentage of cows in various lactation groups with a condition score of 3.5 or higher

Table 5.2 Body Condition Score (c.s.) loss during transition from Dry to Early lactation. Data collected from 353 herds blood tested between March 1997 and March 1998

Fig 5.13 Blood Test Results sheet showing an example of milk yields below expectation

Blood Test Results sheet showing high concentrate DM and low forage DM 
Table 5.3 Percentage of cows with abnormal BHB results. Data collected from cows blood sampled between 1992 and 1998

Fig 5.15 Mean BHB values per month with 95\% Confidence Intervals. Data from cows blood sampled between 1993 and 1997

Fig 5.16 BHB in early lactation cows over years 1992-1998

5.2.4.1.2 Glucose

Table 5.4 Percentage of cows with Abnormal Glucose results. Data collected from cows blood tested between March 1992 and March 1998

Fig 5.17 Mean Glucose values per month with $95 \%$ Confidence Intervals. Data from cows blood sampled between 1993 and 1997

Non Esterified Fatty acid (NEFA)

Table 5.5 Percentage of cows with abnormal NEFA results. Data collected from cows blood tested between March 1992 and March 1998

Fig 5.18 Mean NEFA values per month with 95\% Confidence Intervals. Data from cows blood sampled between 1993 and 1997

Fig 5.19 Percentage of cows tested with elevated NEFA and BOHB parameters in Early lactation and Dry cows (\% in each category taken from over 9000 cows, sampled between March 1992 and March 1998

\section{2 .4 .2}

5.2.4.2.1

Table 5.6

Protein status

Urea Nitrogen

Percentage of cows with Abnormal Urea Nitrogen results. Data collected from cows blood tested between March 1992 and March 1998

Fig 5.20 Mean Urea values per month with $95 \%$ Confidence Intervals. Data from cows blood sampled between 1993 and 1997

Albumin

Table 5.7 Percentage of cows with abnormal Albumin results. Data collected from cows blood tested between March 1992 and March 1998

Fig 5.21 Blood Test Results sheet showing cows with low blood Urea $\mathrm{N}$

Fig 5.22 Mean Albumin values per month with 95\% Confidence Intervals. Data from cows blood sampled between 1993 and 1997
133

134

134

(1) 
Table 5.8 Percentage of cows with Abnormal Globulin results.

Data collected from cows blood tested between March 1992 and March 1998

Table 5.9 Percentage of cows with Abnormal Magnesium results. Data collected from cows blood tested between March 1992 and March 1998

Fig 5. 23 Mean Magnesium values per month with 95\% Confidence Intervals. Data from cows blood sampled between 1993 and 1997

Fig 5.24 Blood Test Results sheet showing low magnesiums in lactating and dry cows

Table 5.9 Percentage of cows with Abnormal Phosphate results. Data collected from cows blood tested between March 1992 and March 1998

Fig 5.25 Mean Phosphate (inorganic) values per month with 95\% Confidence Intervals. Data from cows blood sampled between 1993 and 1997

Table 5.10 Percentage of cows with Abnormal Copper results. Data collected from cows blood tested between March 1992 and March 1998

Fig 5.26 Mean Copper values per month with 95\% Confidence Intervals. Data from cows blood sampled between 1993 and 1997

\subsection{Glutathione Peroxidase (GSHPx)}

Table 5.11 Percentage of cows/heifers with abnormal GSHPx results. Data collected from cows blood tested between March 1992 and March 1998

Fig 5.27 Mean GSHPx values per month with 95\% Confidence Intervals. Data from cows blood sampled between 1993 and 1997 
CHAPTER 6

DHHPS Survey - Introduction 150

6.1 Materials and Methods 150

Dairy Herd Health and Productivity Service -

Farmer's Questionnaire

$151-154$

6.2 Dairy Herd Health and Productivity Service Vet's Questionnaire

Results

6.2.1 Response Rate 159

Table 6.1 Numbers of questionnaires distributed and returned 159

6.2.2

Length of involvement

159

Table 6.2 How long participants have been members 159

6.2 .3

Number of herds vet involved with

160

Table 6.3 Number of herds each veterinary surgeon has as DHHPS members

160

Regional Distribution

160

$\begin{array}{lll}\text { Table 6.4 Number of farms in each region } & 160 \\ & \text { Neason for joining DHHPS } & 161\end{array}$

$\begin{array}{lll}6.2 .5 & \text { Reason for joining DHHPS } & 161 \\ & \text { Why farmer joined DHHPS } & 161\end{array}$

$\begin{array}{lll}\text { Table } 6.5 & \text { Why farmer joined DHHPS } & 161\end{array}$

Table 6.6 Decision to join DHHPS 161

\subsection{6}

Nutritional Advice $\quad 162$

$\begin{array}{lll}\text { Table } 6.7 & \text { Nutritional advice on farm } & 162\end{array}$

\begin{tabular}{ll} 
Table 6.8 & Main source of nutritional advice \\
\hline
\end{tabular}

Table 6.9 Veterinary competence regarding nutritional advice 163

$\begin{array}{lll}\text { Table 6.10 Undergraduate education } & 163\end{array}$

6.2.7

Farmer's perception of their veterinary surgeon $\quad 163$

Table 6.11 Perception of veterinary surgeon 163

6.2.8 Factors which influence the success of a health scheme $\quad 164$

$\begin{array}{ll}\text { Figure 6.3 Main reason for a successful service } & 164\end{array}$

6.2.9 Opinion of the Dairy Herd Health and Productivity Service 165

$\begin{array}{ll}\text { Fig 6.4 Opinion of blood test and profiles } & 165\end{array}$

Fig 6.5 Opinion of presentation of results 166

$\begin{array}{ll}\text { Fig 6.6 Opinion of letter of interpretation } & 166\end{array}$

Fig 6.7 Opinion of speed of turn around 167

$\begin{array}{lll}6.2 .10 & \text { Team Meeting } & 168\end{array}$

$\begin{array}{ll}\text { Fig 6.8 Opinion of team meeting } & 168\end{array}$

$\begin{array}{ll}\text { Fig 6.9 Opinion of discussion form } & 168\end{array}$

Fig 6.10 Opinion of vet participation in meeting (farmers only) 169

$\begin{array}{ll}\text { Fig 6.11 Opinion of ease of communication } & 169\end{array}$

$\begin{array}{lll}\text { Fig 6.12 Opinion of Sheet 2 \& Quarterly reports } & 171\end{array}$

Fig 6.13 Overall opinion of farmers of DHHPS 172

$\begin{array}{ll}\text { Fig 6.14 Overall opinion of vets of DHHPS } & 172\end{array}$ 
6.2.11 Do results reflect on farm situation

Table 6.15 Reflection of results and letter of interpretation on what is happening on farm

173

6.2 .12 Discussion report forms

Table 6.16 Use of Discussion Report Form

6.2.13 Improvement in profitability

Table 6.17 Payment for advice

Table 6.18 Profitability and setting goals

174

Table 6.19 Improvement in profitability

175

Table 6.20 Value for money

175

$\begin{array}{ll}\text { Benefits from Membership DHHPS } & 176\end{array}$

Table 6.21 Benefits to farmer

176

Table 6.22 Benefits to veterinary surgeon

176

Table 6.23

Integrated Services

177

6.2.15

Use of and Comparison with other services

177

Table 6.24 Other services

177

Table 6.25 Comparison of other services with DHHPS

177

Table 6.26 Use of DAISY

178

Table 6.27 Routine health visits

CONCLUSIONS

REFERENCES

\section{APPENDIX 1 Barn Sheet}

\section{APPENDIX $2 \quad$ Blood test report}

\section{RELEVANT PUBLICATIONS}

Changes in serum B hydroxybutyrate concentrations in dairy cows kept under commercial farm conditions (1977).

A dairy herd health and productivity service (1988).

Multidisciplinary approach to dairy herd health and productivity management (2000). 
Chapter One 


\section{INTRODUCTION}

Dairy farming is the largest single enterprise in the UK agriculture accounting for $22 \%$ in value of all agricultural output (Castle and Watkins, 1979). During the past 25 years the UK dairy industry has undergone many changes. Among the more dramatic has been the marked increase in milk production from individual cows. Whereas the number of dairy herds in the country has decreased sharply the size of herds has increased accordingly.

Until the introduction of milk quotas to the UK in 1984 there were almost the same number of cows producing more milk on a smaller number of intensively farmed units. Since 1984 there has been a decline in absolute cow numbers as well as in the number of farms.

Milk marketing has been deregulated and the farmer is able to sell milk to the buyer of their choice. The milk price is governed by a large number of factors many of which are out with the control of the producer.

The discovery of Bovine Spongiform Encephalopathy in 1986 has resulted in cases being confirmed in some $63 \%$ of dairy farms in the UK with the slaughter of over 170,000 dairy cows. This and the subsequent cohort cull has had a dramatic effect on the dairy industry.

Now the problem has become not so much to produce more but to produce with greater economic efficiency in order to maintain a level of profitability. Although the tendency to go for higher yields abated with the introduction of milk quotas it would now appear that the dairy industry in the UK is following the trend of pig and poultry farming over the past years, with the emphasis on fewer larger units aiming for maximum economic production. The increased use in the UK dairy industry of semen and embryos from continental and North American Holstein sires would indicate the trend towards high producing cows whose health status becomes more and more problematical, especially when nutritional inputs are continually constrained by economic considerations.

With changes in husbandry, the pattern of disease has also altered. The classical epidemic infectious disease had a single causal agent. Two of the major infectious diseases, tuberculosis and brucellosis, are under control or are at least 
susceptible to control measures, and their economic importance has been superseded by production diseases such as infertility, mastitis and lameness. Some of these diseases do not produce overt clinical disease and are classed as subclinical. The causes of these diseases are multifactorial and their control is likely to involve a multi-disciplinary approach.

It has long been recognised that the fire brigade approach to farm animal practice will not be effective in solving these herd problems and that maintenance of the health of the whole herd must be the correct objective.

Health is defined by the World Health Organisation as "a state of complete physical, mental and social well being and not merely the absence of disease or infirmity". The ultimate objective of the veterinary and all related professions is to maintain health. The public image of the veterinary surgeon is one of the restorer of health but they are generally less willing to accept the concept of health maintenance. This is a positive concept and means so much more than disease prevention. In the case of the dairy cow it implies an approach which will assist in the development of a vigorous state of health for growth, reproduction and longevity, having regard at all times to the animals' well-being and welfare.

Cow health embraces not only the infectious and non infectious diseases, but also the influence of genetic, nutritional and environmental factors. These in turn are likely to be influenced by husbandry, management and economics. It is therefore essential that any health programme must be broad based and flexible and not confined to a number of selected techniques such as vaccination or fertility examination. It is equally important that the programme is practical and is economically realistic.

The Swann Committee of Enquiry into the veterinary profession in the UK (Swann, 1975) indicated that the profession will be increasingly concerned with preventive medicine on the farm. 'This will include advice on husbandry and management for the purpose of maintaining and improving animal health and welfare, the productivity and profitability of the farm business, and the hygiene of its products'. The profession has found the transition to this preventive approach difficult. 
The veterinary practitioner is normally present on the farm more frequently than any other agricultural adviser and should be in the strongest position to initiate and lead a team approach to improving health and maintaining optimum profitability. Many were so involved with tuberculosis and brucellosis eradication schemes that they lost the initiative in establishing routine health programmes. Many have diversified and expanded their interest in companion animals. Some, who feel that their education did not prepare them for this advisory role, consider themselves vulnerable in matters of nutrition and productivity.

Herd health maintenance must be integrated with other management programmes on nutrition and breeding. Despite acknowledging the fundamental importance of nutrition, most veterinary schemes have concentrated on fertility and nutrition has been the province of feed advisers or agricultural specialists. It has become very clear that nutrition as well as infection plays an important part in animal health. Payne et al. (1970) and Blowey, Wood \& Davies (1973) showed how blood analysis might assist in the nutritional monitoring of dairy cows. This appeared to be an excellent way for veterinary surgeons to be positively involved in giving nutritional advice.

A herd health and productivity service must be capable of providing regular co-ordinated measurements of disease occurrence, overall health status, of adequacy of nutrition and management, productivity and economic performance and of comparing the results of these measurements with levels obtained by other dairy farms using similar management techniques.

It was with these aims in mind that the Dairy Herd Health and Productivity Service (DHHPS) was established. 
The objective of this thesis is:

1) To review the role of herd health in modern dairy practice

2) To describe the evolution of the DHHPS

3) To identify the major disease, nutritional and management problems in some of the larger dairy farms in the UK

4) To evaluate the use of preplanned blood sampling in herd health programmes.

5) To evaluate the advantages of such a service to the farmer and the other participants 
Chapter Two 
A brief consideration of the historical aspects of farm animal medicine helps to explain the development of bovine herd health programmes.

Herd health programmes for dairy cattle are not new! The animal plagues became particularly common in Europe in the mid- $18^{\text {th }}$ century with the introduction of rinderpest from Asia. When rinderpest entered England from Holland in 1714, Thomas Bates, surgeon to George 1, advocated fumigation of premises and owners were also compensated for loss. Half of the cattle in France were destroyed by rinderpest between 1710 and 1714 . The disease occurred spasmodically until 1750 when it again became a serious problem. Little was understood about this disease and other animal plagues. The awareness of the serious impact of these conditions was in part the stimulus for the establishment of the first veterinary school at Lyons in 1762. Alfort was founded in 1766, Hanover in 1778, London in 1791, Edinburgh in 1823 and Toulouse in 1825.

Public concern in the UK, highlighted by the rinderpest outbreak of 1865 , was responsible for the establishment of the Veterinary Department of the Privy Council Office, which was to be the forerunner of the Animal Health Division of the Ministry of Agriculture Fisheries and Food (MAFF, 1965). The main purpose of the original department was the control of cattle plague (rinderpest). The basic principles of proper diagnosis, isolation, slaughter, and control of movement and transit were extremely effective in eliminating the disease from Great Britain. To prevent further re-introduction of cattle plague, the Contagious Diseases (Animals) Act 1867 formalised the procedures for the inspection of cattle entering from a foreign country and the appointment of permanent inspectors for each local authority. The success of a regime of strict isolation and control of transit suggested that as well as cattle plague, pleuropneumonia, foot and mouth disease and other endemic diseases could also be controlled by legislation. To develop this ideal, the Contagious Diseases (Animals) Act 1869 provided comprehensive legislation for dealing with cattle plague, pleuropneumonia, foot and mouth disease, sheep scab and glanders, and any other disease which the Privy Council might specify. 
An innovation which has stood the test of time was introduced in 1875 in the form of a return of the number of places in Great Britain upon which a contagious or infectious disease had been reported to have existed during that week. This was prepared weekly by the Veterinary Department and published in the London Gazette. It was, therefore, recognised at an early stage in the development of veterinary preventive medicine that record keeping was of paramount importance.

By 1900 the Veterinary Department of the Board of Agriculture was functioning smoothly backed by powerful and comprehensive legislation, the 1894 Diseases of Animals Act.

With the eradication of cattle plague, pleuropneumonia and foot and mouth disease, it became obvious that other diseases, although less spectacular, were causing heavy losses to the dairy industry. The most obvious two were tuberculosis and contagious abortion.

In 1934 the Economic Advisory Council Committee on Cattle Diseases (The Gowland Hopkin's Committee) reported on practical measures to secure a reduction of disease among milking cattle in Great Britain, with emphasis on the value and practicability of methods of reducing the incidence of bovine tuberculosis and of improving the milk (MAFF, 1965). As some forty per cent of the bovines throughout the UK were affected this was a problem of some magnitude (Krebs et al., 1997). This was also a time when there was acute financial depression in the country. The Gowland Hopkin's Committee concluded that the total eradication of bovine tuberculosis was the only complete solution to the problem of tuberculous milk. As it was clearly not practical to slaughter all reactors at time of identification, the plan was to encourage a voluntary scheme so that at a later date, when the overall incidence of infection had been reduced to manageable proportions, it would be possible to introduce radical measures to get rid of the remainder. Farmers were encouraged to take part by providing financial incentives e.g. a premium was payable on milk from attested herds. In 1950 area eradication was introduced. Areas were selected in which the percentage of attested animals was already high. In these areas the animals were now tested free of charge, reactors were disposed of immediately and compensation was paid. The plan was very successful, and by 1960 
the whole of Great Britain became an attested area. It seemed that the control of this disease was one of the great public health success stories of the 20th century. The term eradication was used in the original plans but subsequent events appear to make it unlikely that this can be achieved in literal terms. At the end of the 1980 's, the rate of infection in cattle began to rise and has continued to do so ever since, with a total of 740 new herd incidents in 1998 and the consequent slaughter of 6068 cattle (MAFF, 2000). The Krebs' report (1997) reviewed the link between badgers and bovine TB. It concluded that badgers did contribute to cattle TB but that it was not possible to quantify the contribution they made. It is important to note that as a result of this report an independent scientific group recommended a holistic approach, recognising that a sustainable control policy can only be achieved when there is a better understanding of the epidemiology of TB in both cattle and wildlife reservoirs (Bourne et al., 2000).

Abortion was also common in cattle in the $19^{\text {th }}$ century, but the significance of brucellosis in animals as a public health hazard was not recognised until the early part of last century. In cattle it resulted in abortion, loss of milk and infertility. Prior to the Second World War there were limited eradication trials, but they were halted during the war years. In the post war years the main activity of the veterinary profession in Great Britain was the eradication of tuberculosis. It was not until post 1960 that surveys were made in order to identify problems, which may be faced in an eradication programme. A national survey, Leech et al. (1964), showed that 25 to 30 per cent of dairy herds contained infected animals. It was, however, estimated that there were only one or two infected animals in each diseased herd. Brinley-Morgan and Richards (1974) reviewed the diagnosis and eradication of brucellosis in Great Britain. By 1983 Great Britain was virtually free of the disease. Vaccination played a part over the years to reduce the weight of infection, but in later years it had to be strictly controlled to reduce serological complications during the eradication campaign.

These undoubtedly successful examples of disease control in cattle were possible because

a) They dealt with diseases of major economic or public health importance. 
b) Government was sufficiently convinced of their importance to invest public funds in paying farmers incentives to participate in eradication and to fund veterinary and laboratory expenses.

c) All diseases eradicated had a specific, single causal organism as epitomised by Koch's postulates, and by implication had a suitable control strategy directed against the causal agent.

d) Reliable diagnostic tests were available.

This then was the first stage of bovine preventive medicine.

\subsection{Phase Two in Development of Preventive Medicine}

The second stage really began with the increased value of farm livestock, which coincided with the Second World War. Before this time most veterinary work involved the horse and it was not until the decline in the use of horse power and the increase in value of farm livestock, that the veterinary surgeon gradually turned his attention to cattle, sheep and pigs (Henderson, 1960).

From the post war period the standard of living improved and the value of dairy products increased. The Milk Marketing Boards had been established in 1934 and dairy farming was becoming more stable and profitable. It became worth while to employ the veterinary surgeon to treat an individual animal.

During this time the veterinary surgeon became much better equipped to treat animal diseases. Education improved to match an explosion of new biological knowledge. Antibiotics and chemotherapeutics were introduced making the treatment of some bacterial diseases quite spectacular. New aseptic surgical techniques were developed and made caesarean section and abdominal surgery both practical and a sensible economic proposition for the farmer.

While this rapid expansion of large animal work was taking place many practices were short staffed and most veterinary surgeons were fully employed treating individual emergency cases, so called "fire brigade practice", and with keeping up with "Ministry Work" i.e. tuberculin and brucella testing. 
In the next stage, during the sixties, farmers and veterinary surgeons began to appreciate the value of taking positive action on maintaining normal health and efficient production on a herd basis.

In the UK dairy cow yields were increasing, the number of dairy herds was falling but individual units were keeping more cows (Dairy Facts and Figures, 1998).

As dairy farming became more intensive herd owners and their staff became much more knowledgeable. Many, especially of the younger generation had been to college or university. They were able to diagnose and treat many common diseases, such as milk fever, themselves. They were much more willing to cope with dystocia and routine tasks such as disbudding and foot trimming. They were also aware that disease could in some instances be prevented by vaccination, or changes in management or nutrition.

There was also a realisation that suboptimal productivity was not always only as a result of overt clinical disease but that subclinical disease was equally important in causing reduced performance. Sub-clinical disease in its broadest sense was soon recognised as a major cause of economic loss in food producing animals. During this period, the use of the word disease was expanded to include not only clinical and subclinical disease but also management inefficiency, all of which could result in suboptimal performance (Radostits, 1986). The inappropriateness of Koch's postulates as criteria for defining some of the syndromes suggested that more than one factor may operate in the production of a disease. A multifactorial theory of disease has developed which is equally applicable to non-infectious and infectious disease (Thrusfield, 1986).

The recognition that economic benefits could be derived from positive action against both clinical and sub-clinical disease provided the opportunity for the development of planned health programmes. Some veterinary surgeons took this opportunity, some were content to carry on the "fire-brigade" role and many preferred to concentrate on the ever-expanding opportunities in small animal and equine practice. 
The Development of Herd Health and Productivity Schemes

A lead towards the promotion of preventive medicine in the UK was taken by the Mid West Veterinary Association who investigated the advantages to the farmer of this approach (Grunsell et al., 1969). A committee was set up comprising representatives from the Veterinary Investigation Service, the National Advisory Service and the Departments of Agricultural Economics, Animal Husbandry, Veterinary Medicine and Surgery of Bristol University. A representative from the Animal Health Division joined for the last year of the scheme, which ran from 1964-1967.

This far-sighted approach resulted in one of the first recorded interdisciplinary herd or flock schemes. The proposed role of the veterinary profession in relation to the livestock industry was to be as follows:

A. The practitioner should be prepared to take an active interest in and hold the initiative for:

1. The diagnosis and treatment of disease in farm livestock.

2. The prevention of epidemic disease in all its forms.

3. The study of the influence of environment (nutrition, housing and management) on both the incidence of disease and on profitability.

4. The humane aspects of the above.

B. He should be in a position to contribute to advice on new production techniques and on general policy in respect of livestock farming.

C. When circumstances require expert advice the practitioner should be the person to decide which specialist service be consulted.

The main objective of the exercise was to investigate the financial advantage to the livestock of a preventive medicine in the above context by "before and after" measurements of productivity.

This scheme set out very desirable principles. The pilot study had many acknowledged limitations but provided an important basis for discussion as to the veterinary profession's role in this controversial field including the considerable problem of costing such a comprehensive service. 
This study concluded that the veterinarian requires more than just knowledge of the treatment of clinical disease. In many cases the veterinarian may need to enlist further expert help from nutritionists, farm buildings advisers, or farm management specialists who have some knowledge of farm economics.

Stimulated by this pilot scheme, the Ministry of Agriculture, Fisheries and Food (MAFF), the British Veterinary Association (BVA) and the Agricultural Development Advisory Service (ADAS), established a co-operative effort in preventive medicine known as the Joint Exercise in Animal Health and Productivity or Jointex (Anon, 1976). The Headquarters Liaison Committee made the following conclusions and recommendations.

The Joint Exercise in Animal Health and Productivity proved to be a success since its objectives were substantially accomplished.

1. On farms where potential existed and integrated advice was applied, overall significant improvement in health and productivity took place. The exercise led to closer cooperation between the Agricultural Development and Advisory Service (ADAS) and the Veterinary Profession, especially at farm level.

2. The exercise revealed some shortcomings in the collection of data.

3. It was recommended that existing record-keeping systems should be extended to include details of animal health and should be in a simple form acceptable to farmers, veterinarians and advisers alike. Such an extension would be an important factor in enabling farmers to recognise their problems.

4. Since further measures are taken to involve the Agricultural Departments and Veterinary Surgeons they would lead to better use of Agricultural Resources, in giving advice jointly throughout the UK.

The Swann Committee of Enquiry into the veterinary profession in the UK, Swann (1975), recommended the continuance and expansion of Jointex, the consideration of computerised recording, the collection and dissemination of the information from Jointex and a permanent scheme in which as a general principle veterinary surgeons in private practice should be employed as part-time members of the veterinary services of the government's agricultural departments for the purposes of running such a scheme. This extra involvement of the veterinary practitioner 
would have coincided neatly with the diminution of the routine brucella and tuberculin testing.

None of these recommendations have been followed. The prevailing economic circumstances have not been favourable for increased government funding of agriculture. Subsequent government policy has favoured rationalisation of government services and the reduction of subsidies to farmers. It does however remain as an excellent example of how the veterinary practitioner could get involved in preventive medicine.

Over the same period as these developments were taking place in the UK, herd health schemes for cattle were beginning to evolve in most of the major dairying regions throughout the world.

The early programmes which commenced in the 1960's involved regular scheduled visits to the herd where the focus of attention was on reproduction (Cote, 1963 and Morris, 1971). These visits also began to include discussion on management procedures related to mastitis control and calf diseases (Morris, 1971).

Morris (1971) suggested that the main factor determining the acceptability of disease control programmes to the dairy industry was the farmer's expected economic benefit from adopting the programme. Barfoot et al. (1971) examined the economic value of a herd health programme. The results indicated that the application was economically beneficial, and that the return on investment was related to, and increased with, the level of adoption by the farmer.

Morrow (1963), Barfoot et al. (1971), Blood et al. (1978), Whitaker (1978) and Harrington (1979) all described similar techniques and outlined the potential benefits of the herd health approach to the preventive medicine in dairy practice in USA, Canada and Australia.

Often the primary justification for the initiation of a herd health programme is to help to resolve a situation that is considered less than optimal (Blood et al., 1978). The overall goal of a herd health programme has been defined as the maintenance of animal health and production at the most efficient level that will provide economic returns to the farmer (Schnurrenbeger, 1979). In addition it is 
important that the veterinarian should continue to implement new techniques that will result in improved efficiency (Blaxter, 1979).

These concepts were incorporated by Moller (1978) in "Planned Animal Health and Production Services" (PAHAPS). The idea was to provide a veterinary service on a routine, scheduled basis, involving what the farmer perceived to be the healthy animals in the herd. There was a growing awareness of disease conditions that did not manifest themselves as clinical disease, yet resulted in decreased productivity. The effects of sub clinical disease, especially in the areas of mastitis and reproduction, became recognised as the most important impairment of production efficiency.

The need to be able to evaluate the status of the herd with respect to sub clinical disease led to the concept of targets of performance (Morris, 1971). It was emphasised that these targets of performance must be set as herd goals, as the approach is based on assessing the herd as a unit of performance. Performance targets must be defined in biological terms that are related to the economic efficiency of the herd. However, the assumption that biological targets are always equal to economic targets should not be made (Schmidt et al., 1986).

\section{$2.4 \quad$ The Use of the Computer}

In order to be able to evaluate the status of the herd level of health and performance the computer was introduced into herd health programmes. The use of computers in dairy herd health programmes was reviewed by (Lissemore, 1989). During the 1970's several mainframe computer-based data handling systems were developed that essentially dealt with reproductive performance. Through a cooperative effort with the University of Melbourne, the MELBREAD, herd health and fertility reporting scheme was developed by the Veterinary Epidemiology and Economics Research Unit (VEERU), University of Reading (Esslemont and Ellis, 1975). These early programmes entailed collection of data that had been recorded on farm, entry of these data into a mainframe and generation of herd analysis reports, which were then returned to the farmer and his veterinarian. The inevitable problems with this rather cumbersome system resulted in extensive redevelopment 
and transfer to a minicomputer system. In 1979 the latter system became known as DAISY (Esslemont et al., 1982). The use of a minicomputer greatly decreased the turn around time of reports.

In the UK other mainframe based programmes capable of creating herd management action lists and herd analysis reports were developed e.g. VIRUS Veterinary Investigation Recording User System - Martin et al. (1982) and COSREEL - Computerised System for Recording Events in Economically important Livestock- (Russel and Rowlands, 1983). The main limitation of these programmes was the distance of the computer from the data source and neither became widely implemented on a practical basis.

The rapid development of the microcomputer technology has led to the development of many microcomputer programmes for use in the dairy industry (Lissemore, 1989). Examples are Diarycomp 305 for use in Californian dairies (Goodger, 1987), Dairy CHAMP developed in Minnesota (Udomprasert and Williamson, 1990) and the Veterinary Automated Management Production and control Programme (VAMPP) in the Netherlands (Noordhuizen et al., 1986).

The effects of the use of microcomputers and dairy herd management software programmes on dairy farms and in veterinary practices has been evaluated (Menzies et al., 1988). They found that although more expensive to initiate, the computer on farm system was used to a greater extent than when the computer was bureau based. In general information generated by either system was found to be useful to both farmer and veterinary surgeon and 'computer phobia' was not a problem. There is however a need for veterinarians to address herd health schemes as the whole concept of supplying management information and advice, rather than just purchasing a computer and the necessary software (Wassell, 1995). Williamson (1986) also pointed out that a computer will not transform a poorly conceived herd health scheme into a useful one.

The success of any herd health programme will depend almost entirely on the interaction between the veterinary surgeon and the farmer acting on and reacting to the computer generated information (Radostits et al., 1994). 

Approach

Wassell and Esslemont (1992) in a review of herd health schemes identified the principal problems to be:

- Nutrition - Productive efficiency

- Fertility- reproductive efficiency

- Mastitis and lameness were the two main diseases of economic importance

Having defined nutrition as a major problem, they classified it as a specialist area usually left to specialist advisers or feed company representatives. Grunsell et al. (1969), Moller (1978) and Stephens et al. (1982), on the other hand, all argued for the holistic approach in which herd health schemes should encompass the whole farm enterprise. Any scheme, which does not look at management and nutrition as well as fertility and disease, is not going to be able to identify and solve the underlying cause of many of these main problem areas. Veterinarians who intend to serve their dairy clients on a herd basis must become actively involved in the herd's feeding programme (Gerloff, 1991). Veterinary practices that currently obtain a significant proportion of their income from the treatment of dairy cattle, will have to take on board the concept of preventive medicine in the form of herd health schemes if they choose to retain the dairy farms amongst their practice clients (Wassell, 1995).

Radostits and Blood (1985) identified two levels of specialization:

1. Herd health specialist who is aware of nutrition, production and breeding but would not deal with them themselves

2. Specialist skilled in all matters who would deal with the above themselves.

Most would agree that a health programme for dairy herds is defined as a planned and co-ordinated approach to achieving optimal health and productivity efficiency in livestock (Blood, 1979). Any successful herd health scheme must encompass the holistic approach which embraces all aspects of dairy cow health and nutrition. 
In order to play their part in the holistic approach to herd health the veterinary surgeon must understand the development of the dairy cow and her ever increasing nutritional requirements. This information is essential if the veterinary surgeon is going to play a full part in orchestrating the advice given to the farmer on all aspects of production disease.

The modern dairy cow is an elegant sophisticated machine designed to produce milk. The dairy cow is an efficient converter of forage, which man can not eat, and by-products which he does not choose to eat, into milk, an extremely high quality food. Refrigeration, rapid transportation, a more scientific understanding of the fermentation process and an awareness of the nutritive value of milk, especially for the young, have led to the development of the specialist dairy farm. The dairy cow has been likened to the highly charged racing car, which if prepared carefully, fuelled appropriately and driven with skill is capable of outstanding performance. If maintenance and inputs are less than optimum disaster can occur. The physiological demands of lactation for the high genetic merit cow are exceptional. Most welfare

problems can be attributed less to productivity per se than to systems of feeding, milking and management that are unsuitable to the genotype of the high yielding cow (Webster, 1993).

2.7 The Criteria Which Influence the Ability of a Herd to Achieve Optimum Productivity Are:

- Genetic potential

- Digestion and metabolism

- Nutrient requirements

- Management

- Environment

- Disease

Any planned coordinated approach must consider all these important criteria. 


\subsection{1}

\section{Genetic Potential}

During the past fifty years there has been a dramatic change in the breed type considered suitable for producing milk. The Dairy Shorthorn, which was popular in the first half of the last century, has largely been replaced by the Holstein/Friesian. In much of western Europe there has been an almost complete replacement of the black and white population by Holstein genes; whereas in the UK, partly because of our dual purpose industry, the replacement has occurred more slowly and is not yet complete (64\% Holstein in pedigree Holstein Friesian calves registered in 1993 (Hill et al., 1995)). The modern cow has been selected to have a bigger udder, which produces more milk and a larger wedge shaped body, which has a greater capacity for food.

Most dairy farmers would like to improve the quantity and quality of their product, the health and longevity of their cows and the profitability of the enterprise. These could theoretically be improved by improving the following traits (Webster, 1993).

1. Total yield of milk solids; especially butterfat and protein

2. Composition of milk or percentage of butter fat and protein

3. Conformation of the cow, namely legs, udder and quality of calves as beef animals.

4. Reproductive efficiency - selection for easy calving and rapid return to oestrus

5. Feed conversion efficiency - increased milk output per tonne of purchased concentrate feed or MJ of utilised metabolisable energy.

Up until the introduction of milk quotas yield was the most important factor. Although the trend currently is still for the remaining herds still to go for high yields by purchasing more and more quota from neighbours who are retiring or selling up, because they can no longer cope, it is unlikely that yields will always increase. Many farmers are now more interested in selecting for milk composition and efficiency of food conversion.

Until recently the major constraint upon genetic improvement in dairy cattle has been the fact that superiority could only be distributed widely by the male using artificial insemination. It is now possible to increase the contribution of the 
cow to genetic improvement using the technique of multiple ovulation and embryo transfer (MOET). In a review of current and future developments in dairy cattle breeding Hill et al. (1995) concludes that both MOET and more accurate statistical evaluation procedures, including the use of best linear unbiased prediction (BLUP) have achieved higher selection intensities. Individual breeders have been educated to use the information on genetic merit provided to them.

By selecting for the traits, which produce more milk solids per animal, breeders have been able to achieve higher production in quite a short time. Actual annual increase in milk yield is around $0.3 \%$ in the UK with best herds achieving $1.6 \%$. Using a closed MOET scheme improvements of the order of $4.5 \%$ could theoretically be achieved (Hill et al., 1990). More recent predictions (Meuwissen, 1991) have scaled this down to around $2.1 \%$. In practice much of the increase in yield may still be due to improvements in nutrition and management.

The gain in genetic merit for milk production in the United States (US) has been accompanied by a decline in conception to first service of approximately 0.45\% per year between 1975-1995 (Butler and Smith, 1989; Butler et al., 1995). Since 1993 the conception rate in a sample of dairy cows in the United Kingdom (UK) has declined at the rate of $1 \%$ per year (Darwash et al., 1999).

As genetic merit for production rises studies from large populations suggest that in addition to fertility some aspects of health are deteriorating. The more traits chosen for inclusion in a selection programme the slower is the rate of improvement for any individual trait. If a breeder attempted to improve all possible traits at once progress would be very slow. On the other hand selecting rigorously for a single trait inevitably produces changes in other traits, which may not be desirable. For example higher yields may result in large pendulous udders more prone to trauma and mastitis. In a study of $33 \mathrm{UK}$ herds over a six year period Pryce et al. (1998) concluded that all genetic correlations with the production traits were antagonistic and implied that selection for yield may have led to a deterioration in health and fertility. A similar study of registered Canadian Holsteins suggested that selection based solely on yield may increase the incidence of disease and that selection on conformation traits can help reduce the incidence of disease, although 
genetic correlations are low (Van Drop et al., 1998). In the Nordic countries comprehensive efforts have been made to improve traits for health, fertility and calving performance in order to put breeders in a better position to cope with the consumers' increasing concern for animal welfare (Christensen, 1998). The approach could be extended to select animals with desirable attributes in terms of metabolic load. For example it may be more desirable to select animals which depend less on mobilised tissue and more on extra dry matter intake to fuel milk production (Veerkamp et al., 1995).

The profit index number (PIN) has been used successfully and is likely to be replaced by the new Profitable Lifetime Index (PLI) which includes a lifespan score (Pryce, 1998). Future developments may include fertility and health traits.

\subsubsection{Digestion and Metabolism}

Understanding the digestion and metabolism of the dairy cow is essential if advice is going to be given regarding the prevention of metabolic disease and the achievement of optimum health and fertility.

The cow's rumen contains an ecosystem of microbes that is necessary to break down fibre that would otherwise be indigestible (Hoover and Miller, 1991). The rumen flora are also able to use non protein nitrogen sources for microbial protein synthesis. This microbial protein is then available for digestion by the cow. Rumen motility, regurgitation, cud chewing and salivation serve to mix the contents, reduce particle size and produce the essential stable environment for optimum microbial activity.

In ruminants the major part of the carbohydrate is broken down in the rumen to acetic, propionic and butyric acids, together with small amounts of branched chain and higher volatile acids which the rumen wall can absorb. Fibre with small particle size may escape the rumen before there is enough time for the cellulytic microbes to digest it (Ruckebusch et al., 1991). Smaller particles are rapidly saturated and fall to the bottom of the rumen and then pass through to the reticulum and out through the reticulo-omasal orifice. For the rumen to function effectively as a fermentation vat, there should be a mat of long fibre floating on the 
liquid to trap smaller particles. The density of the mat of floating long fibre also affects the passage of feedstuffs from the rumen. Receptors in the reticulo rumen wall are excited by the fibre mat, stimulating rumination. Long fibre also encourages eructation, cud chewing and salivation. At least $50 \%$ of silage particles by weight should be longer than $1 \mathrm{~cm}$ and $15 \%$ should be longer than $4 \mathrm{~cm}$. to maximise rumination and saliva production (Beauchemin, 1991). This review of the relevant literature emphasises that long fibre is essential in the dairy cow diet.

The fermentation of the plant wall is optimal at relatively high rumen $\mathrm{pH}$ (around $\mathrm{pH} 7$ ) because the bacteria responsible are sensitive to excess acidity. Their growth is depressed as $\mathrm{pH}$ falls below 6. Starch and sugar are fermented by organisms more tolerant to acidity than those that ferment the cell wall. One species (Selenomonas ruminantium) produces lactic acid, large amounts of which can predispose to rumen stasis and acidosis (Slyter, 1976). Below pH 6.2 fibre digestion is severely inhibited (Beauchemin, 1991). Low rumen $\mathrm{pH}$ can depress feed intake and increase health disorders including acidosis, parakeratosis of rumen epithelium, bloat, displaced abomasum, laminitis and increased fat mobilisation. It also decreases milk fat concentration in milk. Monitoring factors, which influence rumen $\mathrm{pH}$ and function, may be an important component of a health service.

Saliva which contains bicarbonate and phosphate ions is the major source of buffering capacity for the rumen and provides $70 \%$ of the water present in the rumen (Bartley, 1976). A cow may produce between 100-200 litres of saliva (Bailey, 1961) containing up to $3.5 \mathrm{~kg}$ bicarbonate per day. Depending on the nature of the ration, cows chew their cud between 20 and $40 \%$ of the day (Beauchemin, 1991). Total chewing time should be between 10 and 11 hours per day or longer (Beauchemin, 1991). Mature cattle chew very little when eating and instead they chew while resting. In a comfortable environment most cows would be lying down while chewing the cud. Cudding serves to reduce particle size and makes fibre more accessible to the cellulolytic microbes in the rumen. In practice many cows are restricted by their environment and are not able to achieve optimum lying or chewing time. 
It follows that feeds, which stimulate rumination are more useful in the maintenance of optimal conditions for fermentation in the rumen than those that do not. Some rapidly fermented materials such as finely ground grains or molasses do not stimulate rumination. Straw or hay at the other extreme are chewed extensively. Fibre must be included in any balanced ration to ensure that saliva output is maintained. If the diet is more acid as in grass silage it is essential that salivary secretion is sufficient to prevent a build up of acidity in the rumen or the blood. Clearly if conditions in the rumen are not optimal for the correct microbial growth then maximal utilisation of the diet will not be achieved.

Fats are digested post ruminally using lipase from the duodenum and pancreas. The cow can satisfy her needs for essential, fatty acids by digestion of lipids in microbial cell walls. Up to $5 \%$ can pass through the rumen becoming saturated in the process without effect on normal fermentation. Caution must be taken when feeding fats above $5 \%$ as at higher levels they may be toxic to rumen microbes and interfere with rumen fibre fermentation (Chalupa and Ferguson, 1988). When fat is given in excess it must be protected from microbial action by coating it in some rumen undegradable material.

Once past the rumen the digestive processes are similar to those in animals with small stomachs, except that the cow digests both the ingested material, that bypasses the rumen, and the microflora that are washed out of the rumen

The veterinary surgeon has an important part to play in assessing the overall conditions under which optimum digestion can be achieved.

\subsubsection{Nutrient Requirements}

The dairy cow is the most complex farm animal as she can be growing, lactating and be pregnant all at the one time. Thus the fate of dietary energy and protein is an interaction amongst these various physiological demands plus that for maintenance, all of which are themselves changing almost continuously (Johnson, 1986). The main nutrients required are:

- Energy

- Protein 
- Fibre

- Minerals

- Vitamins

- Water

\subsubsection{Energy Requirements}

It has been appreciated for a long time that that there is a characteristic shape of the lactation curve. It has been postulated that the prediction of the shape of the curve and the amplitude of its peak would theoretically allow matching of energy input with the anticipated energy output in milk (Wood, 1980). These models are widely used in computer programmes to calculate the daily energy requirements for groups of dairy cows. It has to be remembered that these predictions are inevitably based on curves modelled on historical data.

It is well established that cows in early lactation cannot consume enough energy yielding nutrients to meet the needs of production and maintenance (Butler and Smith, 1989). Cows in early lactation are in negative energy balance. Homeorhetic controls in early lactation ensure that body tissue, primarily adipose stores will be mobilised to support milk production despite insufficient intake of nutrients (Bauman and Currie, 1980). Homeorhetic controls orchestrate nutrient priorities for maintenance, growth, lactation and reproduction. The negative energy balance and fat mobilisation stimulate dry matter intake and cows progress to a positive energy balance by about eight weeks post calving (range 4-14 weeks) (Butler and Smith, 1989). Cows have been selected on their ability to mobilise body tissue to provide energy for milk production (Veerkamp et al., 1995).

The concepts of the requirements for energy and protein for the dairy cow is the subject of on going debate (AFRC, 1993).

\section{Metabolisable Energy}

Within the UK, energy is rationed according to the metabolizable energy (ME) system, with diets being formulated to meet these requirements according to the ME components of individual components. The historical development of the ME system is well documented, and despite several years from inception to practical 
recommendations, as advanced by the Ministry of Agriculture Fisheries and Food (MAFF, 1975). The uptake of the system and the reliance placed upon it by the UK dairy industry has been considerable. The system was evaluated by a UK national working party of which the author was a member (AFRC, 1990).

The energy systems which have been most improved have been those for the lactating dairy cow. Efficiency of utilisation of metabolisable energy varies less in the cow than in the fattening animal. The energy content of milk is less variable than liveweight gain. The first essential is to estimate the energy requirements and then to select foods, which can supply these requirements. Energy always is given first consideration because the energy supplying nutrients in food are present in the greatest quantity. If a diet is constructed to meet other nutrient requirements first and is then found to be low in energy a major revision of its constituents will probably be needed. A further feature of the energy containing nutrients which distinguishes them from the others is the manner in which liveweight gain or milk production responds to the changes in quantities supplied (Reynolds and Beever, 1995).

\subsubsection{Protein Requirements}

Cows neither need nor respond to protein. In their metabolism the requirement for protein in the dairy cow is really a requirement for amino acids absorbed from the intestines (Oldham, 1995). The amino acids are derived from two sources, digested protein that escapes rumenal degradation and protein derived from microbial synthesis in the rumen.

Traditionally, proteins in foods for ruminants were evaluated in terms of crude protein and digestible crude protein (DCP). This has for some time been regarded as unsatisfactory because it takes no account of the formation of microbial protein in the rumen. AFRC (1992) laid out the principles for meeting the metabolizable protein demands of the high yielding cow. Metabolizable protein is defined as the total digestible true protein (amino acids) that is available to the animal for maintenance and production purposes after digestion and absorption from the animal's digestive tract. The metabolizable protein (MP) system is now 
recognised as the official UK system for describing the protein requirements of ruminant livestock and replaces the DCP system. It has also been recognised that energy and protein requirements have very important interactions (Oldham, 1984; Oldham, 1995) and that formulating to energy or protein standards in isolation is not sufficient.

Chalupa and Sniffen (1991) reviewed the protein and amino acid nutrition of lactating dairy cattle. Metabolizable protein is made up of two components, a digestible true microbial protein fraction and a digestible undegradable feed protein fraction. Microbial protein is synthesised using amino acids and non protein nitrogen which result from degradation of feed protein in the rumen. This process is energy- dependent and emphasises the critical link between supplies of fermentable energy and degradable protein. Fermentable energy represents that portion of the total energy supplied as sugar e.g. molasses, starch e.g. cereals and digestible fibre e.g. sugar beet pulp). It does not include energy supplied by fat and pre-fermented products e.g. silage fermentation acids.

\subsubsection{Fibre}

In addition to the fact that fibre as contained in forage provides a large portion of energy in the diet it is necessary for optimal digestibility of the ration, as discussed previously.

Fibre levels were expressed as crude fibre but this has largely been replaced by acid detergent fibre (ADF), (Van Soest et al., 1978). ADF is essentially cellulose and lignin and there is a good relationship between it and the extent to which food is digested. In the UK the ADF method was modified using increased strength of acid and increasing boiling time. Thus the term modified acid detergent fibre (MADF) was evolved. Neutral detergent fibre (NDF), which is essentially lignin, cellulose and hemicellulose and can be regarded as a measure of the plant cell wall material, is considered a better measure for predicting total dry matter intake (NRC, 1989). As plants mature their fibre content shifts from hemicellulose to lignin and cellulose and its feed value reduces (Jorgensen, 1988). 
For the high yielding cow the NDF should be $25-28 \%$ of the dry matter of the ration with at least $22 \% \mathrm{NDF}$ in dry matter of forages (NRC, 1989).

\subsubsection{Minerals}

Minerals play an essential role in dairy cow nutrition (Beede, 1991). The total mineral content of the lactating cow's diet is a small percentage of the total dry matter intake. Dairy cows on a good balanced diet with a normal concentrate forage ratio will have a good balance of calcium and phosphorus. Disagreement exists over the nutritional standards (AFRC, 1991) with regard to minerals. One of the main difficulties is in the great variability of absorption. Cows do not choose minerals selectively and they must be fed in a way that forces the cow to consume adequate amounts usually by blending them with the concentrate or as part of a total mixed ration.

Requirements are reviewed in NRC (1989) and AFRC (1991). Supplemented minerals are widely available and are frequently fed to excess. McDowell (1996) commented that some minerals when fed in excess can be more detrimental to cattle production than any benefit derived from providing a mineral supplement.

Minerals and vitamins may affect reproductive function. However the specific roles of nutrients in reproductive tissues are not well defined in dairy cattle (Hurley and Doane, 1989). They suggest that the interface between nutritional science and reproductive physiology provides considerable potential for optimising reproductive efficiency in dairy cattle. Dairy producers are susceptible to advertisements advocating the addition of specific vitamins and minerals to the rations of high producing cows since inadequate or excessive quantities may be detrimental to health, fertility and productivity (Swanson, 1989).

\subsubsection{Vitamins}

The fat soluble vitamins A, D and E are all essential for cattle and are recognised as necessary for the inclusion in dairy cow diets (Herdt and Stowe, 1991). It has been generally assumed that dairy cattle do not require addition of water 
soluble vitamin supplements as under normal circumstances rumen microbes synthesise adequate amounts. Dairy cattle can become vitamin B12 deficient with diets inadequately supplemented with cobalt.

\subsubsection{Water}

Water is an essential nutrient, although it is commonly overlooked (Beede, 1991). A $600 \mathrm{~kg}$ cow eating maize silage and producing $45 \mathrm{~kg}$ milk may drink 113 litres at an environmental temperature of $<16^{\circ} \mathrm{C}$ and 140 litres of water at $>20^{\circ} \mathrm{C}$ (McDonald et al., 1995). Grazing cattle drink 2-5 times a day if they have free access. If access is limited, milk production falls (Little et al., 1984). There should be at least one watering space per 20 head of cattle.

\subsubsection{Dry Matter Intake (DMI)}

When formulating rations for dairy cows by far the most important consideration is how much the cow is capable of eating. Small or subtle refinements in diets are of little relevance if the cow can't consume it all! Numerous factors including body weight, forage quality and digestibility, stage of lactation, milk production levels, exercise, environment, management, cow comfort, social interactions, body condition, balance of ration, palatability and feeding frequency, chemical and osmotic effects on rumen may limit feed intake (Forbes, 1995). It is likely that a combination of these factors is used by the central nervous system to control intake. Dry matter intake is the most important factor in diet formulation and is the most difficult to measure in the on farm situation. DMI increases by approximately 1.5 to $2.5 \mathrm{~kg} / \mathrm{wk}$ during the first 3 weeks of lactation (Bertics et al., 1992).

There are many theories regarding the control of the cow's appetite such as concentrations of blood glucose, volatile fatty acids, rumen distension and peptide hormones and rumen receptors (Beauchemin, 1991). The fact that some cows can get very fat suggests that feed intake is under fairly imprecise control. There is evidence that cattle eat to satisfy their demand for energy for production and maintenance of body weight. 
Dry matter intake is affected by forage digestibility. At grass the rate of herbage intake can be considerably reduced when the mass of herbage is low or when cow is selecting favoured leaves or plants. Cows seem to be unwilling to spend more than $12 \mathrm{~h} /$ day eating (Forbes, 1995). Within a species, stage of maturity at harvest has a major influence on digestibility and therefore on intake of the forage. On average, intake rises by about $0.15 \mathrm{~kg} \mathrm{DM} /$ unit increase in D value of the forage. Palatability has a major influence on feed intake in ruminants and the sense of taste is highly developed in cattle (Albright, 1993). Cows will eat more food than is strictly necessary. The taste of the food such as sugar beet will increase intake as will factors such as competition and novelty e.g. a third feed at mid day.

The standard dry matter intake equation for lactating dairy cows is DMI $(\mathrm{kg} /$ day $)=0.0025 \mathrm{~W}+0.1 \mathrm{Y}$ (where $\mathrm{W}$ is body weight and $\mathrm{Y}$ is yield). In the first 6 weeks of lactation these figures are reduced by 2-3 Kg DMI/day (MAFF 1975). There is no satisfactory equation for predicting the dry matter intake of dry cows. Typically dry matter consumption decreases prior to calving. During the last 1-2 weeks of the dry period dry matter intake declines by $20-30 \%$ (Bertics et al., 1992). In pregnant animals two opposing factors can influence feed intake. The need for increased nutrients for the developing foetus causes intake to rise but the effective volume of the abdominal cavity reduces the room for rumen expansion tending to decrease intake, especially if the diet is mainly roughage. Fat animals similarly have less capacity for rumen expansion (Van Saun, 1991). Older cows have a greater increase in the rate of DMI intake postpartum than heifers. First lactation cows can benefit from separate grouping. When separated, heifers produced significantly more milk (Grant and Albright, 1995).

\subsubsection{Feeds For Dairy Cows}

There are many comprehensive reviews of feeds for dairy cows (Naylor, 1991; Webster, 1993; McDonald et al., 1995; Chamberlain and Wilkinson, 1996; Kelly, 2000). In most high yielding herds in the UK cows are fed forage and some form of concentrate feed. 


\subsection{Concentrate}

Food, including cereals and their by-products, by definition contains a high concentration of nutrients (mainly energy) per kg of fresh weight. When the price of milk is greater than the price of purchased concentrate it is economical to feed purchased concentrates to dairy cows. If the price of concentrate rises or the value of milk falls then it may no longer be a viable proposition to feed large amounts of concentrate. In order to meet the energy requirements of high yielding cows some cows receive up to $70 \%$ of their rations as concentrate with the other $30 \%$ being forage. At this level the rumen microflora are finely balanced and rumen $\mathrm{pH}$ may drop resulting in acidosis and other digestive upsets. Such high levels of concentrate feeding demand good access to high quality forage.

In general, where they have facilities, more farmers are attempting to maximise the utilisation of home produced forage to meet the nutrient requirements of their dairy cows.

\subsection{Forages}

\subsection{Grazing}

The research carried out on grazing systems has shown that using the best techniques, it is possible to obtain a very high milk production per hectare grazed (Greenhalgh et al., 1967; Leaver, 1985; Mayne, 1995). The level of intake is however very variable from 8 to more than $17 \mathrm{~kg}$ dry matter by $600 \mathrm{~kg}$ cows. It is inversely related to the filling effect, which depends on the crude fibre content. Therefore cows have to be fed young highly digestible material if the intake is to be optimal. Spring grass about $10 \mathrm{~cm}$ in height has a $\mathrm{D}$ value of about $75 \%$ and a M/D of around $12 \mathrm{MJ} / \mathrm{kg}$. It can in theory support a milk yield of around 30 litres. After mid-summer D value may fall to around $60 \%$, with a $\mathrm{ME}$ value of $5-10 \mathrm{MJ} / \mathrm{kg}$.

Forage intake is also influenced by the amount of material available. Maximum intake is ensured when around $140 \%$ of intake is offered (Greenhalgh et al., 1967). Lower intakes in late summer and autumn seem to be linked to an increased area contaminated by defaecation (Greenhalgh and Reid, 1969). 
Kolver and Muller (1998) estimated $30 \mathrm{~kg}$ of milk per day was the maximum yield that could be obtained from good quality grass.

Concentrates given during grazing reduced forage intake. The higher the quantity of concentrate the greater the reduction in forage consumption per $\mathrm{kg}$ extra concentrate (Castle et al., 1975).

The main factors, which have an effect on milk production per hectare, would appear to be the stocking rate, the fertilization level and supplementation with concentrates.

\section{Grazing strategies}

The development of grazing systems over the previous 50 years was reviewed by (Davies, 1976). Systems include strip grazing, rotational grazing and set stocking.

These strategies are also reviewed by (Campling, 1975) who suggested that the effects of different systems were small compared with those due to stocking rate. There has been a trend in recent years for farmers to return to simple grazing systems, but the development of more complex systems with the increased use of nitrogenous fertiliser did highlight the potential productivity of grassland.

\subsection{Silage}

The biochemistry of silage making was reviewed by McDonald et al., (1991). Wilkinson (1988) reviewed silage as used in the UK, and Wilkinson and Stark (1992) surveyed silage as used in 17 countries in Western Europe.

Silage is a key component of the diet of the majority of dairy cows in the UK for a large proportion of the year. It is therefore essential that veterinary surgeons involved in giving nutritional advice appreciate the problems associated with consistently producing high quality silage.

Targets for grass silage are a dry matter (DM) content of $250-300 \mathrm{~g} / \mathrm{kg}$, crude protein of $160-180 \mathrm{~g} / \mathrm{kg} \mathrm{DM}$, metabolisable energy (ME) concentration of $>11$ $\mathrm{MJ} / \mathrm{g} / \mathrm{kg} \mathrm{DM}$ and ammonia nitrogen of $<60 \mathrm{~g} / \mathrm{kg}$ total nitrogen. Conventionally these measures of silage have been taken as a guide to its quality and intake characteristics. Newer titrimetric methods of silage analysis (Offer et al., 1993) are 
now available which combine a number of chemical measures to categorise intake characteristics of silages according to a cluster value, with category 4 being the highest and category 1 the lowest.

Intake of silage is affected by time of access. There is an increase in silage intake of up to $30 \%$ when access time is increased from 5 to 24 hours. Chop length may have an effect on silage intake (Marsh, 1978).

Dulphy and Van Os (1996) reviewed the control of voluntary intake of silages by ruminants. Badly preserved silages are frequently produced from crops which are ensiled at too high a moisture content which contain low levels of soluble carbohydrates. Silages of this type have $\mathrm{pH}$ values in range 5.0-7.0. The main fermentation acid present is either acetic or butyric with ammonia levels above 200 $\mathrm{g} / \mathrm{kg}$. The productive performance of cows consuming this type of silage is poor as a result of depressed voluntary food intake and poor utilisation of silage nitrogen. They conclude that the negative effects of poor quality silage are multifactorial. On the other hand well preserved silages, with high quantities of lactic and acetic acids and a low $\mathrm{pH}$, also result in limited DMI despite having a high nutritive value. Attention to detail in silage making is the key to achieving consistent results.

A report in the Farmers Weekly (1995) highlighted the very large variation that can occur in silage analysis. A silage sample was divided into equal portions and sent to 11 different organisations for analysis. There was a wide variation in the results and the conclusion was that 'the cows themselves are the best indicator of silage quality'.

\subsection{Ensiled Whole Crop Cereals}

Maize silage if cut at the correct stage is an excellent feed for dairy cows. It is an excellent source of energy but is low in ERDP (Wilkinson 1988). Maize should be harvested when the ears are fully mature and the tops of the kernels have begun to dent. At this stage the corn is $30-35 \%$ DM. Silages harvested earlier tend to lose nutrients through seepage once ensiled. If it is too dry there may be problems with secondary fermentation. In UK it is now grown extensively in farms in the southern half of England and in Wales. Cows have been shown to perform well on a forage 
with a 50-50 mixture of grass and maize silage. Maize silage, especially when appropriately supplemented, is eaten in greater quantities than grass silage (Forbes, 1995)

Whole crop wheat or barley, Leaver and Hill (1995), has created renewed interest in the past few years. The crop is cut before maturity and treated with urea which hydrolyses to ammonia and preserves the crop at around a $\mathrm{pH}$ of about 5 . It is becoming more popular in areas where it is not possible to grow maize.

\subsection{Hay}

Has a poorer nutritive value than silage because it is cut when the grass is more mature and fibrous. Typical M/D value is $8.5 \mathrm{MJ} / \mathrm{kg}$ which limits its use as an energy provider for the high yielding cow (McDonald et al., 1995). A little hay (1-2 kg) is, however, an excellent source of digestible fibre, encourages rumination and is valuable when balancing the lack of fibre in young spring grass.

\subsection{Straw}

Straw has a low feed value but can play a part in increasing the dry matter of very wet silage and in buffering the lowering of butterfat produced by spring grass. Straw can be nutritionally improved by treating with sodium hydroxide or ammonium hydroxide. This can have the effect of increasing the M/D to around $8.5 \mathrm{MJ} / \mathrm{kg}$ which is similar to hay. When sodium hydroxide is used the non-protein $\mathrm{N}$ content also increases (McDonald et al., 1995).

\subsection{Forage Legumes and Other Green Foods}

Although legumes, such as clover, lucerne, lupins and peas, are able to fix their own nitrogen supply, enrich the soil $\mathrm{N}$ content and have a high nutritive value their role has been limited by the availability of subsidised cheap fertiliser. As UK agriculture becomes more influenced by a more open world market legumes will play an increasingly important role.

Cows are also fed brassicas such as kale, rape, cabbage and the tops of turnips and sugar beet. Kale and rape are good sources of energy and protein but do 
contain toxic substances which can interfere with iodine utilisation. They are best cut and fed, as feeding kale in the field in autumn or winter can expend as much energy as is derived from the crop and leads to dirty udders and foot problems. Not more than one third of total DM intake should be of kale or rape (Webster, 1993).

\subsubsection{Feed Management Strategies}

Feeding strategies are adopted for reasons which may not be strictly nutritional (Webster, 1993). They are governed by the facilities available on a farm, the type of forage that can be grown successfully and the machinery and labour available to handle it. Systems of concentrate distribution were reviewed by (Leaver, 1988).

\subsection{Feeding To Yield}

This strategy involves attempting to meet the calculated requirements of the cow using standard allowances for maintenance and production. Most cows will be fed some concentrate and forage, usually grass in summer and silage in winter supplemented by concentrate.

One of the constraints to the achievement of high yields was the limitation of feeding concentrate in the parlour at milking time. With ever increasing yields cows had difficulty in consuming sufficient concentrate in the parlour. There was the problem of rumen acidosis and slowing down of fibre digestion. The limit for single concentrate feeds is $4-5 \mathrm{~kg} /$ day (Kauffmann, 1976). To increase concentrate intake mid day feeds of compounds or by products such as sugar beet pulp are commonly used.

With the advent of computerised cow identification out of parlour feeders provide the facility to feed a cow little and often. It is possible to divide the daily concentrate ration into up to 12 feeds per day. They have the added advantage of being able to record the amount of concentrate actually consumed.

The practice of feeding to yield depends on the accuracy of the estimations of the nutritive value of the diet and, as always, the uncertainty of dry matter intake. It also depends on accurate and current information on milk yield. If 
historical information is used yields may be chased 'downhill'. Further inaccuracies can occur due to errors in calibration of the feeders.

\subsection{Lead Feeding}

Lead feeding was a strategy to encourage cows to reach their full potential i.e. they were fed extra concentrate in addition to their calculated requirements. In early lactation substitution rate of concentrates for forage is high. This has largely been discontinued partly because of quotas and partly because of the increased awareness of metabolic problems associated with over feeding concentrate.

\subsection{Flat Rate Feeding}

The principle of flat-rate feeding is that all cows receive the same amount of concentrate, irrespective of their actual or potential milk production, together with silage ad libitum (Rakes and Davenport, 1971). The system works best when there is a compact calving pattern, with most cows at the same stage of lactation and when input of concentrates is relatively low (Leaver, 1988). Its success does depend on the cows having free access to good quality silage.

A variation of this system is the less extreme stepped flat rate system where cows are fed a higher rate of concentrate say $8 \mathrm{~kg}$. for the first 16 weeks then $4 \mathrm{~kg}$ for the remainder of the lactation.

\subsection{Complete Diets or Total Mixed Rations (TMR)}

The complete diet system was described by Owen (1981). The main principle of the complete diet system is that the animal receives slowly and rapidly fermentable feeds in an intimate mix, thus balancing the inflow into the rumen of feeds of widely differing rates of fermentation, and thereby maintaining stable conditions in the rumen. Cow intake improves in this system and has generally meant fewer metabolic problems and better butterfat. The system is expensive to set up as relatively costly mixer wagon and facilities to group cows are required. Reviewing the use of TMR, Brand et al. (1996b) estimate increases of $0.91 \mathrm{~kg}$ milk per day for older cows and $1.8 \mathrm{~kg}$ per day for heifers from improved feed 
consumption and utilisation. They suggest that TMR feeding can pay for the initial set up price in 12 to 18 months through more milk, lower feed costs and improved digestion. It is most useful for a farmer buying and feeding by-products. It also affords the opportunity to buy the most competitively priced ingredients and incorporate them in a balanced diet. This does require a degree of skill and nutritional knowledge. Processing and mixing the diet can reduce forage particle size with reduction in time spent ruminating, saliva production and drop in rumen pH (Heinrichs et al., 1999). Kolver and Muller (1998) found that cows on a TMR were able to consume more dry matter, organic matter and net energy compared with comparable cows on high quality pasture. Albright (1993) emphasised that feed accessibility may be more important to cows than the actual amounts of nutrients provided. He also made the interesting observation that cows eating with their heads in the downward position produced 17 per cent more saliva than cows eating with their heads held horizontally.

When first introduced some cows tended to over eat and over fat cows with fatty liver syndrome resulted. Many farmers now adopt a partial complete diet system feeding a large portion of the ration through a mixer wagon topping up with concentrate in the parlour.

\subsection{Buffer Feeding}

The concept of buffer feeding was reviewed by (Mayne and Thomas, 1986). The strategy was developed as a way of reducing losses of output from grazed pasture. This is now commonly used when cows are calving at grass during the summer. Typically silage, hay or straw is used. It is often fed indoors after each milking.

\subsection{Dry Cow Feeding}

The dry cow period should be seen as the beginning of the next lactation. As nutrient requirements are much less than for the lactating cow, dry cows are often fed poorly balanced rations of inferior foodstuffs. Many postpartum diseases find their beginnings in the dry period including hypocalcaemia, 'downer cows', ketosis, 
delayed conception, retained placenta, uterine infection and displaced abomasum (Van Saun, 1991).

More than $60 \%$ of the total weight of the conceptus is gained during the last 2 months of the dry period. During the last 1-3 weeks of the dry period the cow must make the transition from body and foetal tissue deposition to tissue mobilisation to support lactation. There are really two stages of the dry period. The early stage up to 30 days pre calving and the last 3 weeks pre calving. Dry matter intake declines by approximately $30 \%$ during the last 7 to 10 days of pregnancy (Grant and Albright, 1995). The nutrient requirements of the two groups are rather different and the best method of management is to treat them separately (Van Saun, 1991).

During the first thirty days the dry cow can have much of her requirements met with forage. It is essential that dry cows do not get too fat (Morrow, 1976). The high forage diet helps to restore the health and function of the rumen.

Grummer (1995) emphasised the importance of the transition period from 3 weeks before calving to 3 weeks after calving in reducing postpartum health problems and ensuring optimum fertility. Feeding some fermentable carbohydrate during the prepartum transition period acclimatises the microbial population to lactation diets, promotes development of rumen papillae and reduces lipolysis. This concentrate may also act as a vehicle for mineral and vitamin supplementation. Excessive amounts of grass close to calving raises the calcium intake and may predispose to parturient hypocalcaemia. Magnesium is an important cofactor in the absorption and mobilisation of calcium post calving and adequate magnesium intake in the last ten days before calving is also required to prevent hypocalcaemia (Kelly, 1988).

\subsubsection{Management and Environment}

\subsubsection{Housing systems}

Prior to 1950 the majority of dairy cows were housed and fed individually in cow sheds or byres. Dairy herds have become progressively larger 
and producers in the UK and elsewhere in the world have introduced labour saving systems of feeding, milking and manure disposal (Nott, et al., 1981).

Cattle housing has been reviewed by (Scottish Farm Buildings Investigation Unit, 1985; Webster, 1995; Farm Animal Welfare Council, 1997). From these reviews the following consensus can be postulated.

\section{Impact of Housing on the objectives of Dairy Cow Management}

- Dairy housing systems should be designed so that cows can be properly handled, observed and protected. There is now recognition that all this should be provided with cow comfort in mind.

- The housing must make it possible to receive proper amounts of roughage, concentrate, minerals and vitamins and water.

- The housing must allow sufficient protection and comfort for the cow to properly ruminate and digest the available food

- The housing system must allow the herdsman to observe the cows with regard to appetite and general health. Cows must be able to be observed in heat and accurately identified.

- Housing must give protection from inclement weather such as heat, cold, rain, wind and snow.

- It must be possible to mechanically remove manure.

For the average larger herd, in the UK, there are basically two options: cubicles or a straw bedded cattle court. A cubicle house cost in 1985 (Scottish Farm Building Investigation Unit) at $£ 106 / \mathrm{m}^{2}$ and a cattle court at $£ 84 / \mathrm{m}^{2}$. In a cubicle house four cows could be bedded with 1 tonne of straw compared with 1 tonne per cow in a straw yard. If cows can be kept on deep dry clean straw it is ideal. Most cows are kept in the west of the country where cereal growing and hence straw availability is limited. To transport straw across country is expensive and if cows are kept on inadequate straw conditions become intolerable and cows would be better in cubicles.

The situation is further exacerbated by the increased use of silage, which predisposes to increased amounts of urine and wet slurry. These conditions all tend to increase the risk of foot problems and mastitis (Webster, 1995). During a typical 
damp British winter the amount of water lying in a cow house can contribute to humidity levels approaching $100 \%$. Regular scraping, at least twice a day, or use of automatic scrapers is recommended. Good natural ventilation with the use of space boarding on side walls and open ridge roof is essential. Many farms are increasing ventilation by cutting slits in the roof sheets.

The application of automatic milking, with cows loose housed throughout the year may, in future, provide conditions for optimal welfare.

Cubicle design is the subject of great controversy (Cermak, 1990; O'Connell et al., 1991; Faull et al., 1996; Hughes, 2000). The welfare of dairy cows housed in cubicle units can be enhanced by the provision of ample space in cubicles and a comfortable dry lying area. The cow should be able to lie down in a normal position without being trodden or kicked by other cows, to stand with all four feet in the dry cubicle, to get up and down without difficulty. An inadequate number of cubicles, so that not all cows can lie down at once, leads to more aggressive interactions with low-ranking animals having to stand. Potter and Broom (1990) also observed that low ranking individuals spent a greater part of their time standing and suggested that as well as providing a lying space the cubicle provided a zone where effective personal distance is increased. Faull et al. (1996) in a study of cubicles in South West England and Wales estimated that 87 per cent were too short and 50 per cent too wide or too narrow.

A clean dry bed can be made on a base of soil, chalk, concrete or bitumen. Whatever the base it is agreed that the cow will benefit from some form of bedding (Natzke et al., 1982). Chopped straw at a depth of 50-80 cm will give maximum lying time of 14 hours (Cermak, 1990). Chopping straw makes it more absorbent and reduces overall usage by about $25 \%$. Wood shavings or sawdust can make a comfortable bed but in damp conditions provide a good medium for bacterial growth. Sand is inert and does not encourage bacterial growth, but needs to be deep enough to provide comfort $(50-80 \mathrm{~mm})$. A thin layer on concrete can be very abrasive. Mattresses with a covering of chopped straw provide an excellent bed (Cermak, 1990). 
Passageways. The floor surface needs to be skid resistant and kept as clean as possible. Old concrete floors, which are worn and slippery, can be restored by cutting narrow grooves with a special machine.

Calving and isolation boxes. Ideally there should be five or six per 100 cows depending on the calving pattern. Each cow should have a clean disinfected box to calve in. They should be large enough to allow assistance to be given $(4 \times 4 \mathrm{~m})$ (Webster, 1993).

Trough space. In order to allow cows optimal opportunity to maximise dry matter intake they must be given sufficient trough space. The commonly recommended width is $24 \mathrm{~cm}$ in the UK when 24 hour access is allowed (Bines, 1985). When width is reduced to below $20 \mathrm{~cm}$ intake is reduced. The recommended level for access to a clamp is $30 \mathrm{~cm}$. Intake from a clamp may be $20 \%$ lower than for similar cows eating from a trough.

In a study of the behaviour of Friesian cows Potter and Broom (1990) found that many high ranking animals demonstrated a strong preference to feed at a particular section of a feed barrier. Lower ranking animals will feed less if the trough space is not long enough to allow all cows to feed simultaneously. Social dominance and competition for food can markedly influence dry matter intake (Grant and Albright, 1995)

\subsubsection{Disease}

Disease is considered to be an important limiting factor in production of milk by dairy cattle. Epidemiological studies indicate that most cases of disease in dairy cattle occur in early lactation and there are temporal and statistical relationships between many of these (Dohoo et al., 1983; Markusfield 1987b; Shanks et al., 1981). These studies have shown that most disease occurs in the first 12 weeks after calving and can be classed as production diseases. These include milk fever, ketosis, displaced abomasum, digestive disorders, reproductive tract infections, mastitis and lameness. Furthermore diseases such as ketosis, milk fever and mastitis tend to recur in successive lactations. The early lactation is a period of particular susceptibility to disease and diseases of dairy cattle are not necessarily 
distinct and independent clinical entities but are interrelated in complex and as yet poorly understood ways. Cows with milk fever, for example, are at increased risk for dystocia, retained foetal membranes, and metritis (Curtis et al., 1983; Erb et al., 1985).There may be common predisposing factors; physiological, immunological or nutritional associated with the periparturient period which render cows susceptible to metabolic, infectious and reproductive disease (Mather and Melancon 1981; Targowski 1983).

The inter-relationships of periparturient diseases in dairy cows were assessed by (Peeler et al., 1994). Twinning, dystocia, retained foetal membranes and lameness before service increased the risk of mastitis. Rowlands et al. (1986) described the susceptibility to disease in the dairy cow and its relationship with occurrences of other diseases in the current or preceding lactation. Cows with ketosis or hypocalcaemia in one lactation were twice as likely to have hypocalcaemia in the next, and the occurrence of ketosis in consecutive lactations was also related. As might be expected the occurrence of endometritis was strongly associated with dystocia and retained placenta. Endometritis was also linked with an increase in the incidence of ketosis and lameness.

Several reports suggest that cows, which are over fat at calving, as a result of over feeding either in late lactation or in the dry period, have an increased risk for post partum metabolic and reproductive disorders, reproductive failure and culling after calving (Morrow, 1976; Higgins and Anderson, 1983; Milian-Suazo et al., 1989).

\subsubsection{Metabolic Disease}

\subsection{Ketosis}

Clinical ketosis or acetonaemia is a disorder of early lactation and usually associated with high milk yield and negative energy balance (Baird, 1982; Littledike et al., 1981). The precipitating cause is often a marked imbalance between glucose demand and supply which results in mobilisation of body reserves and increased synthesis of ketones by the liver. Ketosis becomes a disease condition when absorption and production of ketone bodies exceeds their use by the cow as an 
energy source. As a consequence, ketone bodies accumulate in blood until they eventually appear in the urine and milk (Kelly, 1984). The occurrence of primary clinical ketosis is a herd problem. A clinical case is usually indicative of the fact that most of the cows at the same stage of lactation will have sub clinical ketosis. They will be in negative energy balance, have high ketone and non-esterified fatty acid (NEFA's) levels and hypoglycaemia (Whitaker et al., 1983). Almost every cow that gets ketosis will suffer, to some degree, from fatty liver (Reid and Roberts, 1982). If the liver can not metabolise all the ketones and fatty acids from body reserves some liver cells are damaged or lose their functional capacity as they fill with fat.

Ketosis may also be secondary to the ingestion of preformed ketones in the diet for example silage high in lactic and butyric acid (Andersson and Lundstrom, 1983).

Guidelines for the prevention of ketosis (Hibbit, 1979; Shultz, 1971) which are very much the basic principles of good nutritional management can be summarised.

- Avoid excessive fatness at calving. Increase concentrate intake moderately at the end of the dry period and as rapidly as possible after calving without reducing appetite.

- Feed at least one third the dry matter of diet as high quality roughage. Avoid abrupt changes in diet, especially if moving to inferior quality forage.

- Maximise feed intake by providing comfort, exercise and minimising stress

\subsection{Milk Fever}

Milk fever is an afebrile paretic condition of dairy cattle occurring close to parturition and associated with the onset of lactation (Allen and Sansom, 1985). More than $90 \%$ of cases occur between $24 \mathrm{hr}$ and $48 \mathrm{hr}$ after parturition. It affects some $7-9 \%$ of the national herd. Predisposing factors have been defined (Allen, 1981; Curtis et al., 1984; Littledike et al., 1981; Kelly, 1988) some of which are related to the nutrition of the cow particularly during the dry period.

\section{Feeding before calving}


Calcium and magnesium intake before calving and body condition at calving, influence the incidence of milk fever after calving (Kelly, 1988).

Reducing the calcium intake before calving, preferably to below $30 \mathrm{~g} /$ day reduces incidence of milk fever. In practice this can often be difficult to achieve because dry cows are often at grass or on other forage with a relatively high calcium content (above $50 \mathrm{~g} /$ day). Such cows may also have a low intake of magnesium. Magnesium is necessary for the adequate absorption and mobilisation of calcium (Kelly, 1988).

In situations where it is difficult to achieve reduction of calcium in prepartum diets the alteration of the ionic balance of the diet may be helpful in reducing milk fever (Block, 1984). Excessive body condition has been associated in some studies with the increased incidence of milk fever, although the reason is unclear (Fronk et al., 1980). It is postulated that fat cows may have reduced ability to mobilise calcium. The crucial feature after calving is to maintain the cows' appetite so that dry matter and thus calcium intake can be maximised as rapidly as possible.

\subsection{Hypomagnesaemia (grass tetany)}

Hypomagnesaemic tetany occurs most often in lactating cows shortly after they are turned out to grass in spring with an annual incidence of around $1 \%$ (Littledike et al., 1981; Whitaker and Kelly, 1982). There are numerous good reviews of hypomagnesaemia (Blood et al., 1983).

Hypomagnesaemia arises when either there is low concentration of magnesium in the diet and or inadequate absorption from the gut. As magnesium uptake is not apparently under hormonal control and body stores are not particularly labile the daily requirement of approximately $20 \mathrm{~g}$ per day must be supplied on a daily basis. When dietary magnesium is low as in lush spring grass, below $0.2 \%$ magnesium concentration is dangerous, the ion is depleted from the cerebrospinal fluid and extracellular fluids due to the demands of lactation. Every $7 \mathrm{~kg}$ of milk produced may drain the whole magnesium pool (Reindhardt et al., 1988) with loss of 
normal neuromuscular function, tetanic spasms and convulsions. Lactation stress and transportation anorexia can be aggravating or precipitating factors.

Autumn grass is frequently low in magnesium and this can contribute to increased incidence of milk fever as discussed previously (Kelly, 1988). Reid and Little (1986), Kelly (1988), reviewed the prevention of hypomagnesaemia.

\subsection{Acidosis}

The sudden introduction of large amounts of readily fermentable carbohydrates can precipitate an acidosis characterised by cows going off feed, diarrhoea, ruminal acidosis and sometimes milk fat depression (Leek, 1983). This is often accompanied by a low forage intake and a $\mathrm{pH}$ of 4-4.5 with an increased lactic acid production.

Systems where feeding of concentrates which operate on the "little and often" principle such as out of parlour feeders or complete diets should reduce the dangers of acidosis. There is evidence that feeding in this way produces less violent fluctuations in rumen $\mathrm{pH}$, less lactic acid and an improved ratio of acetate to propionate (Kauffmann, 1976).

\subsubsection{Mastitis}

Mastitis is an inflammation of the mammary gland, usually bacteriological in cause, which results in changes in the mammary gland and the acinar tissue. Francis (1987) pointed out that nearly five thousand papers have been published on mastitis control in the ten years up to 1987. The incidence in dairy cattle is generally between 20 and $30 \%$ but with wide variation from herd to herd (Dohoo et al., 1983). Hillerton (1997) suggested that the incidence in the UK is 3545 cases/100/year compared with 140 cases/100 cows/year before the 5 point plan control scheme Dodd et al. (1969) was introduced. Many infective agents have been implicated, the most important being, Streptococcus agalactiae, Str. dysgalactiae, Str. uberis, Staphylococcus aureus, Corynybacterium pyogenes and Eschirchia coli. Since the introduction of mastitis control programmes the nature of mastitis has been changing on progressive farms (Booth, 1988). On these farms, cases due to Strep. 
agalactiae and Staphylococcus aureus have been reduced and the proportion of cases due to coliform and environmental bacteria such as Strep. uberis has increased (Wilesmith et al., 1986; Erskine et al., 1988; Hillerton, 1997). Overall these herds produce more milk of higher quality but may in some cases see more clinical mastitis often of a severe type. As herd somatic cell counts decrease (SCC) the frequency of coliform mastitis may increase and may now account for one third of all cases of clinical mastitis (Hillerton, 1997). Environment and management again play an integral part in the multiple causation of mastitis (Bramley and Neave, 1975).

Mastitis is generally considered the most costly disease of dairy cows. The economics of mastitis and mastitis control has been reviewed by DeGraves and Fetrow (1993). Mastitis results in economic loss due to reduction in milk quality and production. There are also economic losses due to discarded milk, early culling, drug costs, veterinary costs, and increased labour.

Losses from mastitis have been for some time attributed mainly to subclinical mastitis. Total milk losses in sub clinically affected quarters have been calculated at from 10-26\% (Degraves and Fetrow, 1993). Lower somatic cell counts are associated with higher herd milk production.

Clinical mastitis results in greater losses when cases occur early in lactation (Lucey and Rowlands, 1984). Clinical mastitis also decreases the duration of lactation and increases the likelihood of culling (Erb et al., 1985).

Milk quality pricing systems will increase the pressure on farmers to produce milk with low cell count and TBC. It is however worth noting that a survey Gunn (1995) suggested that Strep agalactiae was still one the most common organisms isolated from herds in Scotland with persistently high somatic cell counts. Nutrition has been determined at least indirectly to affect mammary resistance to infection. A number of clinical (Morrow, 1976) and experimental studies (Fronk et al., 1980) have implicated excessive body condition at calving as a factor increasing the incidence of mastitis after calving. The reason is not clear. It may be that due to an increase in udder oedema in over fed cows which may increase susceptibility to mastitis. It may be that excessive fat mobilisation in fat cows after calving interferes with the function of leucocytes (Hill et al., 1985). 
Cows with hypocalcaemia had a higher incidence of mastitis (Curtis et al., 1983). Dohoo et al., (1983) showed that cows with ketosis were several times more likely to have mastitis than those which had not.

Secondary to the streak canal, leucocytes are the most important defence mechanism. Antioxidants have been implicated in being critical in the promotion of efficient mammary phagocyte killing. Supplementation with vitamin E or selenium was reported to decrease incidence and duration of clinical mastitis (Smith et al., 1984). There is also a possibility that vitamin A may exert a protective effect against mastitis (Johnston and Chew, 1984).

In summary, dietary supplementation of antioxidant nutrients such as selenium and vitamins $\mathrm{A}$ and $\mathrm{E}$ has a beneficial effect on mammary health, but there is no clear indication that supplementing diets above NCR recommendations will result in improved mammary resistance.

\subsubsection{Fertility}

The gain in genetic merit for milk production has been accompanied by a decline in conception to first service of approximately $0.45 \%$ per year between (1975-1996) in US (Foote, 1996) and a similar trend is anticipated in UK (Lamming and Darwash, 1998). Most reproductive programmes for dairy cows have focused on preventing production losses associated with errors in artificial insemination procedures, heat detection efficiency, and infectious disease. Although the importance of other factors such as environment and nutrition on reproductive efficiency is recognized, these variables tend to be less clearly monitored and controlled.

Relationships between nutrition and reproduction have been extensively reviewed (Weaver, 1987; Butler and Elrod 1992; Nebel and McGilliard, 1993; Staples et al. 1995; Ferguson, 1996; O'Callaghan and Boland, 1999).

\subsection{Energy Deficiency and Fertility}

The possible effect of dietary energy deficiency was reviewed by Butler and Smith (1989); Britt (1992); Staples et al. (1995). Conception rates in heifers 
have remained higher and so it is postulated that it is the greater energy demand that is related to the decline in reproductive performance. The resultant negative energy balance and rate of mobilisation of body reserves appears directly related to the postpartum interval to first ovulation and lowered conception rate. Delays in the onset of normal ovarian activity, thus limiting the number of oestrous cycles before breeding, may account for the observed decrease in fertility. Negative energy balance probably acts by impinging on pulsatile secretion of luteunising hormone (LH). Lowered availability of glucose and insulin may also inhibit LH pulsatility or limit ovarian response to gonadotrophins.

Follicles, which begin to grow when energy balance is most negative, might be exposed to adverse metabolic conditions, which would render them less functional. This would lead to the production of poorer quality oocytes and the secretion of less progesterone after ovulation. Thus a follicle exposed to undesirable conditions during its earliest stages of development may somehow be imprinted so that it reflects that adversity as lower fertility (Britt, 1992).

An important component of energy balance during early lactation period is the mobilisation of body reserves. Excessive mobilisation of body reserves has been associated with postpartum fatty liver and reduced reproductive performance in high yielding dairy cows (Reid and Roberts 1982). Cows with metabolic disorders commonly associated with the fat cow syndrome are at risk to develop subsequent reproductive disorders that result in reduced reproductive performance (Erb et al., 1985).

Nutritional strategies to increase milk yield should be assessed relative to change in body condition if reproductive efficiency is to be maintained. To maintain fertility, body condition loss should be less than two thirds of one unit condition score (Ferguson, 1996).

\subsection{Protein and Fertility}

The effects of protein on fertility have been difficult to assess. Ferguson and Chalupa., 1989; Canfield et al., 1990; Butler and Elrod, 1992) all reported reduced fertility associated with increases in serum urea nitrogen. In a review 
O'Callaghan and Boland (1999) suggested that there was strong evidence in the literature to suggest that high dietary crude protein, resulting in elevated concentrations of urea in circulation may decrease pregnancy in lactating cows. They suggest that the mechanism affecting the reproductive process was primarily operating at the level of the oocyte. Butler et al. (1996) postulated that elevated plasma urea resulting from excess dietary protein can decrease uterine $\mathrm{pH}$. Cows with elevations of serum urea nitrogen $>20 \mathrm{mg} / \mathrm{dl}$ had conception rates under $25 \%$ (Ferguson, 1992). A review by Staples et al. (1995) suggests that elevated intakes of protein may exert its effect through increased energy costs to the animal. Whitaker (1998) in a review concluded that the evidence of causal links between high blood urea and poor fertility was equivocal as many of the reports made little or no reference to the energy status of the animals in question. Barton et al., (1996) found that a high crude protein diet only influenced fertility when cows also had postparturient health problems. They suggested that the implementation of a strict reproductive management programme allowed high reproductive efficiency regardless of plasma urea $\mathrm{N}$ concentrations. When cows were sampled on the day of insemination Trevakis and Fulkerson (1999) found no evidence that high milk urea was associated with poor reproductive performance in dairy cows grazing pasture.

\subsection{Minerals and Reproductive Performance}

Phosphorus has often been implicated in anoestrus, silent heats and low conception rates. Results have been equivocal (Carstairs et al., 1980; Call et al., 1987).

\subsection{Trace Elements}

Trace element deficiencies and fertility was reviewed by Hidiroglou (1979). Controlled trial evidence is generally not available proving that trace element imbalance affects the fertility of dairy cows (Whitaker, 1999). The exceptions are high dietary molybdenum (Phillippo et al., 1987) and selenium. Increased dietary selenium and Vitamin $\mathrm{E}$ has been reported as being beneficial in lowering the incidence of retained placenta and improving immune status (Trinder et al., 1969; 
Hurley and Doane, 1989). Deficiencies of copper, manganese, iodine and cobalt have been associated with poor fertility but much of the evidence is anecdotal.

\subsection{Vitamins and Reproductive Performance}

Vitamin A deficiency may cause abortion, delivery of weak calves, retained placenta and metritis. Deficiency may occur in rations high in maize silage or dried grasses stored for extended periods. Commercial feeds are routinely supplemented. Numerous commercial trials have failed to show benefit of $B$ carotene supplementation (Weaver, 1987).

In summary the diagnosis of nutritional effects on fertility relies on relating the pattern of infertility with ration analysis, appropriate clinical tests, body condition scoring, uterine and ovarian palpation, and clinical signs associated with the suspected cause. Most problems in dairy herds are associated with mismanagement of the macronutrients, energy and protein. Poor quality food, poor feed preparation and presentation, and poor cow comfort predispose to increased energy deficit and reduced reproductive efficiency. Periparturient diseases are related to dry cow nutrition and management problems, and can have a major effect on herd reproductive peformance (Ferguson, 1991).

\subsubsection{Lameness}

Lameness is a multifactorial disease caused by faults in nutrition and management of the cow, by poor building design and poor hygiene; there is probably a large genetic component. It is an important reason for culling dairy cows (Russell et al., 1982). Results from our own DHHPS showed an average incidence of $25 \%$ (Whitaker et al. 1983). Lameness in dairy cattle is a major welfare problem and source of economic loss to the dairy industry (Esslemont and Peeler 1993; Lucey et al. 1986; Collick et al., 1989). Sprecher et al. (1997) showed that lameness increased calving to first service and calving to conception interval. Lameness before service increased the risk of oestrus not observed (Peeler et al., 1994). They suggested that lameness might affect reproductive performance by physically inhibiting a cow from exhibiting oestrus, by reducing food intake and hence 
compromising energy status, or by inducing pain, which might have an inhibitory effect on the release of luteunising hormone (LH). Stress induced reductions of fertility may be mediated by effects at pituitary and hypothalamic levels to reduce LH drive of follicular growth and oestradiol production (Dobson and Smith, 1998).

Approximately $90 \%$ of cases of lameness are caused by lesions in the feet and $10 \%$ by lesions elsewhere on the limb (Toussaint-Raven, 1973).

\subsection{Nutritional or Metabolic Factors}

A varying degree of laminitis is considered to be the underlying lesion that results in metabolic and non infectious lesions of the feet, such as sole ulcer, white line disease, heel erosion and interdigital growths (Greenhough and Vermunt, 1991). It has been proposed that diffuse acute, subacute or chronic aseptic pododermatitis precedes the lesions. The inciting cause is ruminal acidosis as a result of abnormal rumen fermentation associated with feeding a diet with a high level of concentrate and a low level of roughage (Manson and Leaver, 1989). Livesey and Fleming (1984) studied the effect of a low fibre, high starch diet in early lactation on the incidence of laminitis and sole ulcers in Friesian cows. Cows fed the low fibre diet, high starch diet had a $68 \%$ incidence of clinical laminitis and a $64 \%$ incidence of sole ulcers. Cows fed the higher fibre diet had only $8 \%$ clinical laminitis and $8 \%$ sole ulcers (Leaver, 1988). Initially there is toxic release from rumen bacteria unable to survive low rumen $\mathrm{pH}$. These toxins may cause capillary damage resulting in vascular changes in the laminae. Oedema, haemorrhage, stagnant hypoxia and an inadequate supply of nutrients to the keratin producing cells may result. This predisposes to poor horn quality and deterioration of horn (Enevoldsen et al., 1991).

Calving heifers too young may contribute to increased laminitis and its sequelae. Laminitis was identified in the early growing period of young heifers (Greenhaugh and Vermunt, 1991). 


\subsection{Environmental and Behavioural effects}

Feet lesions related to the environment can cause lameness. Constant wetness of the feet, as in cows forced to stand in slurry, probably contributes to infectious diseases of the feet (Williams et al., 1986). Factors such as quality of floor surfaces, rough concrete and condition of paths and roadways all contribute to foot lameness (Rowlands et al., 1983). Cow lying time has been linked to lameness and cow comfort (Potter and Broom, 1990; Faull et al., 1996).

\subsection{Infectious Causes of Lameness}

A number of bacteria are incriminated in foot disorders, such as Bacteroides, Fusobacterium, Spirochaetes and Campylobacter. Interdigital phlegnom (foul of the foot) is an acute painful inflammation of the interdigital tissues and Fusobacterium necrophorum is generally thought to be the cause. It is accepted that bacteria invade through traumatic dermal injuries and also after superficial inflammation of the skin (Peterse, 1992).

Digital dermatitis has only been described in the UK in the last twelve years (Blowey and Sharp,1988). Typically the lesion occurs on the skin at the plantar aspect of the foot. Early lesions produce matting of the hairs, which stand erect in a soft brown exudate, and have a characteristic pungent odour. Hair loss occurs and when the detritis has been removed the lesion, which is extremely sensitive to the touch, is seen as a circular, moist, red, raw, granulating area. The cause is not clear but Bacteroides capillosus and B. fragilis have been isolated (Blowey and Sharp, 1988).

\section{The control of lameness is largely empiric}

A number of guidelines are recommended: Appropriate housing (Faull et al.1996), good surfaces avoiding wetness and slurry (Williams et al., 1986), regular foot bathing (Davies, 1982), regular feet trimming (Toussaint-Raven, 1973), balanced ration (Manson and Leaver, 1989), nutritional management for replacement heifers (Greenhough and Vermunt, 1991) and in the longer term attention to feet when selecting sires. 
Asssessing nutritional status

It is recognised that diet formulation is not an exact science. Our ability to measure the nutrient content of feeds is relatively poor, our understanding of the use of nutrients in the animal is imperfect and there is no guarantee that the proposed ration is actually what is being fed to the animal. Given these limitations it is vital that animal performance is checked against prediction so that appropriate modifications can be made (Radostits et al., 1994; Chamberlain and Wilkinson, 1996; Kelly, 2000). They suggest that to do the appraisal properly many areas need to be monitored.

\subsubsection{Dry Matter Intake}

This can only be done on a group basis unless cows are fed on an individual basis in a byre or cow shed. Many cows are fed through feeder wagons with weigh cells and so it is possible to get reasonably accurate assessment of forage intake of the group. Accuracy will also depend on whether feed that is not consumed is measured. Social dominance and competition for food can markedly influence the dry matter intake of an individual animal (Grant and Albright, 1995).

\subsubsection{Calculated Energy Balance}

Calculation of energy balance requires knowledge of inputs and requirements for maintenance and production (Butler and Smith 1989). Accurate input calculations necessitate individually controlled feeding and detailed feed evaluation. Cow requirements will vary according to genotype, physiological and environmental situation. This information is unlikely to be available on most commercial units.

\subsubsection{Faecal Consistency}

This parameter is often overlooked. Important basic procedures such as examination of the faeces may give invaluable information regarding the balance of a diet (Brand et al., 1996b). Faeces can provide valuable information about a cow's 
digestive status. Faeces, that are too firm, indicate too much fibre or lack of energy in the diet or shortage of water.

Fluid faeces may reflect too little fibre or too much readily fermentable carbohydrate. Whole grain present suggests lack of fibre mat formation in rumen. Greasy faeces may indicate too much rumen-degradable protein.

\subsubsection{Cud Chewing}

Time is well spent watching cows lying down and ruminating. If effective fibre intake is being achieved half the cows should be doing this at any one time.

\subsubsection{Body Condition Scoring}

The advent of condition scoring (Lowman et al., 1973) allowed assessment of subcutaneous fat cover by a simple, quick and repeatable method. The body condition of a cow is assessed subjectively, using a five point system, by feeling with the hand the spinous processes of the loin area and around the tail head. Variations of the system are now in use throughout the world, in Australia (Earle, 1976), and in US (Wildman et al., 1982).

Condition score could be criticised for being a subjective measurement. Some workers have compared condition scoring with ultrasonic measurements and others with carcass composition giving a degree of confidence in the technique (Garnsworthy, 1988). One unit change in condition score is equivalent to between 25 and $40 \mathrm{~kg}$ body weight change with a mean value of $25 \mathrm{~kg}$ (Garnsworthy, 1988). Body condition change is judged to be a more sensitive balance than weight change (Ferguson, 1991). Changes in body weight are confounded by increases in gut fill, dry matter intake and shifts in body water as lipids are mobilised.

Many trials have shown that cows, which are fatter at calving, have lower intakes of dry matter in early lactation. Higher live weight or body condition at calving resulted in greater losses in live weight in early lactation (Garnsworthy, 1988). 
To maintain fertility body condition loss should be less than two thirds of one unit (Ferguson 1991).

\subsubsection{Milk Yield}

Milk yield can be a sensitive indicator of nutritional adequacy but it must be monitored on a regular basis and cow data must be sorted according to number and stage of lactation.

Lactation curves can be summarised by two parameters, peak and persistency and are useful for evaluating the overall effectiveness of management and feeding programmes (Nelson and Redlus, 1989). Peak yield x 200 gives the projected yield for the lactation. Persistency refers to the rate of decline after peak. This is usually between 8 and $10 \%$ per month for cows and 4 and $6 \%$ per month for heifers. The modern high yielding cow has been selected to maintain milk yield in spite of inadequate food intake by mobilising her body resources (Bauman and Currie, 1980). When milk yield and protein content finally fall the animal may have been in negative energy balance for some time.

\subsubsection{Milk Quality}

The factors influencing the constituents of milk are reviewed by Sutton (1986) and Blowey (1992). It is an extremely complex area of study. It is difficult to separate the effects of plane of nutrition, system of allocation of food, frequency of feeding and feed composition. All these factors can have an effect on milk composition. Superimposed on this are the effects of feeding before and after calving and the problem of differentiating between compositional values and overall yield. Breed, age and stage of lactation also have a marked effect. Breeds such as Jersey and Guernsey have better milk quality than other breeds. There is considerable variation of butterfat and milk protein composition within a breed and both are now important components of genetic selection.

Butter fat is synthesised from the fatty acids acetate and butyrate. These volatile fatty acids are the result of the fermentation of forage and other fibrous feeds. When concentrate:forage ratio rises much above $60: 40$ there is a risk of butter 
fat falling. Sutton (1986) calculated that milk fat fell by $0.05 \%$ for every $100 \mathrm{~g} / \mathrm{kg}$ decrease in the proportion of hay in the diet. Butter fat levels in milk respond rapidly to variations in the pattern of rumen fermentation.

Energy levels in the diet have most effect on milk protein. Severe underfeeding prepartum may reduce milk protein concentration. Decreasing concentrate in early lactation can also result in lower milk protein. Much of the milk protein is derived from microbial protein, which depends on the synchrony between fermentable energy and rumen degradable protein in the diet. Factors influencing microbial growth will ultimately be reflected in milk protein.

Infectious disease such as mastitis and liver fluke can influence milk composition.

In broad terms butterfat reflects the fibre content of the diet and milk protein relates to available fermentable energy. The response of milk protein to dietary energy is slower and less well defined.

\subsubsection{Metabolic Profiles}

The metabolic profile test was designed as a diagnostic aid to show the presence or absence of abnormal blood chemistry in dairy herds (Payne et al., 1970). The idea was not new. Blood chemistry had been used for many years to assess the metabolic status of individuals and groups of animals but a comparatively recent trend had been to link a number of these analyses together into a single package or multiphasic screening system. The metabolic test rationalised the use of blood chemistry with full statistical validation (Payne et al., 1974). The development of auto-analysers, which enabled analyses to be done at relatively low cost, helped the progress of this concept.

In the initial work samples from three groups of animals: (i) seven high yielding cows, (ii) seven mid-lactation cows, and (iii) seven dry cows were analysed for 12 blood parameters, namely glucose, urea, albumin, globulin, packed cell volume (PCV), haemoglobin, calcium, magnesium, phosphorus, sodium, potassium and copper.

Work was extended to include 191 herds comparing blood levels in summer and winter (Payne et al., 1974). It was concluded that the main source of 
variation in blood parameters were, the herd from which the herd was selected, level of yield and stage of lactation and the season of year.

Hewett (1974) in a detailed study in Sweden came to similar conclusions. None of these surveys attempted to give any metabolic, nutritional, management or environmental explanation for the fact that there were differences between herds. The fact that the herd is the greatest consistent variation gives validity to the metabolic profile test (Blowey, 1992).

Sampling 21 cows for 12 parameters was an expensive exercise and as a consequence Blowey et al. (1973) introduced a system of mini profiles. Six cows at between four and eight weeks of lactation were analysed primarily for energy and protein status. This system was found to have had considerable practical value in the field. Bauman and Currie (1980) introduced the term homeorrhesis (Greek derivation 'uniform flow') which they defined as the orchestrated changes for the priorities of a physiological state. The successful production of the modern dairy cow depends on the ability of the animal to partition nutrients to support pregnancy and lactation. Neither pregnancy nor lactation confers any special advantage on the animal. Instead they make tremendous demands such that the total metabolism of the pregnant or lactating animal must be altered to accommodate these needs. Nature has accorded a high priority to the functions of pregnancy and milk secretion allowing them to proceed at the expense of other metabolic processes even to the point that a disease state is created. The nutrient needs of the mammary gland are such that the cow might be considered an appendage of the mammary gland rather than the reverse. By measuring appropriate metabolites it may be possible to indicate whether the balance of functions is being maintained sufficiently to avoid the cow's health being impaired.

The metabolic test is intended to measure the balance between "input" in terms of nutrients absorbed from the gastro intestinal tract and "output" in terms of these nutrients in terms of the requirements of these nutrients for maintenance, pregnancy and lactation.

Since the original concept of metabolic profiles a massive literature has accumulated. There have been several comprehensive reviews (Lee et al., 1978; 
Adams et al., 1978; Ingraham and Kappel, 1988; Blowey, 1992; Whitaker, 2000). Opinions of the use of metabolic profiles in these reviews are equivocal and the conclusions of workers in the US (Adams, Lee and Ingraham) seem to be less favourable regarding the original concept. On the other hand Kronfield et al. (1982) were much more optimistic for the application of metabolic profiles. They also predicted that the best prospect was for the prediction of nutritional status.

There are numerous reasons for these differing views on the value of metabolic profiles. It must be appreciated that abnormalities in blood composition are the result of failure in a complex biochemical interplay, and the cause and effect relationships are seldom simple. Following the original suggestion (Payne et al., 1970) that metabolic profiles could detect imbalances between the dietary availability of the various nutrients and the requirements of production, many research workers have tried to find nutritional markers among blood constituents (Manston and Allen, 1981). Such a simple relationship between the concentrations of dietary and blood components is unlikely because of two factors, (a) the homeostatic control mechanisms within the animal which resist changes Blowey (1992) and (b) the complex factors governing rumen function and microbial flow which affect the availability of the nutrients in the diet (Somner, 1975). Although it is well known that a high concentration of one constituent can reduce the availability of another, these factors are far from being completely quantitated or understood. For these reasons a solution to a problem is much more likely if nutritional assessment and blood chemistry are used together than if one or other is used in isolation. One is no substitute for the other (Manston and Allen, 1981). They suggest that a form of profile used on a regular basis together with some monitoring of the diet is an attractive idea.

Elsley (1978) summarised the important features of any useful index of metabolic activity as follows:

- A defined methodology, including a satisfactory assay giving reproducible results under standard conditions.

- Satisfactory biochemical or physiological explanation for changes in blood concentration of the metabolite. 
- Knowledge of homeostatic control mechanisms, diurnal and prandial variations.

- Stability of metabolite.

- Correlation between parameter and health or production traits.

- Knowledge of how the index responds to major changes in environment, age, sex, genotype or body condition.

The original concept of the metabolic profile was to measure energy, protein, and mineral status of the herd (Payne et al., 1970).

\subsubsection{Energy Status}

Energy is the first limiting dietary component for optimal dairy cow performance in early lactation. Negative energy balance results in a reduction of glucose in the blood and liver, an increased fat metabolism and ketosis. Glucose metabolism in the ruminant as related to hypoglycaemia and ketosis was comprehensively reviewed by (Schwalm et al., 1971; Bergman, 1973). To offset the negative energy balance experienced by the high yielding cow in early lactation the cow mobilises fat and protein stores in the form of triglycerides and amino acids for gluconeogenesis. The supply of propionate and other precursors such as oxaloacetate appears to be an important determinant of the portion of fatty acids that is metabolised to ketone bodies.

For some considerable time the concentrations of plasma glucose, free fatty acids and ketone bodies have been used as indicators of energy status (Bowden, 1971). This review indicated that levels of non-esterified fatty acids and ketones in blood of sheep might be useful in defining the nutritional status of sheep, particularly during pregnancy and lactation. The authors indicated that further research was needed to investigate the possibility of using these blood constituents as criteria of nutritional status in cattle.

\subsection{Glucose}

Glucose is a key nutrient in the production of milk and would therefore be an attractive metabolite to measure with respect to energy balance. In cattle 
because of their established fermentative digestion only a small amount of glucose is absorbed and its main synthesis is from absorbed volatile fatty acids, in particular propionate and from some amino acids. The maximally secreting mammary gland may require up to $80 \%$ of the total glucose turnover (Bauman and Currie, 1980). The major need for glucose by the mammary gland is for the synthesis of lactose. A cow producing up to $40 \mathrm{~kg}$ of milk, containing $4.5 \%$ lactose would need over $2 \mathrm{~kg}$ glucose just for lactose synthesis. A coordinated response meets this need; rates of gluconeogenesis in the liver are increased dramatically, and glycogen is mobilised. The preference of other body tissues for nutrients to be oxidised for energy also is altered to allow partitioning of a greater percentage of glucose to the mammary gland. At day 30 prepartum, $34 \%$ of the total glucose is oxidised to $\mathrm{CO}_{2}$, whereas this decreases to only 8 to $9 \%$ by day seven of lactation.

Glucose then, not surprisingly, has been commonly used as an indicator of energy status although the correlation is by no means precise (Hewett, 1974; Parker and Blowey, 1976). An important control factor for the homeostasis of glucose in the lactating cow is that hypoglycaemia results in reduced milk production. In early lactation, however this control mechanism can be over-ridden by the hormones responsible for stimulating milk secretion and the cow may continue to secrete milk in the face of hypoglycaemia. Probably because of homeostatic mechanisms there are not particularly good relationships between glucose turnover rate or flow and blood concentration. Glucose would appear to be best used as a parameter in early lactation or perhaps late pregnancy (Lindsay, 1978).

It is necessary to interpret plasma glucose results with some caution from a diagnostic and prognostic viewpoint because plasma glucose may be normal or above normal in secondary ketosis and in cows fasted for some time. This may be due to glucocorticoid release from the adrenals (Roberts et al., 1978; West, 1990).

\subsection{Ketone Bodies}

Beta-hydroxy butyrate (BHB) is the ketone body, which is present in the greatest quantity in the blood of normal well fed ruminants (Bergman 1973; Kelly, 1984). It is stable and is not subject to stress or strong homeostatic control. Leng 
(1965) found a straight line relationship between blood concentration and entry rate of $\mathrm{BHB}$ up to $10 \mathrm{mg} / 100 \mathrm{ml}$, but thereafter small increases in entry rate were reflected in large increases in blood levels. When animals are under energy stress plasma ketones rise due to the incomplete oxidation of non-esterified fatty acids.

The two principal ketone bodies are acetoacetate and beta-hydroxy butyrate. Plasma acetoacetate would be the preferred ketone body to measure as it only rises to significant levels in plasma during times of energy stress (Lindsay, 1978). It is however unstable in plasma and the sample requires immediate deproteinisation which precludes its use from routine sampling under field conditions. In normal ruminants the ratio of beta-hydroxybutyrate: acetone is 7-8:1, but in the ketotic cow it may be closer to 1:1 (Menahan et al., 1966; Baird et al.,1968). There is a very close correlation between the blood concentrations of the two main ketone bodies $(r=0.9)$ and the concentration of BHB approximates to that of the total ketone bodies (Grohn et al., 1983).

One of the main disadvantages suggested for the use of betahydroxybutyrate is the fact that it is produced not only in the liver but also in the rumen epithelium derived from the volatile fatty acid butyrate (Menahan et al., 1966). As rumen $\mathrm{pH}$ decreases VFA absorption increases, butyrate greater than propionate, greater than acetate (Hoover et al. , 1991). Thus beta-hydroxybutyrate production in the rumen wall may be increased when acidotic conditions prevail e.g. when large concentrate feeds are fed or when large amounts of butyrate are produced in the rumen from butyric silage. Production of beta-hydroxybutyrate from the rumen wall will account for the prandial variations on BHB levels reported by (Coggins and Field, 1976; Manston and Allen, 1981 and Eicher et al., 1999). The variations reported on by Coggins were using beef cows and although the differences were significant the values of BHB were extremely low and well within the normal range for cattle. Manston working with dairy cows did show significant variation related to time of concentrate feeding and this would affect consideration of results. Cows are now generally fed concentrate in smaller more regular feeds and this is likely to minimise this effect. Eicher et al. (1999) found that concentrations of betahydroxybutyrate were relatively constant in herd with automatic concentrate 
distribution but significant diurnal variation was found in a herd fed concentrate only twice a day. In this trial the mean concentrations for BHB were all within the normal range. It is likely that large diurnal or prandial swings in plasma BHB concentration will be associated with feeding systems that have large single concentrate feeds resulting in fluctuations of rumen $\mathrm{pH}$ which are undesirable for optimum production.

Early experiments using BHB as an indicator of energy status were in sheep (Russel et al., 1967) and (Bowden, 1971) and were mainly concerned with assessing energy deficit in late pregnancy. Working with ketotic and control cows (Erfle et al., 1974) reported a strong inverse relationship with blood glucose and acetoacetate and beta-hydroxybutyrate. The correlation between energy balance and these parameters was weak. The relationship must have been confounded by the fact that animals were on propylene glycol and glycerol feeding experiments. Fisher et al. (1975) in experiments with mid lactation cows found differences in pre and post prandial blood levels. Samples before feeding had lower beta hydroxybutyrate and higher glucose and non-esterified fatty acids than those taken after feeding. They also found NEFA to relate most closely to each feeding level.

Kelly (1977) measured beta-hydroxybutyrate in groups of cows, on a regular basis, throughout a lactation on three commercial dairy farms. In this survey BHB concentrations did appear to reflect changes in dietary energy intake.

Herdt et al. (1981a) concluded that plasma glucose and BHB were not accurate indicators of energy balance when comparing a high concentrate diet $(60 \%$ of dry matter) with a low concentrate diet ( $40 \%$ of dry matter). Herdt did concede that blood $\mathrm{BHB}$ might be used as an indicator of the relative glucogenic potential of dairy rations and that blood concentrations of this metabolite could potentially be used to adjust factors in the ration which influence glucose availability. This would suggest that $\mathrm{BHB}$ concentrations reflect directly or indirectly diet utilisation by the cow rather than calculated energy requirement. It is also important to note that the experiments by Erfle, Fisher and Herdt all quote mean BHB levels in all groups well within the normal range of below $10 \mathrm{mg} / 100 \mathrm{ml}$ (Whitaker et al., 1983). 
Herdt et al. (1981) in another survey established that herds experiencing a high prevalence of ketosis had higher BHB log means than did normal herds. Grohn et al. (1983) identified cut off points for BHB in dairy cows: at healthy (below $1 \mathrm{mM}$ ), mildly ketotic (1-3 mM), and severely ketotic (over $3 \mathrm{mM}$ ), agreeing with the normal range of Whitaker et al. (1983).

Russel et al. (1979) in trials with suckler cows found BHB concentrations in late pregnancy to be closely and inversely related to energy intake. $\mathrm{BHB}$ is more likely to be more closely related to the difference between energy intake and energy expenditure than to energy intake per se. He indicated that $\mathrm{BHB}$ is likely to prove useful as a means of assessing energy status in situations where energy intake and/or expenditure cannot be measured or estimated.

\subsection{Non-esterified Fatty Acids (NEFA's ) or Free Fatty Acids (FFA's)}

In response to underfeeding, an animal mobilises body reserve by hydrolysing the neutral fat molecule. The long -chain fatty acids (NEFA) thus produced pass to the liver for degradation and subsequent release of energy (Bowden, 1971). They are transported in the blood bound to albumin and their concentration can be measured. An elevated concentration indicates excessive mobilisation of fat and hence energy deficit. It is susceptible to diurnal and prandial fluctuations (Coggins and Field, 1976) and (Fisher et al., 1975). Lindsay (1978) was of the opinion that NEFA was a most sensitive index of the adequacy of feed intake but the major disadvantage is the fact that it is stress sensitive. These authors referring to the diurnal, prandial and stress sensitivity of NEFA all quote Holmes and Lambourne, (1970) who reported that NEFA varied inversely with energy intake, fell after a meal and was elevated by excitement. They also observed that rises in NEFA due to excitement, were reduced by training. All results reported are, however, well within the normal range for early lactating cows.

Radloff et al. (1966) suggested that plasma NEFA's are a primary source of ketones under fasting conditions but that blood sugar is the controlling factor under both fed and fasting conditions. It would seem likely that NEFA's are most useful during times of energy stress in late pregnancy and early lactation (Kelly, 
1984). Huszenicza et al. (1988) quoted threshold levels as below $0.8 \mathrm{mmol} / \mathrm{l}$ in $1 \mathrm{st}$ week post calving and $0.4 \mathrm{mmol} / 1$ in weeks $2-8$.

Gerloff (1988) reviewed the factors, which lead to NEFA mobilisation in the run up to parturition. He advocated reducing stress, maximising quality roughage intake and avoidance of body condition loss as being important in avoiding high plasma NEFA levels with the risk of fatty liver. Harrison et al. (1990) found that both BHB and NEFA were correlated negatively with energy balance and suggested that they may provide general indications of overall energy status.

Many parameters or combinations of parameters have been suggested as being useful to identify the extent of fatty infiltration of the liver (Reid et al. 1983; Grohn et al. 1983). West (1990) investigating cows with primary acetonaemia found plasma bilirubin and total bile acids to correlate with the extent of fatty liver.

The hormones predominantly responsible for glucose homeostasis are insulin and glucagon. Glucagon is decreased in the blood of cows that are obese at calving and declines further during ketonaemia (Hippen et al., 1999). All these parameters or combinations may have their place in investigations of individual sick cows, but the cost of some of the combinations would currently limit their use on a wide scale. There is no doubt that increasing the number of metabolites measured, provided the results are interpreted by an experienced clinician, as part of a full investigation, may enhance the accuracy of an investigation.

Recently a peptide hormone leptin has been shown to regulate body weight by signalling the amount of fat stored. The discovery of leptin has improved the understanding of the relationship between adipose tissue and energy homeostasis (Caro et al., 1996). Barb (1999) suggests that leptin may serve as a metabolic signal communicating to the brain how much stored energy is available from fat deposits. He suggests that leptin may be the fat signal that links reproductive and adipose tissue. At the present time a reliable assay is not available for use in the cow (O’Callaghan and Boland, 1999).

\subsubsection{Protein Status}

\subsection{Urea}


Urea levels in plasma are primarily derived from rumen ammonia, although a certain amount may arise from hepatic deamination of amino acids. The metabolism of urea was reviewed by Blowey (1972). He concluded that there was a range of factors that could lead to an increase in urea levels.

- An increase in protein intake. This has also been demonstrated experimentally by Treacher (1978).

- An increased proportion of RDP in the diet, since this would result in a higher proportion of dietary protein being converted to ammonia

- A decreased energy intake, leading to depressed microbial assimilation and an increased 'leakage ' of ammonia from the rumen.

- An increase in rumen $\mathrm{pH}$ again allowing for greater loss of ammonia from the rumen.

- Increased body catabolism. This is unlikely to occur on a herd basis.

There is good evidence that urea entry rates and excretion rates are well correlated with plasma urea $\mathrm{N}$ concentration (Lindsay, 1978). Serum urea concentrations respond within days to changes in protein intake whereas haemoglobin, PCV and total protein take several weeks to respond to change (Treacher, 1978).

\subsection{Albumin}

Treacher (1978) reviewed the use of albumin as an indicator of protein status. Albumin, which is a protein synthesised in the liver, is an indicator of long term protein status and of the intake of undegradable protein. Albumin may take several weeks to reflect a change in protein intake. Although albumin was related to protein intake the relationship was not always consistent. It is thought that the variations in dietary protein pre calving can effect albumin levels post calving. Albumin falls sharply in some cows following calving, but not all cows are affected (Little, 1974). Cows may have to catabolise muscle protein to counteract the massive demands for protein in early lactation, which can not always be met by dietary protein. A more rapid rate of recovery of blood albumin levels has been correlated with improved fertility and higher milk yields (Rowlands, 1978). 


\subsection{Globulin}

Globulin confers immunological competence. High levels in the blood commonly link with recent immunological events such as infection or vaccination. (Payne, 1989). Albumin and to some extent globulin, need effective homeostatic control as they influence osmolarity of the blood. The concentration of albumin and globulin thus compensate each other to some extent. When albumin is low, globulin is high and vice versa.

\subsubsection{Mineral Status}

\subsection{Calcium}

The firm homeostasis for calcium limits its use in the metabolic profile (Pickard 1978; Kelly, 1988). The concentration of calcium in the blood may be used to confirm a diagnosis of parturient paresis. There is no satisfactory means of assessing the calcium status of cows so that the probability of hypocalcaemia occurring could be forecast.

\subsection{Magnesium}

There is little or no hormonal control of blood magnesium levels and that which is absorbed in excess of requirements is excreted in the urine. Low blood magnesium levels equate with dietary deficiency or more accurately low gut absorption levels.

The normal range is $0.7-1.3 \mathrm{mM} / 1$ and when levels fall to below 0.4 , tetany is likely (Pickard, 1978).

\subsection{Phosphorus}

Phosphorus tends to have a place intermediate between calcium and magnesium, in that blood levels do tend to reflect phosphorus intakes but there is some hormonal regulation (Pickard, 1978). Low blood phosphate levels are commonly found in grazing cattle (Parker and Blowey, 1976). They estimated that pasture alone could only sustain yields of 20 litres. Phosphorus availability is 
reduced by a high intake of aluminium calcium or magnesium. The question of availability of phosphorus is difficult to resolve (Pickard, 1978).

\subsection{Trace elements}

\subsection{Copper}

Blood copper values are not an accurate guide to body and liver status, where most of the mineral is found (Suttle, 1986). The optimum value is over 9.4 micromol for blood and $7.5 \mathrm{micromol} / \mathrm{litre}$ for serum (Suttle, 1993). If levels are low health and productivity may be affected as copper plays an integral part in many biochemical processes.

A copper responsive fertility problem is only likely to be found where the forage contains $5 \mathrm{mg} / \mathrm{kg}$ DM molybdenum or more (Suttle, 1993).

\subsection{Selenium (Glutathione peroxidase (GSHPx))}

GSHPx is a selenium containing enzyme. Estimation of it allows a judgement to be made of selenium intake over the previous month or two. Optimum GSHPx concentrations are over 50 units per $g$ of haemoglobin (Suttle, 1986).

\subsection{Iodine (Thyroxine (T4))}

This is a measure of iodine status but interpretation is difficult because of the variety of factors, which affect thyroxine levels. Optimum values are above $20 \mathrm{nmol} /$ litre. Low values in milkers may be associated with poor production but the main interest is low values in dry cows associated with abortions or the birth of dead calves (Whitaker, 1999).

\subsubsection{Milk Profiles}

The use of milk profiles was reviewed by Plymm Forshell (1994). If the same rigour in cow selection, timing of tests and assessment of background information is made when interpreting biochemical results then milk testing may have considerable value. Milk results should be assumed to reflect nutritional status rather than dietary intake. Dry cows cannot be monitored using milk testing. 
This wide ranging review is an attempt to draw together some of the important factors which have to be considered in monitoring a herd in a manner that is likely to ensure optimum health, productivity and profitability. 
Chapter Three 
This chapter gives the background to the establishment of the Dairy Herd Health and Productivity Service (DHHPS)

\subsection{Establishment of the DHHPS}

Prior to the establishment of the Dairy Herd Health and Productivity Service (DHHPS) one year was spent routinely blood sampling dairy cows throughout their lactation and dry period. These samples were analysed for plasma glucose, beta-hydroxybutyrate (BHB), non esterified fatty acid (NEFA), plasma urea $\mathrm{N}$, albumin, total protein, globulin, calcium, magnesium and inorganic phosphate. The biochemical results were interpreted together with the background information relating to the age, production, body weight change, condition score and stage of lactation of the individual cows. The results reported by Kelly (1977) were of sufficient interest to form the basis of a service to be offered to selected dairy farmers.

The service (DHHPS) offers accurate monitoring and assessment of the status of dairy herds vis-à-vis the balance between health, productivity and management (including nutrition).

The service is essentially a co-operative exercise, depending on the participants both for the collection of data and the interpretation of findings and implementation of recommendations

\section{The principal participants are:}

- The farmer

- The farmer's veterinary surgeon

- The nutritional adviser

- The University based consultant 


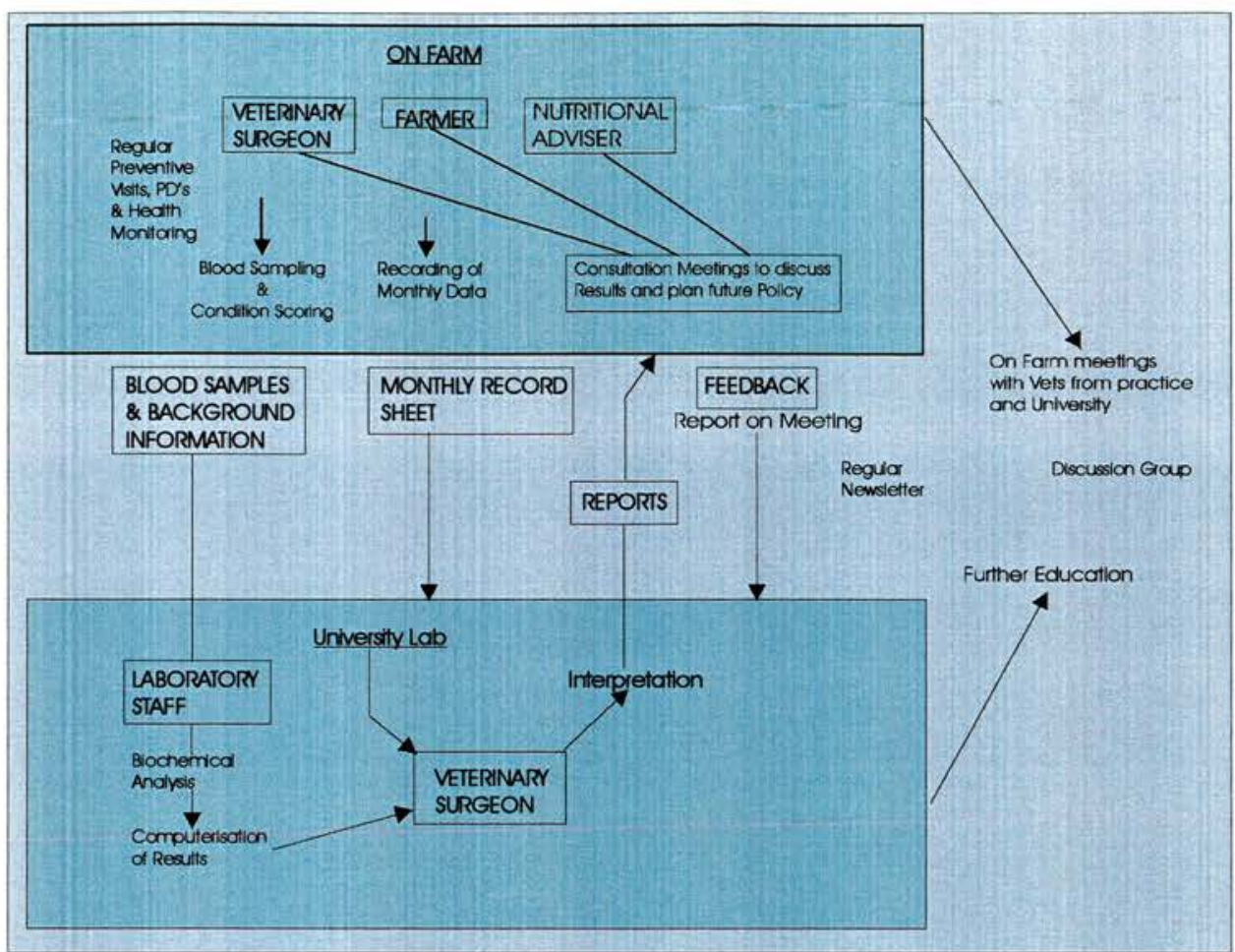

Fig 3.1 How the service operates

\section{The service involves:}

- Keeping herd records relating to production, breeding, health and management practices

- Food analysis and ration formulation

- Biochemical examination of representative blood samples

- Interpretation of biochemical results by a laboratory based veterinary surgeon using all relevant information and reporting findings to all concerned

- Meeting on farm to discuss results and implement any corrective measures indicated

- $\quad$ Reporting back to all concerned with the feedback summary of the meeting 


\subsection{Materials and Methods}

\subsubsection{Farmers are recruited according to the following criteria:}

- They are judged to be receptive to the concept of maintaining optimum health by appropriate nutrition and management (i.e. they are convinced of the preventive as opposed to the fire brigade approach to veterinary medicine)

- They must be willing to keep some well defined records

- The dairy herd has normally at least seventy cows

- They must be prepared to use their veterinary surgeons regularly and use information produced constructively

- The farmer's veterinary surgeon is like-minded and agrees to play their part in the exercise

- The farmer must be prepared to pay his veterinary surgeon for collection of samples and follow up visit. Except in the first year the farmer also paid the sponsors (Spillers and subsequently Dalgety/Spillers) a membership fee. This fee was recouped from the farmer to offset part of the grant paid by the sponsors to Edinburgh University

- The farmers will use the sponsor's dairy concentrate.

\subsubsection{The veterinary surgeon's commitments are:}

- To be actively and positively involved

- To participate in the planning of tests and selection of cows

- To carry out blood sampling

- $\quad$ Pack and post blood samples and background data (Sheet 3, Fig 5 2. ) promptly to the Edinburgh University laboratory

- Call and attend post-sampling discussion meetings

- $\quad$ Supervise record keeping and be proactive in acting on Quarterly Herd Health Reports (Fig 4.2)

3.2.3 The nutritional adviser must have an interest in co-operation with the veterinary profession and must be prepared to participate in planning the timing of tests, condition scoring and weighing cows and attending discussion meetings. 


\subsubsection{Procedure for new DHHPS members}

- Identification of potential member by veterinary surgeon or nutritional adviser

- Direct contact with farmer's veterinary surgeon if they have not been involved in suggesting that herd would benefit from membership. This must be done before any final decisions are made. This is essential to ensure good relationships with all concerned and also to ascertain the suitability of a particular farm for participation in this type of exercise

- University based veterinary surgeon will contact veterinary practice if those concerned had no previous experience of DHHPS

- $\quad$ Clarify with the farmer the commitments of membership of the DHHPS

- Obtain a signed agreement from the farmer

In order to promote the service, the author visited many individual farms and addressed numerous farmer and veterinary meetings throughout the United Kingdom. The important thrust of this activity was to promote the concept of a positive team approach to attaining and sustaining good animal health the consequence of which would be optimal productivity and ultimately profitability. A major effort was also made to enthuse, inform and appraise the sponsor's nutritional advisers whom it was anticipated would play a key role in the operation of this exercise.

When the farmer has signed an agreement form a Sheet 1 (Fig 3.2) is prepared giving basic background information on the dairy herd. 


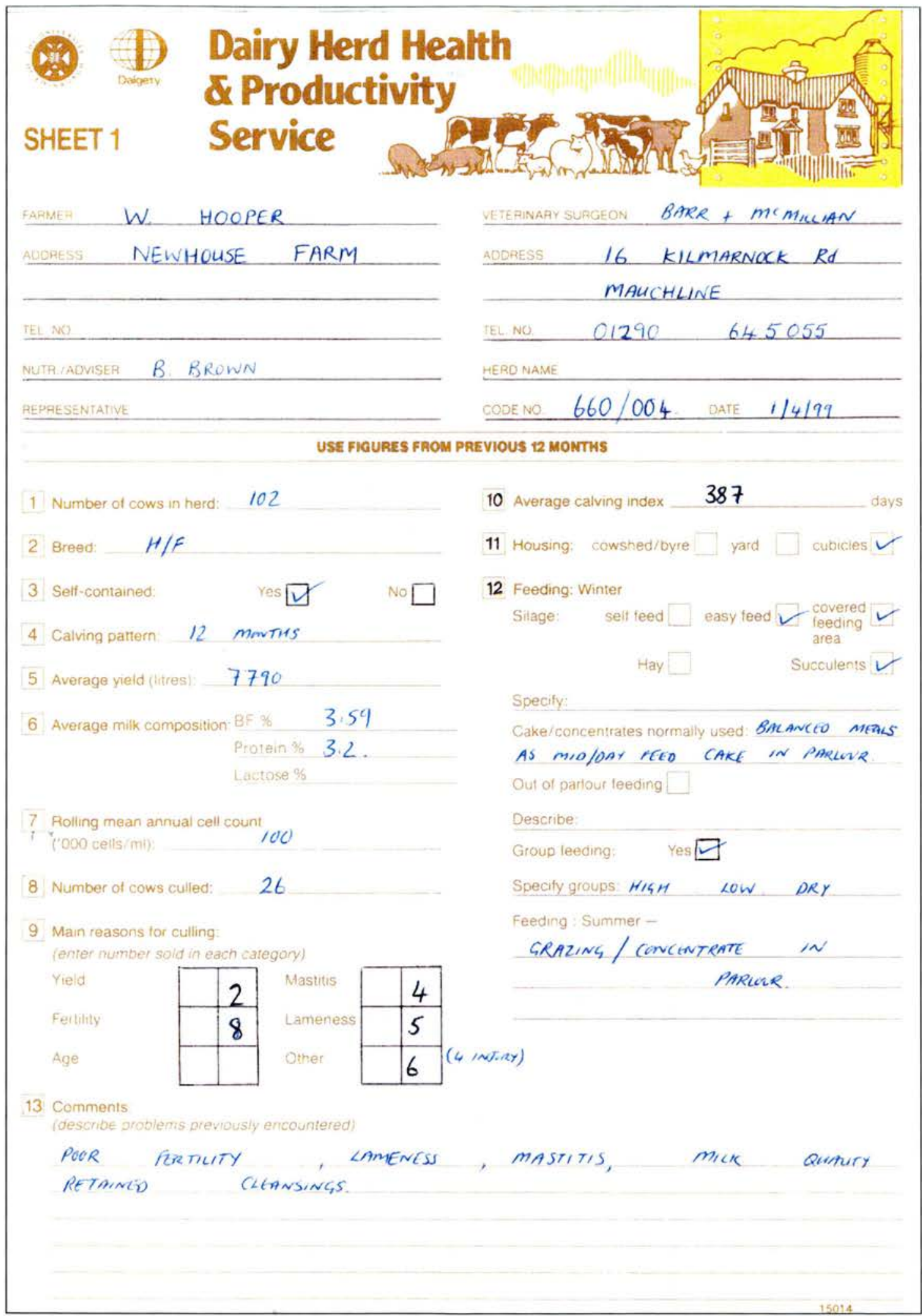

Fig 3.2 Sheet 1 
Sheet 1 (Fig 3.2) The function of this form is to:

- Record appropriate contact addresses of all concerned with the operation of DHHPS on a particular unit

- Indicate the aims and objectives of herd management

- Provide details of herd size, breed, structure and recent productivity

- Identify housing and management systems used

- Document particular health or production problems which herd owner would wish the DHHPS to particularly address

3.2.5 Statistics Microsoft Excel 97 and Sigma Stat for Windows Statistical Software (SSPS) Version 2.0 was used to analyse the data in this thesis. Raw data was extracted from the Dairy Herd Health and Productivity Service Access Version 2 database using Structured Query Language (SQL). The Descriptive Statistics procedure was run on extracted data performing tests and counts such as sample size, mean, standard deviation, standard error, range, confidence intervals and maximum and minimum values. 


\subsection{Results}

\subsubsection{Number of DHHPS members}

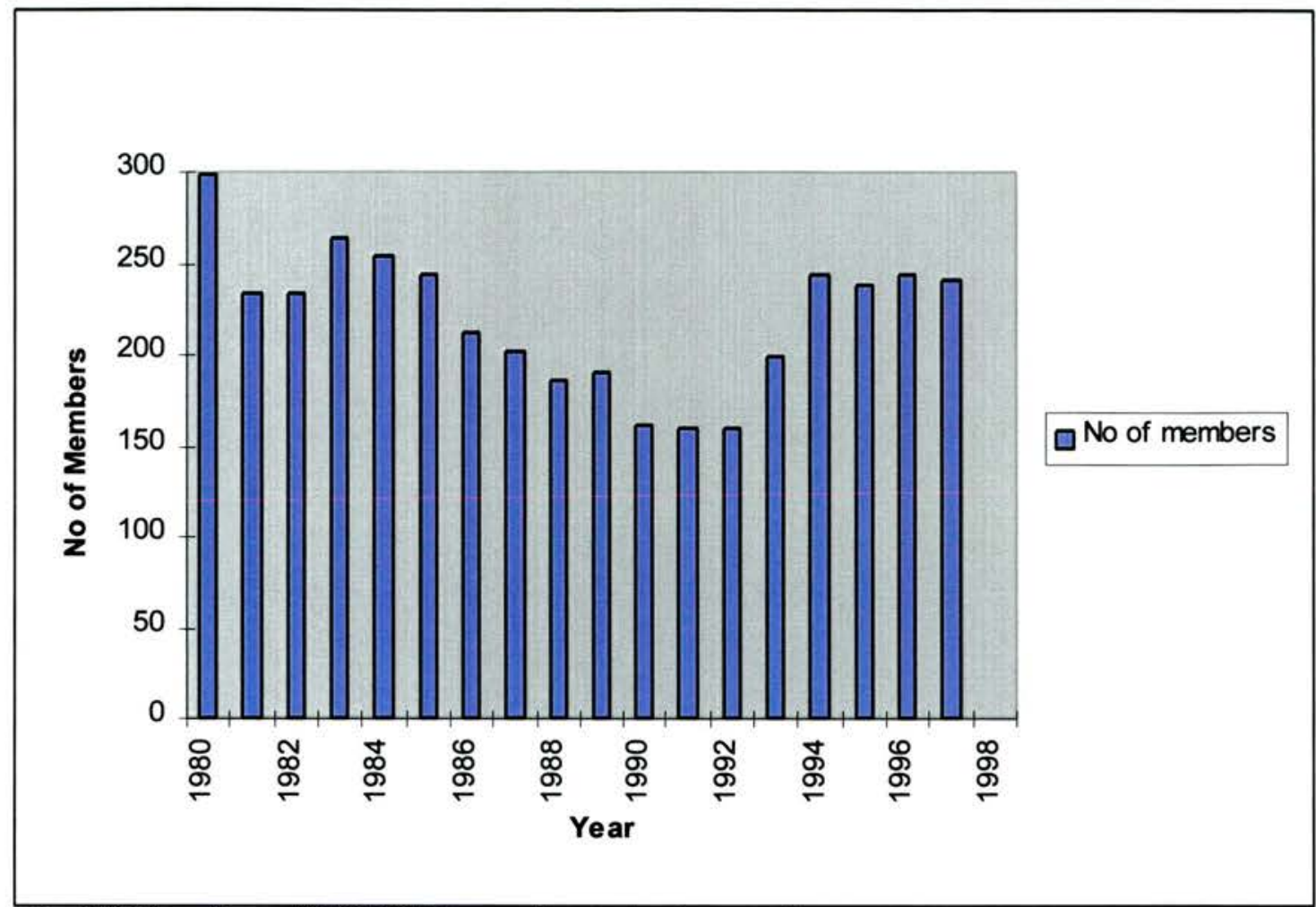

Fig 3.3 Number of DHHPS members during each year

The average number of members each year since the service was established has been 220 . The number of members fluctuates each year often because of external pressures on the agricultural industry and for other commercial reasons. Only $16 \%$ gave the reason for withdrawing as lack of interest. 


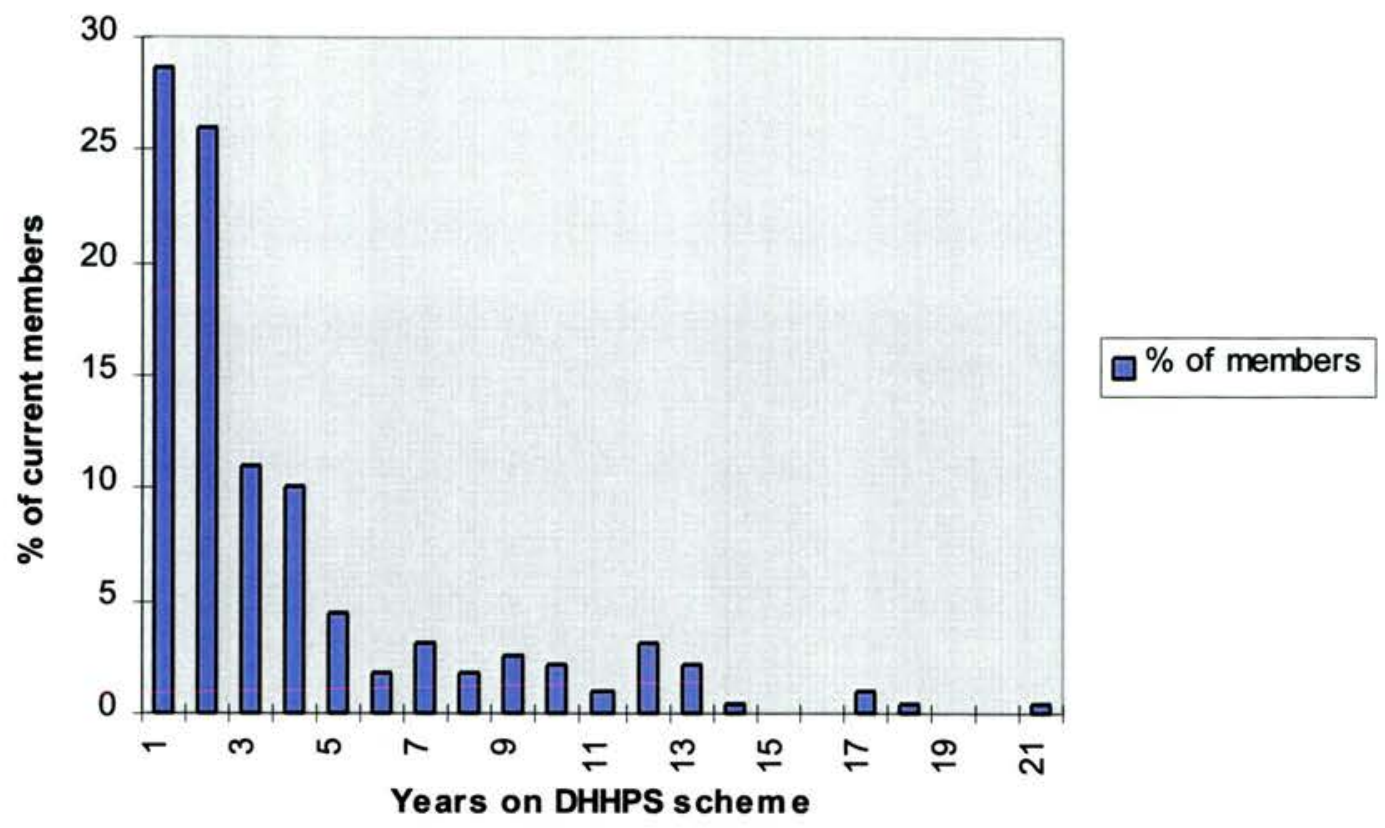

Fig 3.4 Number of years current members have been on DHHPS (results calculated from 227 members, 14/07/97)

Herds which have withdrawn from DHHPS have remained members for an average of 28 months. However herds which regularly return monthly data (Sheet 2, Fig 4.1) remained members for an average of 36 months. 


\subsubsection{Cow breeds from DHHPS farms}

Table 3.1 Cow Breeds from 309 DHHPS Sheet 1's to May 1998

\begin{tabular}{|l|c|c|}
\hline \multicolumn{1}{|c|}{ Breed } & $\begin{array}{c}\text { Number of } \\
\text { Farms }\end{array}$ & $\begin{array}{c}\text { \% of DHHPS } \\
\text { Farms }\end{array}$ \\
\hline Ayrshire & 7 & 2.3 \\
\hline Dairy Shorthorn & 0 & 0.0 \\
\hline Guernsey/Holstein/Friesian & 1 & 0.3 \\
\hline Guernsey & 1 & 0.3 \\
\hline Holstein/Friesian & 283 & 91.6 \\
\hline Jersey & 7 & 2.3 \\
\hline Mixed breeds & 10 & 3.2 \\
\hline
\end{tabular}

The main breed is Holstein/Friesian

\subsubsection{Herd Size at May 1998}

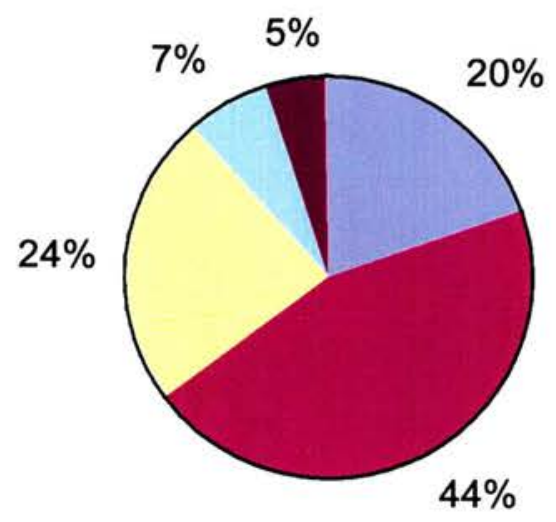

$\square<100$ cows

ㅁ 100-149 cows

150-199 cows

200-249 cows

$>250$ cows

Fig 3.5 Herd size range of DHHPS farms. Data collected from 316 DHHPS Sheet 1's (correct to May 1998)

The average herd size is 141 cows 
3.3.4 Milk yields in DHHPS herds

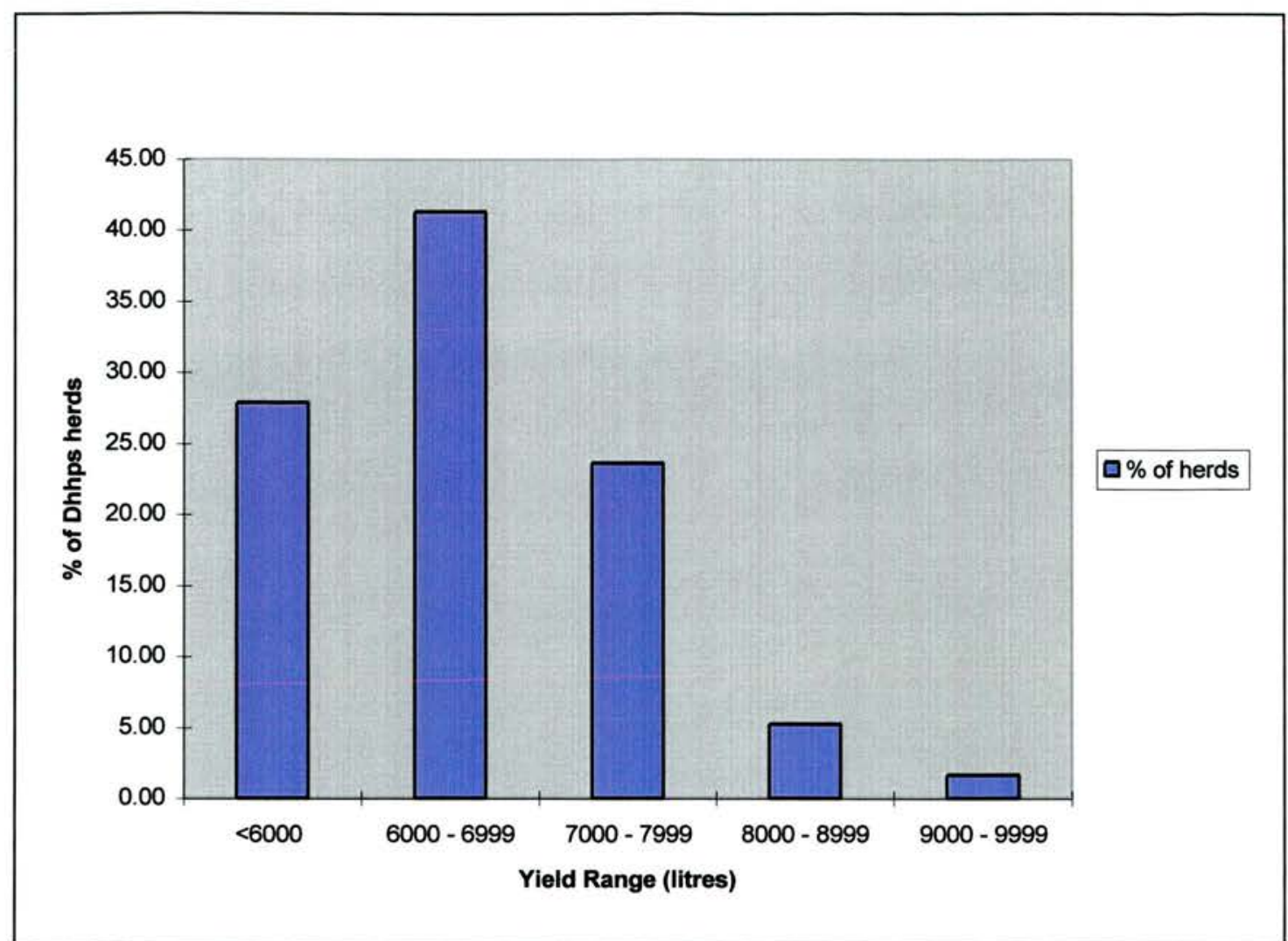

Fig 3.6 Varying milk yields of DHHPS farms, data collected from 305 DHHPS Sheet 1's (correct to May 1998)

72 per cent of DHHPS herds have herd average yields over 6000 litres. 31 per cent are over 7000 litres. 


\subsubsection{Forage feeding systems}

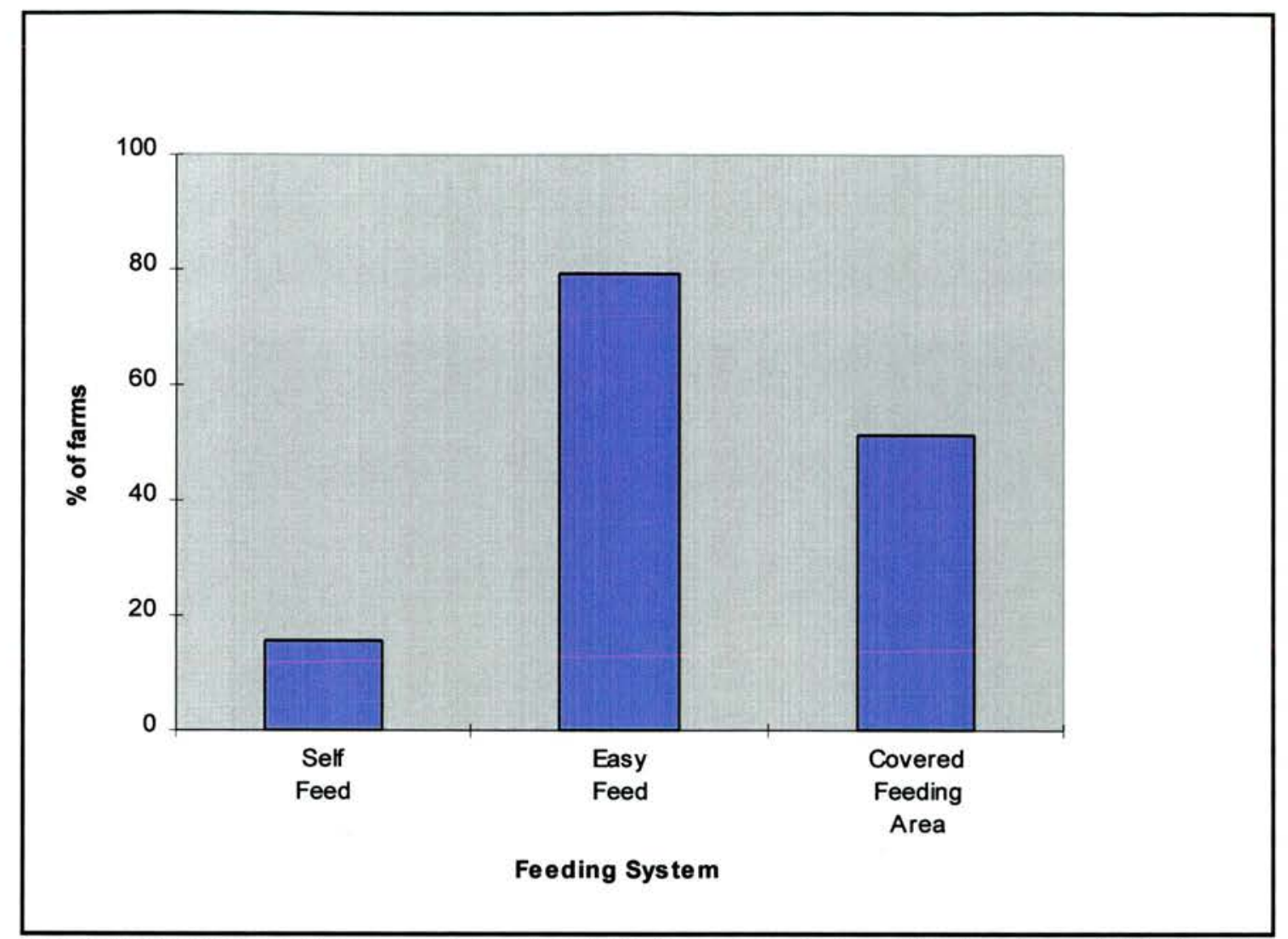

Fig 3.7 Feeding systems used by DHHPS farmers, data collected from 294 Sheet 1's (correct to May 1998)

79.3 per cent of farms provide forage on an easy feed basis. 51.4 per cent of DHHPS farms have a covered feeding area.

\subsection{Discussion}

\subsubsection{The Farmer}

From the outset there has been no difficulty in getting farmers interested in the DHHPS. Any new project will always attract interest because of its novelty value. The fact that the service was launched with the backing of the Royal (Dick) School of Veterinary Studies, was obviously attractive to some. As was expected, some of the first members were well known leaders in the agricultural industry. Some were approached because they were well known personalities or leading farmers in the area e.g. National Farmers' Union Chairmen. Some were chosen because they were personal friends of the nutritional adviser or veterinary surgeon. 
In the first year many no doubt were attracted by the fact that there was no charge for the service.

The membership over the years has followed the trends and fortunes in the dairy industry. When morale was low, i.e. following the introduction of milk quotas, membership suffered. When profitability was being marginalised the numbers tended to drop. This is in fact the situation at the present time when the milk price is depressed and the whole of UK agriculture is experiencing severe financial pressure.

Over the period that the DHHPS has been in operation there have been dramatic changes in the industry. Unit size and individual cow production is expanding as the number of herds decreases. The deregulation of the dairy industry in November 1994 meant that at least in the short term dairy farming was highly profitable but also extremely competitive. The recent down turn in agriculture is likely to be followed by a cyclical upturn in the profitability of dairy farming. The problem for many farmers will be to survive the current severe depression. From the farmer's point of view, many have invested a great deal of money and the stakes are high. The majority of dairy managers will have had some form of formal training either at college or university. The dairy industry now has a younger, better educated work force and this trend is predicted to continue. There will be fewer dairy farms in the future but those remaining will tend to be larger, more progressive and more inclined to use specialist consultancy services. These recent events must be in part responsible for the maintenance of membership in the face of a sharp decline in the number of dairy units. There is still considerable interest in the concept of the DHHPS and new members are still being recruited.

\subsubsection{The Veterinary Practitioner}

The attitude and involvement of the veterinary surgeon has also changed quite dramatically over the years. At the outset many veterinary surgeons gave tacit approval of the scheme but in practice were often not particularly supportive. At this time many practices were still receiving a significant portion of their income from MAFF tuberculin and brucella testing and were fully stretched to fulfil these contracts in addition to the normal routine clinical work. Some recognised that the 
pattern of dairy work would change in the future but were themselves neither prepared or equipped to become involved. It may well be that some considered that their undergraduate education had not prepared them to feel confident in advising on nutrition and management. At the same time many veterinary surgeons were diversifying their practices and were concentrating much more on small animal and equine work. For whatever the reason, many practitioners were slow or reluctant to become involved in dairy herd advisory work. Some farmers nearer the bigger urban conurbations expressed difficulty in obtaining a veterinary surgeon willing to become involved in this type of exercise.

The situation has changed considerably over recent years. Advisory work is now an integral part of the modern dairy practice. The undergraduate curriculum at most UK veterinary schools attempts to prepare veterinary graduates for routine advisory programmes. Many Continuing Professional Development Courses (CPD) have dealt with the whole herd approach to farm animal practice. As a result many younger members of the profession now feel much more comfortable with aspects of nutrition and management. Specialist divisions of the British Veterinary Association e.g. the British Cattle Veterinary Association and other world-wide associations regularly feature management and nutrition as topics of interest and relevance. Many veterinary surgeons spend a large part of their time in routine advisory work and several have evolved their own monitoring services. The recent introduction of Farm Assurance Schemes has given the veterinary surgeon the opportunity to become involved in many aspects of preventive medicine and disease recording

\subsubsection{The Nutritional Adviser}

The nutritional advisers employed by the sponsors have proved to be extremely important members of this co-operative exercise. At the outset many of them were traditional in their approach to giving a service to the farmer. Many would be content to supply feed to the farmer according to his perceived requirements without getting involved with wider issues such as management, health and disease. The relationship between the agricultural trade and the veterinary profession frequently left a lot to be desired. Veterinary involvement with a feed 
firm was traditionally because of a complaint! Veterinary surgeons on the other hand tended to be resentful of other people advising their clients! The relationship between nutritional advisers and veterinary practices has vastly improved over the past fifteen years. There is recognition that the major disease and production problems can only be resolved by a co-operative effort and it is no longer possible for any one profession to have comprehensive knowledge of all complex, rapidly developing scientific areas such as animal nutrition.

Many of the sponsor's nutritional advisers have a university training in animal nutrition and several have a post graduate qualification. The success of the service in some areas has been a reflection of the enthusiasm and skill of the nutritional adviser who has often taken the initiative in organisation and record keeping.

\subsubsection{Reasons for Leaving the Service}

Farmers have left the DHHPS for a variety of reasons. However the most common have been outwith our control. Many dairy farms have ceased to dairy or have been sold. Another common reason for leaving is because the farmer ceased to trade with the feed manufacturer for commercial or financial reasons. In times of depression in the dairy industry, farmers cut costs and these savings often result in reduction in use of their veterinary surgeon. Some farms which have been members for two or three years consider that they have had problem areas identified and that there is no need for further monitoring. Many of these farms use the service again when problems reappear.

The success of the service depends entirely on the enthusiasm of all concerned. The ideal situation of farmer, veterinary surgeon and nutritional adviser working together as a team ensures that the DHHPS will work well with benefits to all concerned. If one or two members of the team are not fully committed then the service functions less efficiently, enthusiasm wanes and the herd leaves the scheme. Membership success has been clearly associated with enthusiastic vets and advisers.

These findings are similar to those of Goodger and Ruppanner (1982b) who discussed why the dairy industry in the US does not make greater use of veterinarians. They concluded that dairy operators do not look to veterinarians to 
provide an integrated approach to herd management. They rely instead on feed representatives, nutritionists, accountants and staff of dairy co-operatives. Dairy farmers tend to perceive veterinarians only as providers of clinical services. This perception of the veterinary surgeon as being only a clinician deprives the dairy operator of an objective appraisal of herd health, management and production. 
Chapter Four 
This chapter deals with the monthly data collection from the farm. It describes how these data are processed, interpreted and utilised.

\subsection{Monthly Data Input}

Collection of this data is an integral part of DHHPS membership. It accumulates information for the Quarterly Health Report and ensures communication of health and production data between all those involved with the operation of the DHHPS on the farm.

\subsubsection{Sheet 2 (Fig 4.1)}

These are completed during regular monthly calls by the sponsor's nominee (normally nutritional adviser). The person responsible on the farm should be expecting the call and have the relevant data available. If a regular recording system is not in use on the farm a barn sheet (Appendix 1) is provided.

Copies are made available as follows:

- $\quad$ Left on farm

- Sent to veterinary practitioner

- Sent to DHHPS unit in Edinburgh

- Retained by nutritional adviser

- $\quad$ Filed at sponsor's regional technical services office

Clear instructions are given to farm staff to ensure that the information given is accurate and consistent.

The following are recorded:

- The farm name, code number, relevant month and year

- $\quad$ Parlour feed

- Out of parlour concentrate

- Identification of forages in use

- Herd Assessment 


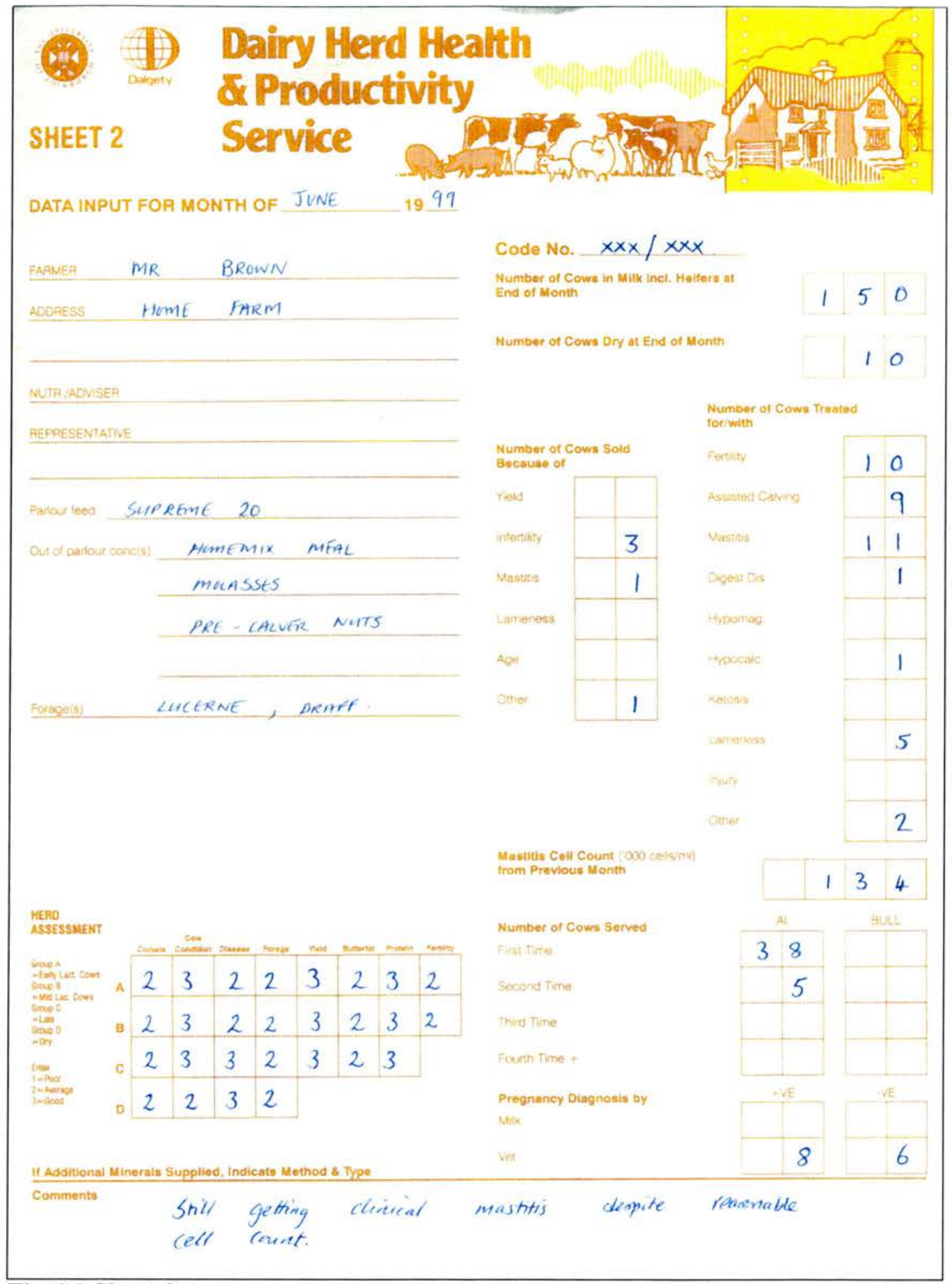

\section{Fig 4.1 Sheet 2}


This scoring system of:

- $1=$ poor

- 2 = average

- 3 = good

is an assessment by farm staff of some important aspects of production or of key factors likely to influence productivity

- Number of cows in milk (including heifers) on last day of the month

- Number of cows dry at the end of the month (not including heifers about to calve for the first time)

- Number of cows sold because of - If, as is common, cows are disposed of for more than one reason enter farmer's judgement as to primary cause. Under 'other' specify if possible. Deaths entered under 'other' and again specify if possible

- Number of cows treated for: Each case entered only once even if treated for three consecutive days.

- Fertility - Entries should be made for vaginal discharge (or metritis), vaginitis, prolapse, retained placenta, ovarian cysts, unobserved oestrus, abortion or repeat breeder. Routine treatments for synchronisation of oestrus are not recorded.

- Mastitis - All clinical cases, including summer mastitis, should be entered. Where treatment lasts for several consecutive days, it should only be entered as one case of mastitis. If mastitis occurs in the same quarter in the same month it should not be entered again. Routine dry cow therapy should not be recorded.

- Mastitis cell count ('000 cells $/ \mathrm{ml}$ ). To avoid delay in distributing data previous monthly average figure is used.

- Digestive disease/upset - All conditions apparently of digestive origin such as diarrhoea, rumen acidosis, rumen atony/stasis or displaced abomasum.

- Hypomagnesaemia (staggers) - Clinical cases should be recorded only once even if treatment is carried out for several days.

- Hypocalcaemia (milk fever) - Clinical cases only should be recorded. Routine preventive treatment with calcium or vitamin $\mathrm{D}$ injection should not be recorded 
as cases of hypocalcaemia. Recurrence of clinical signs within one week should not be recorded.

- Ketosis (acetonaemia, slow fever) - Only primary cases should be recorded. Cases which occur as a secondary result of conditions such as metritis, toxic mastitis or displaced abomasum should not be recorded in this category.

- Lameness: Enter each incident once even if treatment is carried out for several days or has to be started again in one or two weeks later. If lameness occurs in an other leg it constitutes another case. Routine foot trimming or dressing should not be recorded.

- Number of cows served. First time AI means first service after calving whether by natural service or AI.

- BULL services - If a bull is run with the herd, stockmen should still record services for their own purposes as well as for the report and they should record observed heats as services during this period too. If natural services are not recorded the analysis figures on the report will be inaccurate.

- Pregnancy diagnosis by milk (note whether sampled 19, 24 or $45+$ days after service).

- Pregnancy diagnosis by vet. Note whether scanning or rectal palpation. Always enter negatives as well as positives.

- Comments

Any comments, queries or additional information

\subsubsection{Quarterly Herd Health Report (Fig 4.2)}

This report is generated four times a year and requires continuity of monthly Sheet 2's. The first quarterly report is issued after four sheet 2's have been received. Sixteen consecutive reports are required before a complete annual report can be produced. The annual report produces annual percentage figures for each parameter and compares specific results with the previous quarter and with the same quarter last year. The report summarises and compares culling rates and disease incidence and contains information required for Quality Assurance Schemes. 


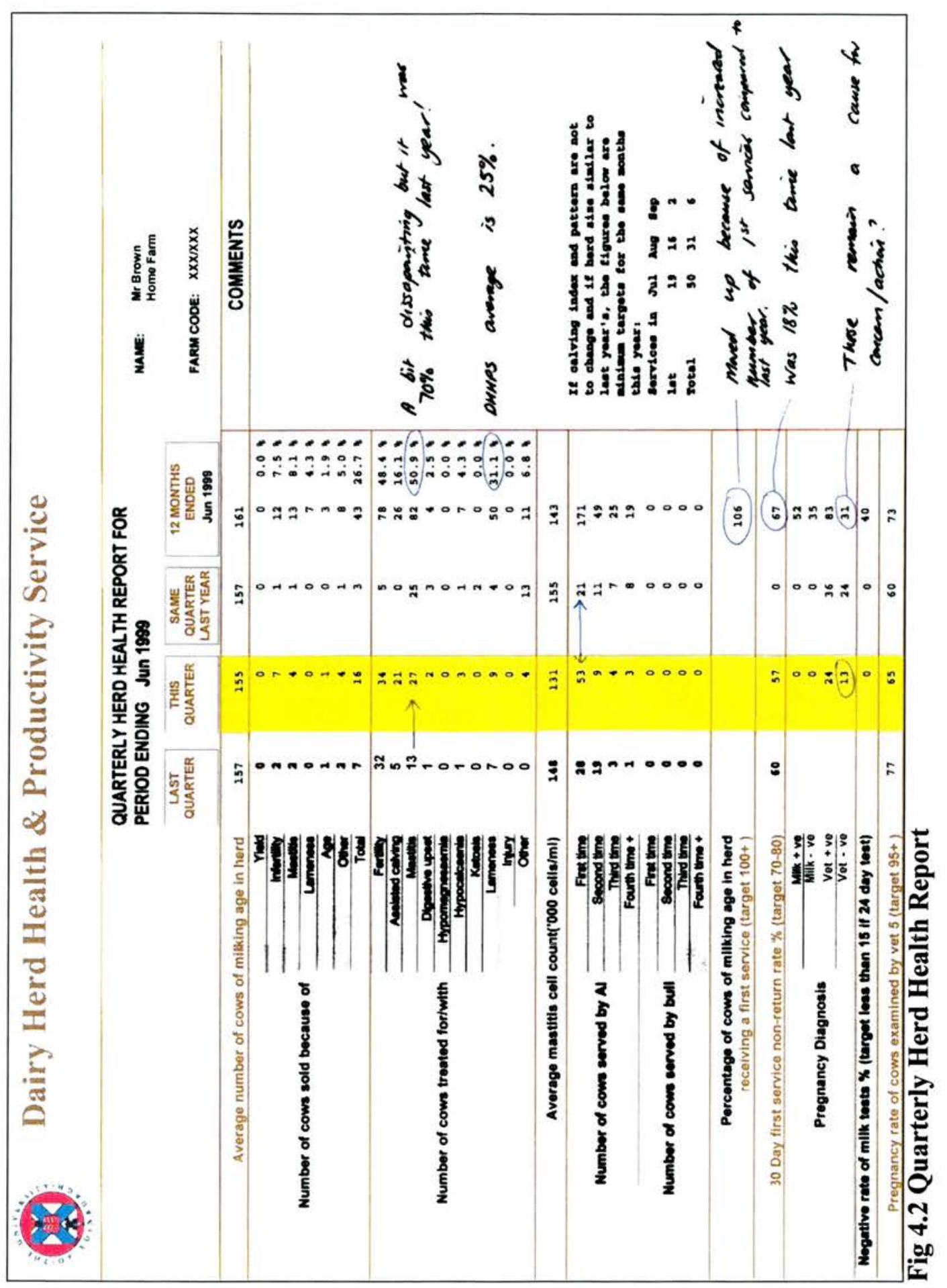




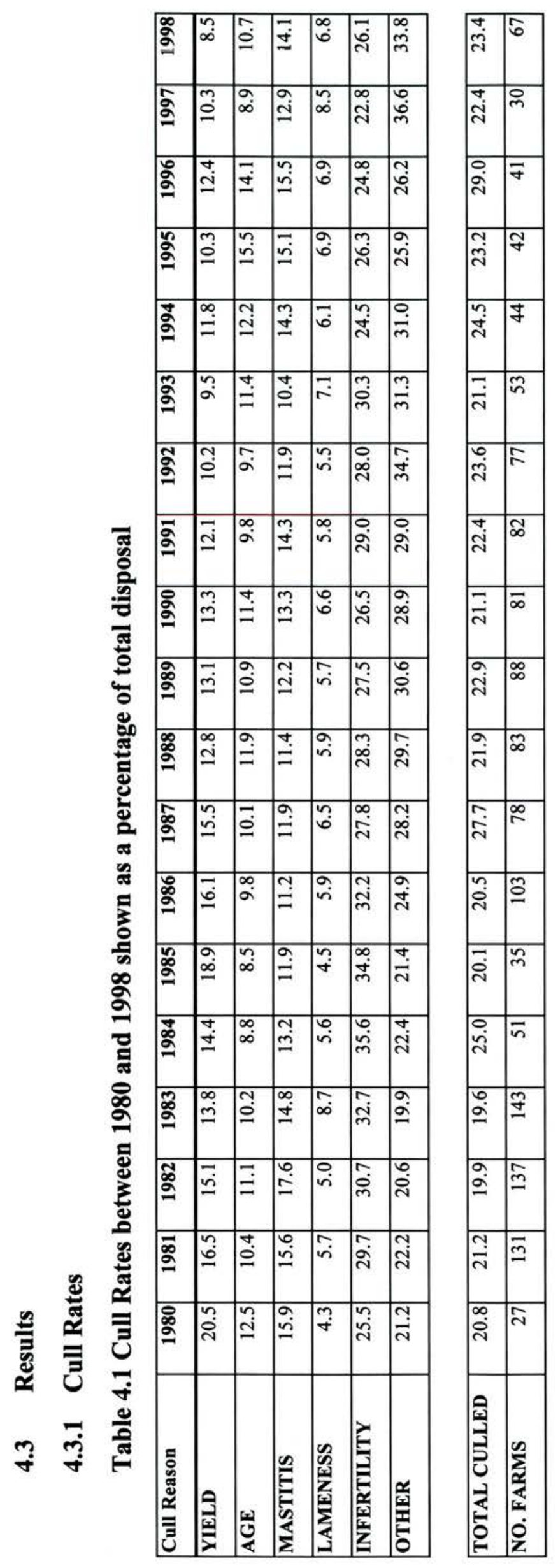


The laboratory-based veterinary surgeon highlights points for discussion and may add additional comments before dispatching copies to the DHHPS member, his veterinary surgeon and the nutritional adviser. Discussion arising from this report should be initiated by the veterinary surgeon. It should also be discussed at the next meeting held to discuss results of relevant blood test.

The average cull rate over nineteen years was 23 per cent (ranging from 19-29 per cent). This is within the same range as reported by Castle and Watkins (1979) as an average culling rate in the national dairy herd. It is very similar to the 23.6 per cent quoted by Esslemont and Kossaibati (1997). This is twenty per cent better than the 29.2 per cent reported in a survey in the mid 1950 s by the Milk Marketing Board. Esslemont and Kossaibati (1997) quoted 18 per cent as an optimum culling rate for an efficient dairy herd. This figure takes into account the cost of heifers, the value of culls, genetic development, age and disease.

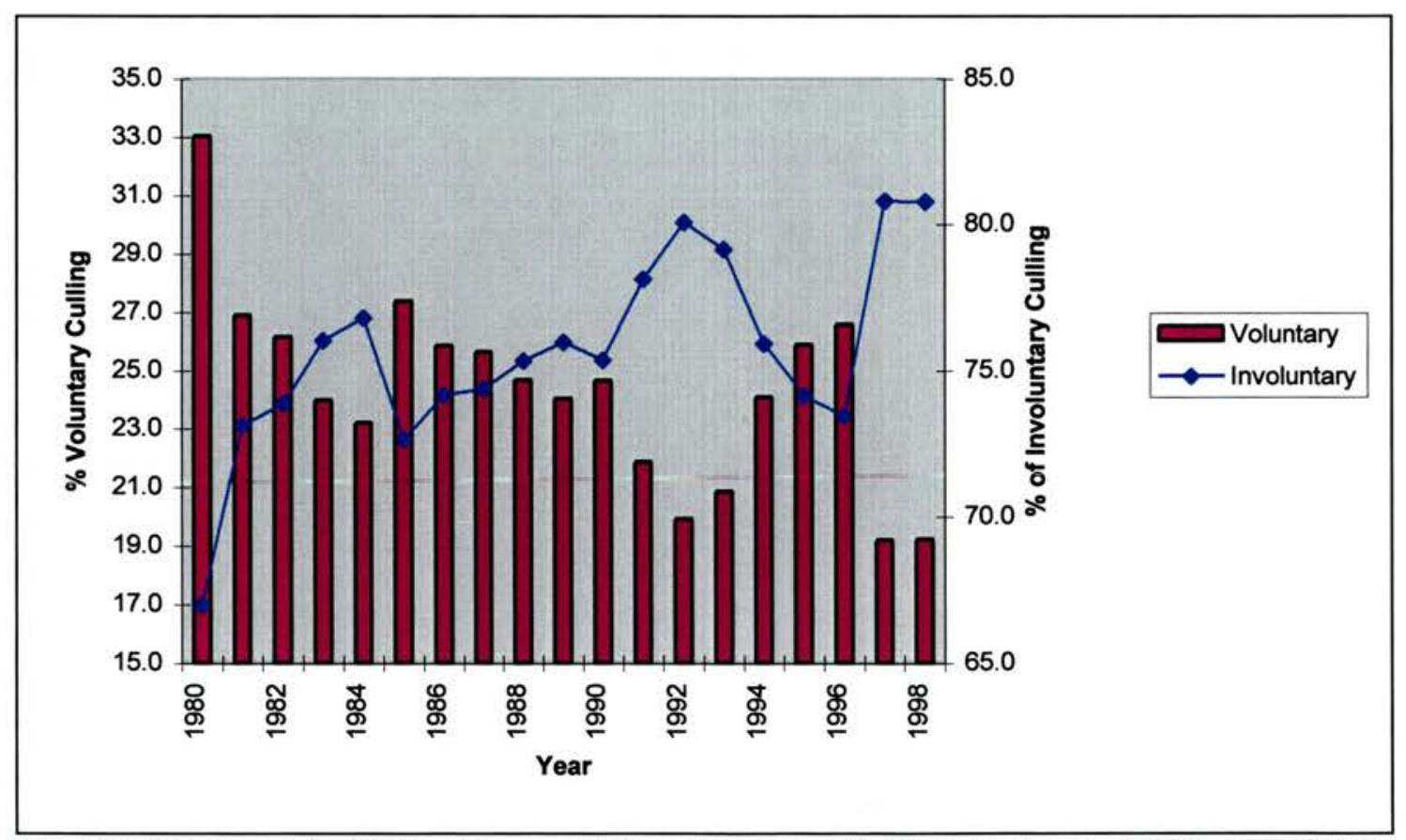

Fig 4.3 Changes in Voluntary and Involuntary Culling between 1980 and 1998, shown as percentages of total disposal 


\subsubsection{Reasons for Culling}

The reasons for culling were classified into broad categories and when there was more than one reason farmers were asked to use the reason which they ranked highest.

\subsubsection{Voluntary Culling}

This would include culling for age and yield. Culling for age was of the order of 2.5 per cent of all cows or 10.8 per cent of all disposals this is lower than the 3.1 per cent quoted by Esslemont and Kossaibati (1997). The Milk Marketing Board (1971-72) estimated 11 per cent which is the same as the results of this survey.

The cull rate for low milk yield was around 2.8 per cent. This gives a voluntary cull rate, for age and yield, of around 23 per cent of all disposals compared with 11 per cent quoted by Esslemont and Kossaibati (1997). These discrepancies may be in part due to the emphasis put on age and yield as primary reasons for culling when disease may also have been a major factor.

\subsubsection{Involuntary Culling}

The main individual reason for culling was infertility. 27.3 per cent of disposals were for this reason. This figure is similar to an earlier figure (Kelly and Whitaker, 1982). Esslemont and Kossaibati (1997) quoted a figure of 36.5 per cent for disposals due to poor fertility. Seegers et al. (1998) in a study of French Holstein cows found that reproductive disorders accounted for 28.5 per cent of reasons for culling.

Mastitis accounted for 13 per cent of disposals. The average value quoted by Esslemont and Kossaibati (1997) was 10.1 per cent of disposals; Young et al. (1983) quoted 12.5 and Esslemont et al (1985) 15.5 per cent. Cull rates for mastitis will vary between herds as there is now a greater incentive for herds to achieve bonuses paid for low somatic cell counts.

Lameness accounted for 5.8 per cent of disposals and this is almost identical to the figure quoted by Esslemont and Kossaibati (1997).

Culling for other reasons would include deaths. Since 1987 this figure would also include disposals due to bovine spongiform encephalopathy (BSE). 
The DHHPS target cull rate is less than 20 per cent culled each year. The annual disposal rates for infertility, mastitis and lameness should each be less than 6 per cent.

\subsubsection{Treatment rates for all areas for 12 month periods (Table 4.2)}

The quarterly treatment results allow comparison between the previous quarter the same quarter last year and the overall annual figure.

4.3.2.1 Fertility treatment figures suggest that around one third of cows receive some treatment post-calving. In 1996 and 1997 the herds recorded 44 treatments per 100 cows. This data will include treatment for removal of placenta, metritis, endometritis or hormonal treatment for anoestrus or cysts. It does not include routine treatments for synchronisation of oestrus with intra-uterine devices or with prostaglandins.

4.3.2.2 Mastitis annual treatment rates have declined significantly over the period for which DHHPS data are available. Treatment rates in November 1997 were just above 30 per 100 cows compared with 46 per 100 cows in 1980. Somatic cell counts have been reduced from 418,000 per $\mathrm{ml}$ in 1980 to 141,000 in 1998.

4.3.2.3 Digestive disease treatment rate has reduced from 2.3 per 100 cow treatments in 1980 to an average of 1.1 over the past three years.

4.3.2.4. Ketosis treatment rate has also decreased from 1.3 to 0.5 cases per 100 cows each year. The number of clinical cases of ketosis has been reduced on many farms as a result of the new management and feeding systems that have been introduced.

4.3.2.5 Hypocalcaemia treatment rate has remained stable at between 5 to 8 per 100 cows per annum. Some farms experience a very high incidence of hypocalcaemia at certain times of the year. 
4.3.2.6 Hypomagnesaemia treatment rates vary from season to season (Whitaker and Kelly, 1982). The introduction of quotas produced a marked fall in the amount of concentrate fed to dairy cows at grass in 1984 and this coincided with an increase in the number of clinical cases of hypomagnesaemia treated in that year.

4.3.2.7 Lameness treatment rates remain very high at around thirty five cases per 100 cows. Whitaker et al. (1983) quoted the annual treatment rate at 25 per 100 cows.

4.3.2.8 Other treatments will include respiratory disease, leptospirosis, traumatic injury or any condition likely to occur sporadically in adult dairy cows such as carcinomas, Johne's disease etc. This accounts for between 3.5 to 14.5 of treatments per 100 cows each year.

\subsection{Discussion}

In the early days of herd health development the inclination was to fill the programme with every known preventive measure and to ask all manner of conceivable questions regarding disease and its cost. The recording system used was a compromise between requesting large amounts of detailed information in systems such as COSREEL (Russell and Rowlands, 1983) or selecting a simplified system that was more likely to achieve a reasonably high level of returns from the farms. The fluctuating figures of farms included in a single year reflects the number of farms which submitted full 12 months of sheet 2's during that year. The farms are not necessarily the same farms each year. They are the farms which were members of the DHHPS in that particular year.

When the service was started Sheet 2 was more extensive and ambitious. It also included questions reflecting costs of disease and treatment by both farmers and veterinary surgeons. These questions were dropped simply because of poor farmer response. Since the introduction of Farm Assurance Schemes there has been a sharp increase in the number of farmers sending in Sheet 2 data on a regular basis (at the present time (2000) some 500 herds are forwarding this information). 


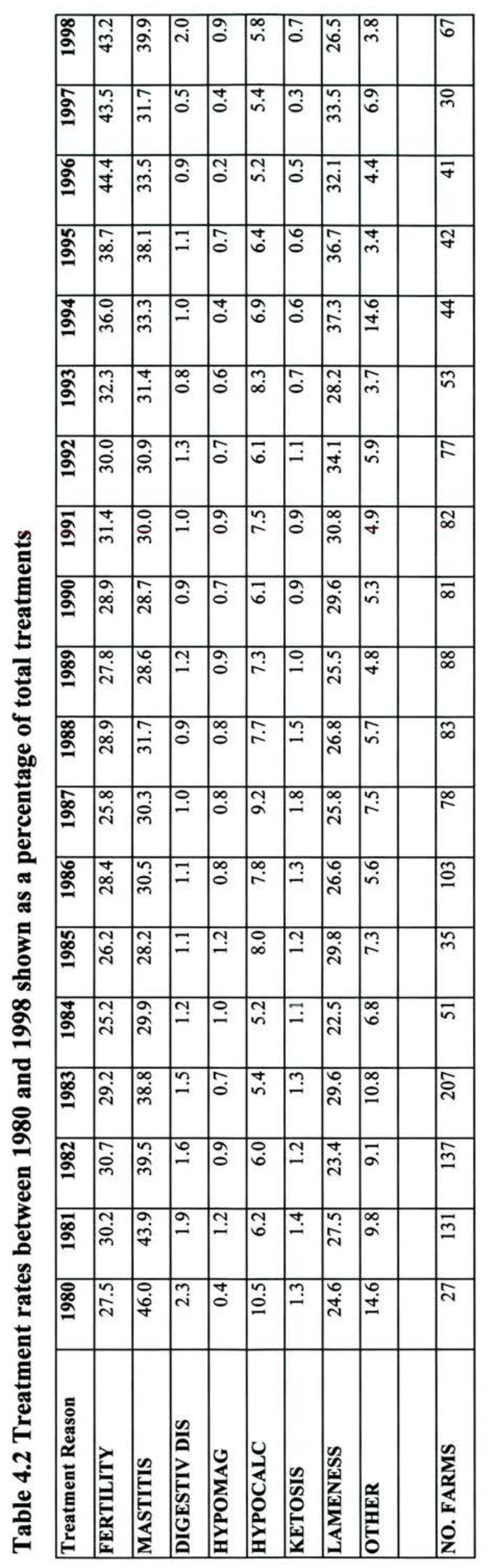


Animals are disposed of from a dairy herd for a large number of varied reasons. The cull cow price which can vary greatly will clearly have a strong influence on any decision made to sell cows. Since the introduction of 'milk quotas' in 1984 many farmers will have sold cows in order to avoid producing too much milk and incurring Super Levy payments. In recent years the number culled for 'other reasons' has increased and this is largely because of the large number of BSE cases removed from the national herd. The total number of BSE cows slaughtered is in excess of 170,000 and some $63 \%$ of UK dairy herds have been affected (MAFF, 2000). The 'cohort cull' which has involved removing animals in the same age group as clinical BSE cases has had a marked effect on the cull rate from some individual farms. Farms which are establishing a herd or increasing herd size will often retain animals which would normally be culled.

Records from the DHHPS consistently identify the main reasons for disposal of cows from UK dairy farms to be infertility, mastitis and lameness. Theoretically a farmer should be disposing of cows for voluntary reasons i.e. because they are old and ready to be replaced by a young animal of higher genetic potential. The rate for involuntary culling has fallen from 38 per cent in 1980 to 17 per cent in 1998. Cows will often be sold for more than one reason and the figures quoted are for the main reason influencing the decision to sell. These figures are very similar to those quoted by Esslemont and Kossaibati (1997) in a review of culling in 50 dairy herds between 1990 and 1992.

The number of cows culled has fluctuated following major changes in the dairy industry. Milk quotas were introduced in 1984 and resulted in an increased cull rate in that year as farmers were apprehensive about exceeding their quota and disposed of cows accordingly. The introduction of Super Levy in 1987 produced a similar response.

Longevity is important if a cow is going to be profitable in its lifetime. Esslemont and Kossaibati (1997) suggests that it is only by the time that a cow is into its fourth lactation that it is becoming profitable. With a culling rate of 25 per cent many cows will be culled before their fourth lactation. The cost of culling a cow is estimated to be $£ 762$ (Esslemont and Spincer, 1993) and reducing the cull 
rate to an optimum of 18 per cent would be of considerable financial benefit to many farmers. The proportion of involuntary culls should be falling in contrast to the findings of DHHPS. Ideally the decision to cull should be under the control of management and not forced upon them by presence of disease. The target cull rate for infertility, mastitis and lameness should each be under $6 \%$.

Treatment rates support the finding that fertility, mastitis and lameness are the main health issues on many farms.

Fertility: The treatment rate for infertility remains remarkably stable over the years suggesting that getting cows pregnant is an ongoing problem on most farms. Treatment rate for fertility recorded for DHHPS purposes is not supposed to be for routine treatments for oestrus-not-observed. Esslemont and Kossaibati (1996) recorded that 33.6 per cent of cows were treated for this condition and that each affected cow had 1.4 treatments. This is a very high figure in light of the fact that many cases of anoestrus will be the result of low energy status and will be unlikely to respond to treatment until this is being reversed (Nebel and McGilliard, 1993).

The DHHPS data refer mainly to cows treated for retained placenta, vulval discharge and endometritis which in particular, have detrimental effects on fertility indices (Fonseca et al., 1983; Thompson et al., 1983; Markusfield, 1987b and Borsberry and Dobson, 1989). Dystocia, twinning and abortion may result in retained placenta and endometritis (Peeler et al., 1994). The average incidence of retained foetal membranes was observed to be 3.9 per cent by Esselmont and Spincer (1993). The incidence in the UK appears lower than in North America, 8.6 per cent (Dohoo et al., 1983), and 17.8 per cent (Markusfield, 1987b). The treatment rate for vulval discharge was quoted as 21.8 treatments per 100 cows Esslemont and Spincer (1993) and 25.3 per 100 cows by Peeler et al. (1994).

Higher rates of fertility treatments on individual farms may reflect the degree of involvement of the veterinary surgeon e.g. routine examination of cows after parturition. It is not possible from the DHHPS data to speculate whether all the treatments administered to dairy cows in the postparturient period are justified and this is a subject for further research. 
Mastitis: The clinical mastitis rate for DHHPS members over the past 18 years has fluctuated between 28 and 46 cases per 100 cows. This is very similar to figures quoted by Esslemont and Kossaibati (1996). Booth (1988) recorded 37 to 34 cases and Blowey (1986) recorded a fall of 51 to 32 cases in a period from 1979 to 1985. All of these are very much lower than the 135 cases per 100 cows reported by Wilson and Kingwell (1975).

The reduction of cell count and number of clinical cases is due in part to an increasing awareness of the problem. The mastitis awareness campaign and the introduction of mastitis control programmes have all played their part. e.g. National Institute for Research in Dairying's 'Five Point Plan' (Dodd et al., 1969).

The reduction in treatment rates in 1984 and 1985 was presumably due to farmers taking the opportunity to cull chronic mastitis carriers as they reduced herd size in response to the introduction of quotas. A similar decline over this period was recorded by Blowey (1986). The introduction of financial reward or penalty for the level of the total bacterial count (TBC) in the bulk tank milk introduced in 1982 had a dramatic effect on improving TBCs and presumably greatly increased the awareness of the significance of mastitis in the herd. Before the scheme only 25 per cent of producers in England and Wales had TBC's under 20,000 and within four months of the launch 61 per cent of producers were under this level (Blowey and Edmondson, 1995).

With the deregulation of milk sales in November 1994 those groups purchasing milk have increased standards as the more powerful retailers of milk such as the supermarkets have demanded a product of a higher standard and of uniform quality.

The undoubted improvement in the overall treatment rates and reduction in the bulk tank somatic cell count (BTSCC) is a good example of what can be achieved by the application of well researched control programmes. Mastitis is one disease which can be monitored successfully using individual or bulk somatic cell counts. Perhaps most significant of all is the fact that the farmers can see the improvement in cow health reflected in their monthly milk cheque. In short 
improvement can easily be measured and brings relatively quick rewards. It is regrettable that this is not possible with the other important production diseases.

There is however a great danger of being complacent regarding mastitis. Although many farms have attained a low incidence of the disease in the herd many others still have BTSCC, in penalty bands. A survey by Gunn (1995) in Scotland has shown that herds with persistently high BTSCC often have Streptococcus agalactiae as the predominant causal organism. This is disappointing in as much as an organism which is susceptible to control measures (five point plan) and is also very responsive to antibiotic treatment should still be prevalent in many dairy herds. It is also very easy for herd to return into the penalty bands if they do not sustain their control programmes. Low cell counts do not necessarily mean that a herd will not experience problems with mastitis. After initial rapid progress in reducing mastitis incidence following the introduction of control measures some DHHPS members have found mastitis still to be a problem despite low cell counts. Kossaibati et al. (1998) also reported that the incidence of mastitis had remained relatively high on some farms despite falling cell counts. Some cases of mastitis associated with environmental organisms such as $E$. coli can be extremely severe and may result in death. Such outbreaks of environmental mastitis frequently occur in early lactation and are associated with metabolic stress encountered at this time (Wentink et al., 1996). Whitaker et. al. (2000) reported that in a study of 340 herds there was a significantly higher rate of mastitis in herds housed in straw yards compared with those housed in cubicles.

Mastitis may also be linked with metabolic disease such as hypocalcaemia. Cows recumbent after calving may be exposed to environmental contamination. Control of mastitis does not only require good milking technique but also overall maintenance of cow health by appropriate management and nutrition

Lameness: The figure of 25 per cent for lameness cases per 100 cows reported by Whitaker et al. (1983) were regarded as much higher than previous reports (Russell et al., 1982). However these data was among the first to record farmer as well as veterinary treatments. More recent reports (Esslemont and Kossaibati, 1996) 
reporting 24 cases per 100 cows confirm the high incidence of lameness in dairy herds. Some herds have a treatment rate as high as 70-80 cases per annum. In recent years lameness has tended to increase on DHHPS farms and has averaged 33 cases per 100 cows. A detailed study by Clarkson et al. (1996) on 37 farms reported a high figure of 54.6 cases per 100 cows. This survey used 'locomotion scores' (Manson and Leaver, 1988), as a measurement of lameness. In all such reports there was a wide variation between farms. Some 24 farms had a high incidence during the winter and 8 had a peak incidence in summer. This higher incidence agrees with the DHHPS findings that over the years lameness has become more common on many farms. Clarkson et al. (1996) do raise the important issue regarding the reliability of data on the incidence of lameness. The reliability does very much rely on the observer's perception of lameness and the accuracy of completion of forms. Using a scoring system may well increase the awareness of the problem on the farm. Clarkson et al.(1996) discuss the importance of measuring the prevalence of lameness. They did show a highly significant correlation between incidence and prevalence on many farms. In one area, Somerset, the correlation was not good and this was thought to be because either there was over enthusiastic identification of lame cows or the under identification of prevalence. The latter might have been because the incidents of lameness were very short. In the recording scheme used by DHHPS it is not at the present time possible to record the length of time a cow is lame, however, this matter is under review.

Lameness is normally associated with winter housing and there is a good relationship between type of housing and incidence of lameness. Cows housed in straw yards have a lower incidence of lameness than those in cubicles. Whitaker et. al. (2000) found less lameness in the summer months and a higher incidence in cows housed in cubicles when compared with straw yards. Unfortunately more cows are kept in areas where grass grows well e.g. the South West of England and Scotland and fewer cows are kept in the arable areas in the East. The main problem is that straw is not generally in abundance in the areas with a high population of dairy cows. Transportation is expensive and straw bedding is not considered an economic proposition on many farms. 
Some herds are now providing straw beds for the first 90 days of lactation, when the stressful period of lactation is over and when cows are pregnant again, they are moved into cubicle accommodation. Much can be done to improve cubicle design to ensure optimum comfort and to ensure adequate lying time (Cermak, 1990). The importance of foot trimming has also been widely publicised and many farmers have had formal training in foot trimming and/or use professional foot trimmers in addition to veterinary services. The value of foot bathing has also been publicized by DHHPS and on many farms where an aggressive policy with regard to regular foot bathing and trimming has been adopted then considerable improvements have been achieved.

Nutrition has been implicated as being a major causal factor of lameness (Manson and Leaver, 1989). DHHPS does not have factual evidence to prove the link. However diets with high concentrate to forage ratios are implicated in causing laminitis considered to be the forerunner of many cases of clinical lameness e.g. solar ulcer. Many regard a diet high in protein is the cause of lameness but the evidence is equivocal. Hedges et al. (2000) suggested that biotin supplementation reduced the incidence of white line lesions in dairy cows.

In recent years 59.2 per cent of DHHPS farms reported problems with digital dermatitis. Clarkson et al. (1996) observed that in their survey digital dermatitis was responsible for 8.6 per cent of all foot lesions.

The high incidence of lameness now being reported in the UK suggest that lameness is a major problem on many farms and must have a significant influence on cow welfare, productivity and profitability. Kossaibati and Esslemont (1997), using the milk price in 1997, calculated the average total cost of a lame cow to be $£ 273$, or nearly $£ 160$ million per annum to the national herd.

Hypocalcaemia: The DHHPS range has been from 5.2 to 10.5 treatments per 100 cows each year. Borsberry and Dobson (1989) and Esslemont and Kossaibatti (1996) reported an incidence of 9.4 and 7.7 cases per 100 cows respectively.

Hypocalcaemia is often associated with periods of feeding high calcium diets prior to calving e.g. grass, beet pulp, and concentrate intended for milking 
cows. This has the effect of suppressing the activity of the parathyroid gland prior to calving and may reduce the production of parathyroid hormone post calving.

Low levels of magnesium in dry cows are frequently associated with hypocalcaemia post calving. Magnesium is an important cofactor in the release of PTH, the hydroxylation of vitamin D and in the absorption of calcium from the gut (Kelly, 1988). Cows at grass in the autumn frequently have a diet of wet grass which is high in calcium and low in magnesium content. They may also experience additional stress due to adverse weather. The replacement of grass with another forage source such as silage or hay and the supply of additional magnesium can often dramatically lower the incidence of hypocalcaemia. Magnesium can be supplied to dry cows in a concentrate, by magnesium bullet or via the water supply. Housing may be necessary if the problem persists.

In recent years attention has been given to the alteration of the ionic balance of the diet in the prevention of milk fever.

Longer term management of dry cow condition may be necessary as fat cows (condition score 4 or more) are more likely to succumb to hypocalcaemia. There is a considerable body of literature which indicates that hypocalcaemia is a risk factor for several reproductive disorders (Grohn et al., 1990). Hypocalcaemia is related to dystocia (Thompson et al., 1983; Erb et al., 1985), retained placenta (Thompson et al., 1983; Erb et al., 1985 and Markusfield, 1987), metritis (Dohoo et al., 1984; Erb et al., 1985; Markusfield, 1987b) and uterine prolapse (Markusfield, 1987b). Borsberry and Dobson (1989) found that milk fever (hypocalcaemia) extended calving to conception intervals. Risco et al. (1994) reported that milk fever resulted in a delay in time to first ovulation post partum and delayed uterine involution. At a direct average cost of $£ 59$ per case (Esslemont and Kossaibati, 1996), hypocalcaemia represents a cost to the dairy industry of more than $£ 7$ million per year.

Hypomagnesaemia: Since Whitaker and Kelly (1982) reported the DHHPS figures the average annual rate has been between 0.7 and 0.9 per cent. The average rate was relatively low, but 29 per cent of farms experienced cases, and on individual farms 
as many as 9 per cent of cows were affected. On average 30 per cent of cows with clinical hypomagnesaemia die (Butler, 1963). These figures suggest that with a national herd of around 2.5 million cows approx 5,000 would die for this reason each year. Despite a great deal of publicity some farmers find it difficult to supplement dairy cows with sufficient magnesium especially in wet weather. The main difficulty would appear to be in the variability of magnesium absorption especially in wet weather. At best only $35 \%$ of magnesium may be absorbed and at worst only $10 \%$.

- Modern monocultures of Italian ryegrass will have less magnesium than traditional pasture.

- Fertiliser, especially high in potash will interfere with magnesium absorption.

- High ammonia levels in the rumen, often as a result of high rumen degradable protein in the rumen will inhibit absorption.

- Highly digestible forages with very quick rates of passage through the rumen will reduce uptake.

It is clear from the above that many of the modern trends in pasture management mitigate against the absorption of magnesium from the diet and it is essential to provide the high yielding cow with supplementary magnesium.

Digestive Disorders: Since the introduction of milk quotas in 1984, farmers have been encouraged to make more use of home grown forage and to place less dependence on concentrate feeding. More of the concentrate fed is being mixed with forage using mixer wagons. These management changes on many farms have helped to reduce the incidence of digestive disease such as acidosis and displaced abomasum. These conditions were frequently associated with the feeding of too much concentrate in relation to the quantity of forage being consumed.

Ketosis: DHHPS recorded a range from 0.3 to 1.5 clinical cases per year. Borsberry and Dobson (1989) reported a mean incidence of 1.4 per cent, and Curtis et al. (1983) 1.5 per cent. Clinical ketosis was associated with silent heat, cystic ovary and other infertility (Grohn et al., 1990). Ketosis was related to metritis in the 
work of (Dohoo and Martin, 1984). Problems in postpartum cows tend to occur in clusters (Oltenacu et al., 1984) and have significant effects on fertility. Metabolic disease has been implicated in association with cystic ovarian disease (Andersson et al., 1991), anoestrus (Huszenicza et al., 1988) and reduced immunity (Ropstad et al., 1989). Prevention of periparturient disease and metabolic disease are important components of nutrition and fertility relationships (Ferguson, 1996).

The trend in the DHHPS farms is to allow cows maximum access to fodder, and as a result, cows are able to attain optimum dry matter intakes. The fact that most cows are loose housed and thus receive reasonable exercise may help reduce the incidence of clinical ketosis. One clinical case of primary clinical ketosis indicates that all the cows in the herd at a similar stage of lactation are likely to be short of dietary energy although not showing symptoms of clinical ketosis. A clinical case is an early warning that the nutrition and management of the early lactation cows requires urgent review.

On average a dairy herd of 100 cows is going to have more than 100 treatments per annum for conditions which may directly or indirectly influence subsequent reproductive performance. Some cows will have had more than one treatment such is the relationship between the periparturient disorders.

Data from a further 350 herds, which are not DHHPS members Whitaker et al. (2000) are very similar with respect to cull and treatment rates.

The results of the cull and treatment rates established by the DHHPS over many years give the opportunity for the setting of realistic goals or targets on the farms of individual members. At the team meetings, which should be held regularly, problem areas can be identified and discussed. Control or preventative programmes can be established. Targets can be set and progress monitored by means of the quarterly reports.

\subsection{Reproductive Performance}

This part of the Quarterly report (Fig 4.2) is not detailed or comprehensive and is not intended to replace computer based systems such as DAISY. It does however provide basic information on current reproductive 
performance which can provide valuable indicators for further discussion and investigation by those involved at farm level.

Number of cows served by AI/bull: First time: comparisons with the same quarter last year can give an indication of the efficiency of presentation for first service. If the calving pattern is to remain the same and herd size has not altered, fewer first services means lower herd fertility efficiency. Second and subsequent services give an indication of non-return rates.

\section{Percentage of cows of milking age in herd receiving a first service (target $100+$ ):}

This index is a very useful guide to the average calving to first service interval in a herd. This is a critical measure of fertility efficiency and one which depends on management policy and heat detection efficiency i.e. 'pecple factors'.

To achieve a herd calving index of 365 days, there must be theoretically one first service and one calving per cow per year. In practice, herds which achieve a real calving index of 365-375 days, several cows receive one service, calve and receive another first service all within 365 days. This produces a 'Percentage cows of milking age etc.' of $100+$, usually $105-110$, with an average cull rate of $20-25 \%$. It is clear that if this index is below $100 \%$, the control of calving to first service intervals should be discussed. If very high, i.e. $120 \%+$, then maiden heifers may have been included in first service data. A significant reduction in herd size could also result in this figure being artificially high. The percentage can also be lowered by deferral of services to fit a tight calving pattern or unrecorded services. If the percentage is too high or low the topic should be discussed and an explanation found.

30 Day service non-return rate \% (target 70-80): This is not the conception rate which will normally be lower, but it does give an indication of what it is likely to be. If the non -return rate is low, conception rates will be low. If the non-return rate is high, conception rates may be good or returns to service are being missed.

For example: (no. 1st services Dec, Jan. Feb)-(no 2nd services Jan, Feb. Mar) x100 (No 1st services Dec, Jan, Feb)

Negative rate of milk tests \% (target less than 15 if 24 day test): If the rate is over the target, conception rates may be low and if milk sampled at 24 days served, 
returns to service are being missed. If the negative rate, i.e. low milk progesterone, is below $15 \%$ but the confirmed pregnancy rate is disappointing, then the proportion of false positives is too high. This is caused mainly by cows being served when not in oestrus and/or mistiming of milk sampling. Negative results are reliable but positive milk tests are not and should be submitted to vet PD or scanning.

Pregnancy rate of cows examined by vet \% (target 95\%): Not many herds achieve the target. Lower figures are chiefly a consequence of failure to detect return to service at a high enough rate. In herds where there has been a bull running with no recorded services, PD rates are normally lower. If scanning is being used at 30 or more days served, the target is the same as on average very small percentages of foetuses are lost after 24 days served.

COMMENTS: If the services section on the sheet 2 is being completed a message will appear in this part of the report once sufficient data have accumulated. The purpose of this message is to provide targets for the number of first services and total services in each of the following three months, if it is wished to maintain the existing calving index and calving pattern. There are a number of qualifications which are listed below and which may need to be taken into account in modifying targets. Milk production requires calvings and in turn calvings require first services! Establishment and awareness of basic target figures is the first essential step to good reproductive efficiency. (Maiden heifers are not included in the targets).

\section{If monthly targets are not being met possible courses of action would be:}

- Reduce the interval after calving by which a cow is served if observed in oestrus.

- Check that there are no obvious nutritional or environmental problems. Consider blood profiling when appropriate

- Increase oestrus detection efficiency. Increase frequency of observation. Use of appropriate records (computer generated action lists, 3 week calendars, recording boards). Use of heat mount detectors. Use of veterinary examination to confirm ovarian cyclicity and approximate timing of next oestrus.

- Use of prostaglandins or PRID (progesterone-releasing intravaginal device)

- Run with the bull and record services and oestrus as a service. 
In a month where the target looks like being heavily exceeded and calving pattern is of paramount importance, only cows returning to service should be served. Those not yet having received their first service could be left if oestrus occurs.

\section{Reasons for increasing the monthly targets would include:}

- larger herd size,

- lower conception rates,

- fewer heifer replacements coming into the herd next year.

- bull running with herd for 9 to 10 months and no services recorded,

- alteration in calving pattern desired,

- reduced calving index required-applies to first services principally;

- period of poor nutrition or adverse environmental conditions anticipated.

\section{Reasons for decreasing target numbers:}

- smaller herd size

- improved conception rate based on confirmed pregnancy (not non return rate)

- more heifer replacements available next year

- alteration in calving pattern desired

This information is intended to stimulate further discussion and action when necessary. 
Chapter Five 
This chapter deals with the use of planned blood sampling as it forms an integral part of the DHHPS.

\subsection{Materials and Methods}

\subsubsection{Selection of Cows for Blood Sampling}

At each test a maximum of seventeen cows are selected. The design of the analysis system does not permit extra cows to be analysed. If more cows are thought to be essential then they form a separate test.

Usually a test will include seven early lactation cows, five mid-lactation cows and five dry animals. Where possible no group should contain less than five cows.

Early lactation cows should be between ten and twenty days calved. There is a metabolic upheaval during the transition period before and after calving but it is important to test at a period of maximum metabolic stress before cows adjust to a dietary shortfall by dropping milk production. Cows calved more than forty two days should not be included in the early lactation group. Dry cows should preferably be in the last ten days of pregnancy. This is a herd test and it is essential that selected cows are typical of the group they represent. It is advisable to avoid the best and the very worst. Cows with obvious clinical disease or long-standing health or reproductive problems should not be tested.

\subsubsection{Timing of Blood Tests}

Blood tests are done in a planned manner in order to assess the current dietary and management regime. Blood sampling should take place as soon as cows are fully stabilised on a particular diet (normally at least ten days after change in diet). The early lactation cows are the most important in any dairy herd. As soon as a group have calved following any change in diet or management they should be tested in order that any changes or adjustments can be made before the main group of early lactation cows have its productivity or health compromised. 


\subsubsection{Some Suggested Blood Sampling Times}

- In spring or early summer when diet is often optimal. Results at this time can provide a base line for future comparison when diet is less predictable.

- Mid to late summer (seasonal milk pricing has resulted in more cows calving in summer)

- Autumn (when grass quality is very variable)

- After winter housing

- After change of forage

- After change of concentrate

- After any major dietary or management change

- When there is perceived to be a specific problem

\subsubsection{Blood Sampling Procedure}

- Samples should be taken only on Monday, Tuesday and Wednesday to avoid delays over the weekend and despatched to the Edinburgh laboratory by special delivery

- Samples should be taken two to four hours after main morning feed

- Samples are taken from the jugular or coccygeal vein (the mammary vein is not suitable)

- One green top (lithium/heparin) and one $5 \mathrm{ml}$ grey top (oxalate/fluoride) are required from each cow

- Each cow sampled is weigh banded and condition scored

\subsubsection{Biochemical Analysis}

Samples are analysed on an automated system for:

- B-hydroxybutyrate (BHB)

- plasma glucose

- non esterified fatty acids (NEFA)

- albumin

- urea nitrogen

- globulin 
- magnesium

- inorganic phosphate.

Metabolites were measured using a Bayer Opera Random Access Analyser. Fig 5.1 RANOX KITS were used for BHB and glutathione peroxidase (Randox Laboratories Crumlin, Co Antrim)

BAYER KITS were used for glucose, urea, albumin, total protein, magnesium and inorganic phosphate (Bayer Diagnostics Division Bayer House, Newbury).

A WAKO KIT was used for NEFA analysis (Alpha Laboratories 40 Parham Drive Eastleigh Hants.)

When a herd is tested for the first time samples were also analysed for copper (Abe et al., 1989); thyroxine (T4) (Siegel and Treu, 1982) to reflect iodine status; glutathione peroxidase (GSHPx) (Paglia and Valentine, 1967) as an indicator of selenium status. If a deficiency of these trace elements is identified, or if specially requested, these parameters will also be included in subsequent tests.

Optimal values (Fig 5.1) have been established over the time that the service has been in operation. The normal values were derived originally looking at the population mean plus or minus two standard deviations (Payne et al. 1974) in the thousands of samples submitted every year to our laboratory since 1978. The values for BHB have a skewed distribution and optimum values have been established using a natural-log transformation (Scott, 1982). Trial work involving detailed monitoring of cow weight, body condition and yield together with detailed nutritional analyses have confirmed these values (Kelly 1977: Scott 1982, Whitaker et al. 1993). There is large body of anecdotal evidence from the 'summary of discussion' forms from DHHPS consultations which indicates that the optimum range is realistic. It is essentially a herd test and biochemical results from a minimum of five cows should be considered. Variations in results within the group should be evaluated against individual performance, weight, body condition, number and stage of lactation and nutrition. A small fat heifer, for example, may well have results different from the other group members because she has had her dry matter intake compromised by bullying from mature cows. 


\begin{tabular}{|l|l|l|}
\hline \multicolumn{1}{|c|}{ METABOLITE } & \multicolumn{1}{|c|}{ METHOD } & OPTIMUM VALUES \\
\hline \multicolumn{3}{|c|}{ ENERGY } \\
\hline $\begin{array}{l}\text { Beta-hydroxybutyrate } \\
\text { (BHB) }\end{array}$ & RANBUT* & $\begin{array}{l}\text { Milkers below } 1.0 \mathrm{mmol} / 1 \\
\text { Dry below } 0.60 \mathrm{mmol} / 1\end{array}$ \\
\hline Plasma glucose & Hexakinase** & Over $3.0 \mathrm{mmol} / 1$ \\
\hline $\begin{array}{l}\text { Non esterified fatty acids } \\
\text { (NEFA) }\end{array}$ & NEFA-C*** & $\begin{array}{l}\text { Milkers below } 0.7 \mathrm{mmol} / 1 \\
\text { Dry below } 0.40 \mathrm{mmol} / 1\end{array}$ \\
\hline \multicolumn{3}{|c|}{ PROTEIN } \\
\hline Urea & Enzymatic Kinetic** & $1.7-5 \mathrm{mmol} / 1$ \\
\hline Albumin & Bromocresol Green** & Over 30.0 g/1 \\
\hline Total Protein & Biuret** & \\
\hline Globulin & By difference & Under $50.0 \mathrm{~g} / 1$ \\
\hline \multicolumn{3}{|c|}{ MINERALS } \\
\hline Magnesium & Xylidine Blue** & $0.80-1.30 \mathrm{mmol} / 1$ \\
\hline Phosphate (Inorganic) & UV** & $1.40-2.50 \mathrm{mmol} / 1$ \\
\hline Copper & Direct colometric assay & $9.40-19.00 \mathrm{micromol} / 1$ \\
\hline Glutathione Peroxidase & RANSEL* & Over $50 \mathrm{units} / \mathrm{g} \mathrm{Hb}$ \\
\hline
\end{tabular}

* Randox Laboratories ${ }^{* *}$ Bayer Diagnostics ${ }^{* * *}$ Alpha Laboratories

Fig 5. 1 Table showing metabolite analysed, method and optimal values

Biochemical results are printed alongside the background information and the nutritional inputs and requirements which are considered essential for meaningful interpretation.

\subsubsection{Quality Control}

Samples are regularly sent to an independent laboratory for an assessment of the precision and accuracy in the clinical chemistry (Randox International Quality Assessment Scheme). 


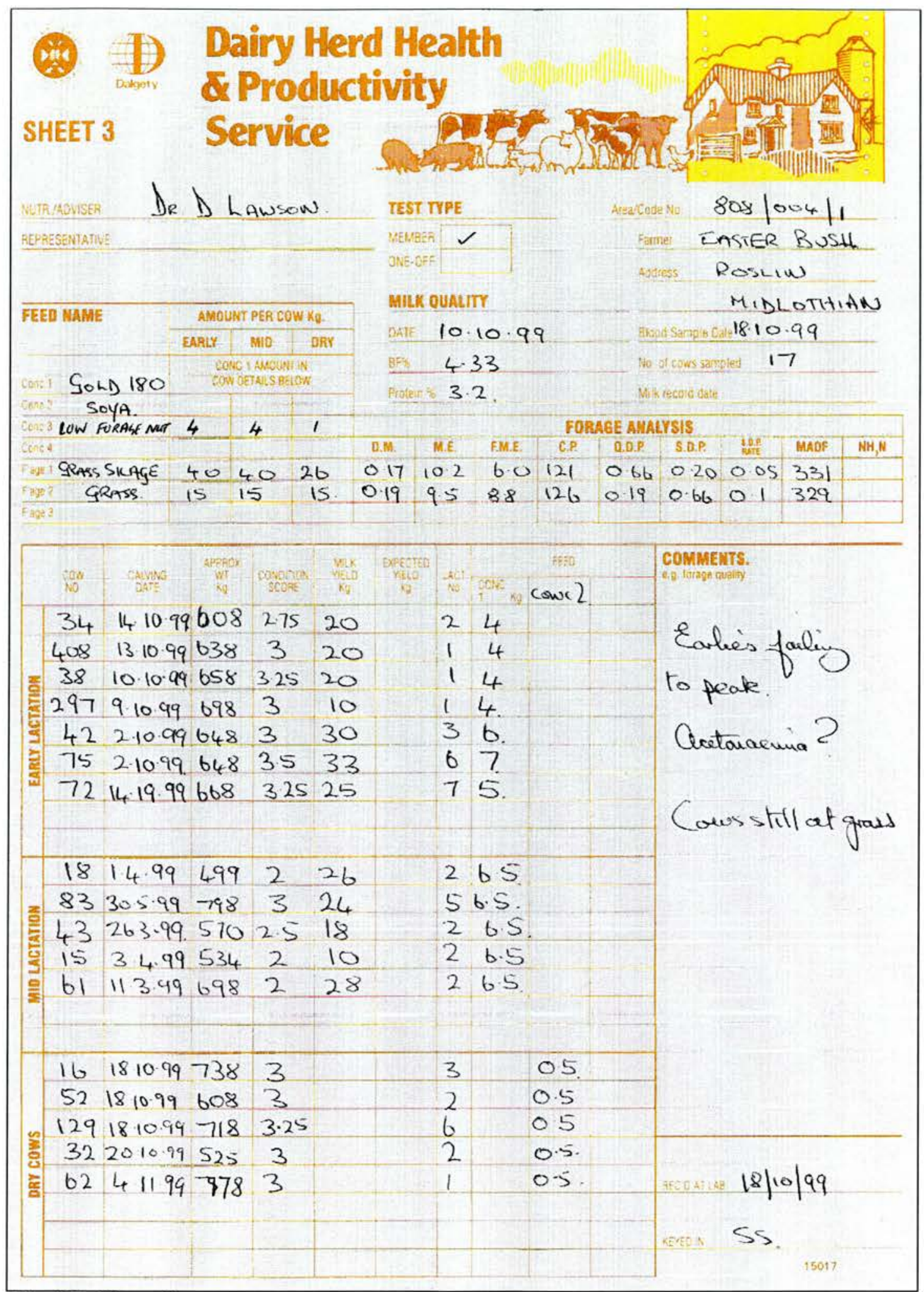

\section{Fig 5.2 Sheet 3}


Sheet 3 (Fig 5.2)

This form records the detailed information which must accompany the samples. No report is written concerning biochemical results if complete Sheet 3 information is not available.

\subsubsection{Herd Data Recorded}

The following are recorded on a sheet 3 :

- Farm code and farmer's name and address

- Sample date and number of cows sampled

- Milk quality figures and the date to which they refer

- Feed name (all concentrates and forages fed are identified)

Amount per cow

- Conc. 1 This is the variable parlour feed or variable amounts fed in out-of-parlour feeders

- Conc. 2 This is the fixed amount of concentrate for each lactation group per cow per day in $\mathrm{kg}$

- Conc. 3 and Conc. 4 if fed are entered the same way

- F'age 1, F'age 2 and F'age 3. Normally forages would include grass, grass or maize silage and hay or straw. The fresh weights of all forages fed are entered (this will often be an estimate)

- F'age analysis (DM, ME, DCP, pH, D and NH3N) is recorded where available. Otherwise standard values are assumed

- Complete diets are entered as forages with their analyses

\subsubsection{Individual Cow Data Recorded}

- Cow identification is entered as a three digit number

- Calving date. For lactating cows the previous calving date is used. For dry cows the next expected calving date is used.

- Approximate weight. This is obtained using a weighband (Kelly, 1977). A spring balance is used to pull the band to a standard tension of $5 \mathrm{~kg}$ round the heart girth.

- Condition score is recorded using a standard technique (Lowman et al., 1973). 


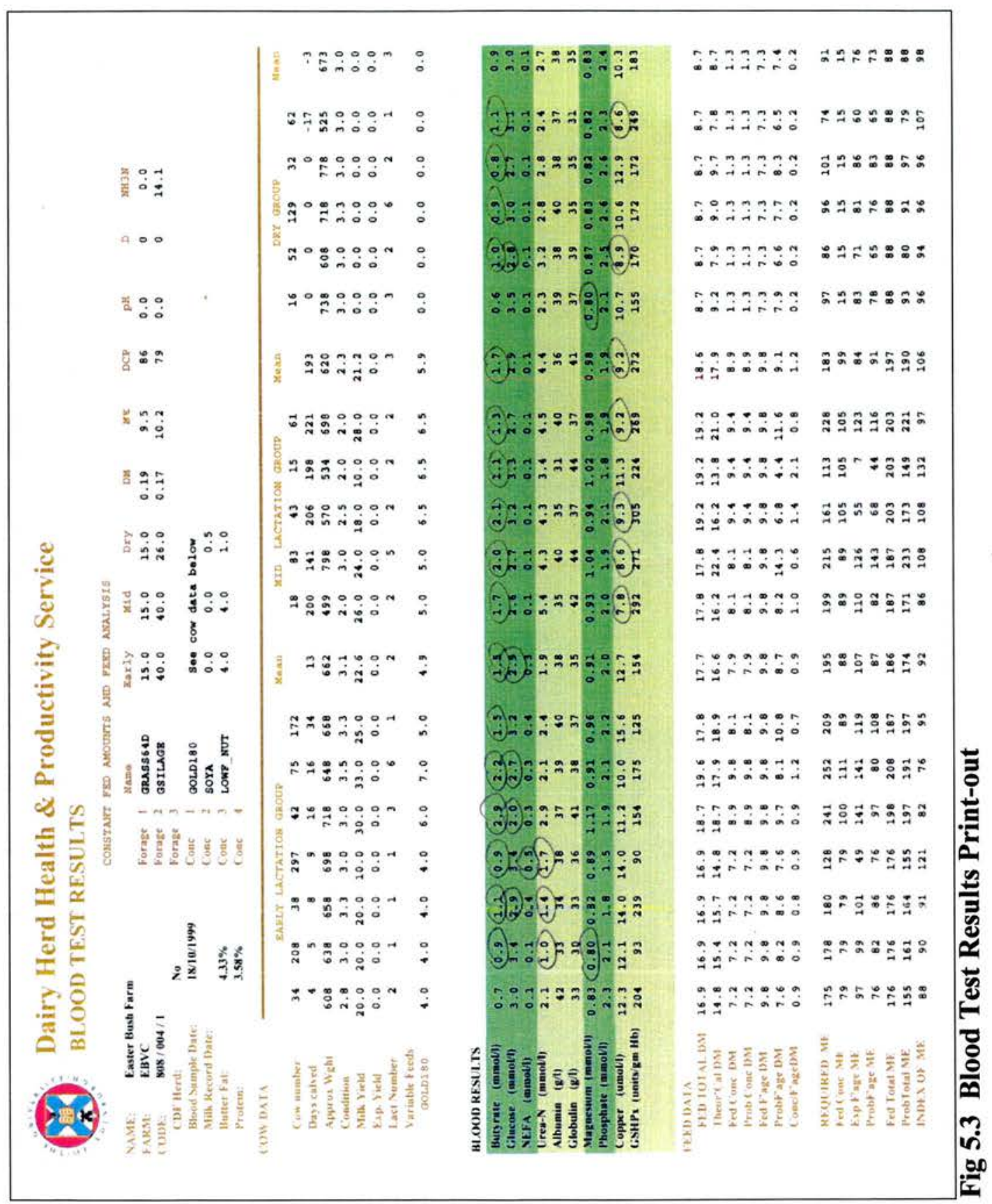


- Milk yield is recorded using the most recent available daily total.

- Expected yield is an estimate of the yield the stockperson considers the cow should be producing that day. The purpose is to communicate concern or satisfaction with performance.

- The lactation number is the current lactation for milking cows and the next lactation for dry cows.

- Comments: this section is particularly useful to note any general or specific comments regarding cow performance.

The date the samples are received is recorded, as is the name of the person keying in information to the computer.

\subsubsection{Blood Test Results Print-out (Fig 5.3)}

\subsubsection{Background Information}

The top section of the printout displays the background data collected on sheet 3 .

\subsubsection{Blood Results}

The middle section displays the Blood Results. The individual result for each animal is printed as well as the group mean values for the early mid lactation and dry cows. The parameters used as an indication of energy balance, Butyrate (beta-hydroxybutyrate), Glucose (plasma glucose) and NEFA (non esterified fatty acid) are grouped together. Urea $\mathrm{N}$ (urea nitrogen), Albumin and Globulin, are those used as indicators of protein status. Magnesium and Phosphate (inorganic phosphate) give an indication of mineral balance. If copper, T4 and GSHPSx have also been included the results will be listed below Phosphate. Values out with the normal range are circled. 


\subsubsection{Quantities of Forage and Concentrate}

The bottom section presents the theoretical calculations of the quantities of forage and concentrate being fed and how far they meet the calculated requirements for the stated milk production. It largely depends on the Sheet 3 data for its accuracy.

\section{FEED DATA}

FED TOTAL DM: This is the sum of the fed concentrate dry matter (Fed Conc DM) in kilogrammes $(\mathrm{kg})$ and the fed forage dry matter (Fed F'ge DM) according to the figures given on Sheet 3.

Theor'cal DM: Theoretical dry matter intake (TDMI) calculated using the individual body weight in $\mathrm{kg}$ and the fat-corrected milk yield in $\mathrm{kg}$. (MAFF, 1975)

Fed Conc. DM: This is the sum of the dry matter of concentrates fed (as recorded on Sheet 3). Analyses of the concentrates used are stored in the computer memory.

Prob Conc DM: The programme assumes that at least $25 \%$ of the total DMI will always be forage. If concentrate feeding is very high, TDMI limits may then be exceeded and all concentrates may not be eaten. Prob Conc DM is the consequent theoretical reduction in intake down to $75 \%$ under those circumstances. Otherwise it is the same as the Fed Conc DM.

Fed F'age DM: This is the total dry matter of forages fed according to the Sheet 3 information.

Prob F'age DM: This is the TDMI minus the Prob Conc DM, so it is never less than $25 \%$ of the TDMI but it is often different to the Fed F'age DM

Conc/F'age DM: This is calculated using the Fed Conc DM and the Prob F'age DM REQUIRED ME: This the metabolisable energy (MJ) each cow requires (MAFF, 1975)

Fed Conc ME: This is calculated from the Fed Conc DM and ME of concentrates fed.

Exp F'age ME: This is calculated from forage ME and expected forage DM.

Prob F'age ME: This is calculated from the ME value of the forage and the Prob F'age DM. 
Fed Total ME: This is the sum of the Fed Conc ME and the Fed F'age ME.

Prob Total ME: This is the sum of Prob F'age ME and the Prob Conc ME. Index of ME: This is Prob Total ME/ Required ME x $100 \%$.

\subsubsection{Test Results}

The results in the form of a print out (Fig 5.3) and an explanatory written report (appendix 2) are issued from the laboratory at Edinburgh to the farmer, his veterinary surgeon and the nutritional adviser. On receipt of the results the veterinary surgeon should convene a meeting of all concerned to discuss the report and the findings. Often this meeting is set up at the time of sampling. Decisions can be made to make appropriate management or nutritional changes which may be necessary when the results of the test are assessed in conjunction with the current productivity, health and profitability of the herd.

\subsubsection{Summary of Discussion Form}

With the results the veterinary surgeon receives 'Summary of Discussion' forms (Fig 5.4). These are completed and provide a written record of any discussion, decisions or forward plans made at the meeting. This forms the 'minutes of the meeting' and copies are distributed to the farmer, veterinary surgeon, nutritional adviser and the university based veterinary surgeon.

All members of the DHHPS have their herds fully costed and this information is available at these discussion meetings. The date for the next blood sampling can often be arranged at this time. 


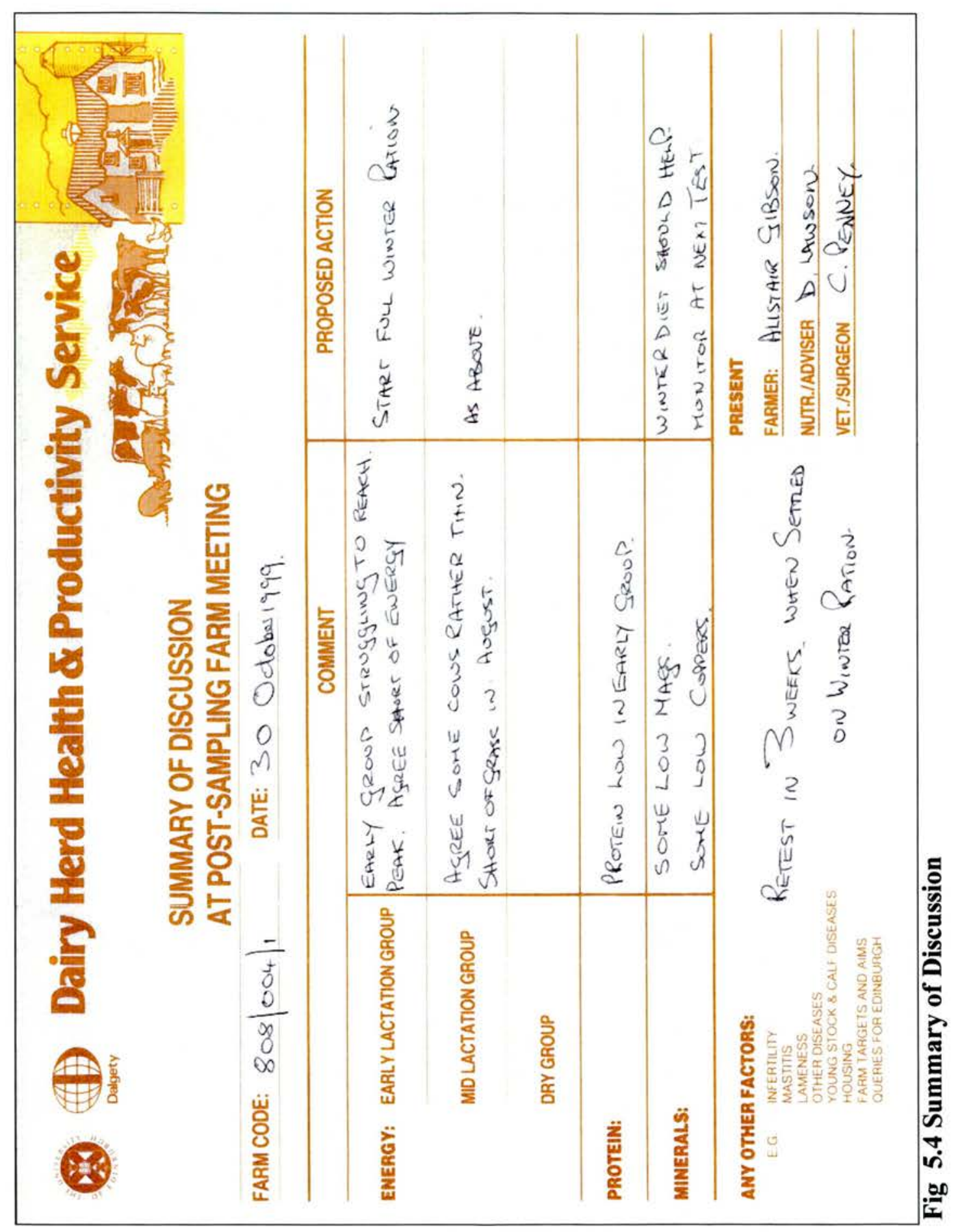


5.2.1 Number of farm blood tests performed between 1996 and 1997

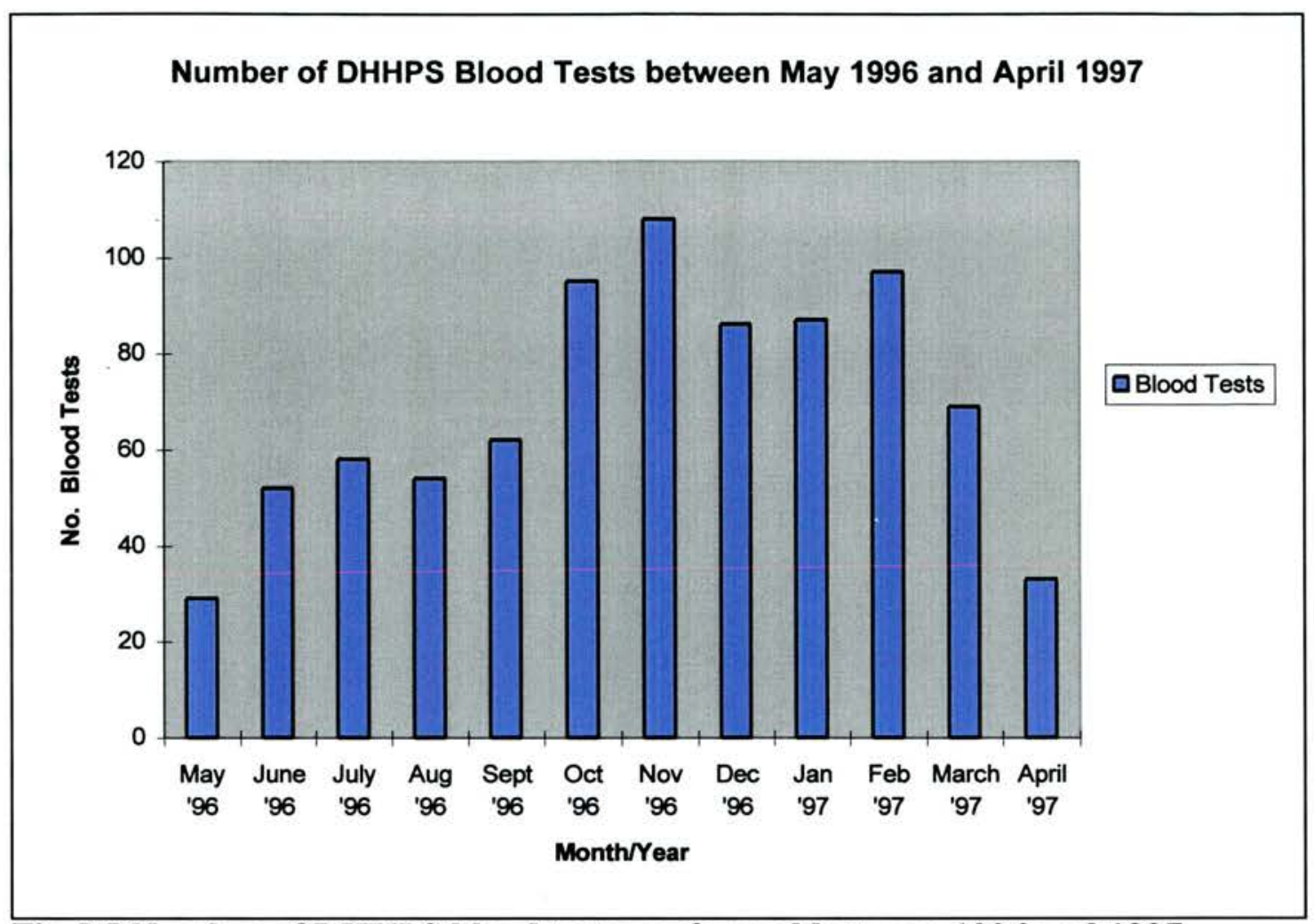

Fig 5.5 Number of DHHPS blood tests performed between 1996 and 1997

Fig 5.5 illustrates the pattern of blood tests throughout the year. The greatest number of tests are performed in late autumn and early winter, generally when herds have become settled on the full winter feeding regime. The number of tests is also high in January and February which is a time when many autumn calving cows are being served. The quality of forage may also be changing at this time with second cut silage being introduced. Herds may also find that they are running under quota at this time and wish to check ration in order to make adjustments which may boost yield. On average each herd was tested 2.5 times each year.

\subsubsection{Background Information}

The assimilation and review of all the background information is essential before the biochemical results are appraised. Interpretation of the 
biochemical values without consideration of the relevant data is of limited value at best and at worst can result in misleading conclusions being made.

\subsubsection{Milk quality}

Milk Butterfat: Butterfat (Fig 5.6) gives an indication of the amount of fibre currently being consumed by the cows. Typically cows only being fed lush grass in May or early June may be short of dietary fibre and this may be reflected in the bulk milk butterfat concentration. Butter fat concentration is influenced by genetics and there is wide variation between herds.

Cows being fed a diet with high concentrate to forage ratio, typically >3:1 may experience a drop in butter fat, again as a result of low dietary fibre. Such cows may also be liable to suffer from acidosis.

\section{Milk protein}

Protein in milk gives an indirect indication of the energy status of the diet. Lack of FME results in less than optimum growth of rumen microbial protein. Less microbial protein is then available for digestion in the small intestine with a reduction in protein available for milk production. A fall in milk protein on a weekly basis would generally indicate an energy deficient diet. There is generally an initial period of energy deficit when body fat will be mobilised to compensate for inadequate energy intake. Milk protein tends, then, to be a more historical indicator of energy status. Typically underfeeding in autumn would be followed by low milk protein early in January and February of the following year (Fig 5.7). Low milk protein will be frequently found in herds in poor body condition or suffering from chronic infection (Fig 5.8).

Trends in milk protein provide a good starting point for a veterinary surgeon investigating a fertility problem. Cows with low milk protein will frequently have low body condition scores and poor fertility. 


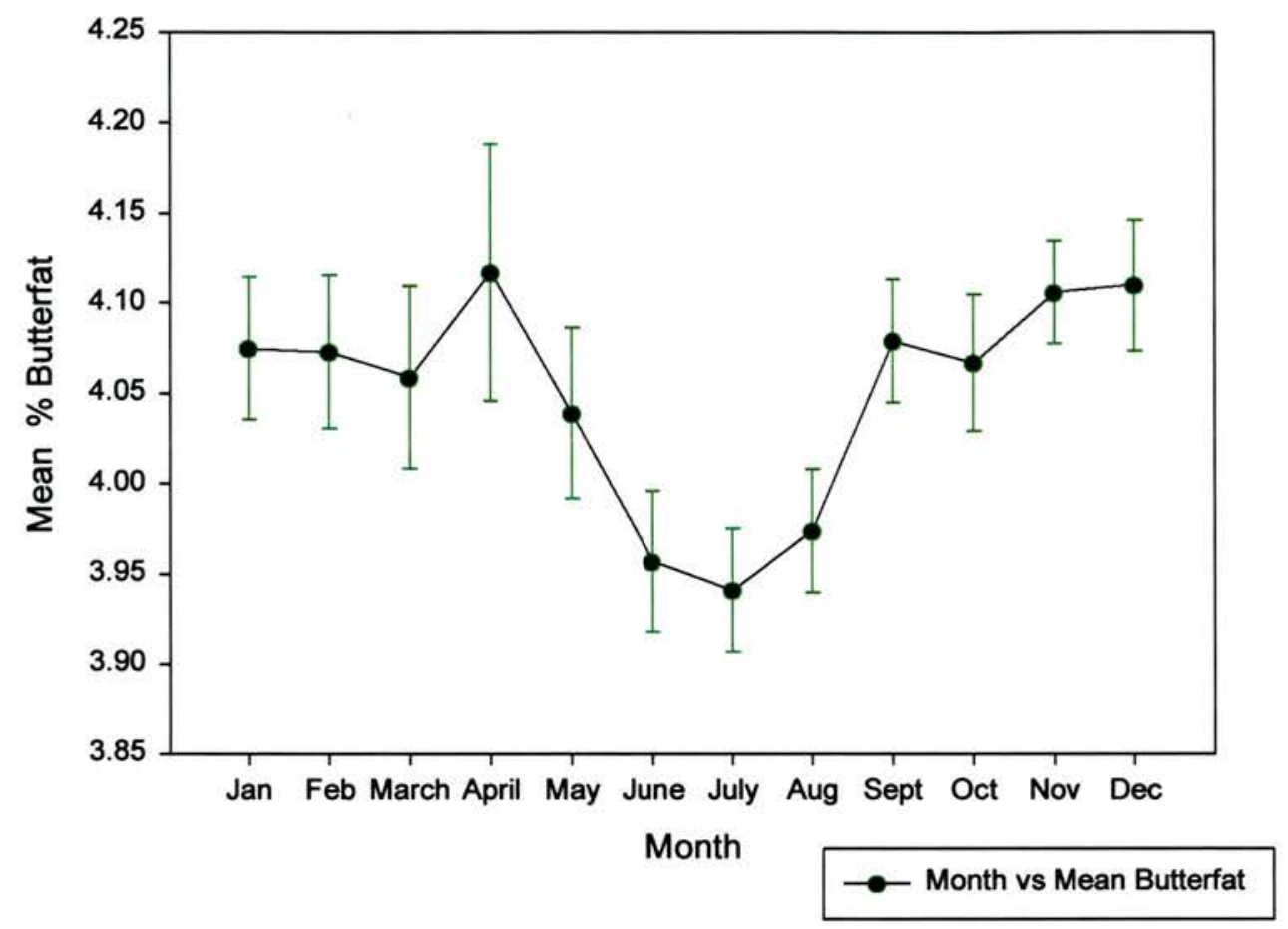

Fig 5.6 Mean butterfat values per month with $95 \%$ Confidence Intervals. Data taken from Friesian and Holstein herds blood sampled between January 1993 and May 2000. Ranges from 46-294 herds per month, average 159. 


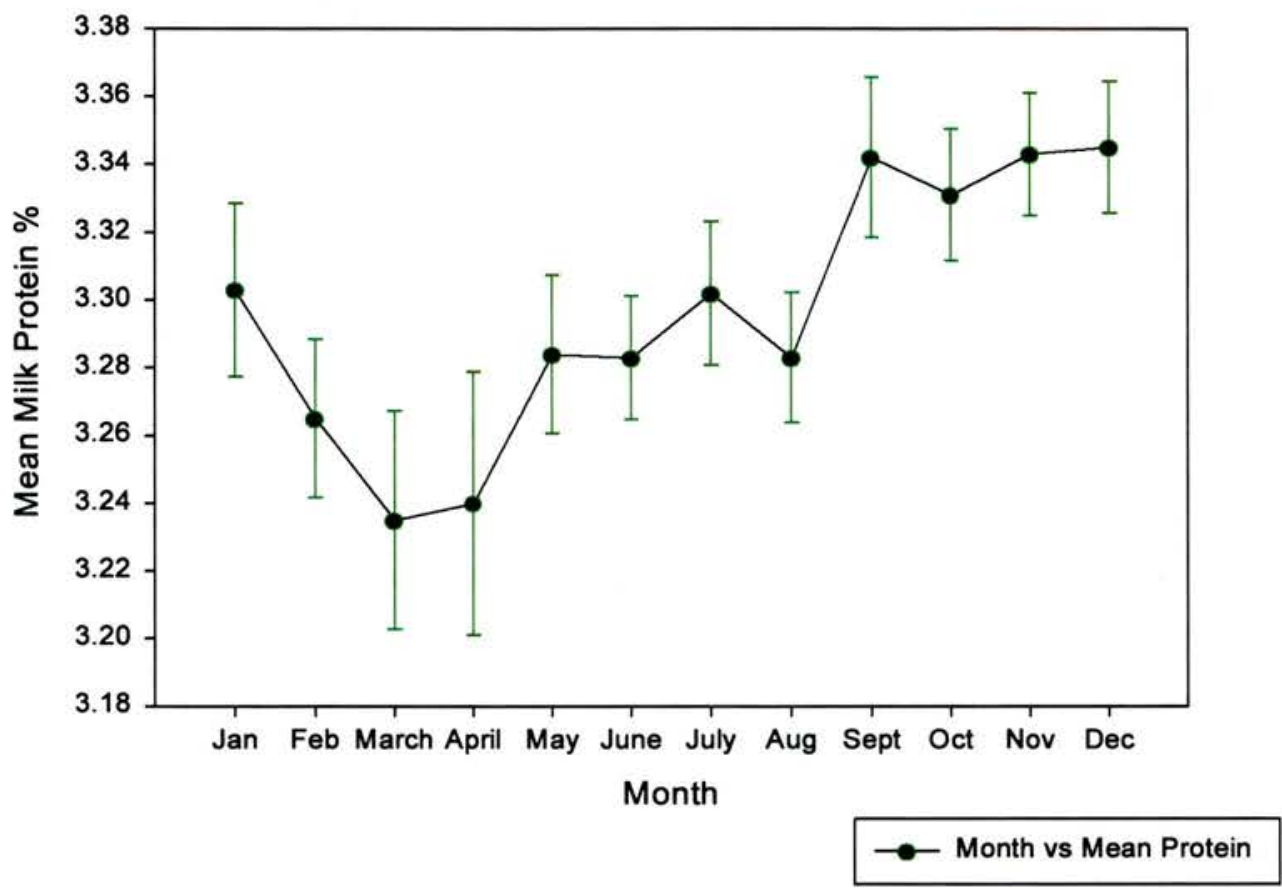

Fig 5.7 Mean Milk Protein values per month with 95\% Confidence Intervals. Data taken from Friesian and Holstein herds blood sampled between January 1993 and May 2000. Ranges from 46-294 herds per month, average 159. 


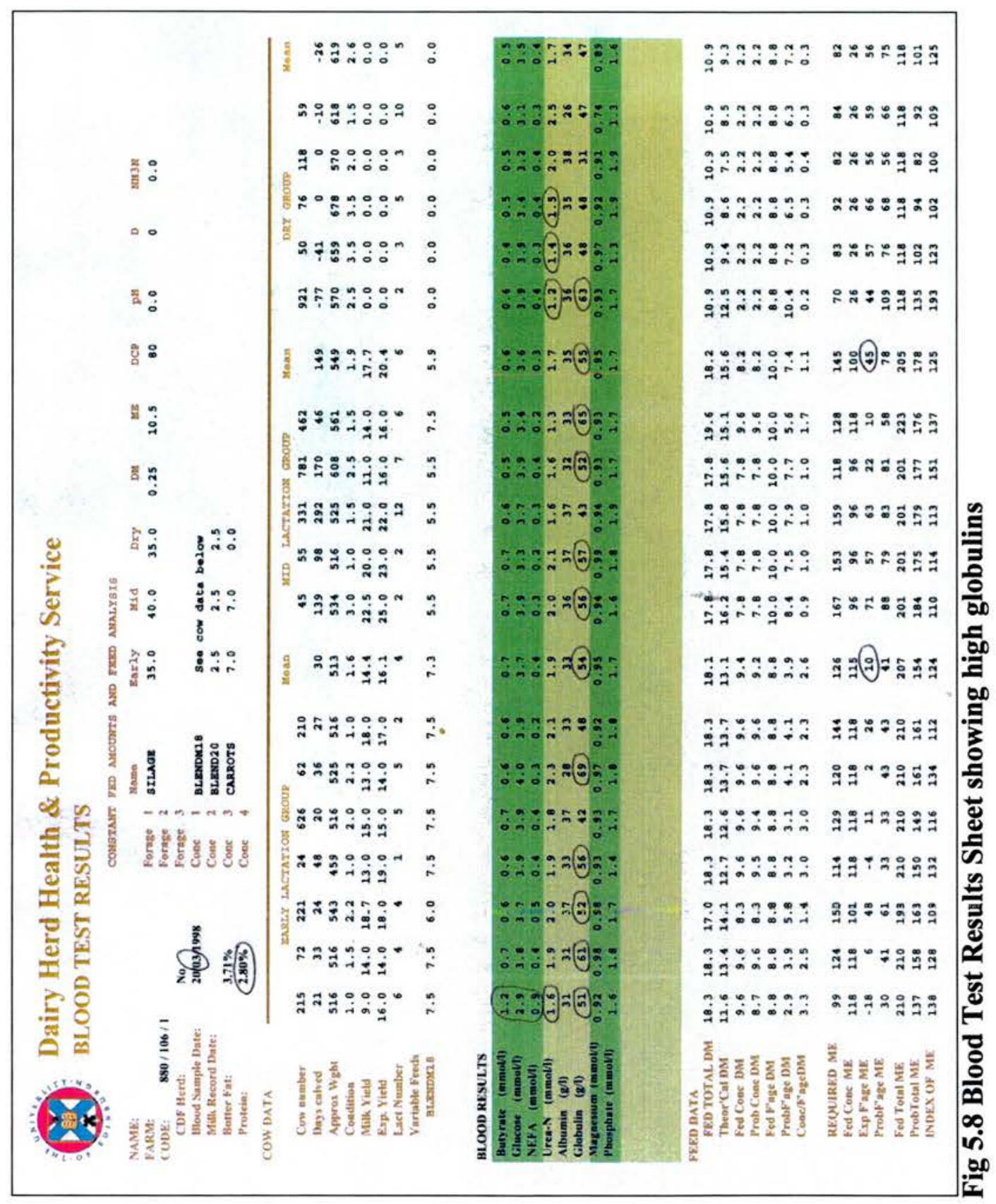




\subsubsection{Forage Amounts and Analysis}

Forage intake is an approximate figure based at best on how much the group are being fed. Forage analysis gives indication of quality and will indicate possible intake restriction.

\begin{tabular}{|c|l|l|l|l|l|l|l|}
\hline Feed & $\begin{array}{c}\text { DM } \\
(\%)\end{array}$ & $\begin{array}{c}\text { ME } \\
(\mathrm{MJ} / \mathrm{kg} \text { DM) }\end{array}$ & $\begin{array}{c}\text { CP } \\
(\mathrm{g} / \mathrm{kg} \text { DM) }\end{array}$ & $\begin{array}{l}\text { DCP } \\
(\mathrm{g} / \mathrm{kg} \text { DM) }\end{array}$ & \multicolumn{1}{|c|}{ pH } & $\begin{array}{c}\text { D } \\
\text { Value }\end{array}$ & $\begin{array}{l}\mathbf{N H}_{3} \mathbf{N} \\
(\mathrm{g} / \mathrm{kg} \text { DM) }\end{array}$ \\
\hline Grass Silage & $18-50$ & $9.6-11.2$ & $120-180$ & $80-120$ & $3.8-4.2$ & $60-70$ & $50-115$ \\
\hline Maize Silage & 28 & 11 & 90 & 58.5 & 3.7 & $67-73$ & $50-150$ \\
\hline
\end{tabular}

Fig 5.9 Typical composition of grass and maize silages (Dalgety Agriculture)

The following factors commonly influence silage intakes

- Low $\mathrm{pH}<3.7$ may be unpalatable

- High $\mathrm{pH}$ is associated with poor fermentation characteristics.

- High ammonia nitrogen $>10(\%$ total $N)$ is associated with low intakes.

- Low dry matter $<20 \%$ limits overall dietary intake due to high water content of diet

Herds, fed poor silage, will often also be experiencing poor fertility.

\subsubsection{Cow Data}

\subsection{Days Calved}

Ideally early lactation group will be 10 to 21 days calved. If sampled too early may still be upset after parturition. If too long calved cow may adjust to under feeding by dropping yield and results may not reflect biochemical changes associated with metabolic stress. Ideally dry cow group should be in last ten days prior to calving. If sampled earlier may not be under metabolic stress.

\section{(Fig 5.10) Dry cow groups}

The first group are still some thirty days from parturition and have normal biochemical results. The cows which are close to calving are, however, showing signs of metabolic stress. 


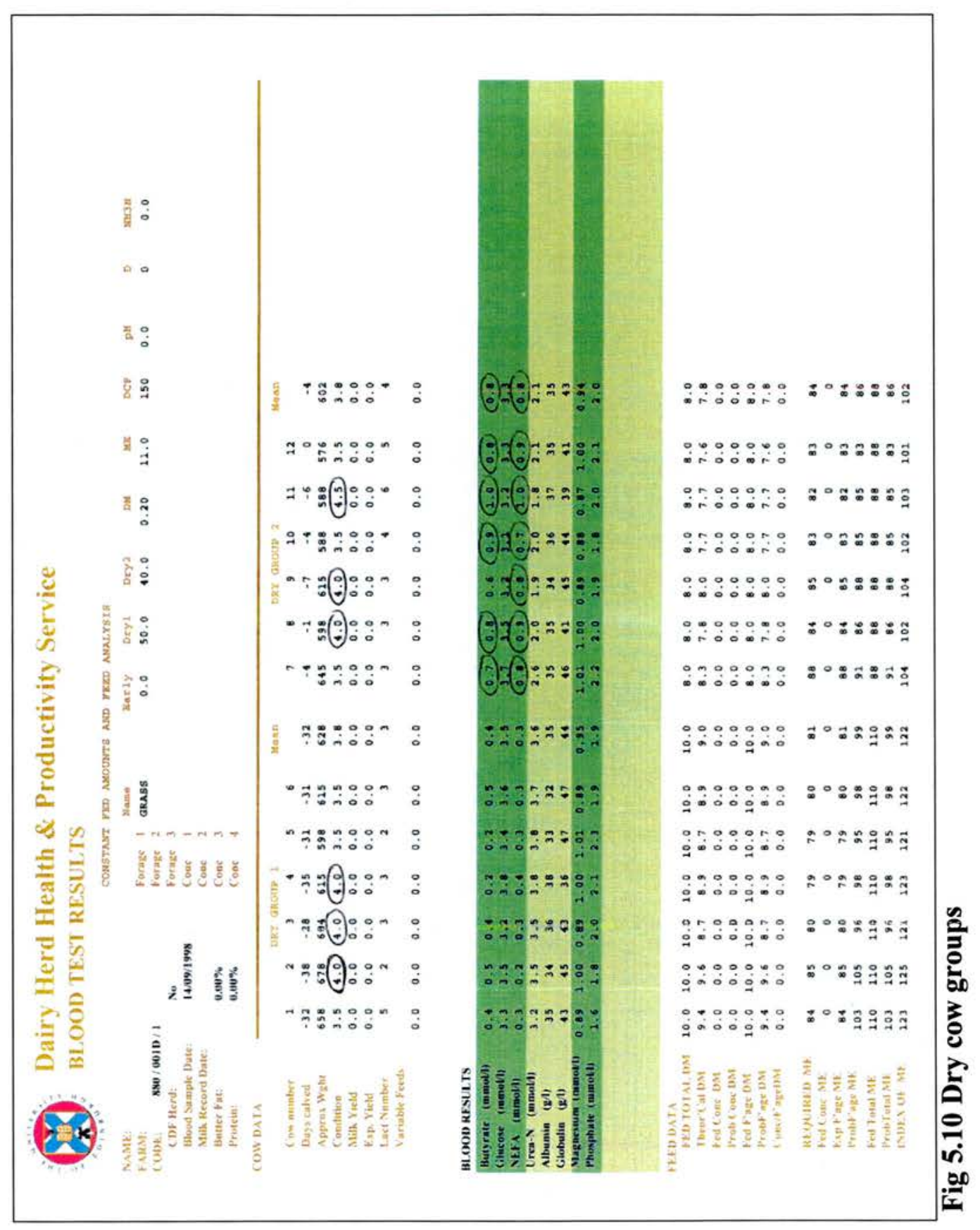




\subsection{Approximate weight}

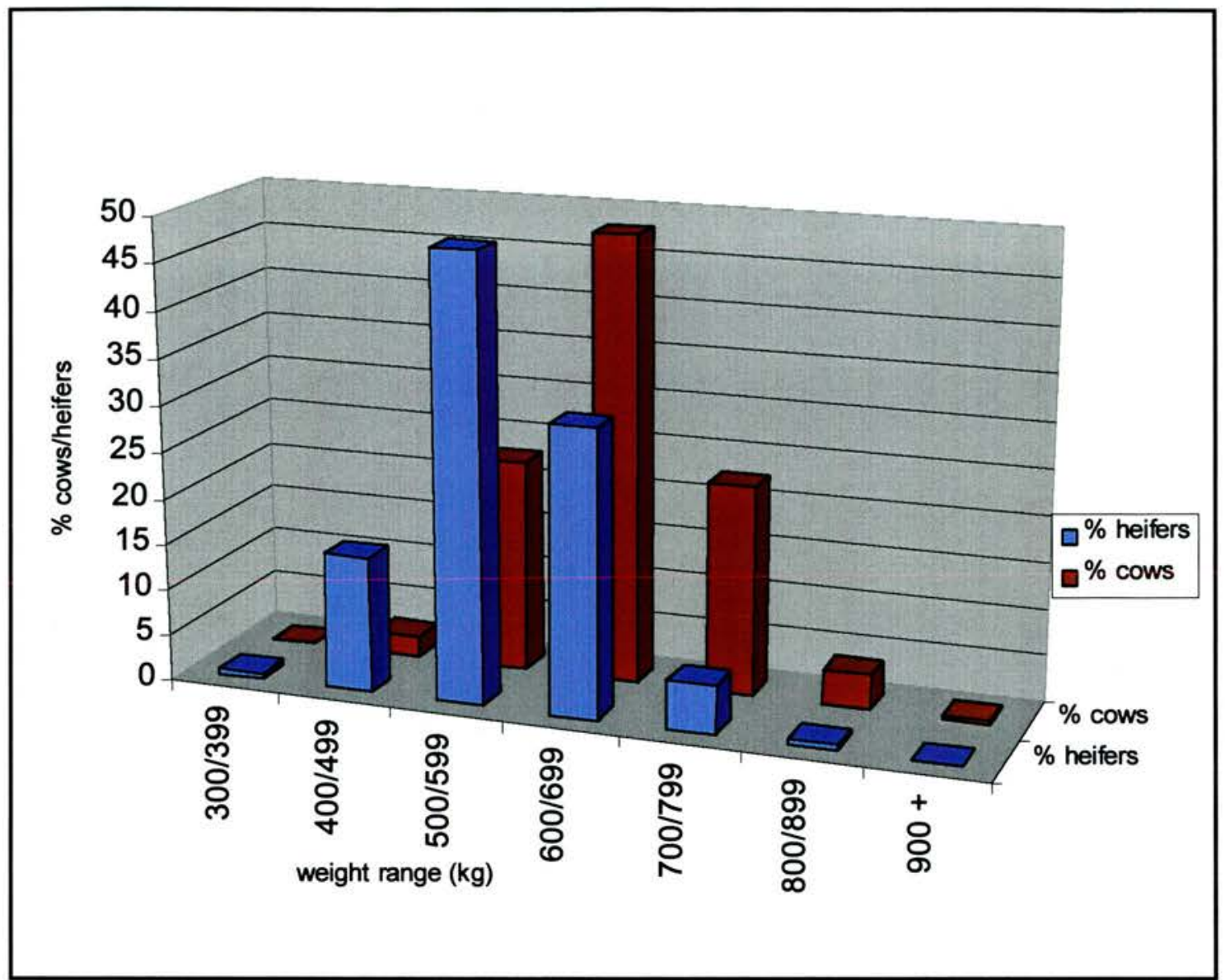

Fig 5.11 Percentage of cows/heifers within various weight ranges. Mean cow weight $651 \mathrm{Kg}$, mean heifer weight $576 \mathrm{Kg}$. Data from 1580 heifers and 6843 cows blood tested between March'97 and March '98

Veterinary surgeons are often surprised to find how heavy cows actually are. Body weight is important for consideration of dry matter intake and also for judgement of cubicle size. Many cows are now some 40 per cent larger than thirty years ago when their cubicles may have been constructed. 


\subsection{Condition Score}

Table 5.1 Body Condition Score (c.s.) from dairy cows blood sampled between March 1997 and March 1998

\begin{tabular}{|l|c|c|c|c|c|}
\cline { 2 - 6 } \multicolumn{1}{c|}{} & $\begin{array}{l}\text { Number of } \\
\text { cows }\end{array}$ & $\begin{array}{l}\text { \% cows } \\
\text { with } \\
\text { c.s. } \Rightarrow \mathbf{3 . 5}\end{array}$ & $\begin{array}{l}\text { \% cows } \\
\text { with } \\
\text { c.s. }>3.0\end{array}$ & $\begin{array}{l}\text { \% cows } \\
\text { with } \\
\text { c.s. } \Rightarrow 3.0\end{array}$ & $\begin{array}{l}\text { \% } \\
\text { with } \\
\text { c.s. }<3.0\end{array}$ \\
\hline Dry (0-14 days pre calving) & 1521 & 39.4 & 42.5 & 70.8 & 29.2 \\
\hline Early (5-21 post calving) & 1840 & 9.6 & 11.3 & 34.3 & 65.7 \\
\hline Mid (>100 days post calving) & 1679 & 12.2 & 13.8 & 37.5 & 62.5 \\
\hline
\end{tabular}

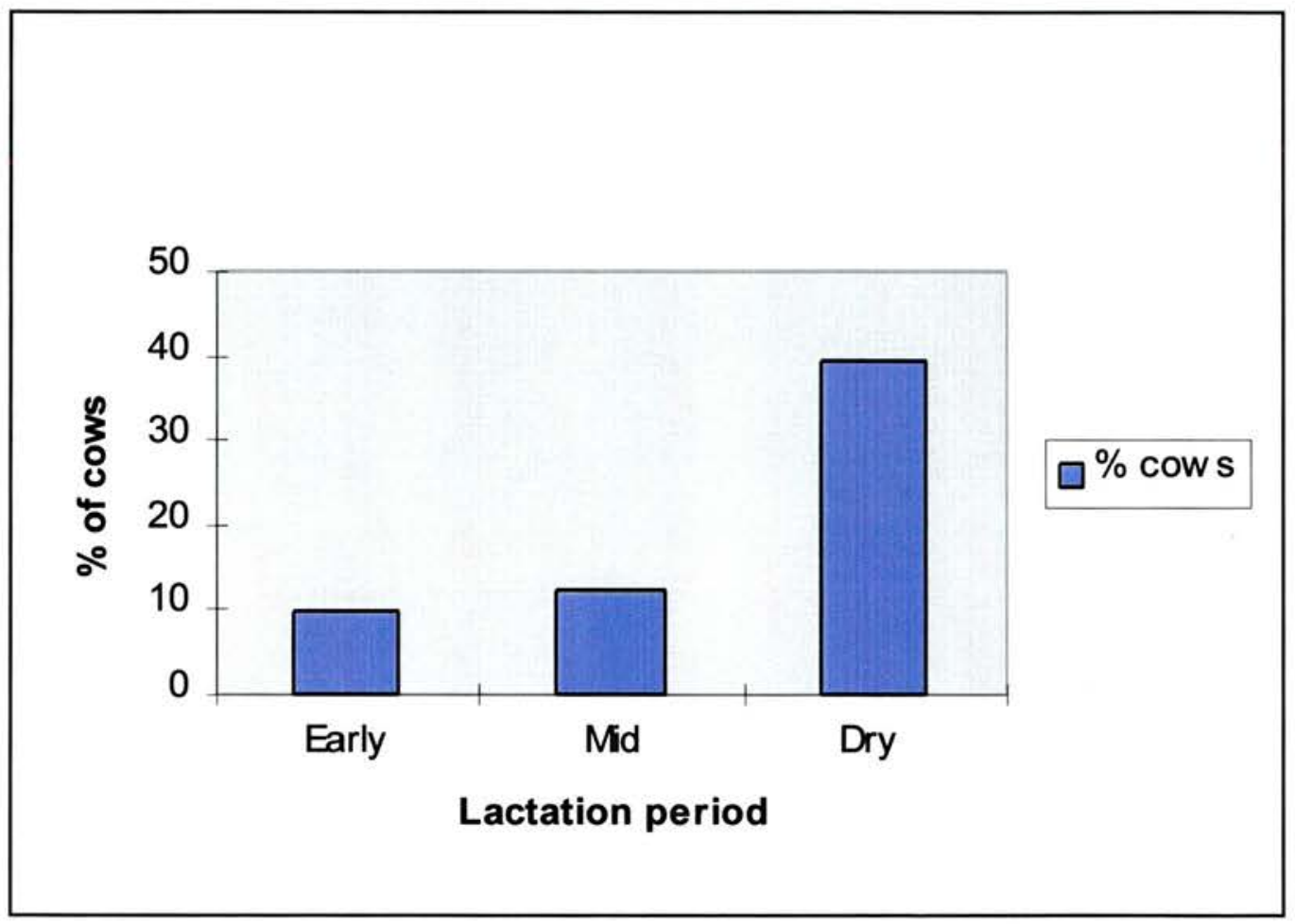

Fig 5.12 Percentage of cows in various lactation groups with a condition score of 3.5 or higher 
Table 5.2 Body Condition Score (c.s.) loss during transition from Dry to Early lactation. Data collected from 353 herds blood tested between March 1997 and March 1998

\begin{tabular}{|l|c|}
\hline c.s. loss between Dry and Early lactation & \% of herds \\
\hline loss $<0.5$ & 42 \\
\hline loss $=>0.5$ & 58 \\
\hline loss $=>1.0$ & 20 \\
\hline
\end{tabular}

In year 1997-98 58 per cent of herds have had an average condition score loss $=>0.5$ in the transition from dry to early lactation and 20 per cent have an average loss $=>1$. Loss of more than 0.75 is associated with fertility problems (Nebel and McGilliard 1993).

Ward et al., (1996) reported that 57 per cent of dry cows sampled were above condition score 3 and 22 per cent of cows under 6 weeks calved were below score 2.5

Over condition in dry cows Fig 5.10 is associated with increased parturient and post parturient diseases. Cows which are too fat at calving have reduced dry matter intake in early lactation (Garnsworthy, 1988).

\subsection{Milk Yield}

Early lactation milk yields give an indication if cows are achieving expected peak e.g. a 6000 litre annual yield requires cows to peak at 30 litres (6000/200 litres). A cow achieving a yield of 45 litres per day would have very much higher energy requirements than one expected to produce 25 litres.

When milk yield is stated to be below expectation one of the most common reasons will be energy deficiency in early lactation (Fig 5.13).

\subsection{Lactation Number}

It is important to note the age range of animals sampled. Inclusion of too many heifers in a group can give misleading results. 


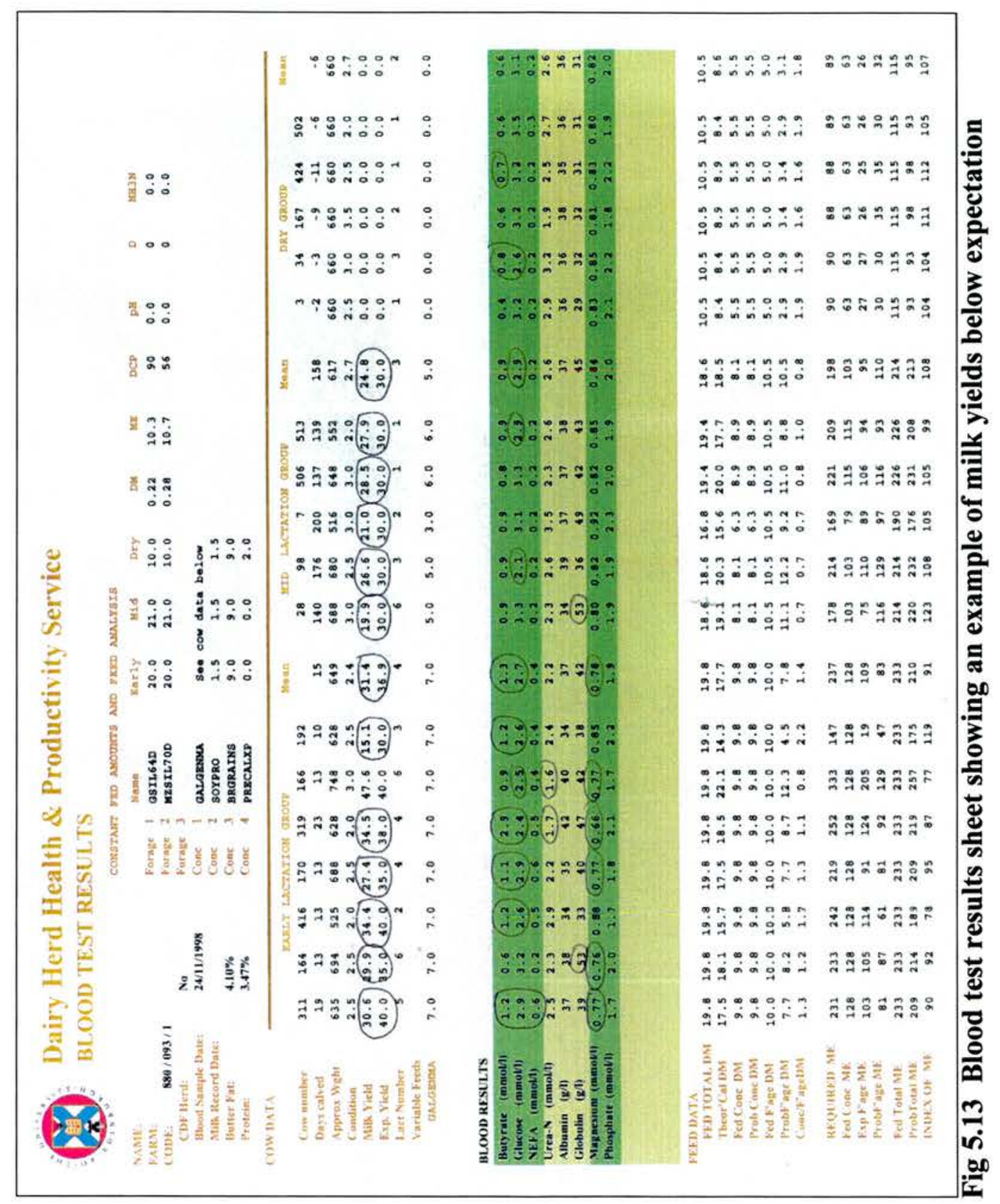




\subsubsection{Feed Data}

5.2.3.1 The Fed total DM is based on the farmer or adviser's estimation of what cows are eating.

5.2.3.2 The Theoretical DM is what the computer calculates they will eat using the above information on body weight, milk yield and stage of lactation. If these figures are widely different it is likely that the amount the cows can eat is being over estimated.

5.2.3.3 Conc/F'age DM is useful in alerting the danger of inadequate forage in the diet. It should be less than 3:1. At 3:1 it implies that three quarters of the total dry matter is made up of concentrate (Fig 5.14). Despite there being sufficient energy in the ration there is a strong possibility of acidosis due to lack of fibre in the diet.

5.2.3.4 Expected forage ME calculates how much energy is being expected from the forage component of the diet.

5.2.3.5 Index of $\mathbf{M E}$ is an expression of the probable energy that is being consumed as a percentage of what is required. If this is over 95 per cent it would imply that the cow is being supplied with sufficient energy. If the biochemistry suggests otherwise (high BHB and NEFA with some correspondingly low plasma glucose levels) then the reason must be discussed and investigated (Fig 5.14). In this example although there is theoretically sufficient energy on offer the lack of fibre when supplied with too much concentrate will result in ruminal acidosis, lack of appetite and failure to achieve expected yield. The solution to this problem was to provide more access to forage for a much longer period. High blood ketone levels do not always indicate feeding more high energy feed!

All the above information is essential for the correct interpretation of the biochemical results. 


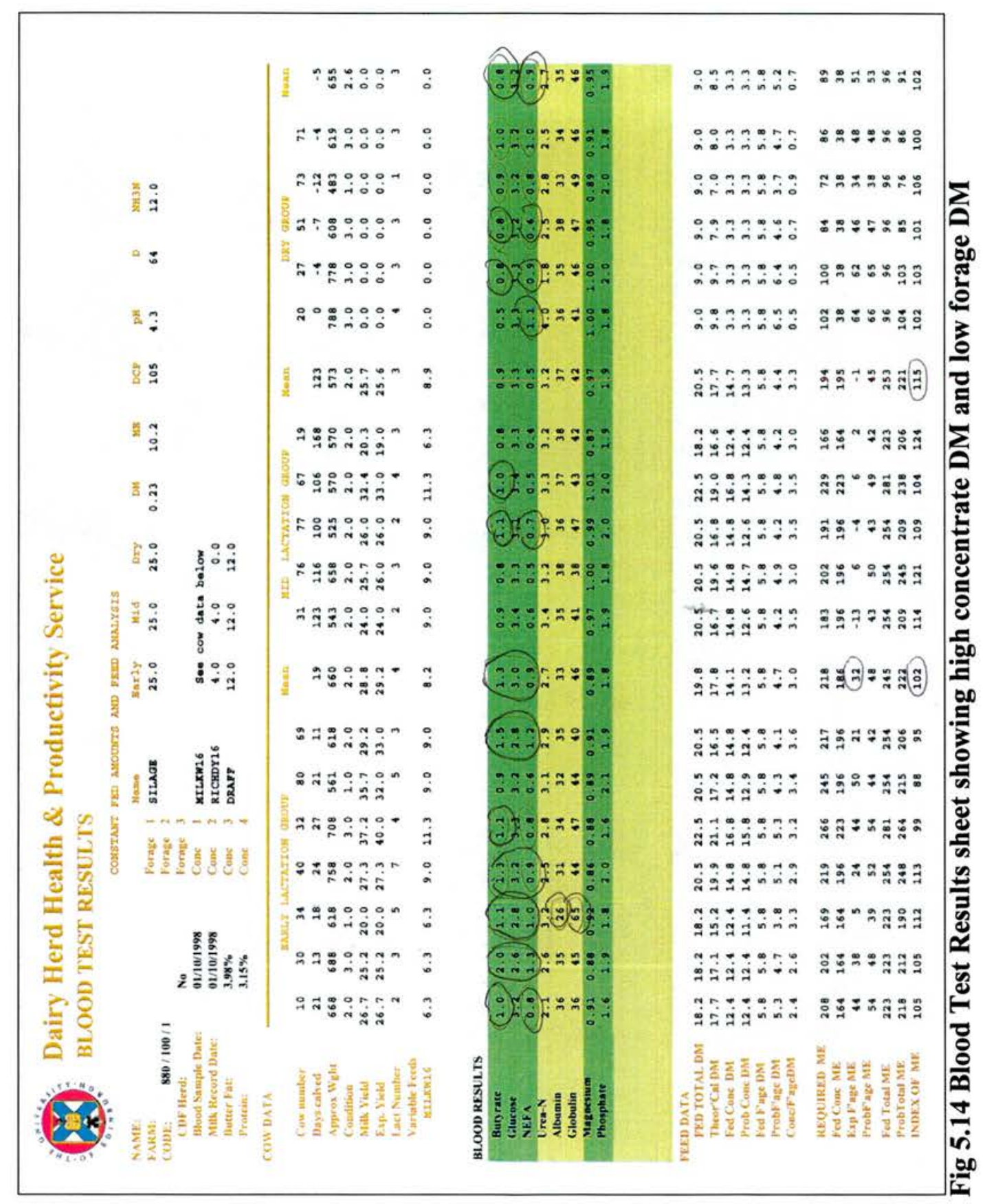




\subsubsection{Blood results}

\subsubsection{Energy Balance}

\subsection{Butyrate (BHB)}

Table 5.3 Percentage of cows with abnormal BHB results. Data collected from cows blood sampled between 1992 and 1998.

\begin{tabular}{|l|c|c|c|}
\hline Lactation & $\begin{array}{c}\text { Abnormal } \\
\text { Range }\end{array}$ & No. of Cows & $\begin{array}{l}\text { \% cows with } \\
\text { Abnormal BHB }\end{array}$ \\
\hline Dry (-14 - 0 days) & $>=0.6 \mathrm{mmol} / 1$ & 9235 & 28.4 \\
\hline Early (5 - 21 days) & $>=1.0 \mathrm{mmol} / 1$ & 12103 & 27.2 \\
\hline Early (5 - 40 days) & $>=1.0 \mathrm{mmol} / 1$ & 20502 & 28.0 \\
\hline Mid (> 100 days) & $>=1.0 \mathrm{mmol} / 1$ & 10393 & 12.0 \\
\hline
\end{tabular}

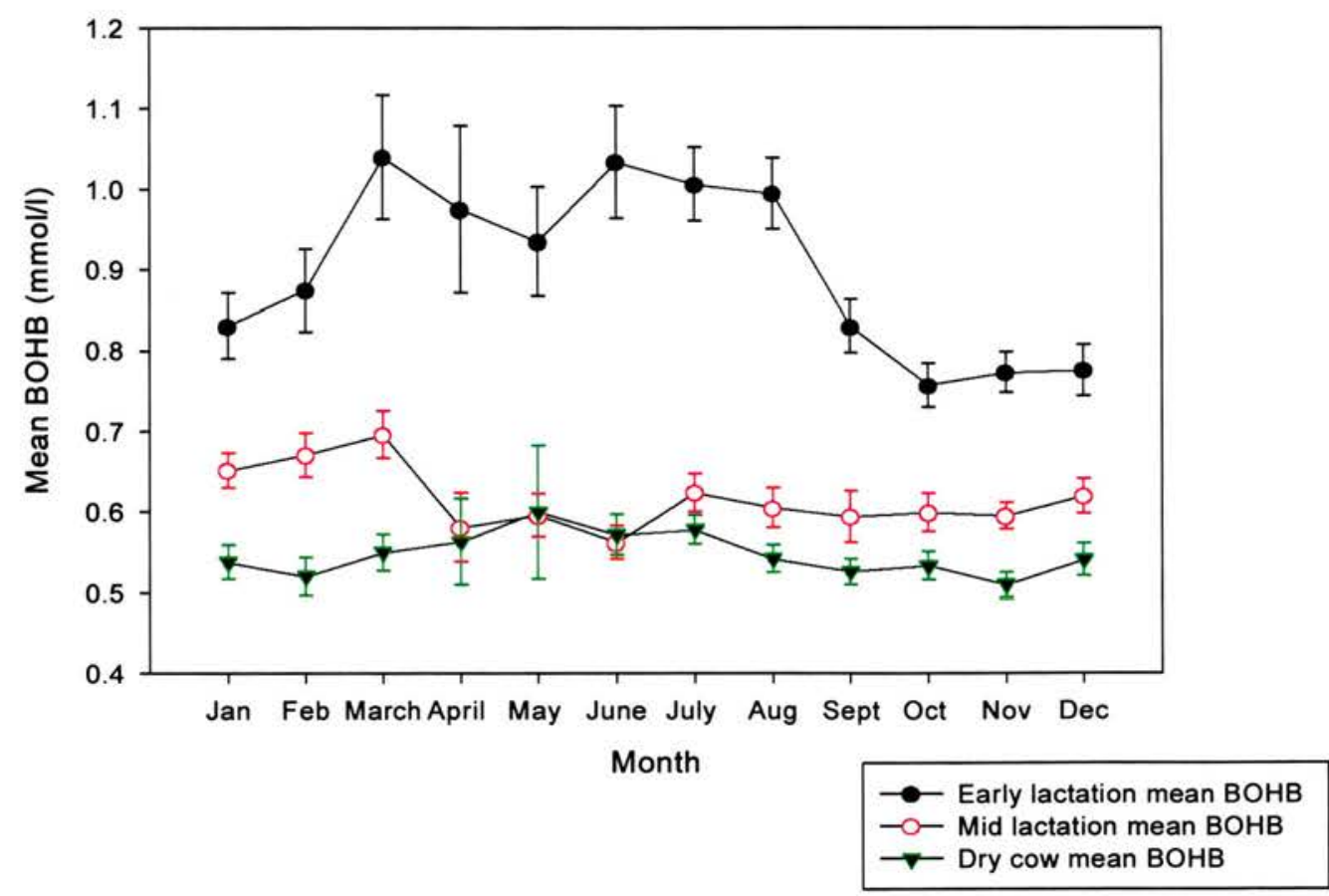

Fig 5.15 Mean BHB values per month with $95 \%$ Confidence Intervals. Data from cows blood sampled between 1993 and 1997 


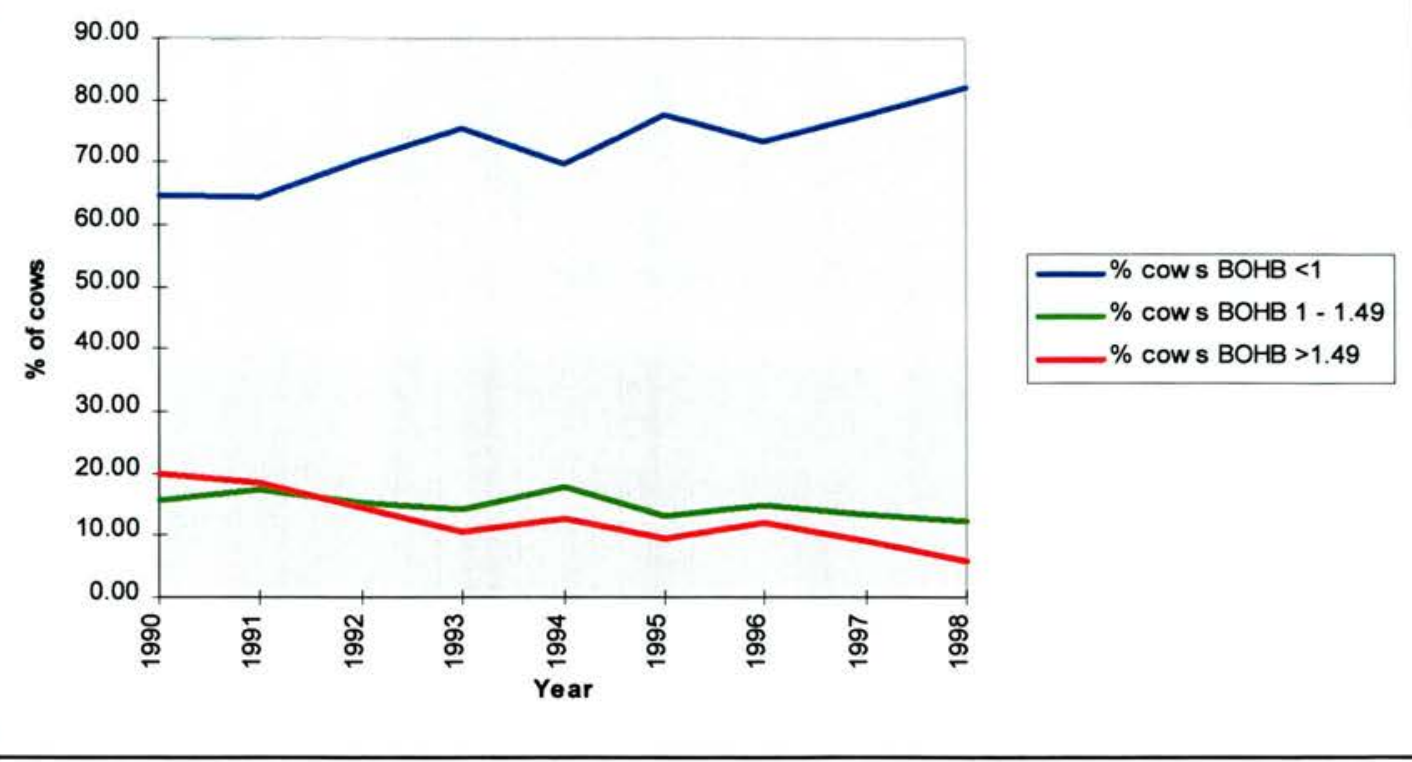

Fig 5.16 BHB in early lactation cows over years 1992 - 1998

The optimum range for early lactation cows is below $1 \mathrm{mmol} /$ litre and dry cows at end of pregnancy below $0.6 \mathrm{mmol} /$ litre (Whitaker and Kelly 1983). In 1990 35 per cent of early lactation cows had BHB blood concentration $>1$ mmole/litre in 1990 , with 20 per cent $>1.5$ mmole/litre. In 1998 the results were 18 per cent $>1 \mathrm{mmole} /$ litre and 6 per cent $>1.5 \mathrm{mmole} / \mathrm{litre}$.

From 1992-98, DHHPS found 28.4 of 9,235 dry cows, sampled 0-14 days before calving and 28 per cent of 20,502 cows between 5-40 days post calving, had raised BHB results. Ward et al. (1995) reported similar results with one third cows in post partum groups having raised BHB blood concentrations and 22 per cent of dry cows had raised $\mathrm{BHB}$ results $(>0.6 \mathrm{mmole} / \mathrm{litre})$.

BHB has proved to be a reliable parameter. It is stable in blood and concentrations do not alter following transit. In many cases the blood concentration increases when the animal is in negative energy balance. Increases due to ingestion of butyric silage can be identified by the fact that all groups fed the same forage will tend to have raised levels irrespective of how long they have been calved. This demonstrates the merit of having a mid lactation group for comparison.

Raised BHB concentrations, for whatever reason, are associated with reduced dry matter intake. 


\subsection{Glucose}

Table 5.4 Percentage of cows with Abnormal Glucose results. Data collected from cows blood tested between March 1992 and March 1998

\begin{tabular}{|l|l|c|c|}
\hline Lactation & $\begin{array}{l}\text { Abnormal } \\
\text { Range }\end{array}$ & No. of Cows & $\begin{array}{l}\text { \% cows with } \\
\text { Abnormal Glucose }\end{array}$ \\
\hline Dry (-14 - 0 days) & $<3.0 \mathrm{mmol} / 1$ & 8961 & 14.1 \\
\hline Early (5 - 21 days) & $<3.0 \mathrm{mmol} / 1$ & 11727 & 31.2 \\
\hline Early (5 - 40 days) & $<3.0 \mathrm{mmol} / 1$ & 19434 & 28.5 \\
\hline Mid (>100 days) & $<3.0 \mathrm{mmol} / 1$ & 9980 & 10.2 \\
\hline
\end{tabular}

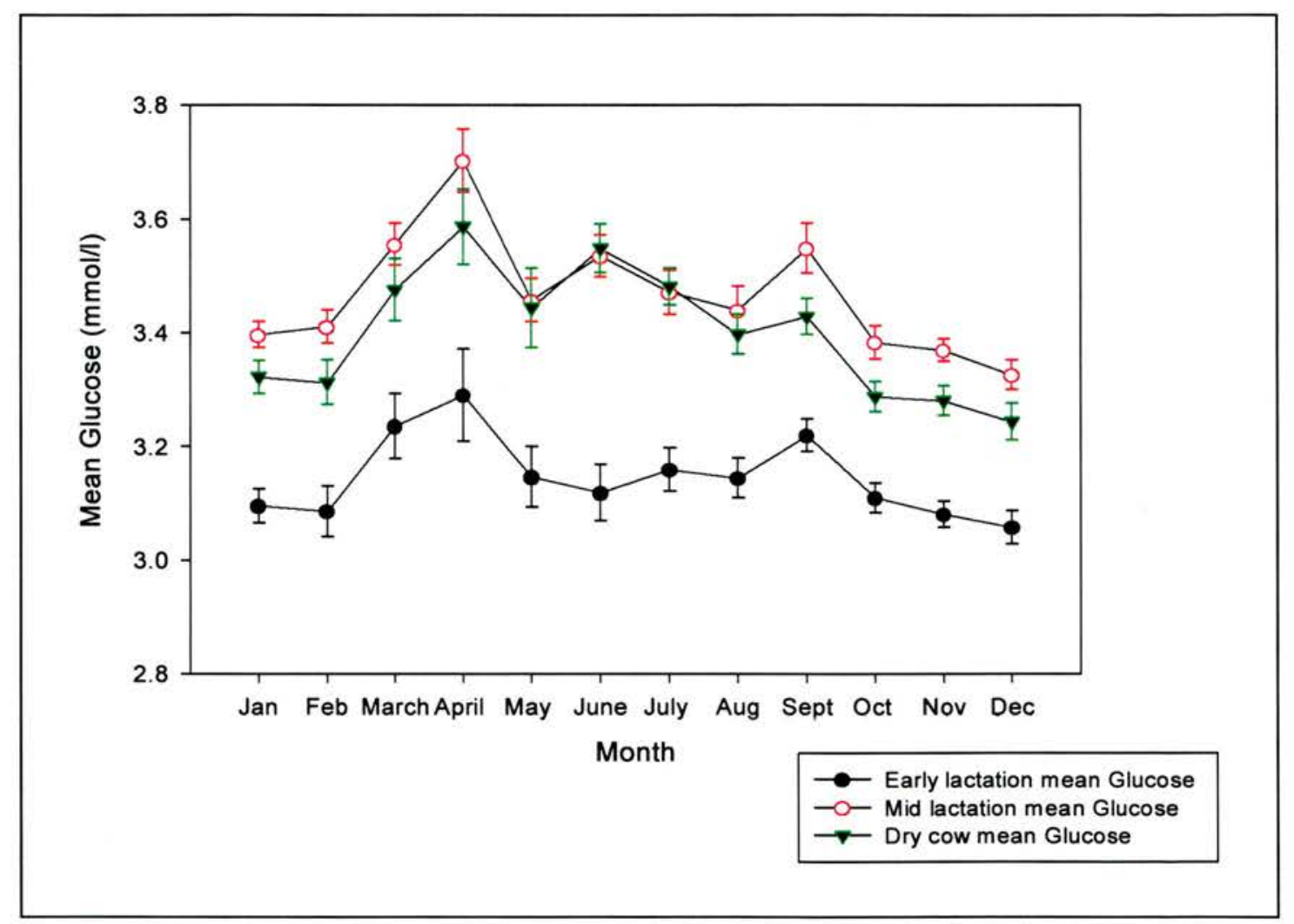

Fig 5.17 Mean Glucose values per month with 95\% Confidence Intervals. Data from cows blood sampled between 1993 and 1997

The optimum range is over $3.0 \mathrm{mmol} /$ litre. In the period 1992-98, DHHPS found that 28.5 per cent of 19,434 cows sampled between 5-42 days calved were below $3 \mathrm{mmol} / \mathrm{litre}$. Ward et al. (1995) reported that a quarter of cows calved less that 42 days had low glucose results. 
Mean glucose for early lactation cows were consistently lower than in the mid or dry groups. The lactating dairy cow has a high demand for glucose, the main precursor of lactose in the milk. As discussed earlier in the literature review glucose, although frequently used, has limitations as an indicator of energy status because the correlation is not precise (Hewett, 1974; Parker and Blowey, 1976). It is under homeostatic control and is elevated by stress. Plasma glucose concentrations did not follow changes in food intake as closely as serum BHB (Kelly, 1977). However, in cows where high concentrations of BHB were found, e.g. in clinical cases of ketosis, low glucose results were useful as an additional indicator of the severity of the condition.

Plasma glucose concentrations remain relatively stable during the prepartum transition period, increase dramatically at calving and then decrease immediately postpartum (Vazquez-Anon et al., 1994). Low glucose results are likely to be significant but normal results may not necessarily reflect a positive energy balance. Low concentrations of plasma glucose have been associated with decreased reproductive efficiency (Harrison et al., 1990) and ovarian energy supply (Rabiee et al., 1999). On occasion low results were obtained when out of date vacutainers were used or when samples were incompletely mixed.

\subsection{Non Esterified Fatty acid (NEFA)}

Table 5.5 Percentage of cows with abnormal NEFA results. Data collected from cows blood tested between March 1992 and March 1998

\begin{tabular}{|l|c|c|c|}
\hline Lactation & $\begin{array}{c}\text { Abnormal } \\
\text { Range }\end{array}$ & No. of Cows & $\begin{array}{l}\text { \% cows with } \\
\text { Abnormal NEFA }\end{array}$ \\
\hline Dry (-14 - 0 days) & $>=0.4 \mathrm{mmol} / 1$ & 9235 & 30.6 \\
\hline Early (5 - 21 days) & $>=0.7 \mathrm{mmol} / 1$ & 12103 & 26.2 \\
\hline Early (5 - 40 days) & $>=0.7 \mathrm{mmol} / 1$ & 20502 & 21.9 \\
\hline Mid (>100 days) & $>=0.7 \mathrm{mmol} / 1$ & 10393 & 2.4 \\
\hline
\end{tabular}




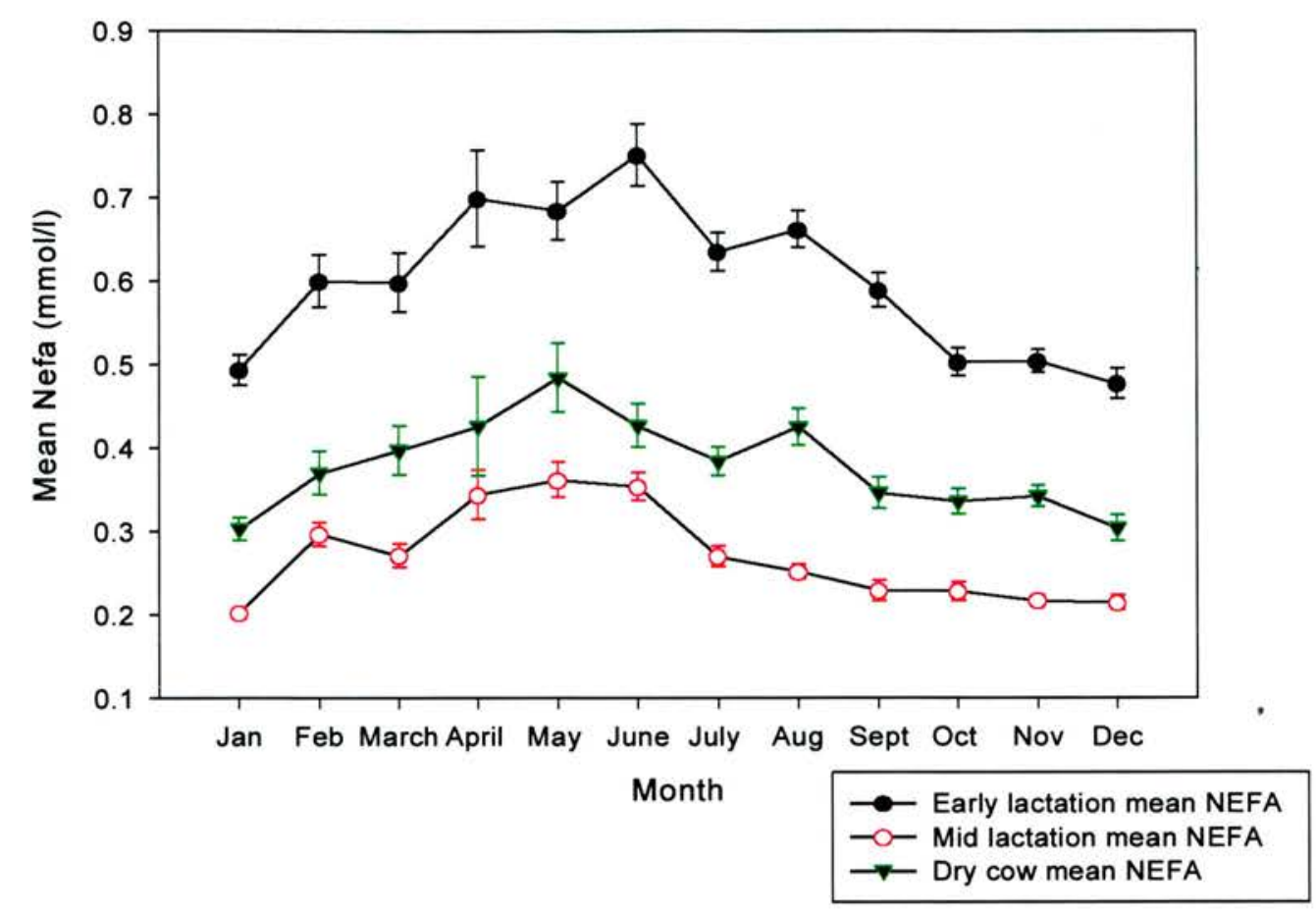

Fig 5.18 Mean NEFA values per month with 95\% Confidence Intervals. Data from cows blood sampled between 1993 and 1997

The optimum range for milking cows is $<0.7 \mathrm{mmole} /$ litre and for dry cows at the end of pregnancy is $<0.4 \mathrm{mmole} /$ litre (Huszenicza et. al., 1988; Whitaker et al., 1993). In period 1993-1998, 26 per cent of early lactation cows and 31 per cent of dry cows had elevated results. NEFA's may not be stable in transit and blood concentrations may rise after 48 hours (Whitaker et. al., 1993). Cows stressed prior to testing may have elevated results (Holmes and Lambourne, 1970; Kelly, 1977). It has, however, proved to be a very sensitive parameter and is of particular value in identifying cows which are under metabolic stress in the late dry period and in early lactation. This has confirmed earlier reports by Kelly (1984). Grummer (1993) also found that plasma NEFA concentrations increase prior to and at parturition, resulting in increased fatty acid uptake by the liver, fatty acid esterification and triglyceride storage. Export of newly synthesised triglycerides occurs slowly and is a major factor in the development of fatty liver. Nutritional strategies to minimise the rise in 
plasma NEFA prior to calving results in lower liver triglyceride at calving. Fatty liver probably precedes clinical ketosis. NEFA concentrations are not sustained for an indefinite time and may fall to normal after a period of time despite the cow still being in negative energy balance.

\subsection{Elevated BHB and NEFA}

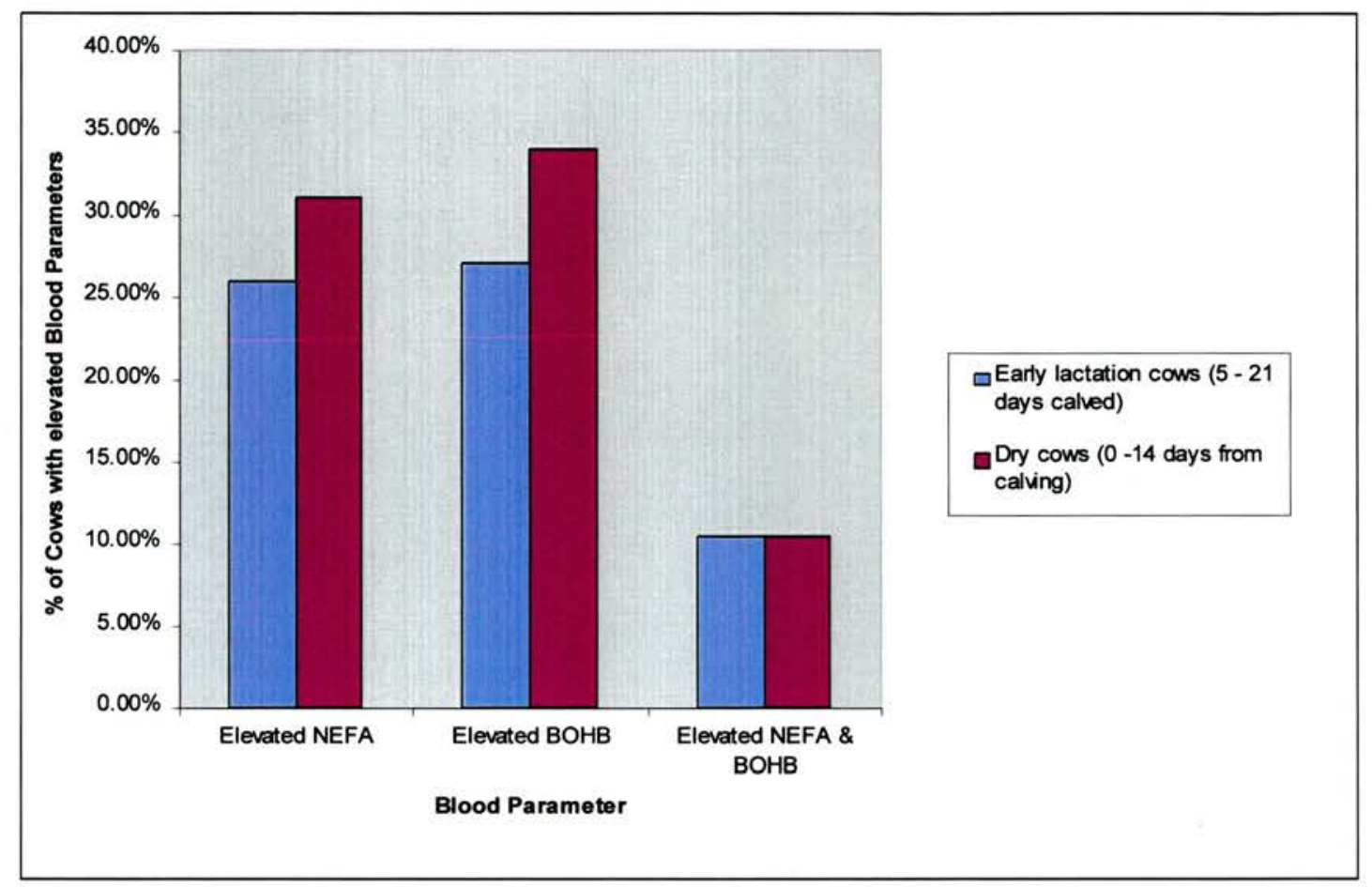

Fig 5.19 Percentage of cows tested with elevated NEFA and BOHB parameters in Early lactation and Dry cows (\% in each category taken from over 9000 cows, sampled between March 1992 and March 1998

$\mathrm{BHB}, \mathrm{NEFA}$ and glucose in plasma were strongly correlated with liver triglyceride at day 1 post partum (Studer et al.,1993). Herdt and Stow (1996) postulated $(<0.3 \mathrm{mEq} /$ litre $)$ as goal values for NEFA for the prevention of fatty liver. Harrison et al. (1990) found energy balance correlated negatively with NEFA and BHB. Common to the occurrence of both fatty liver and ketosis are elevated plasma NEFA concentrations, fat infiltration into the liver and negative energy balance. Excessive fat accumulation in the liver compromises glycogenesis. Enhanced levels of circulating ketones may diminish appetite and feed intake. 


\subsubsection{Protein status}

\subsection{Urea Nitrogen}

Table 5.6 Percentage of cows with Abnormal Urea Nitrogen results. Data collected from cows blood tested between March 1992 and March 1998

\begin{tabular}{|l|l|c|c|}
\hline Lactation & $\begin{array}{l}\text { No of } \\
\text { Cows }\end{array}$ & $\begin{array}{l}\text { \% cows with Low } \\
\text { UreaN }(<\mathbf{1 . 7 m m o l} / \mathbf{l})\end{array}$ & $\begin{array}{l}\text { \% cows with High } \\
\text { UreaN }>\mathbf{5 . 0 m m o l} / \mathbf{m})\end{array}$ \\
\hline Dry (-14 - 0 days) & 9235 & 14.0 & 3.9 \\
\hline Early (5- 21 days) & 12103 & 11.1 & 3.3 \\
\hline Early (5- 40 days) & 20502 & 9.5 & 3.4 \\
\hline Mid (>100 days) & 10398 & 6.2 & 4.8 \\
\hline
\end{tabular}

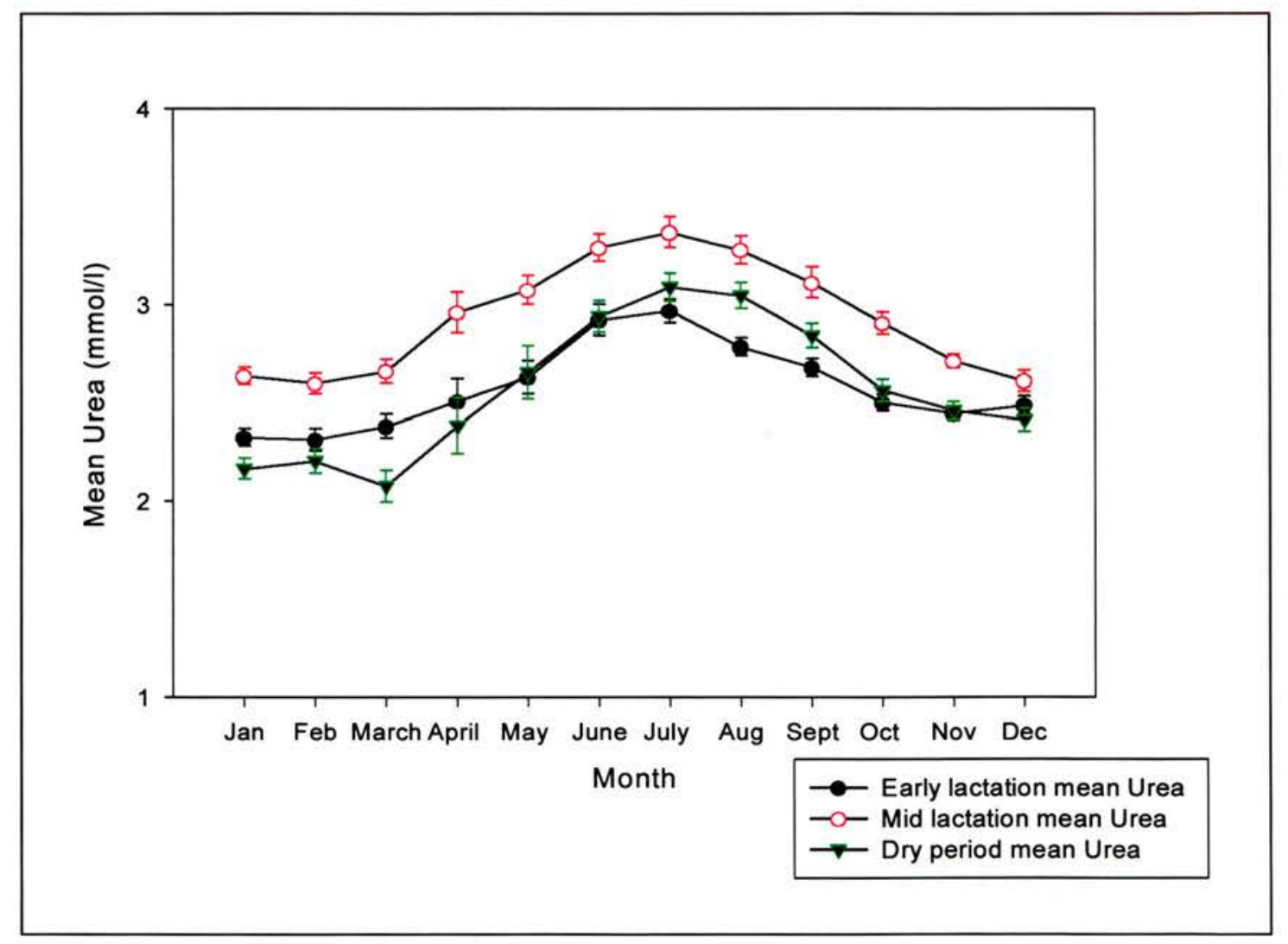

Fig 5.20 Mean Urea values per month with $95 \%$ Confidence Intervals. Data from cows blood sampled between 1993 and 1997

Blood urea nitrogen accurately reflects the intake of effective rumen degradable protein (ERDP) and its balance with fermentable metabolisable energy (FME). The optimum range is over $1.7 \mathrm{mmole} / \mathrm{litre}$. 
Blood urea nitrogen (BUN) values tend to be high in spring and summer when cows are receiving a significant proportion of their nutrients from grass. At this time there is often an excess of ERDP in relation to FME in the diet. In housed animals blood urea concentrations may be high due to lack of FME being available to the rumen bacteria to utilise the ERDP in the rumen. The best solution is to increase FME. Reduction in ERDP may also mean a reduction of digestible undegradable protein (DUP) which may result in loss of milk yield.

Low urea $\mathrm{N}$ in blood indicates inadequate ERDP in the rumen and represents a situation which may inhibit productivity. Low values do not, however, distinguish between a low dietary content of ERDP or a low intake of diet. A cow, which has not eaten properly in the last 12-24 hours, will frequently have a low blood urea. If it is only one or two animals affected it may be that the individual animal was ill or did not eat properly because she was being bullied. The latter is a not infrequent occurrence with heifers and does support the view that they must be big enough to compete with mature cows especially in a self feed system. A situation where the cows have low BUN, Fig 5.21 will frequently respond to additional dietary ERDP by increasing milk yield within 48 hours.

\subsection{Albumin}

Table 5.7 Percentage of cows with abnormal Albumin results. Data collected from cows blood tested between March 1992 and March 1998

\begin{tabular}{|l|l|c|c|}
\hline Lactation & $\begin{array}{l}\text { Abnormal } \\
\text { Range }\end{array}$ & $\begin{array}{l}\text { No of } \\
\text { Cows }\end{array}$ & $\begin{array}{c}\text { \% cows with } \\
\text { Abnormal Albumin }\end{array}$ \\
\hline Dry (-14 - 0 days) & $<=30 \mathrm{~g} / 1$ & 9235 & 3.2 \\
\hline Early (5 - 21 days) & $<=30 \mathrm{~g} / 1$ & 12103 & 4.6 \\
\hline Early (5 - 40 days) & $<=30 \mathrm{~g} / 1$ & 20502 & 4.3 \\
\hline Mid (>100 days) & $<=30 \mathrm{~g} / 1$ & 10393 & 3.8 \\
\hline
\end{tabular}




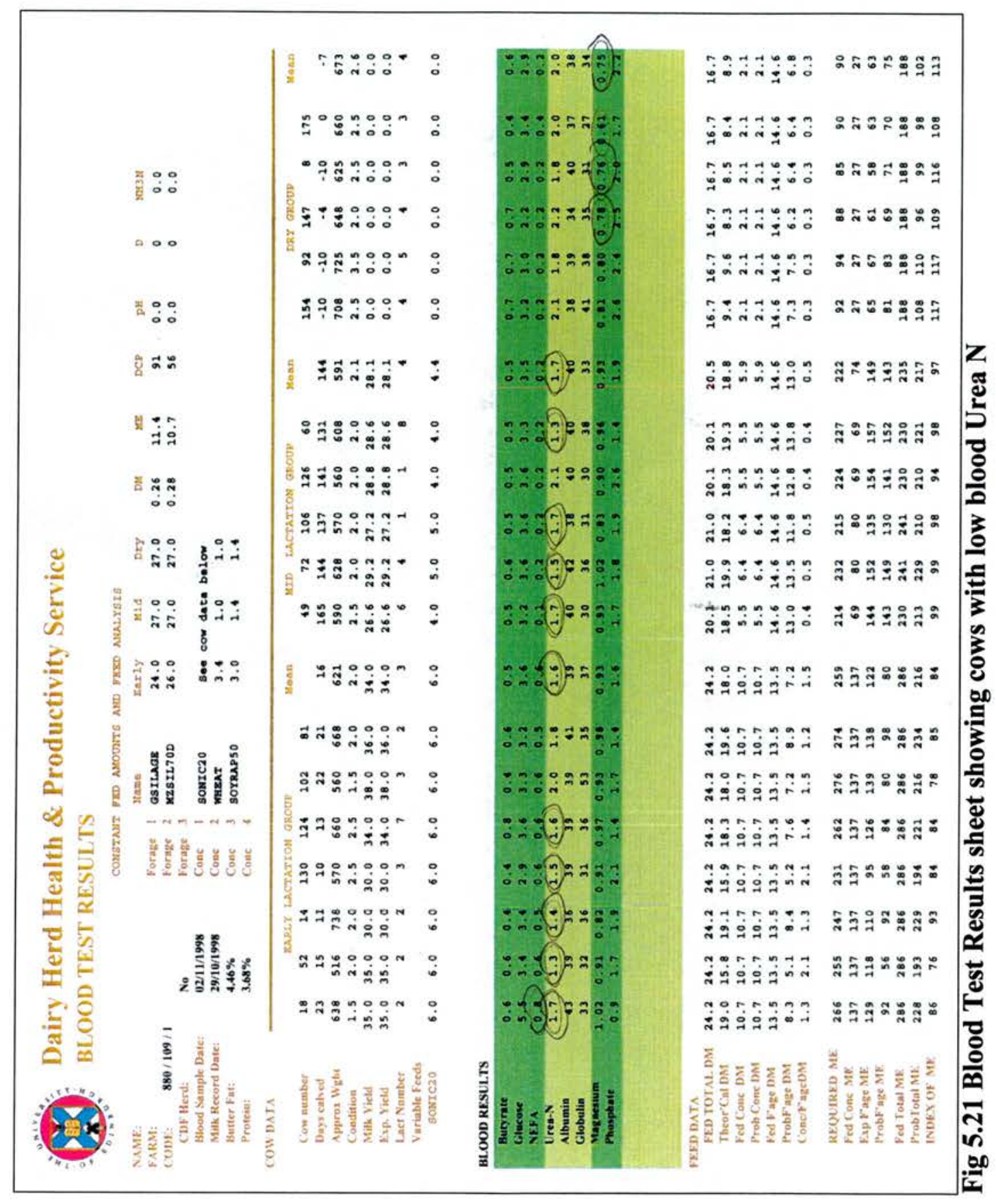




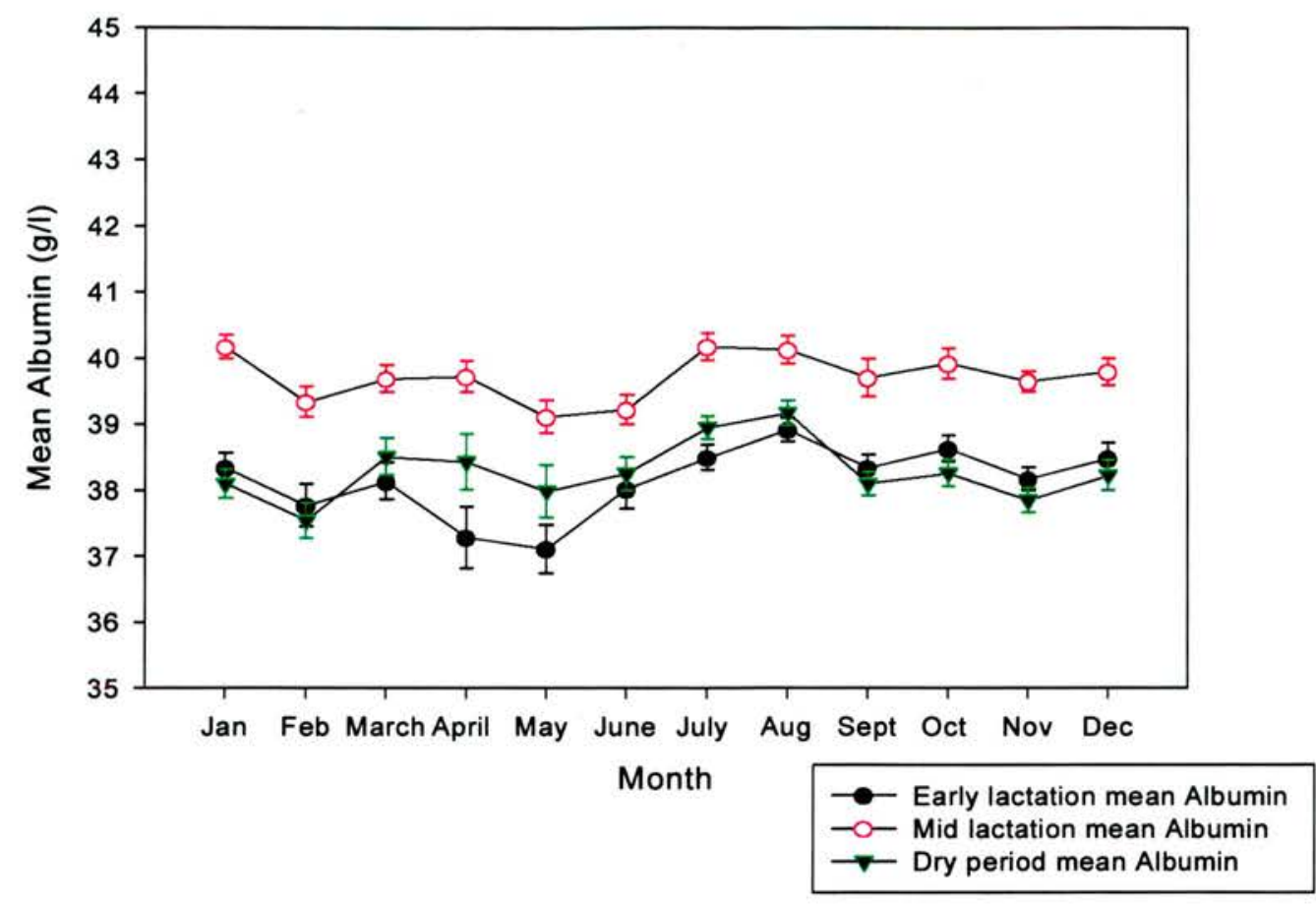

Fig 5.22 Mean Albumin values per month with 95\% Confidence Intervals. Data from cows blood sampled between 1993 and 1997

Optimum blood concentrations are over 30 gm/litre (Payne et al., 1974). Results are relatively stable (Fig 5.22) but early lactation results are consistently lower than those of mid lactation cows. With dry group tending to have intermediate values. These results may reflect the longer term protein intake of the cows. This agrees with the findings of Little (1974) who suggested that albumins may drop sharply after calving. Rowlands et al. (1983) linked the speed of restoration of albumin concentrations post calving to improved production and fertility. Albumin is produced in the liver and blood concentrations take some time to respond to protein changes in the diet (Payne et al., 1970). 


\subsection{Globulin}

Table 5.8 Percentage of cows with Abnormal Globulin results. Data collected from cows blood tested between March 1992 and March 1998

\begin{tabular}{|l|l|c|c|}
\hline Lactation & $\begin{array}{c}\text { Abnormal } \\
\text { Range }\end{array}$ & $\begin{array}{c}\text { No of } \\
\text { Cows }\end{array}$ & $\begin{array}{c}\text { \% cows with } \\
\text { Abnormal Globulin }\end{array}$ \\
\hline Dry (-14 - 0 days) & $>=50 \mathrm{~g} / 1$ & 9200 & 3.5 \\
\hline Early (5 - 21 days) & $>=50 \mathrm{~g} / 1$ & 12075 & 4.1 \\
\hline Early (5 - 40 days) & $>=50 \mathrm{~g} / 1$ & 20452 & 5.4 \\
\hline Mid (> 100 days) & $>=50 \mathrm{~g} / 1$ & 10352 & 6.6 \\
\hline
\end{tabular}

In (Fig 5.8) the high globulins were as a result of liver fluke infection. The DHHPS normal range is $<50 \mathrm{~g} /$ litre. Individual high globulin concentrations were associated with chronic conditions such as mastitis, metritis or lameness. Ward et al. (1995) reported that 5 per cent of cows sampled had raised globulin results using a standard range $<40 \mathrm{~g} /$ litre.

Globulin concentrations are calculated from total protein less albumin. They are most useful as an indicator of whether reduced performance is due to nutritional deficiency or the presence of disease. It is completely non-specific, but suggests that the cow in question should be further discussed or investigated.

\subsubsection{Minerals and trace elements}

\subsection{Magnesium}

Table 5.9 Percentage of cows with Abnormal Magnesium results. Data collected from cows blood tested between March 1992 and March 1998

\begin{tabular}{|l|c|c|c|}
\hline Lactation & $\begin{array}{c}\text { Abnormal } \\
\text { Range }\end{array}$ & $\begin{array}{c}\text { No of } \\
\text { Cows }\end{array}$ & $\begin{array}{c}\text { \% cows with } \\
\text { Abnormal Magnesium }\end{array}$ \\
\hline Dry (-14 - 0 days) & $<0.8 \mathrm{mmol} / 1$ & 9235 & 9.2 \\
\hline Early (5 - 21 days) & $<0.8 \mathrm{mmol} / 1$ & 12103 & 7.0 \\
\hline Early (5 - 40 days) & $<0.8 \mathrm{mmol} / 1$ & 19378 & 5.8 \\
\hline Mid (> 100 days) & $<0.8 \mathrm{mmol} / 1$ & 10398 & 3.0 \\
\hline
\end{tabular}




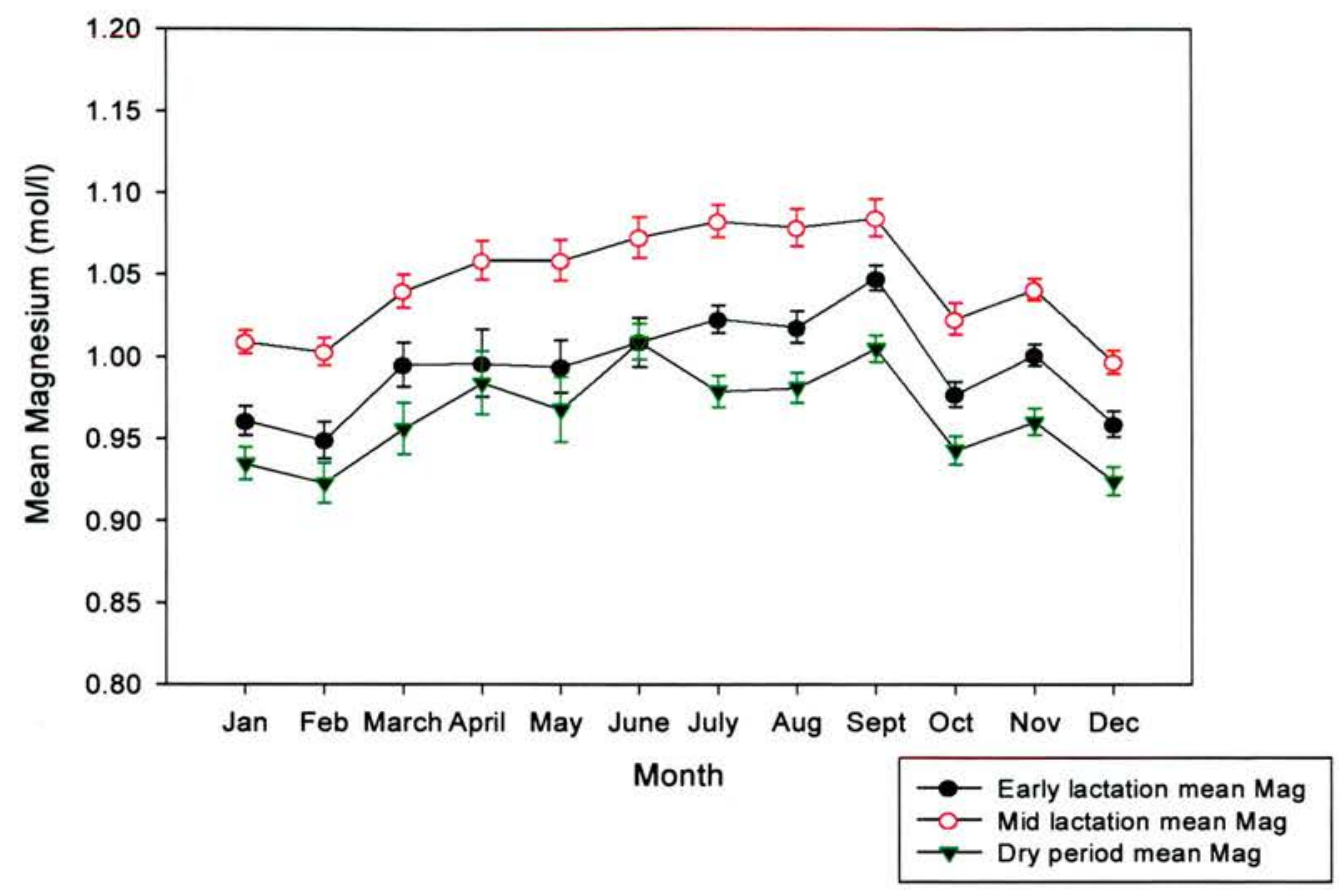

Fig 5.23 Mean Magnesium values per month with $95 \%$ Confidence Intervals. Data from cows blood sampled between 1993 and 1997

The optimum range for blood magnesium is between 0.8 and 1.3 mmol/litre (Whitaker and Kelly, 1982). Plasma magnesium reflects the daily balance between input and output, as magnesium reserves are not readily available. Traditionally hypomagnesaemia is associated with spring grazing, however, the DHHPS reported low blood magnesiums in all months of the year (Fig 5.24).

The mean of the dry groups were lower than the early lactation groups which were in turn lower than the mid lactation animals. In dry cows low blood magnesium may be associated with a depressing effect on calcium absorption and mobilisation and consequently hypocalcaemia (Kelly, 1988).

Ward et al. (1996) reported 9 per cent of dry cows with low magnesium values. 


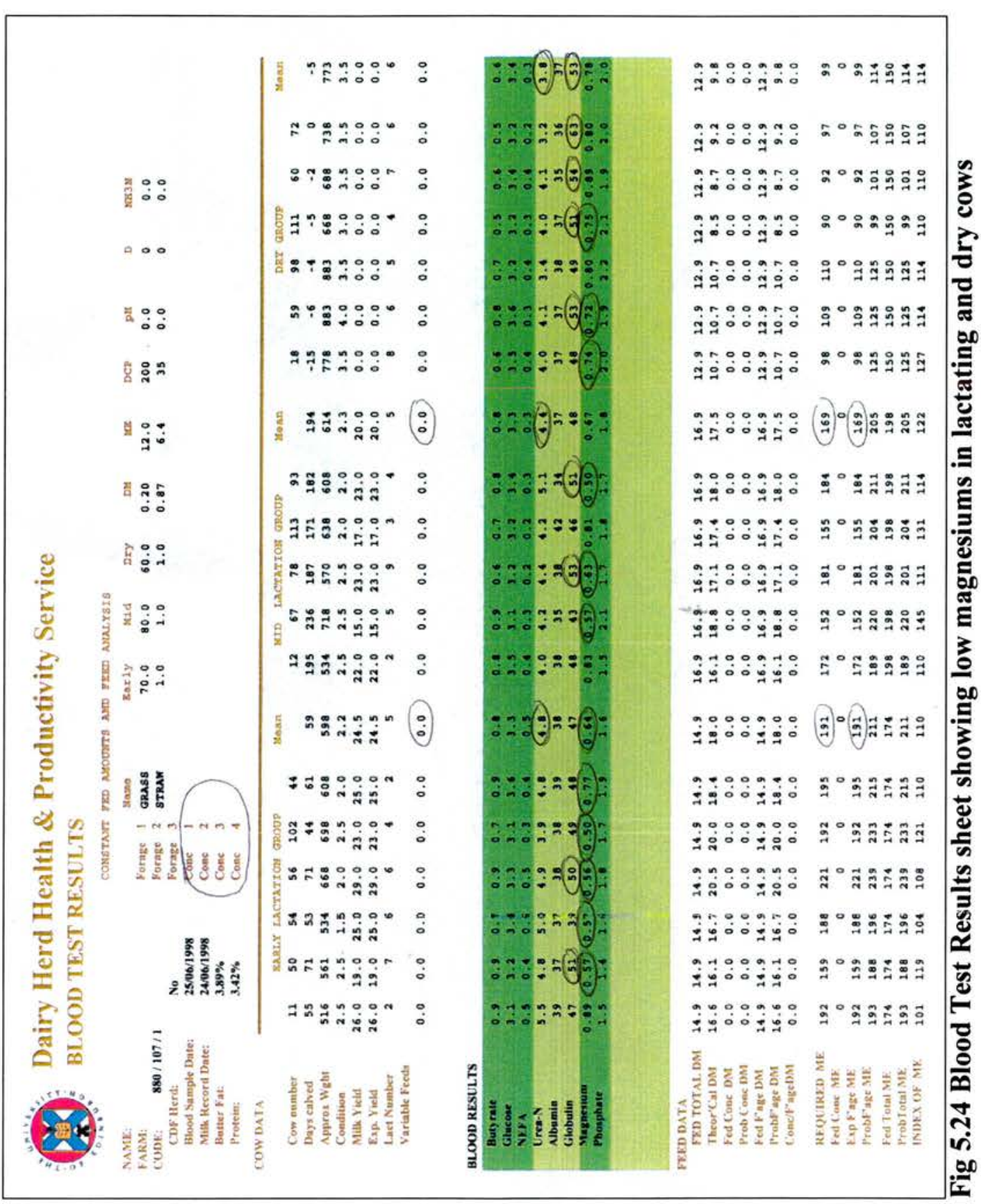




\subsection{Inorganic Phosphate}

Table 5.9 Percentage of cows with Abnormal Phosphate results. Data collected from cows blood tested between March 1992 and March 1998

\begin{tabular}{|l|c|c|c|}
\hline Lactation & $\begin{array}{l}\text { No. of } \\
\text { Cows }\end{array}$ & $\begin{array}{l}\text { \% cows with Low } \\
\text { Phos }(<\mathbf{1 . 4 m m o l} / \mathbf{l})\end{array}$ & $\begin{array}{l}\text { \% cows with High } \\
\text { Phos }(>\mathbf{2 . 5 m m o l} / \mathbf{l})\end{array}$ \\
\hline Dry (-14 - 0 days) & 9235 & 2.0 & 17.5 \\
\hline Early (5- 21 days) & 12103 & 4.0 & 13.2 \\
\hline Early ( 5 - 40 days) & 20502 & 3.4 & 12.5 \\
\hline Mid (>100 days) & 10398 & 2.3 & 11.1 \\
\hline
\end{tabular}

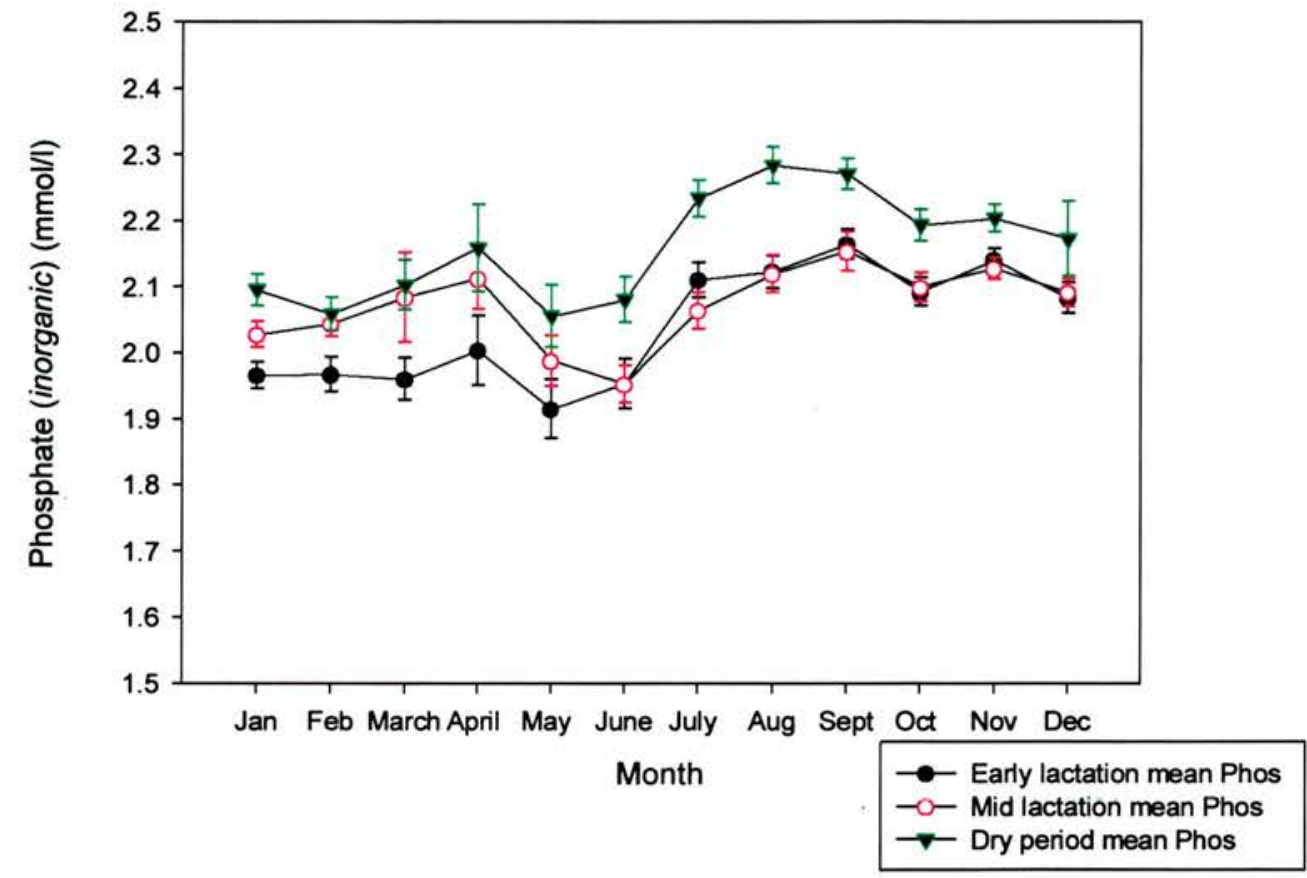

Fig 5.25 Mean Phosphate (inorganic) values per month with 95\% Confidence Intervals. Data from cows blood sampled between 1993 and 1997

Plasma phosphate concentrations principally reflect current dietary intake. Optimum range is between 1.4 and $2.5 \mathrm{mmol} / \mathrm{litre}$. Ward et al. (1996) reported 20 per cent early lactation cows and 17 per cent dry cows below $1.8 \mathrm{mmol} / \mathrm{litre}$.

Dry cows were consistently higher than the early and mid groups for each month of the year. Blood phosphate concentrations tend to be lowest in May 
and June during the peak season for grass growth. Frequently blood phosphate concentrations at grass rose in July without any additional supplementation.

\subsubsection{Trace Elements}

Copper and glutathione peroxidase estimations were performed on the first occasion samples were received from a farm. These parameters were measured in 'one-off' tests or when problems with trace element deficiency had previously been identified.

\subsection{Copper}

Table 5.10 Percentage of cows with Abnormal Copper results. Data collected from cows blood tested between March 1992 and March 1998

\begin{tabular}{|l|l|c|c|}
\hline Lactation & $\begin{array}{l}\text { No. of } \\
\text { Cows }\end{array}$ & $\begin{array}{l}\text { \% cows with Low } \\
\text { Copper (<9.4micro } \\
\text { mol/l) }\end{array}$ & $\begin{array}{l}\text { \% cows with High } \\
\text { Copper (>19.0 } \\
\text { micromol/1) }\end{array}$ \\
\hline Dry (-14 - 0 days) & 4220 & 17.8 & 5.2 \\
\hline Early (5 - 21 days) & 5010 & 5.8 & 10.0 \\
\hline Early (5 - 40 days) & 8684 & 6.4 & 9.2 \\
\hline Mid (>100 days) & 5270 & 9.8 & 7.2 \\
\hline
\end{tabular}




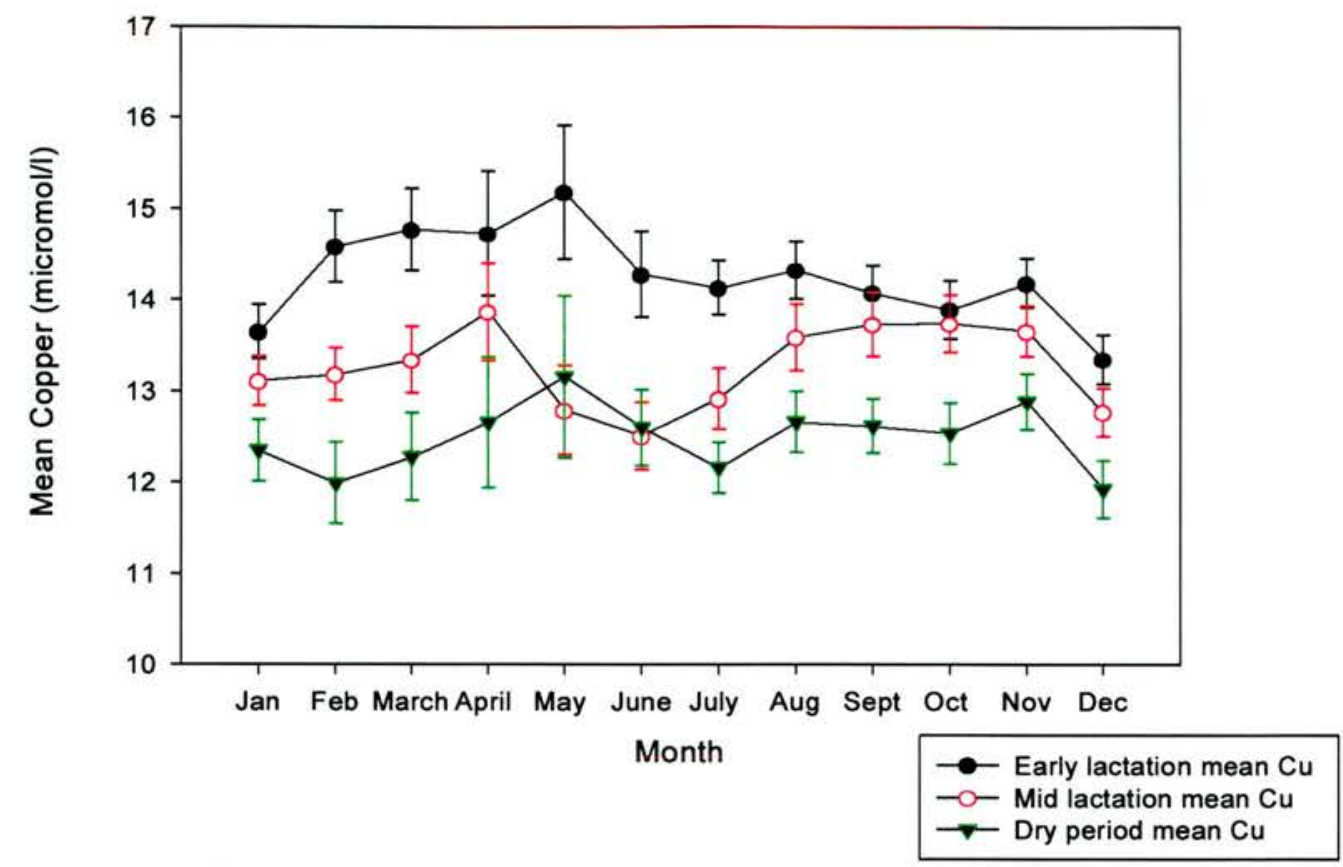

Fig 5.26 Mean Copper values per month with 95\% Confidence Intervals. Data from cows blood sampled between 1993 and 1997

Copper concentrations tend to be higher in lactating cows than in dry animals presumably reflecting the copper concentration of the diet. Blood copper values are not an accurate guide to body or liver reserves (Telfer, 1996). The optimum plasma concentration is 9.4 micromol/litre (Suttle, 1993).

\subsection{Glutathione Peroxidase (GSHPx)}

Table 5.11 Percentage of cows/heifers with abnormal GSHPx results. Data collected from cows blood tested between March 1992 and March 1998

\begin{tabular}{|l|l|c|c|c|}
\hline Lactation & $\begin{array}{l}\text { No. of } \\
\text { Cows }\end{array}$ & $\begin{array}{l}\text { \% cows with } \\
\text { Abnormal GSHPx } \\
\text { (<50units/gm Hb) }\end{array}$ & $\begin{array}{l}\text { No of } \\
\text { heifers }\end{array}$ & $\begin{array}{l}\text { \% heifers with } \\
\text { Abnormal GSHPx } \\
(<\mathbf{5 0 u n i t s} / \mathbf{g m} \text { Hb) }\end{array}$ \\
\hline Dry (-14-0 days) & 4016 & 2.8 & 353 & 7.4 \\
\hline Early (5-21 days) & 4748 & 6.8 & 676 & 16.7 \\
\hline Early (5-40 days) & 8204 & 6.6 & 1206 & 16.3 \\
\hline Mid (>100 days) & 4995 & 0.6 & 914 & 0.9 \\
\hline
\end{tabular}




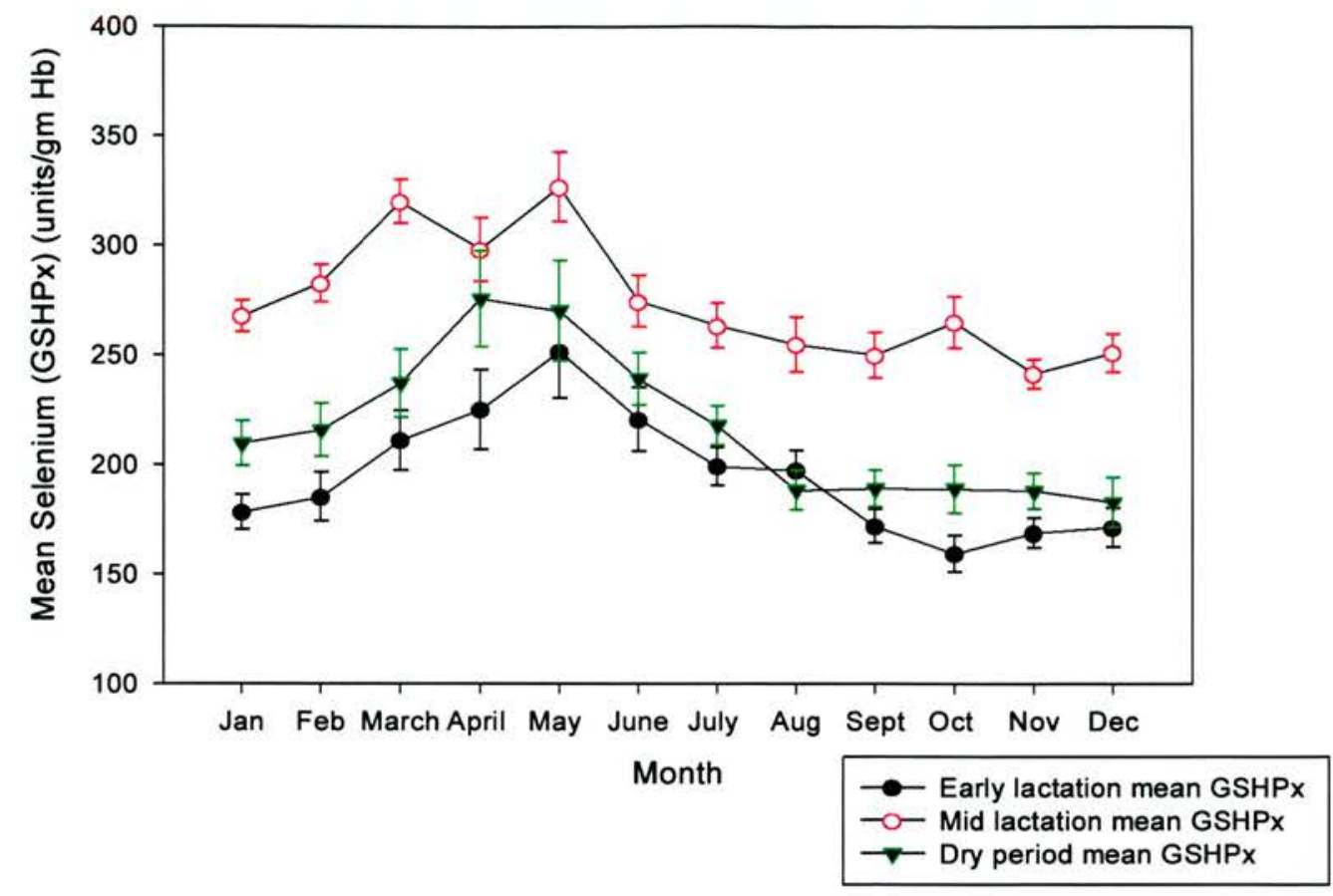

Fig 5.27 Mean GSHPx values per month with 95\% Confidence Intervals. Data from cows blood sampled between 1993 and 1997

GSHPx is a selenium containing enzyme and is incorporated into erythrocytes. The blood concentration, therefore reflects the absorption of selenium 6 weeks earlier. Optimum GSHPx concentrations are over 50 units per gm of haemoglobin. Low values in early lactation cows are indicative of a low intake of selenium by the dry cows. Mid lactation values are consistently higher than those in dry or early lactation. This suggests that when cows are on the lactation diet GSPHx concentrations rise. Ward et al. (1996) also identified low GSHPx in 17 per cent of first lactation cows.

\subsection{Thyroxine (T4)}

This is a measure of iodine status, particularly useful in dry cows. Low T4 in plasma reflects poor iodine status, as opposed to inorganic iodine measurements which reflect current daily intake. Optimum values are above 20nmol/litre (Whitaker, 2000). 


\section{3}

\section{General Discussion}

In the interpretation it is important that the assessment is made on a group basis and that too much is not read into individual results. Individual aberrant results may occur for a number of reasons. A cow which is ill on the day of test may not be eating, have abnormal blood results, completely independent of the composition of the diet. It is essential that cows which are selected for the test are representative of the rest of the animals in the herd.

\section{Common errors in selection are}

- Cows atypical of the rest of cows in group e.g. exceptionally high yielders.

- Cows with health problems.

- Cows with a history of long standing poor productivity or fertility.

- Cows included in early lactation group which are too long calved and past the period of metabolic stress.

It has been found on numerous occasions that it is important to have the mid lactation group, which will be on full dry matter intake, be pregnant again and past the period of metabolic stress. This group forms an important control group cows which can be used for comparison with the early lactation cows. BHB concentrations can be influenced by diurnal and prandial variation (Manston et al., 1981) or by high concentrations of butyric acid in the silage. If all three groups have elevated BHB values it is likely it will be for one of these reasons. It is this important group which can be used to assess just how much the cows can obtain from the forage component of the ration. Frequently it will be found that mid lactation cows are expected to obtain less from the forage than early lactation animals. The advice would be to reverse the situation. Often improvements can be made not by feeding more, but by redistributing the supply to the early from the mid lactation cows. 


\section{Errors in the timing of tests}

- Testing just before a major management change is fruitless. Results of test will be historical as cows will be already on a new diet by the time the discussion meeting takes place.

- Sampling just after dietary change can produce misleading results. The rumen microflora require from 10 to 14 days to fully adjust to a change in substrate.

- On many occasions in the past metabolic profiles have fallen into disrepute because the timing of the test has not been appropriate. Frequently when faced with a productivity problem veterinary surgeons or feed advisers will first recommend dietary changes. When these changes have been made and productivity has not responded they may then decide to 'blood sample the cows'. By this time yield will have fallen and as a result of homeostasis most blood parameters will be within the normal range. All concerned will be naturally disappointed with the outcome and the farmer will probably view the whole exercise as a waste of money!

\section{Composition of ration}

\section{Check List}

- It is important to ensure that energy density of ration is capable of meeting requirements. Index of $\mathrm{ME}$ gives a guide to what the cows selected are capable of consuming provided that the details provided on the Sheet 3 are correct. (The typical metabolisable energy density of ration for high yielding cows is $11.7-12$ $\mathrm{MJ} / \mathrm{kg}$.)

- Too much concentrate being fed. Overall concentrate to forage ratio should not exceed 3:1.

- Too much concentrate fed at each milking. Above $4 \mathrm{~kg}$ at each feed may result in rumen acidosis.

- Too much concentrate fed on top of silage unmixed. $2 \mathrm{~kg}$ per cow per feed is maximum or greedy cows get too much and those cows in early lactation for whom the extra feed is intended will get too little.

- There must be sufficient supply of effective rumen degradable protein (ERDP) in ration (Low blood urea nitrogen suggests lack of available ERDP). 
- If there is not sufficient digestible undegradable protein (DUP) in the ration cows may fail to peak even when energy and ERDP are not thought to be limiting. This is more common at higher yields.

- Adequate long fibre in the diet is essential for optimum digestion (30-40 per cent of DM should be Neutral Detergent fibre). Provision of $1 / 2-1 \mathrm{~kg}$ of hay or straw will often make all the difference to cow performance.

\section{Dry matter intake}

By far the most common error in dairy cow nutrition is failing to get the cows to achieve maximum dry matter intake. So many carefully balanced rations produced with the aid of a sophisticated computer programme fail in practice, simply because the cows do not consume the calculated amounts. Dry matter intake is frequently a much more important issue than debating the energy or protein densities of the individual components of the ration. This is a key area in which the veterinary surgeon can become involved. In order to fully investigate whether the cows are likely to consume as much dry matter as possible it is essential to observe the cows feeding.

\section{Check list}

- Cows must be comfortable and happy, with adequate lying space and sufficient clean bedding. Number and design of cubicles must be considered relative to the number and size of cows in the herd.

- The cows should be observed when undisturbed to obtain a good indication of cow comfort. At least $60 \%$ should be lying ruminating if not at feed trough.

- The extent of bullying should be assessed. The body weight of the heifers at calving determines if they will be able to compete at feed trough with mature cows. Blind alleys in cubicle houses should be avoided. The siting of out of parlour feeders is equally important.

- The adequacy of trough space must be evaluated. The provision of ring feeders may allow heifers or cows low down in the pecking order better access to feed. 
- The height of the trough should be measured. If too high it discourages less dominant cows (45 cm high is maximum). If many cows observed with feed on backs then trough is too high.

- The attention to detail with feed presentation makes all the difference in achieving optimum food intake. Fresh feedstuffs should always be on offer. Troughs should be cleaned out regularly and spoiled or stale food removed. A rough pitted trough may result in feed spoilage.

- The silage pit should be inspected. A well managed silage face, and a clamp that is kept well covered markedly reduces silage deterioration. Use of an electric fence can markedly reduce intake.

- The menu should be reviewed with a view to avoiding large single concentrate feeds. The concentrates are best mixed with forage when possible. Mixtures of forage e.g. maize and grass silage increase overall dry matter intake. Using palatable feeds e.g. maize silage, brewers' grains and molasses will all increase palatability of a ration.

- Availability of grass should be assessed. Restricted grazing occurs when not enough grass is available, when set stocking systems allow uneven fibrous growth or when there is too much restriction on strip grazing.

- Inspection of the form and colour of the faeces is all too often neglected! Loose faeces suggests shortage of fibre. Stiff faeces suggests low energy intake with possibly too much fibre.

- It is important to ensure that adequate clean drinking water is always available.

\section{Dry Cows}

The dry period is very important for the success of the following lactation.

\section{Check list}

- The body condition of the dry and early lactation groups should be assessed and the transition from the dry to lactating diet should be reviewed.

- Fat cows have a depressed appetite and low dry matter intake. Overfeeding in late lactation often results in fat cows. 
- Good transition from dry to early lactation requires the introduction of some of the early lactation diet (forage and concentrate) in the last two weeks of the dry period. This ensures rumen microflora have time to adjust to a new substrate to be fed in early lactation and assists in restoration of rumen papillae.

- Ensure that the forage on offer to dry cow has adequate ERDP. Diets based largely on maize, straw or whole crop silage can be deficient in ERDP unless specifically supplemented with a protein source.

- The management and nutrition of the cow at calving should be reviewed. This should include proper use of calving box to ensure the cow is clean, quiet and comfortable and is supplied with food and water.

\section{Mineral supply}

\section{Common errors}

- Failure to appreciate that the cow requires a daily supply. Minerals run out and farmer assumes that cows will have sufficient stored in body. This is especially the case with hypomagnesaemia.

- Wrong level of mineral in concentrate due to manufacturer's error.

- Feeding at wrong concentration. Many mineral mixes will contain magnesium but not at sufficiently high a concentration to meet the requirements of the high yielding cow.

- Inadequate supply, especially when relying on self help system e. g. licks or tubs.

- Not ensuring that medicated water is only source available to the cows.

- Problems with solubility when putting mineral in water.

- Minerals not available for absorption because of interaction with other minerals.

Concentrates, sold by feed manufacturers, normally have a balanced mineral inclusion. The trend to the reliance more on home produced cereals and 'straights' means that correct mineral supplementation is essential for optimum health and productivity. 
Chapter Six 


\section{DHHPS SURVEY}

\section{INTRODUCTION}

In 1996 in order to assess the value of the DHHPS an anonymous postal survey was carried out of all the farmers and veterinary surgeons currently involved with the service.

\subsection{Materials and Methods}

A four page questionnaire was produced in conjunction with the Centre for Educational Sociology (CES) Survey team for the farmers and for the veterinary surgeons. The questionnaires were despatched by post along with a personally signed explanatory letter. Pre-paid envelopes for return of the questionnaires were also provided. Reminder letters were sent to all farmers and veterinary surgeons three weeks after the questionnaire was sent out. The data was entered using SIR FORMS and transferred to the Statistical Package for Social Sciences (SPSS) for analysis. 


\section{Dairy Herd Health and Productivity Service Farmer's Questionnaire}

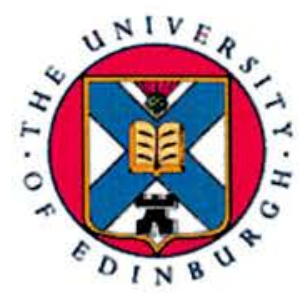

1. When did you join this service?

tick one box

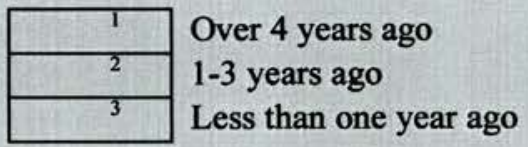

2. Which one of these regions is your farm in?

tick one box

\begin{tabular}{|c|c|}
\hline$T$ & Scotland \\
\hline 2 & Northern Ireland \\
\hline 3 & South West England \\
\hline$\sqrt{4}$ & South East England \\
\hline 5 & The Midlands \\
\hline 6 & North of England \\
\hline 7 & Wales \\
\hline
\end{tabular}

3. Why did you join our service?

tick all that apply

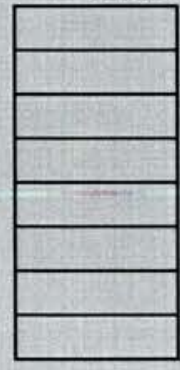

To increase milk yields

To improve milk quality

To increase profitability

As an aid to better management

Because of problems with fertility

Because of problems with mastitis

Because of problems with lameness

Because of other health problems (please specify)

4. Who (or what) influenced your decision to join the service? tick one box

\begin{tabular}{|c|}
\hline 1 \\
\hline 2 \\
\hline 3 \\
\hline 4 \\
\hline 5 \\
\hline
\end{tabular}

Local veterinary surgeon

Feed technical adviser or representative

University of Edinburgh staff

A meeting or farm visit

A leaflet or press information

Fig 6.1 Farmer's Questionnaire 
5. What benefits are you getting from our service?

tick all that apply

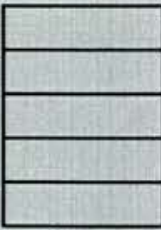

Early warning of potential problems

Reassurance on diet

Information for management decisions

Other benefits (please specify)

Fewer than expected

6. Who do you rely on for nutritional advice?

tick all that apply

\begin{tabular}{|l|l}
\hline & Feed technical adviser or representative \\
Independent nutritional adviser (eg ADAS, Genus, SAC) \\
Veterinary surgeon \\
Other benefits (please specify)
\end{tabular}

7. Which of the above do you rely on most for nutritional advice?

please underline on the list above

8. Do you perceive your veterinary surgeon as......

tick one box

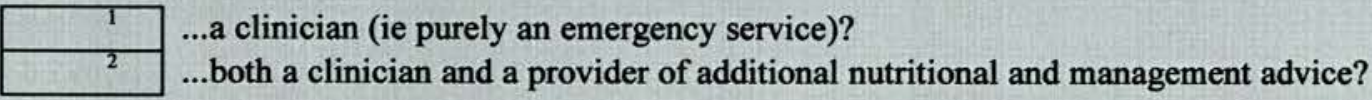

9. Are you willing to, or do you already, pay your veterinary

surgeon for advice as well as clinical work?

tick one box

\begin{tabular}{|l|l|}
\hline I & Yes I'd be willing to pay for advice \\
Yes, I already pay for advice \\
\cline { 1 - 1 } No, I'd not be willing to pay for advice \\
\cline { 1 - 1 } Don't know
\end{tabular}

10. What do you think a successful service depends on?

tick all that apply

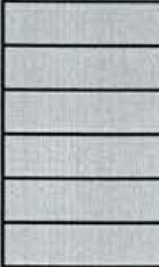

The competence and enthusiasm of the veterinary surgeon

The enthusiasm of the feed adviser

Your own enthusiasm and expertise

The establishment of a team approach

The ability of the service to identify problems

The ability of the service to identify progress

11. What do you think is the main reason for a successful service?

please underline on the list above 
Page 3

12. What is your opinion of our service? tick one box for each row

Blood testing and metabolic profiles
Presentation of results
Speed of turnaround of results
Letter of interpretation
Discussion report form
Sheet 2 and quarterly reports
Team meeting to discuss results
Vets' participation in meeting
Ease of communication among team

13. Have the results and the letter of interpretation reflected what was happening on the farm?

tick one box

\begin{tabular}{|l|l}
\hline 1 & Often \\
\hline 2 & Sometimes \\
\hline 3 & Seldom
\end{tabular}

14. Do you use the discussion report form?

tick one box

\begin{tabular}{|l|l}
\hline 1 & \begin{tabular}{l} 
Often \\
\hline 2
\end{tabular} \\
\hline 3 & $\begin{array}{l}\text { Sometimes } \\
\text { Seldom }\end{array}$ \\
\hline
\end{tabular}

15. Has the herd productivity and profitability benefited as a result of membership of our service?

tick one box

\begin{tabular}{|l|l|}
\hline 1 & $\begin{array}{l}\text { Significantly } \\
\text { Moderately }\end{array}$ \\
\hline 3 & $\begin{array}{l}\text { Not discernably } \\
\text { Too soon to say }\end{array}$ \\
\cline { 1 - 1 } &
\end{tabular}

16. Does our service provide good value for money?

tick one box

\begin{tabular}{|l|l|}
\hline 1 & Yes \\
\hline 2 & No \\
\hline 3 & Don't know yet
\end{tabular}


Page 4

17. Have you ever used a similar service offered by another laboratory? tick one box

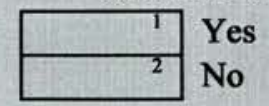

18. If YES: How do you think our services compare with those offered by other laboratories?

tick one box

\begin{tabular}{|l|l|}
\hline 1 & Better \\
\hline 2 & Same \\
\cline { 1 - 1 } 3 & Worse \\
\cline { 1 - 1 } 4 & Don't know \\
\cline { 1 - 2 } &
\end{tabular}

19. Do you use DAISY or a similar recording service?

tick one box

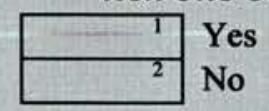

20. Is your vet involved on your farm in a routine.......

tick one box for each row

...fertility control program?

...mastitis control program?

...lameness control program?

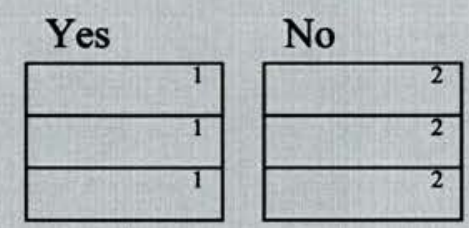

21. Has digital dermatitis been diagnosed on your farm?

tick one box

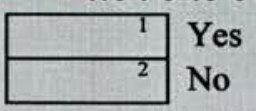

22. if we were to enhance our service, what would you like to see introduced? please write in your suggestions here

Thank you very much for completing this questionnaire.

Please return it in the pre-paid envelope provided.

Questionnaire produced by CES Survey Team,

The University of Edinburgh Tel 01316502563 


\section{Dairy Herd Health and Productivity Service Vet's Questionnaire}

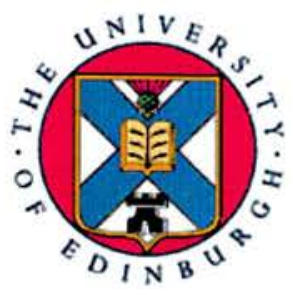

1. How long have you been involved in this service?

tick one box

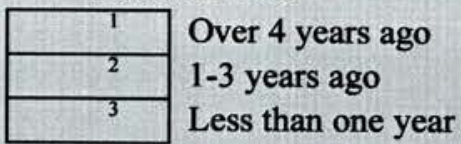

2. Are you convinced integrated health and production management services... tick one box for each row

....are feasible?

....are cost effective for the milk producer?

....are rewarding to the veterinary surgeon?

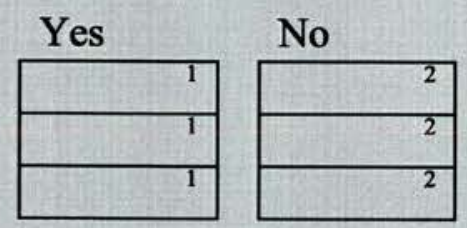

3. Do you feel competent in giving nutritional advice? tick one box

\begin{tabular}{|r|l}
\hline 1 & $\begin{array}{l}\text { Competent and confident } \\
\text { Competent }\end{array}$ \\
\cline { 1 - 1 } Not very competent
\end{tabular}

4. Do you consider your undergraduate education prepared you to give advice on production management and nutrition?

tick one box

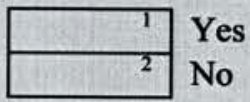

5. How many herds have you been involved with? tick one box

\begin{tabular}{|l|l|l}
\hline 1 & $\begin{array}{l}\text { One or two } \\
\text { Three or more }\end{array}$
\end{tabular}

6. Are you aware of the herd's profitability?

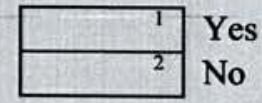

tick one box

7. Are you involved in setting goals to improve herd profitability?

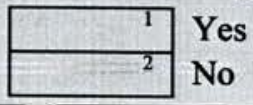

tick one box

Fig 6.2 Vet's Questionnaire 
8. Why do you think your clients joined our service?

tick all that apply

\begin{tabular}{|c|}
\hline 1 \\
\hline 2 \\
\hline 3 \\
\hline 4 \\
\hline 5 \\
\hline 6 \\
\hline 7 \\
\hline 8 \\
\hline
\end{tabular}

To increase milk yields

To improve milk quality

To increase profitability

As an aid to better management

Because of problems with fertility

Because of problems with mastitis

Because of problems with lameness

Because of other health problems (please specify)

9. What benefits are your clients getting from our service?

tick all that apply

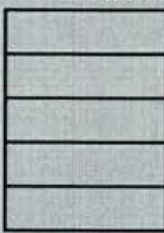

Early warning of potential problems

Reassurance on diet

Information for management decisions

Other benefits (please specify)

Fewer than expected

\section{What benefits are you getting from our service?}

tick all that apply

\begin{tabular}{|l|}
\hline A \\
\hline \\
\hline
\end{tabular}

An involvement with nutritional and management advice

An opportunity to initiate preventive programmes or approaches

An opportunity to learn more about current dairy cow nutrition

Fewer than expected

\section{Who do your clients rely on for nutritional advice?}

tick all that apply

\begin{tabular}{|l|}
\hline \\
\hline \\
\hline
\end{tabular}

Feed technical adviser or representative

Independent nutritional adviser (eg ADAS, Genus, SAC)

Veterinary surgeon

Other (please specify)

12. Which of the above do you think your clients rely on most for nutritional advice?

please underline on the list above

13. Do you charge for advice in addition to clinical work?

tick one box

\begin{tabular}{|l|l}
\hline 1 & Yes \\
\cline { 1 - 1 } No
\end{tabular}


14. What do you think a successful service depends on? tick all that apply

The competence and enthusiasm of the veterinary surgeon

The enthusiasm of the feed adviser

The enthusiasm and expertise of the farmer

The establishment of a team approach

The ability of the service to identify problems

The ability of the service to identify progress

15. What do you think is the main reason for a successful service? please underline on the list above

16. What is your opinion of our service?

tick one box for each row

Excellent

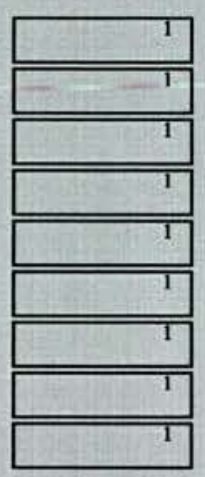

Good

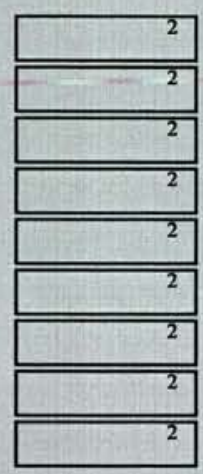

Poor

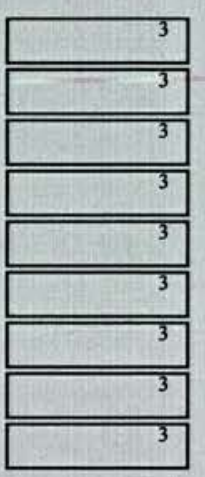

Don't

know

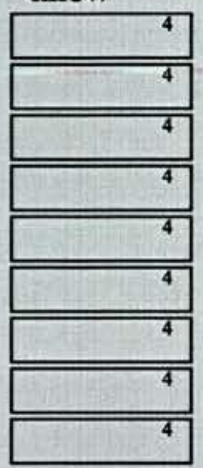

17. Do you chair the meeting? tick one box

\begin{tabular}{|l|l}
\hline 1 & Yes \\
\hline 2 & No
\end{tabular}

18. Have the results and the letter of interpretation reflected what was happening on the farm?

tick one box

\begin{tabular}{|l|l|}
\hline 1 & Often \\
\cline { 1 - 1 } 2 & \begin{tabular}{l} 
Sometimes \\
\cline { 1 - 1 } 3
\end{tabular} \\
\cline { 1 - 2 } & Seldom
\end{tabular}

19. Do you use the discussion report form?

tick one box

\begin{tabular}{|l|l}
\hline 1 & $\begin{array}{l}\text { Often } \\
\text { Sn }\end{array}$ \\
\hline 3 & Sometimes \\
\cline { 1 - 2 } & Seldom
\end{tabular}




\section{Page 4}

20. Has the herd productivity and profitability benefited as a result of membership of our service?

tick one box

\begin{tabular}{|r|l|}
\hline 1 & $\begin{array}{l}\text { Significantly } \\
\text { Moderately }\end{array}$ \\
\hline 3 & $\begin{array}{l}\text { Not discernably } \\
\text { Too soon to say }\end{array}$ \\
\cline { 1 - 1 } &
\end{tabular}

21. Have you ever used a similar service offered by your own or other laboratories?

tick one box

\begin{tabular}{|l|l|l|l|l|l}
\hline 1 & Yes \\
\hline 2 & No
\end{tabular}

22. If YES: How do you think our services compare with those offered by other laboratories?

tick one box

\begin{tabular}{|l|l|}
\hline 1 & Better \\
\hline 2 & Same \\
\hline 3 & Worse \\
\hline 4 & Don't know \\
\hline
\end{tabular}

23. Do you use DAISY or a similar recording service?

tick one box

\begin{tabular}{|l|l|l|l|l}
\hline 2 & Yes \\
\hline 2 & No
\end{tabular}

24. Do you get involved on the member's farm(s) in a routine....... tick one box for each row

...fertility control program?

...mastitis control program?

...lameness control program?
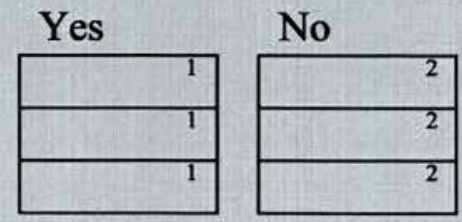

25. If we were to enhance our service, what would you like to see introduced? please write in your suggestions here

Thank you very much for completing this questionnaire.

Please return it in the pre-paid envelope provided.

Questionnaire produced by CES Survey Team,

The University of Edinburgh Tel 01316502563 


\subsection{Results}

The figures quoted in the following tables are the relative frequency of the responses expressed as a percentage of total responses

\subsubsection{Response Rate}

Table 6.1 Numbers of questionnaires distributed and returned

\begin{tabular}{|l|c|c|c|}
\hline & Farmer Response & Vet Response & Total Response \\
\hline Total despatch & 272 & 208 & 480 \\
\hline Return & 168 & 134 & 302 \\
\hline$\%$ Return & 61.8 & 64.4 & 62.3 \\
\hline
\end{tabular}

A response rate from veterinary surgeons of 64.4 per cent was rather better than a response rate 59.4 for studies using surveys of veterinarians quoted by Vaillancourt et al. (1991). The response rate from farmers at 61.8 per cent was not significantly different. In total the response rate was above average for surveys of this type. Wassell and Esslemont (1992) quoted a return of $56 \%$ from a postal veterinary survey on the use of herd health schemes. Many factors can influence the response rate not the least of which is interest in the topic being surveyed.

\subsubsection{Length of involvement}

Table 6.2 How long participants have been members

\begin{tabular}{|l|c|c|}
\hline How long involved? & Vet Response (\%) & Farmer Response(\%) \\
\hline Over 4 years & 57.9 & 31.7 \\
\hline 1 to 3 years & 28.6 & 44.3 \\
\hline Less than 1 year & 13.5 & 24.0 \\
\hline
\end{tabular}


6.2.3 Number of herds vet involved with

Table 6.3 Number of herds each veterinary surgeon has as DHHPS members

\begin{tabular}{|l|c|}
\hline Herds per Vet & $\%$ \\
\hline One or two & 52.2 \\
\hline Three or more & 47.8 \\
\hline
\end{tabular}

\subsubsection{Regional Distribution}

Table 6.4 Number of farms in each region

\begin{tabular}{|l|c|}
\hline Farm Region & $\begin{array}{c}\text { Questionnaire Response } \\
\text { Farms per Region }\end{array}$ \\
\hline Scotland & 16.8 \\
\hline Northern Ireland & 1.2 \\
\hline South West England & 26.4 \\
\hline South East England & 19.2 \\
\hline The Midlands & 25.0 \\
\hline North of England & 5.4 \\
\hline Wales & 6.6 \\
\hline
\end{tabular}

Some $70 \%$ of farms are located from the Midlands to the South of England. This may be in part due to the activity of the sponsors but it does also agree with the findings of Wassell and Esslemont (1992) who found this area accounted for $60 \%$ of the herd health schemes in his survey. 


\subsubsection{Reason for joining DHHPS}

Table 6.5 Why farmer joined DHHPS

\begin{tabular}{|l|c|c|}
\hline Reason for farmer joining service & $\begin{array}{c}\text { Vet Response } \\
\text { (\%) }\end{array}$ & $\begin{array}{c}\text { Farmer Response } \\
\text { (\%) }\end{array}$ \\
\hline To increase yield & 45.5 & 23.8 \\
\hline To improve milk quality & 38.1 & 22.0 \\
\hline To increase profit & 70.9 & 51.2 \\
\hline As an aid to management & 70.2 & 76.2 \\
\hline To improve fertility & 58.2 & 52.4 \\
\hline To reduce mastitis & 1.5 & 4.8 \\
\hline To reduce lameness & 3.0 & 7.7 \\
\hline Because of other problems & 10.5 & 7.1 \\
\hline
\end{tabular}

The most important reason for joining the service was as an aid to management in general. It is generally considered that farm managers are more likely to join herd health schemes (Wassel and Esslemont, 1992). As one veterinary surgeon stated 'managers like herd health schemes to cover their backs'. Improving fertility and increasing profitability were the other main reasons given for choosing the service.

Table 6.6 Decision to join DHHPS

\begin{tabular}{|l|c|}
\hline Who/What influenced decision to join DHHPS? & $\begin{array}{c}\text { Farmer Response } \\
\text { (\%) }\end{array}$ \\
\hline Local veterinary surgeon & 9.9 \\
\hline Feed adviser or representative & 86.1 \\
\hline Meeting, farm visit & 2.0 \\
\hline Leaflet, press information & 2.0 \\
\hline
\end{tabular}

It is perhaps not surprising that the sponsors' representatives had the most influence on the farmers' decision to join the service. Over the years it has become obvious that those of the sponsors' nutritional advisory staff, most of whom 
have qualifications in animal nutrition some to $\mathrm{PhD}$ standard, who are committed to the herd health approach to herd management, have a strong influence on farmers. Indeed the success of the DHHPS on an individual farm is in part dependent on the enthusiastic participation of nutritional advisers.

Some veterinary surgeons are much involved in running and promoting herd health schemes and in many cases they have encouraged farmers to become involved. However, Wassell and Esslemont (1992) summarising the results of his herd health survey observed that few veterinary surgeons offered potential methods of attracting farmers on to a scheme.

\subsubsection{Nutritional Advice}

Table 6.7 Nutritional advice on farm

\begin{tabular}{|l|c|c|}
\hline Who does farmer rely on for nutritional advice? & $\begin{array}{c}\text { Vet Response } \\
(\%)\end{array}$ & $\begin{array}{c}\text { Farmer } \\
\text { Response (\%) }\end{array}$ \\
\hline Feed representative & 95.5 & 89.9 \\
\hline Independent nutritional adviser & 61.2 & 42.9 \\
\hline Veterinary surgeon & 45.5 & 26.2 \\
\hline Other & 6.0 & 11.3 \\
\hline
\end{tabular}

Table 6.8 Main source of nutritional advice

\begin{tabular}{|l|c|c|}
\hline Who does farmer rely on most for nutritional advice? & $\begin{array}{c}\text { Vet Response } \\
(\mathbf{( \% )}\end{array}$ & $\begin{array}{c}\text { Farmer } \\
\text { Response (\%) }\end{array}$ \\
\hline Feed adviser & 86.3 & 72.4 \\
\hline Independent adviser & 12.9 & 22.1 \\
\hline Other & 0.8 & 5.5 \\
\hline
\end{tabular}

The results show that nutritional advice is sought from either the feed representative or their specialist colleagues or from independent nutritional advisers. $26 \%$ of farmers do recognise the nutritional input they receive from their veterinary surgeons. This however is not as high as the vet would perceive. 
Table 6.9 Veterinary competence regarding nutritional advice

\begin{tabular}{|l|c|}
\hline Does vet feel competent giving nutritional advice? & Vet Response (\%) \\
\hline Competent and confident & 6.8 \\
\hline Competent & 40.2 \\
\hline Not very competent & 53.0 \\
\hline
\end{tabular}

Table 6.10 Undergraduate education

\begin{tabular}{|l|c|}
\hline Did undergraduate education prepare you to give advice & $\begin{array}{c}\text { Vet } \\
\text { Response (\%) }\end{array}$ \\
\hline Yes & 9.7 \\
\hline No & 90.3 \\
\hline
\end{tabular}

Less than half of the veterinary surgeons who responded felt confident or competent in giving nutritional advice. A large percentage of them also considered that their undergraduate education did not give them adequate preparation for giving nutritional advice. This gives support to the need for a review of the undergraduate curriculum expressed in correspondence in the veterinary press (Munro 1997; Orpin, 1997).

\subsubsection{Farmer's perception of their veterinary surgeon}

Table 6.11 Perception of veterinary surgeon

\begin{tabular}{|l|c|}
\hline How do you perceive your vet & $\begin{array}{c}\text { Farmer } \\
\text { Response (\%) }\end{array}$ \\
\hline A clinician only & 30.91 \\
\hline A clinician and adviser & 69.09 \\
\hline
\end{tabular}

Seventy percent of farmers in this survey perceive their veterinary surgeon as both a clinician and someone who is able to give advice on wider matters relating to herd health. 


\subsubsection{Factors which influence the success of a health scheme}

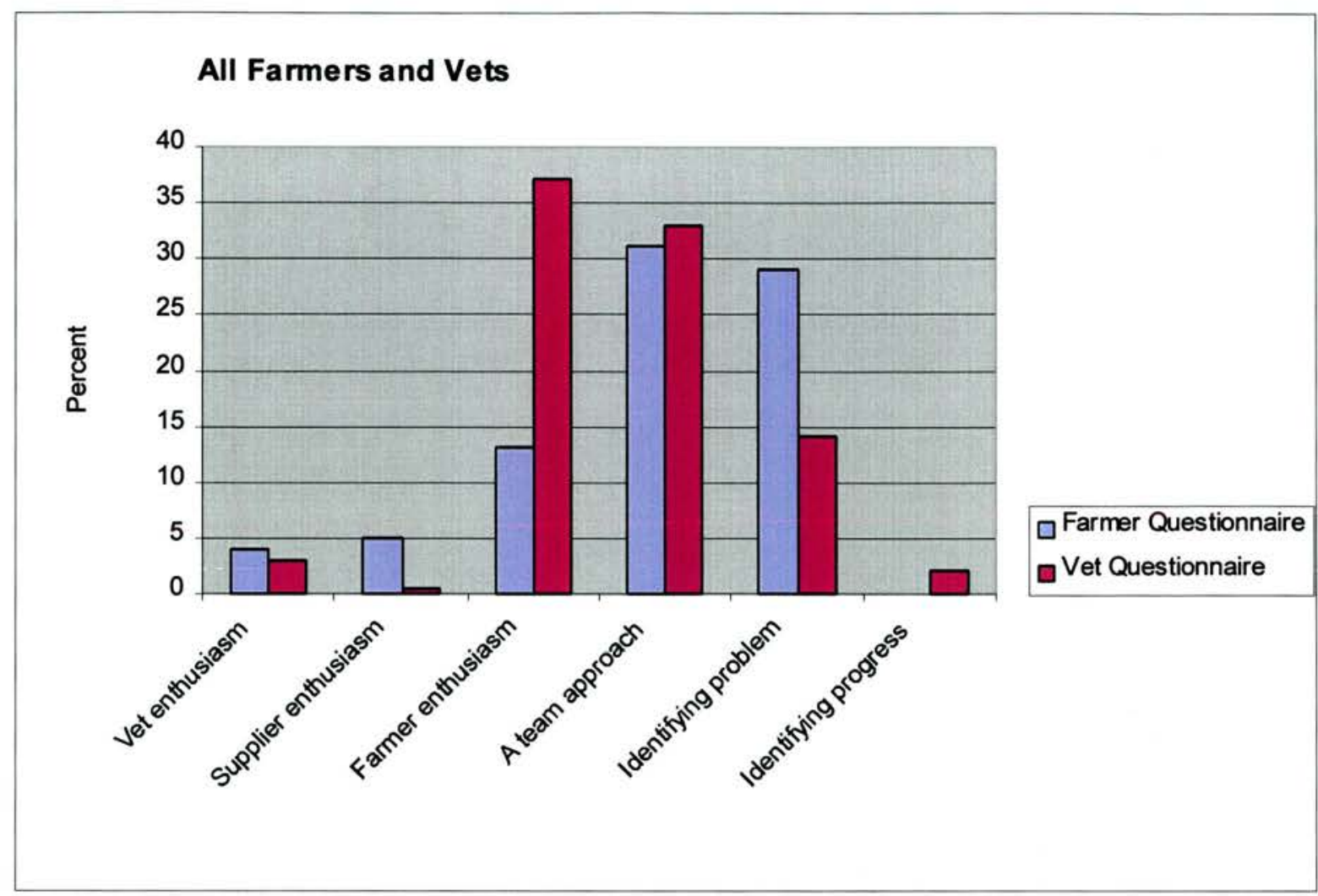

Figure 6.3 Main reason for a successful service

\section{Enthusiasm of Farmer}

The veterinary surgeons considered the enthusiasm of the farmer to be the key element for the service to be successful. There is no doubt that if the farmer adopts a negative approach or is not convinced of the value of such a service then it will not run successfully on that particular herd.

\section{Team approach}

In the opinion of both the farmers and their veterinary surgeons the main reasons for the success of a herd health service was the team approach. So much information is available to the farmer today and so much of it appears contradictory and biased, however, the opportunity to discuss health and productivity with the veterinary practitioner and the nutritional adviser was valued. Establishing a good 
working relationship between all members of the team was considered by many to be to their mutual advantage.

\section{Identification of Problems}

Perhaps not surprisingly farmers considered the identification of problems as an important component in the success of a scheme. The veterinary surgeons did not consider this as important as the enthusiasm of the farmer or the team approach

\subsubsection{Opinion of the Dairy Herd Health and Productivity Service}

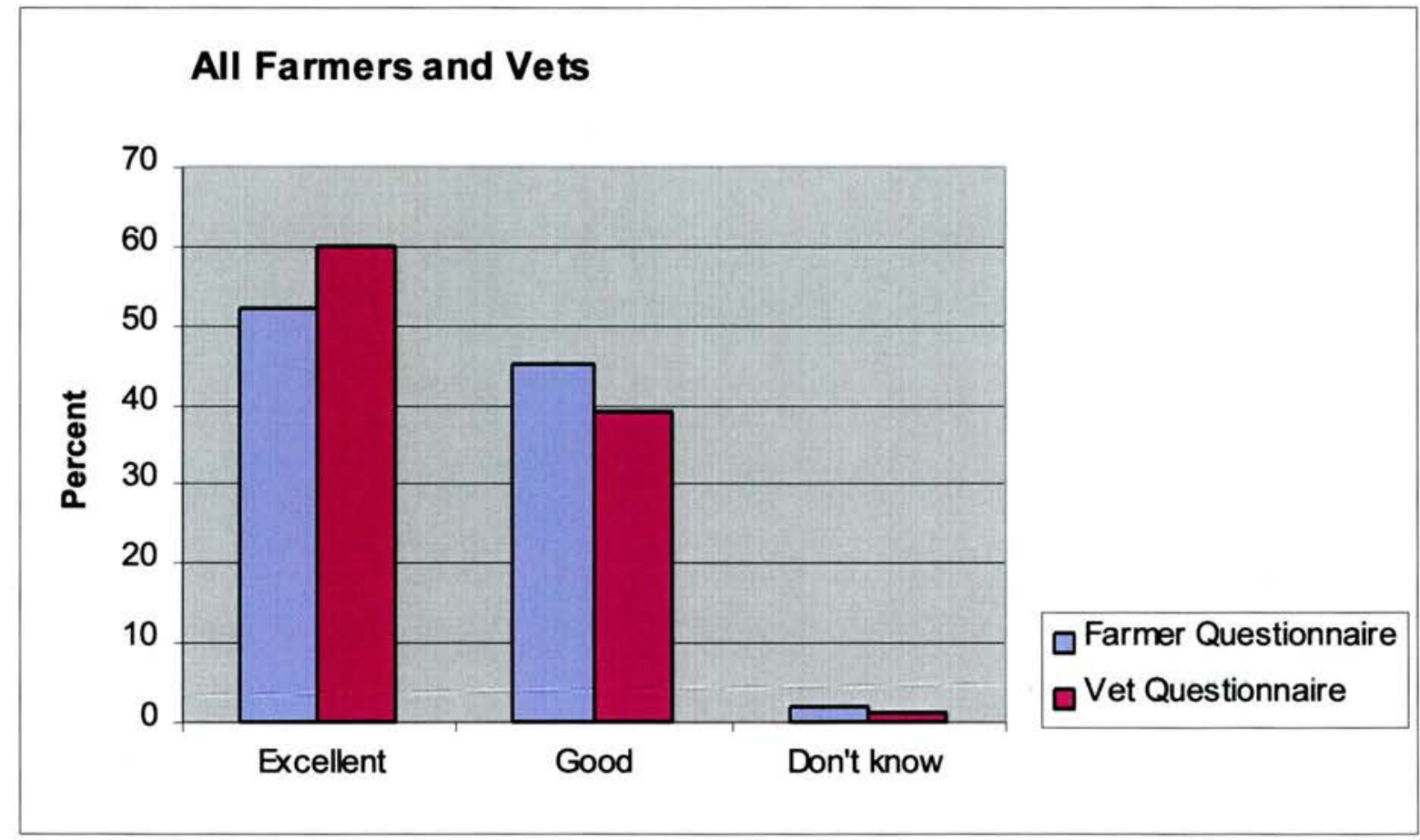

Fig 6.4 Opinion of blood test and profiles

Almost all veterinary surgeons and farmers indicated that blood profiles used as an integral part of a health service are worth while. 


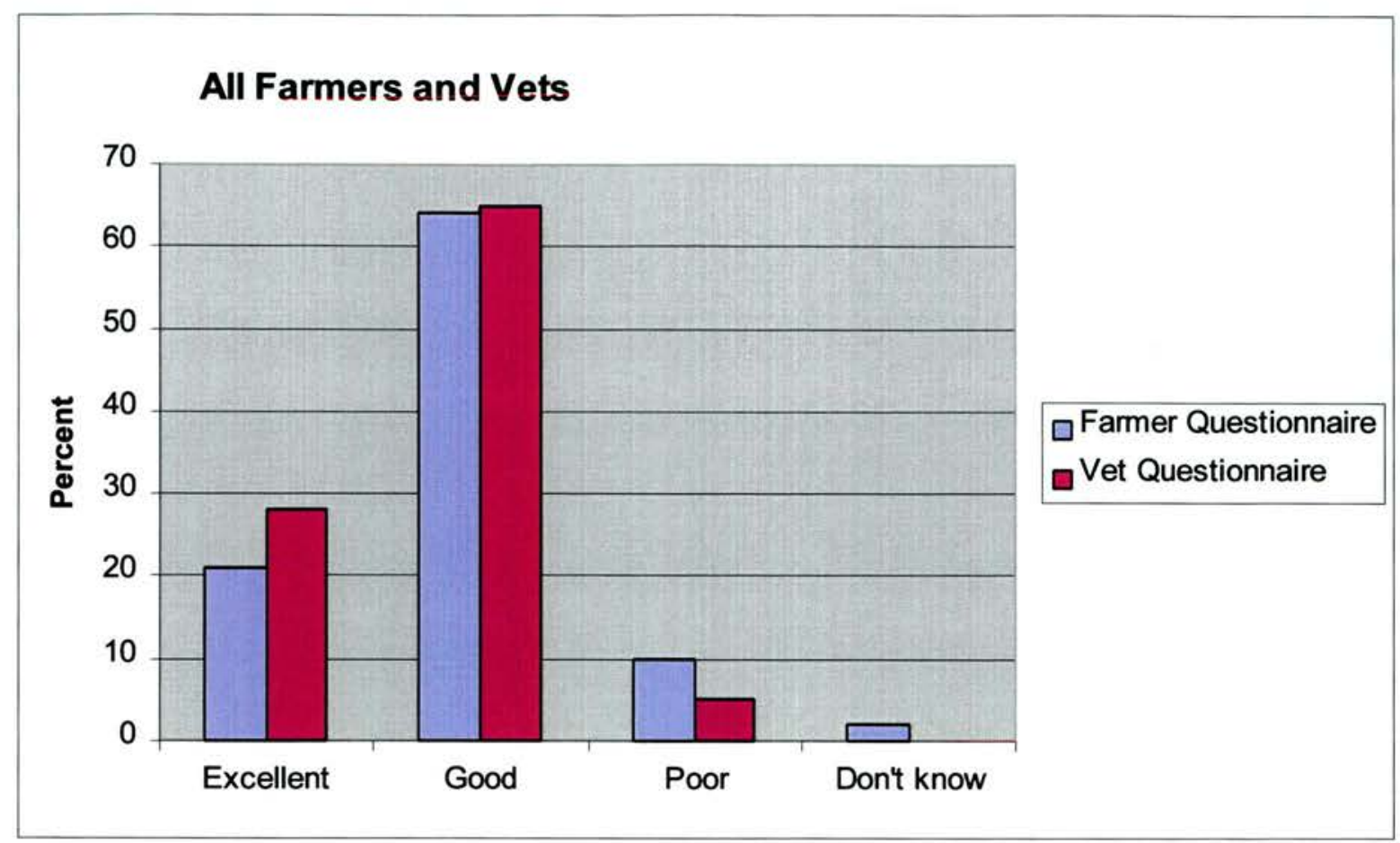

Fig 6.5 Opinion of presentation of results

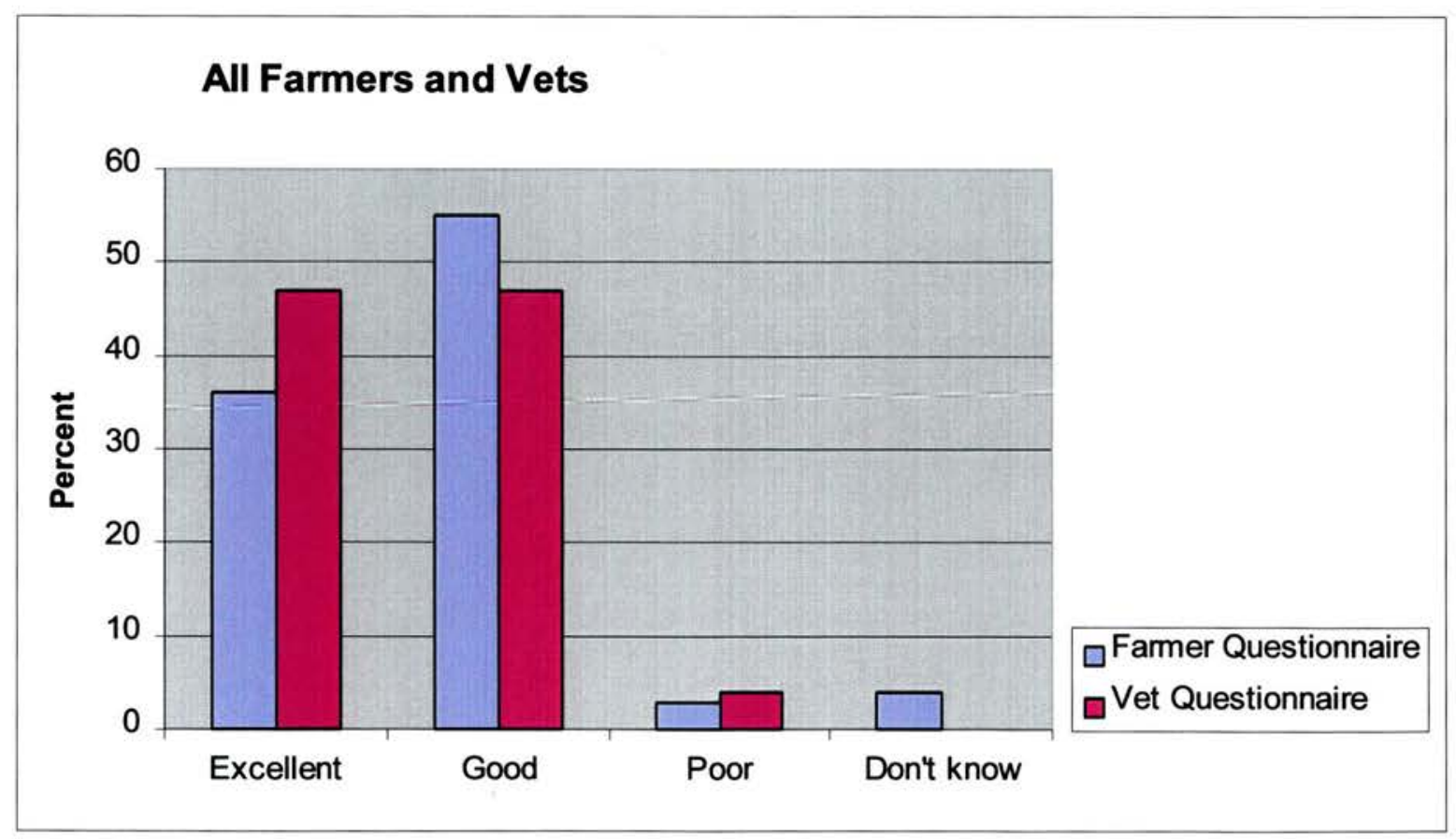

Fig 6.6 Opinion of letter of interpretation 
Ninety four per cent of vets and 87 per cent of farmers thought that the presentation of results was either excellent or good, and the vast majority approved of the interpretation.

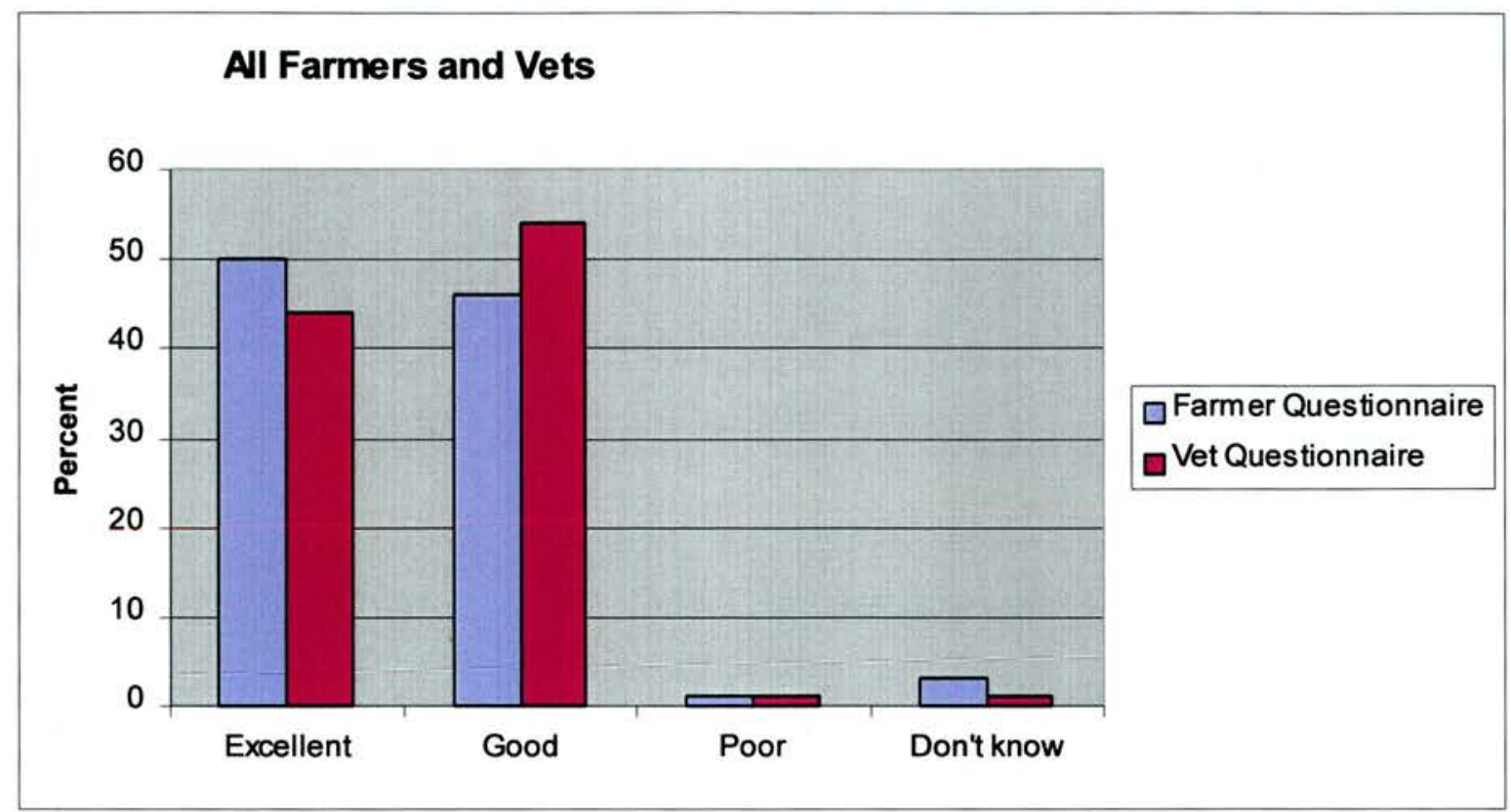

Fig 6.7 Opinion of speed of turn around

Almost all farmers and veterinary surgeons were well satisfied with speed of turnaround of the results. The average turnaround time i.e. time from taking samples to receipt of results and letter of interpretation was four days. It is important to ensure that there is prompt delivery of results to ensure that the enthusiasm and interest triggered by the blood sampling is maintained. It is essential that the momentum is not lost. 


\subsubsection{Team Meeting}

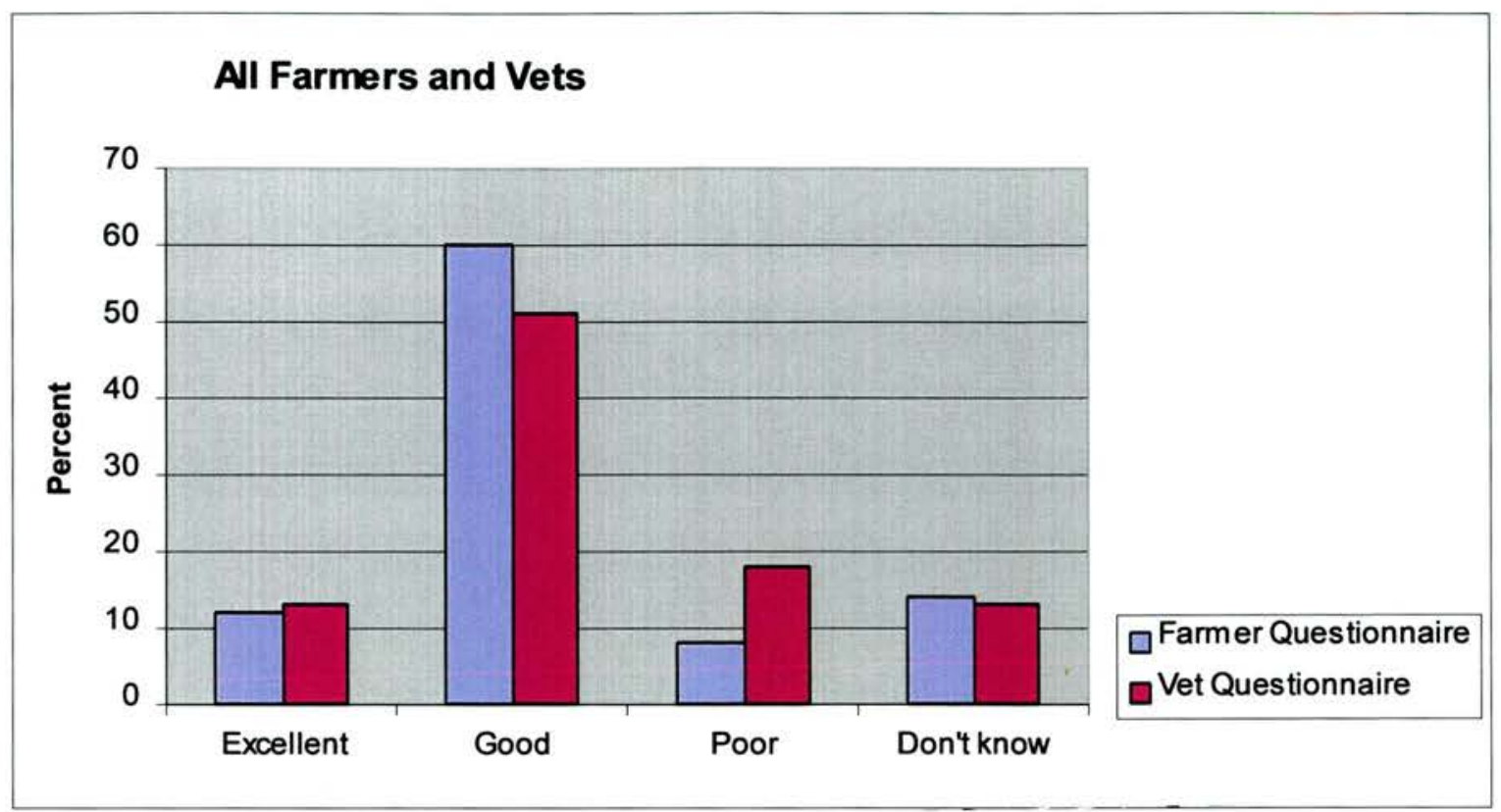

Fig 6.8 Opinion of team meeting

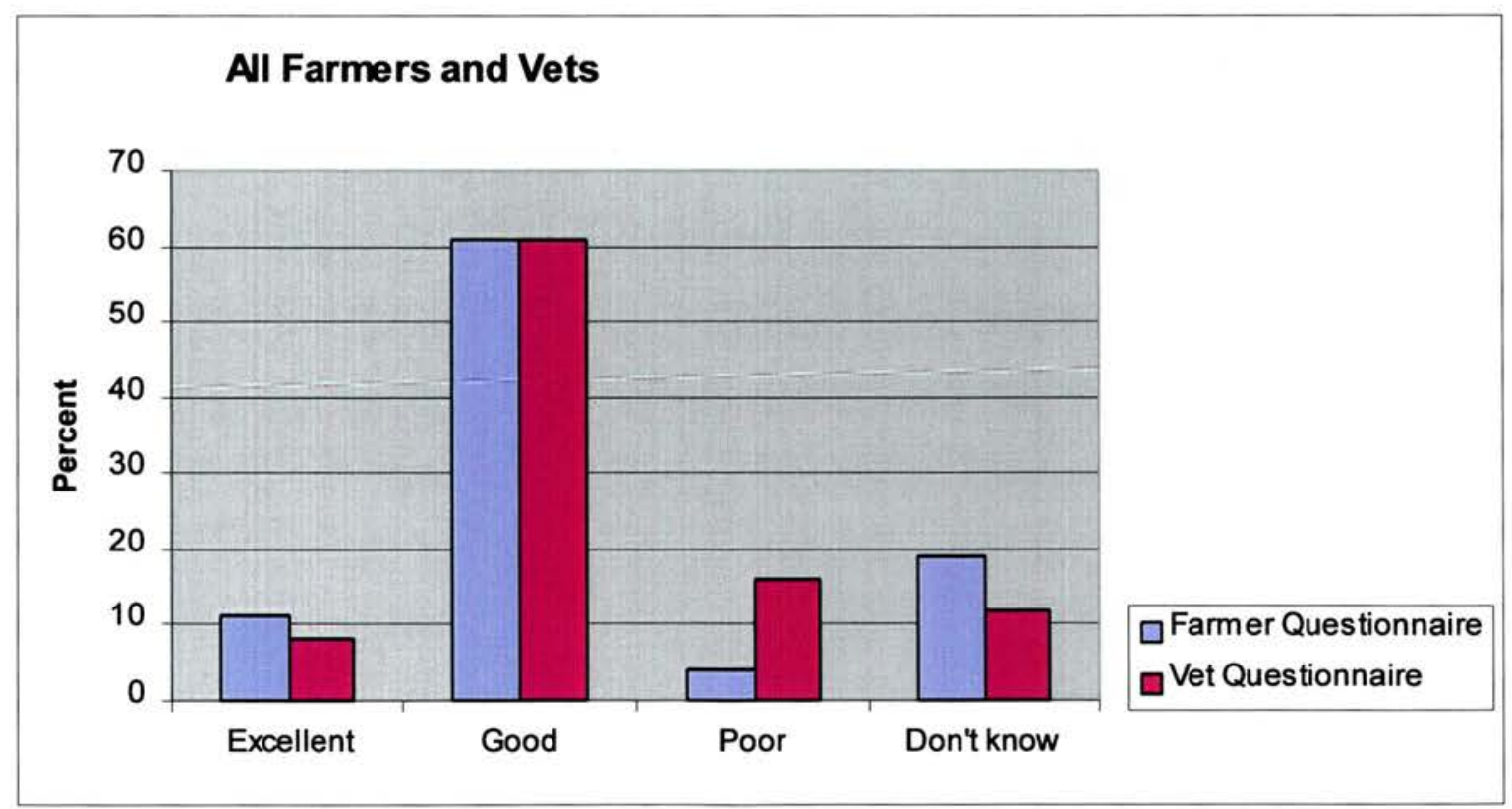

Fig 6.9 Opinion of discussion form 


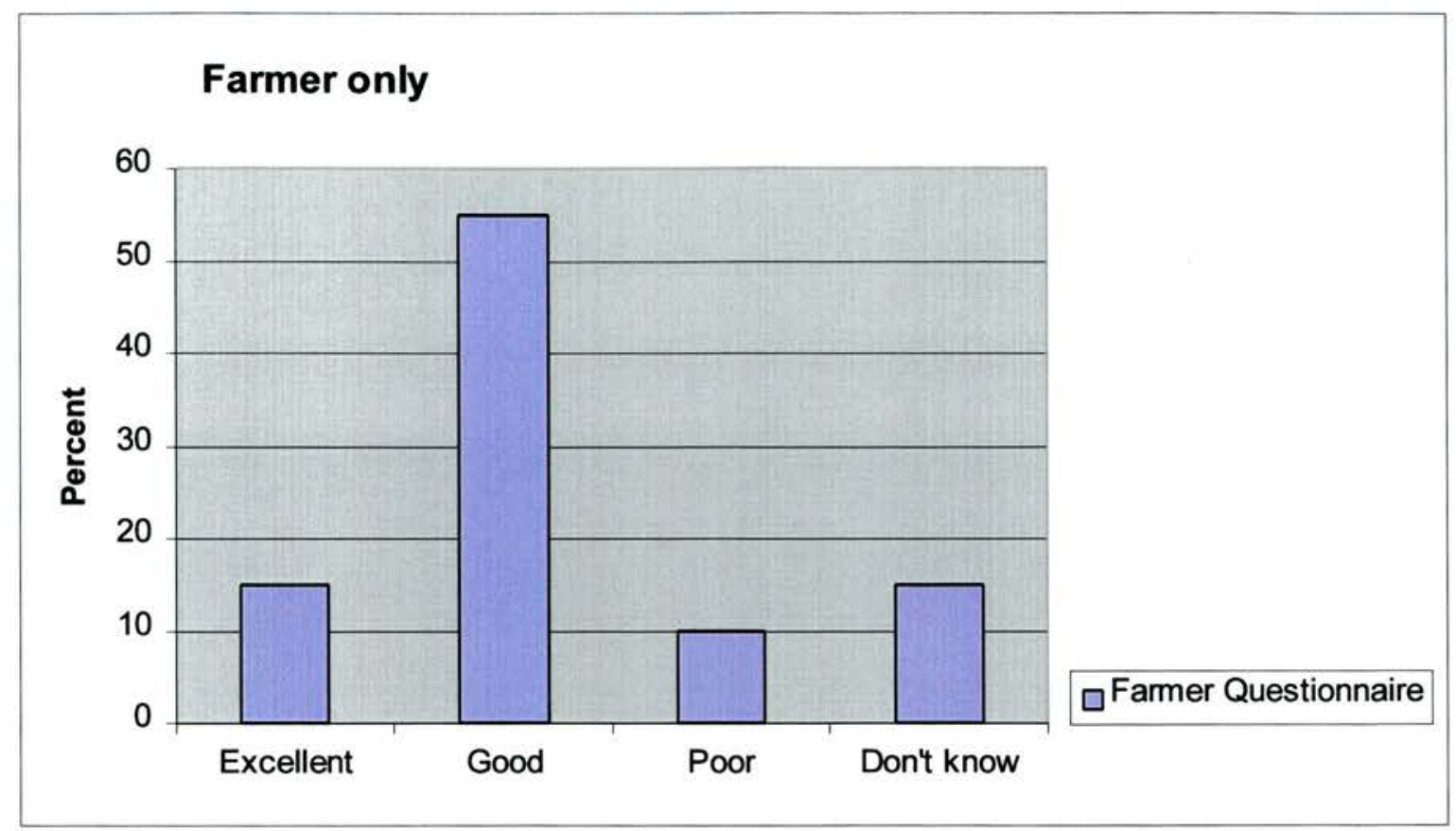

Fig 6.10 Opinion of vet participation in meeting (farmers only)

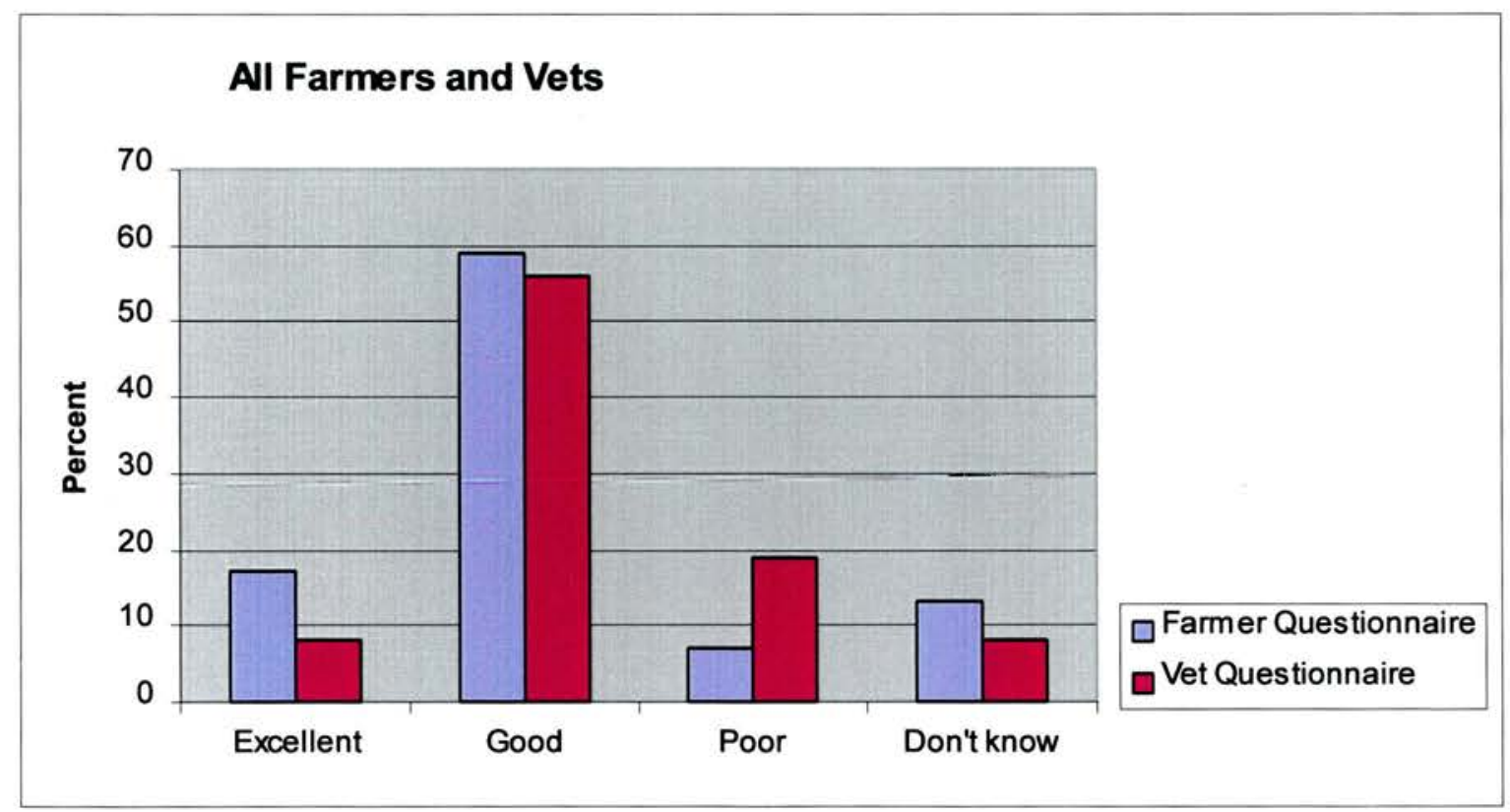

Fig 6.11 Opinion of ease of communication

All copies of results and letter of interpretation are sent by the same post to all members of the advisory team. The onus is on the veterinary surgeon to call a meeting to discuss the results. The farmer will have received his results on the same 
day as the veterinary surgeon and may well stimulate the arrangement of a discussion meeting. Frequently the discussion meeting is set-up on the day of sampling. It is essential that this post sampling discussion takes place if all participants are going to obtain maximum value from the service. This meeting should act as a catalyst to a wider discussion on aspects of health and productivity. Seventy per cent of farmers thought that veterinary participation in the meeting was good or excellent. Only 10 per cent considered the veterinary input to be poor. It is disappointing that only 22.6 per cent of veterinary surgeons chair this meeting and suggests that some vets lack confidence in taking the initiative.

The results should be discussed in light of all the other background information on the farm. This might include

- quality of available forage

- cost of alternative feeds

- on farm facilities

- quality and availability of labour

- calving pattern

- current economic situation

- current quota situation

- prevailing climatic conditions

- review of fertility

- review of herd health

This meeting affords the opportunity for future targets to be established or appraised. Goals or objectives must be established to give the farmer and veterinary surgeon something to work towards. This view is supported by many authors (Williamson (1986); Noordhuizen et al., (1986); Radostits and Blood, (1985) and Esslemont et al., (1985)). The setting of unrealistic objectives or targets for a farmer to aim at can have the effect of quickly demoralising him, if he realises that he has little chance of achieving it.

The discussion report form is disseminated to all parties including the DHHPS laboratory and acts as a minute of the meeting. 
The perceived value of this team meeting and discussion report is much more variable as is the opinion of the ease of communication. This very much depends on the individual personality of all the main participants, farmer, veterinary surgeon and nutritional adviser.

\section{Some reasons for breakdown in communication.}

- Veterinary surgeons were strongly of the opinion that the success of the service was highly dependent on farmer enthusiasm.

- Some nutritional advisers undoubtedly wish to dominate the service and do not encourage, for whatever reason, the full participation of the veterinary surgeons.

- Some farmers, although in the minority, do not rate the contribution of the veterinary surgeon highly, and may wish to attempt to save money by minimising the veterinary input

- Some veterinary surgeons, by there own admission, feel uncomfortable attending discussions on nutritional matters and may only attend if on farm performing clinical work. They would not consider their attendance at the post sampling meeting as very important for the success of the service.

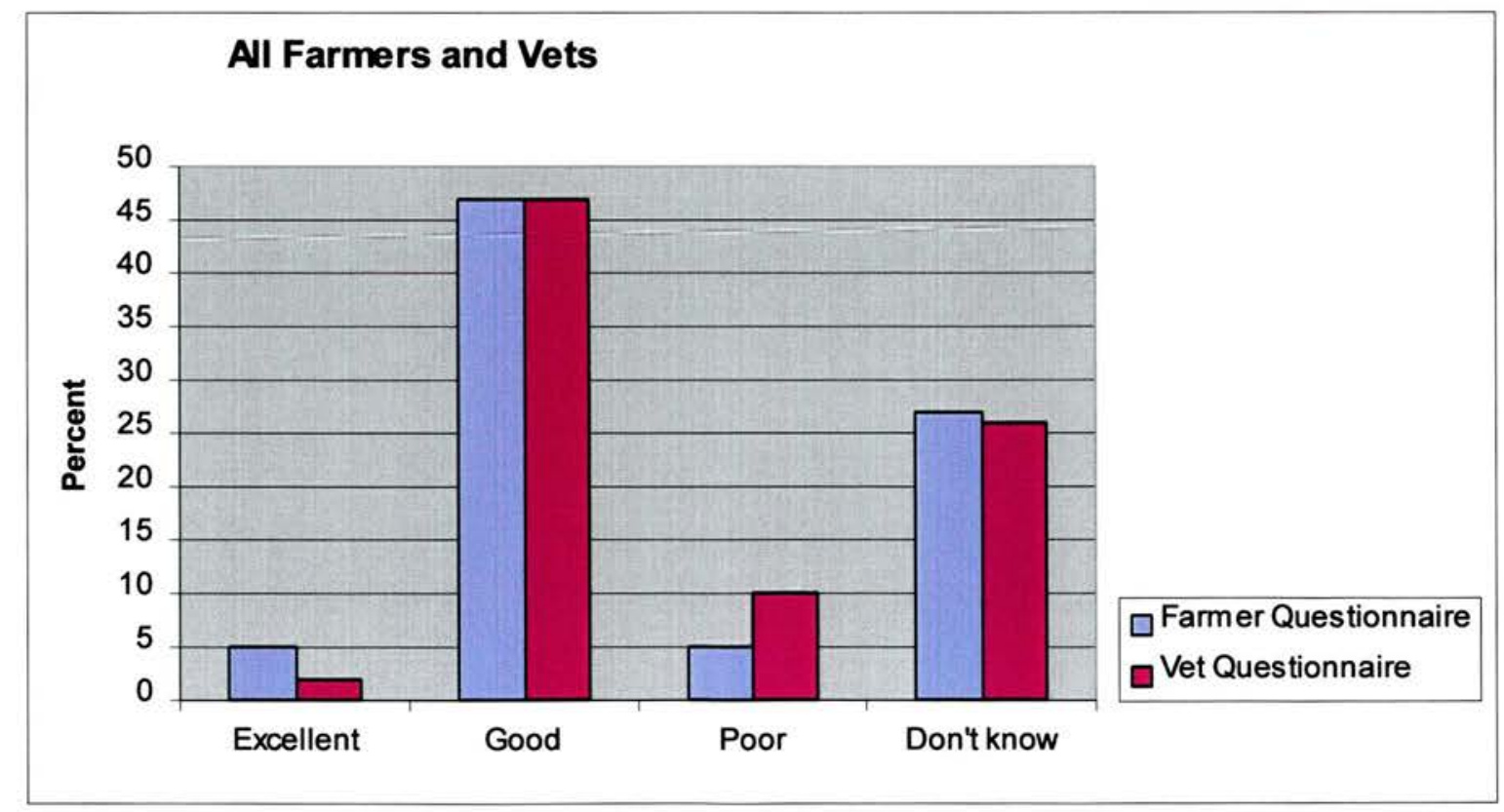

Fig 6.12 Opinion of Sheet $2 \&$ Quarterly reports 
The responses to the above query are again variable. A significant number of don't know responses would reflect the number of farms where this part of the service is not used to its full potential. The sheet 2 information and quarterly reports can provide a valuable basis for discussion on herd health and productivity. They assist in monitoring progress in achieving goals and targets.

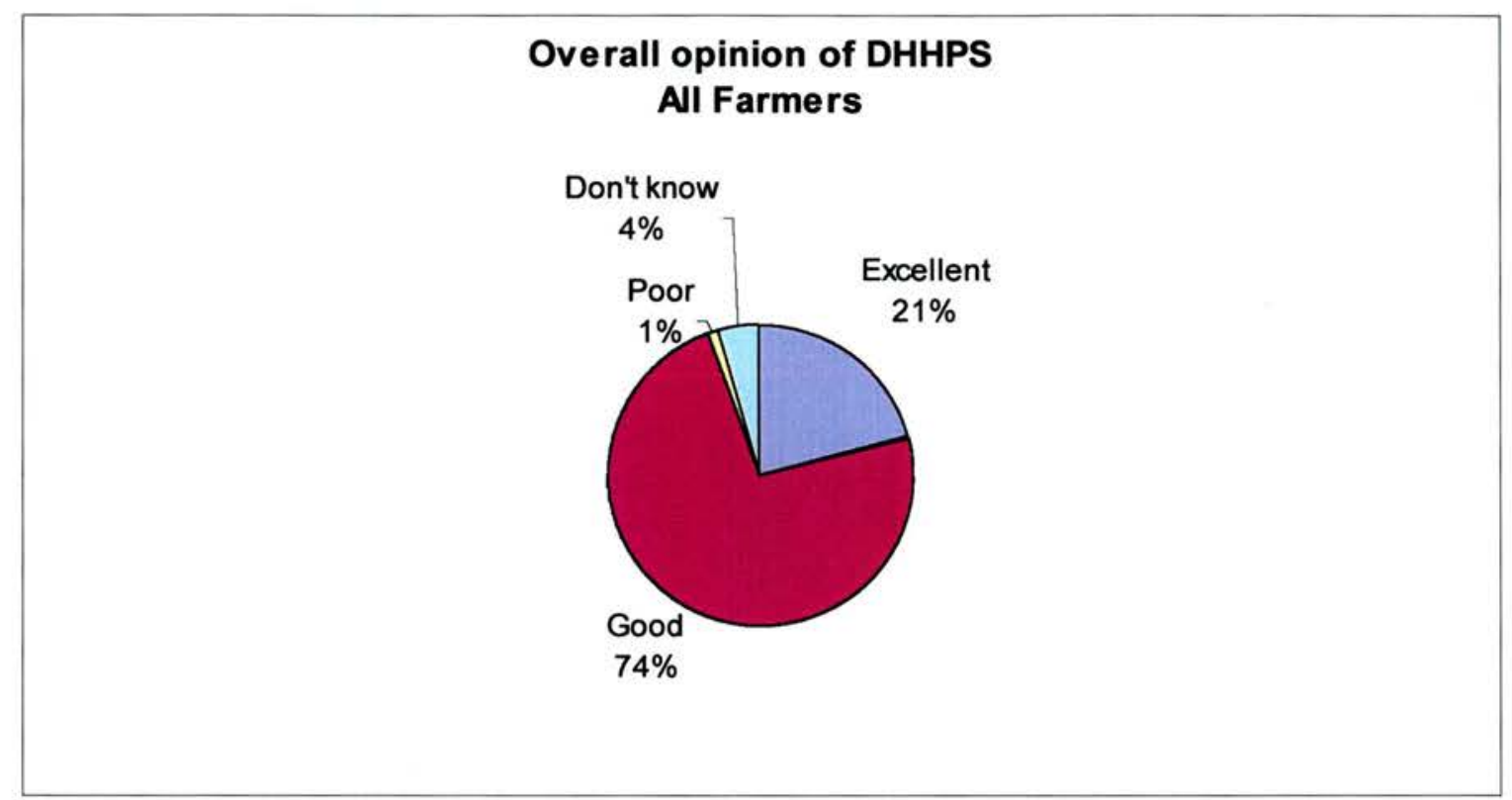

Fig 6.13 Overall opinion of farmers of DHHPS

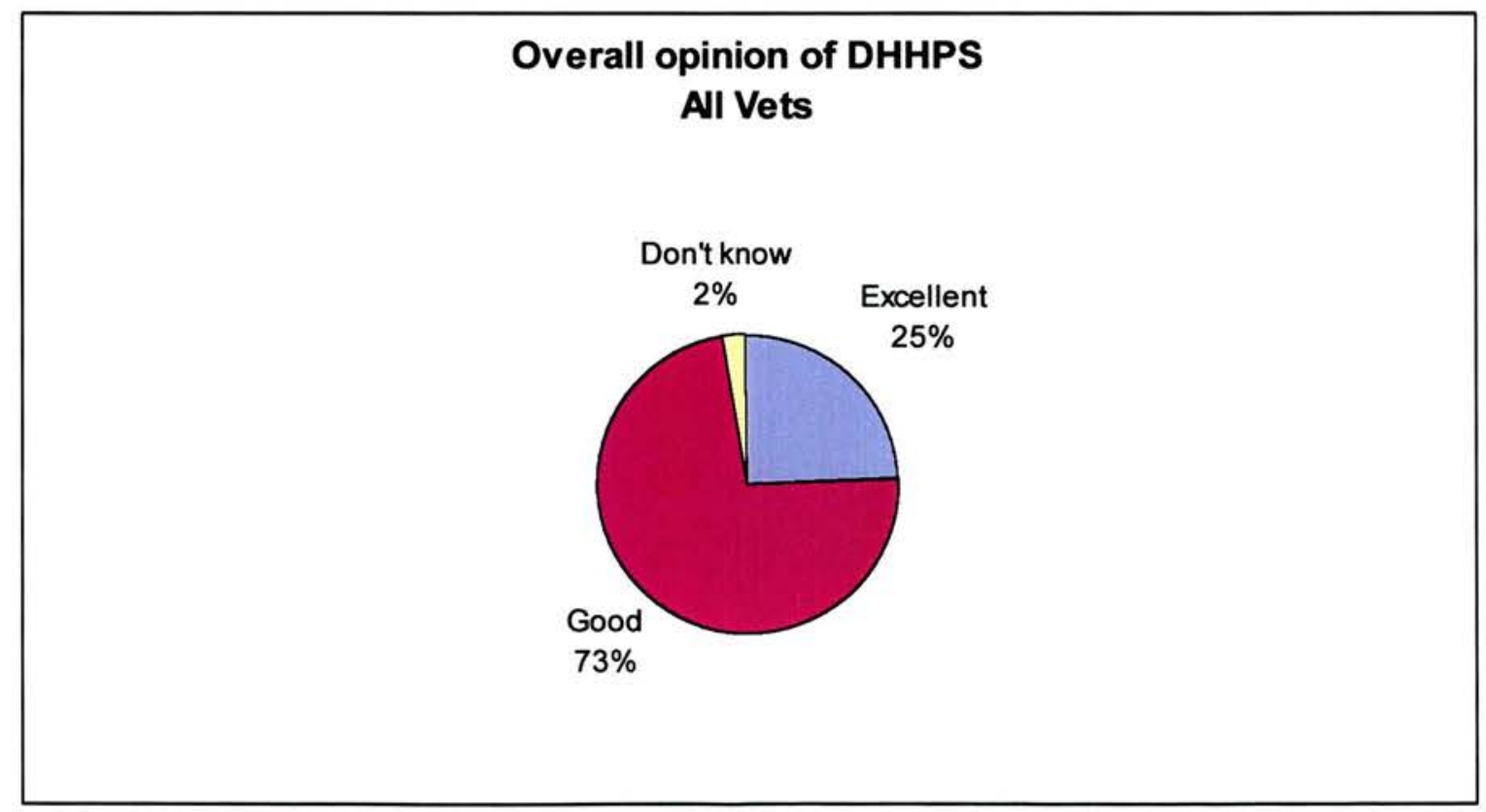

Fig 6.14 Overall opinion of vets of DHHPS 
In general the 97 per cent of responding veterinary surgeons and 94 per cent of the farmers using the service considered it to be good or excellent.

\subsubsection{Do results reflect on farm situation?}

Table 6.15 Reflection of results and letter of interpretation on what is happening on farm

\begin{tabular}{|l|c|c|}
\hline Do results reflect what happens on the farm? & $\begin{array}{c}\text { Vet } \\
\text { Response (\%) }\end{array}$ & $\begin{array}{c}\text { Farmer } \\
\text { Response (\%) }\end{array}$ \\
\hline Often & 60.9 & 60.7 \\
\hline Sometimes & 37.6 & 36.2 \\
\hline Seldom & 1.5 & 3.1 \\
\hline
\end{tabular}

Both farmers and veterinary surgeons were in close agreement that the majority of the results and interpretation accurately reflect what is actually happening on the farm.

\subsubsection{Discussion report forms}

Table 6.16 Use of Discussion Report Form

\begin{tabular}{|l|c|c|}
\hline Do you use discussion report form? & $\begin{array}{c}\text { Vet } \\
\text { Response } \\
\text { (\%) }\end{array}$ & $\begin{array}{c}\text { Farmer } \\
\text { Response } \\
\text { (\%) }\end{array}$ \\
\hline Often & 32.0 & 31.6 \\
\hline Sometimes & 40.5 & 50.7 \\
\hline Seldom & 27.5 & 17.8 \\
\hline
\end{tabular}

Farmers use the report more frequently than veterinary surgeons. This supports the view that the veterinary surgeon is not always invited, or does not always attend the post sampling discussion meeting. It is disappointing that the discussion report forms are not more frequently used. 


\subsubsection{Improvement in profitability}

Table 6.17 Payment for advice

\begin{tabular}{|l|c|}
\hline Prepared to pay for advice from vet? & Farmer Response (\%) \\
\hline Willing to pay & 19.3 \\
\hline Already pay & 42.9 \\
\hline Not willing to pay & 17.4 \\
\hline Don't know & 20.5 \\
\hline
\end{tabular}

Only 17.4 per cent of farmers stated that they would be unwilling to pay for advice. This would suggest that all the rest might at least be potential payers, with some 42.7 per cent already paying. A further 19.3 per cent would be willing to pay but presumably had not been asked! 20.5 per cent did not know. This may mean that they are waiting to see how they value the veterinary surgeons input to the herd health service or perhaps because the matter has never been raised or discussed!

In reply to the question do you charge for giving advice only 39.7 per cent of veterinary surgeons said that they did and the other 60 . per cent said they did not. The forty per cent of farmers who pay are presumably employing the forty per cent of veterinary surgeons who charge. These responses would suggest that there is considerable scope for veterinary surgeons to become more positive in their approach to charging farmers for advice. It would appear that veterinary surgeons are not always aware that their advice is valued by farmers, many of whom would pay if asked.

Table 6.18 Profitability and setting goals

\begin{tabular}{|l|c|c|}
\hline Profitability - Vet Response & \% Yes & \% No \\
\hline Aware of herd profitability & 43.6 & 56.4 \\
\hline Involved in setting profitability goals & 26.3 & 73.7 \\
\hline
\end{tabular}

Less than half the veterinary surgeons involved appeared to be aware of herd profitability. Only $26 \%$ were involved in setting profitability targets. One of 
the major problems that vets perceived with marketing health schemes was the difficulty in identifying financial benefits (Wassell and Esslemont 1992). It would appear from this survey that there is scope for vets becoming more involved in setting targets with financial benefits attached. This would be a positive way forward.

Table 6.19 Improvement in profitability

\begin{tabular}{|l|c|c|}
\hline $\begin{array}{l}\text { Has profitability improved since joining } \\
\text { DHHPS ? }\end{array}$ & $\begin{array}{c}\text { Vet } \\
\text { Response (\%) }\end{array}$ & $\begin{array}{c}\text { Farmer } \\
\text { Response (\%) }\end{array}$ \\
\hline Significantly & 16.4 & 22.4 \\
\hline Moderately & 60.7 & 43.6 \\
\hline Not Discernibly & 11.5 & 15.2 \\
\hline Too soon to say & 11.5 & 18.8 \\
\hline
\end{tabular}

Only $15 \%$ of members assess that they have seen no appreciable improvement in profitability since joining the service. The veterinary surgeons independently gave a similar response. This suggests that the majority of farmers were willing to associate membership of the scheme with improved profitability. In this survey two thirds of respondents claim to have seen a significant or moderate increase. A further 18.79 per cent of farmers indicated that they had not been members for sufficiently long to form an opinion.

Table 6.20 Value for money

\begin{tabular}{|l|c|}
\hline Does service give good value for money? & $\begin{array}{c}\text { Farmers } \\
\text { Response (\%) }\end{array}$ \\
\hline Yes & 64.8 \\
\hline No & 4.9 \\
\hline Don't Know yet & 30.3 \\
\hline
\end{tabular}

Only 5 per cent of farmers felt that the service did not represent good value for money. 


\subsubsection{Benefits from Membership DHHPS}

Table 6.21 Benefits to farmer

\begin{tabular}{|l|c|c|}
\hline Benefit farmer is getting from DHHPS & $\begin{array}{c}\text { Vet } \\
\text { Response (\%) }\end{array}$ & $\begin{array}{c}\text { Farmer } \\
\text { Response (\%) }\end{array}$ \\
\hline Early warning of potential problems & 74.6 & 73.2 \\
\hline Reassurance on nutrition and management & 90.3 & 76.2 \\
\hline Benefit of information & 61.5 & 54.2 \\
\hline Other benefits & 13.4 & 5.4 \\
\hline Fewer than expected... & 2.2 & 7.7 \\
\hline
\end{tabular}

This set of data suggests that farmers are getting considerable benefits from the service and relatively few are disappointed. The benefits of reassurance are often not emphasised but are very important especially as farmers are forced to become more and more aware of costs and profitability. This has led them, in many cases to reduce cost of inputs, often with more reliance on home grown forage and cereals. It is therefore important that they can monitor effects closely and be either reassured that all is well or be given an early warning of potential problem areas. It is perhaps not surprising that reassurance and support is particularly valued by managers of large herds. Benefits of information would include regular newsletters and awareness of problems and solutions encountered by other members.

Table 6.22 Benefits to veterinary surgeon

\begin{tabular}{|l|c|}
\hline Veterinary surgeons perceived benefit & Vet Response (\%) \\
\hline Involved with nutritional advice & 90.0 \\
\hline Initiate a preventive medicine programme & 53.0 \\
\hline Learn about dairy cow nutrition & 82.8 \\
\hline Fewer benefits than expected & 3.3 \\
\hline
\end{tabular}


Table 6.23 Integrated Services

\begin{tabular}{|l|c|}
\hline Are integrated services & Vet Response (\%) \\
\hline Feasible & 99.2 \\
\hline Cost effective & 97.6 \\
\hline Rewarding to vet & 95.5 \\
\hline
\end{tabular}

The majority of veterinary surgeons find the service of value in allowing them to become involved in giving nutritional advice and in many cases learning more about dairy cow nutrition. More than half also considered it gave them the opportunity to initiate preventive medicine programmes.

\subsubsection{Use of and Comparison with other services}

Table 6.24 Other services

\begin{tabular}{|l|c|c|}
\hline Do you use similar service from another lab? & $\begin{array}{c}\text { Vet } \\
\text { Response (\%) }\end{array}$ & $\begin{array}{c}\text { Farmer } \\
\text { Response (\%) }\end{array}$ \\
\hline Yes & 69.4 & 13.7 \\
\hline No & 30.6 & 86.3 \\
\hline
\end{tabular}

Table 6.25 Comparison of other services with DHHPS

\begin{tabular}{|l|c|c|}
\hline $\begin{array}{l}\text { How does DHHPS compare with other } \\
\text { services? }\end{array}$ & $\begin{array}{c}\text { Vet } \\
\text { Response (\%) }\end{array}$ & $\begin{array}{c}\text { Farmer } \\
\text { Response (\%) }\end{array}$ \\
\hline Better & 64.5 & 69.6 \\
\hline Same & 23.7 & 13.0 \\
\hline Worse & 9.7 & 4.4 \\
\hline Don't know & 2.2 & 13.0 \\
\hline
\end{tabular}

Since the DHHPS has been established similar services (Ward et al., 1996) have been introduced. The survey suggests that the format of the DHHPS is judged by both farmers and veterinary surgeons to be better than some of the other services on offer to farmers. 
Table 6.26 Use of DAISY

\begin{tabular}{|l|c|c|}
\hline Do you use DAISY recording service? & $\begin{array}{c}\text { Vet } \\
\text { Response (\%) }\end{array}$ & $\begin{array}{c}\text { Farmer } \\
\text { Response (\%) }\end{array}$ \\
\hline Yes & 33.6 & 48.8 \\
\hline No & 66.4 & 51.2 \\
\hline
\end{tabular}

It has long been recognised that getting the farmer involved in fertility control is the basis of most herd health schemes (Esslemont et al., 1985). Almost half of the farmers using the service were using the DAISY recording service suggesting that the same type of farmer was attracted to this type of concept. However only one third of the veterinary surgeons had experience of DAISY, which further suggests that it is certain farmers who see the value of health schemes rather than the fact that the concept is being promoted by the veterinary profession.

Table 6.27 Routine health visits

\begin{tabular}{|l|c|}
\hline Is your vet involved on your farm in & $\begin{array}{c}\text { Farmer Response } \\
(\%)\end{array}$ \\
\hline Fertility control & 83.3 \\
\hline Mastitis control & 34.8 \\
\hline Lameness control & 30.7 \\
\hline
\end{tabular}

Veterinary surgeons were more than twice as likely to be involved with fertility control than with mastitis or lameness. There would appear to be considerable scope for more veterinary surgeons to establish mastitis and lameness control programmes on their clients' farms. 


\section{Chapter Seven}




\section{CONCLUSIONS}

From the early days of the DHHPS there has never been any difficulty in getting farmers interested in the concept. Even in the present climate of financial difficulties for the dairy industry those farmers who are determined to survive are more than ever willing to participate in the DHHPS. In the early days some undoubtedly saw the service as an instant answer to some of their most acute problems. They had high expectations of quick progress in improving long standing problems and would have been disappointed that the service did not always identify instant solutions!

\section{It has become clear that the farmer must fulfil the following requirements}

- Farmer must be convinced of the merits of an inter disciplinary approach to preventive medicine on his unit. In other words they must 'enter into the spirit' of the exercise. Any farmer who perceives this approach to be an expensive way of providing employment for veterinary surgeons and other advisers will clearly not get advantage from DHHPS.

- They must have the ability to operate a dairy unit using contemporary techniques in animal husbandry and management.

- They must work to a defined management cycle

- They must have up-to-date recording of individual and herd health and productivity data.

\section{Similar criteria could be apportioned to the veterinary practitioners}

- Perhaps the most important is the broad knowledge of, and above all else interest in, the current dairy industry

- They must be able to communicate at all levels with those involved on the farm.

- They must appreciate the interactions between health, disease, management, cow welfare and economics.

- They must be prepared to become proactive in decision making and in the setting of realistic goals and targets. It is of little use finding fault with too much of the husbandry at the initial stage of the exercise. If the targets set for a particular farm are unrealistic in the short or medium term the farmer will soon become disinterested or disillusioned. 
- The practitioner will always be mindful of sound epidemiological principles

- The practitioner must have a wide knowledge base of scientific information which they have the ability to communicate to the rest of the on farm team

- The veterinary practitioner must be a sentinel and advocate for animal welfare on the farm even when this can prove to be a contentious issue.

- There must be a practice structure that permits the veterinary surgeon to be punctual for scheduled blood tests and advisory meetings. These meetings must be seen to be a priority and sufficient time should be allocated to allow full discussion and if necessary investigation to take place.

The DHHPS relies very much on the participation of the sponsor's representative or nutritional specialist. They are important for their contribution by way of nutritional advice but also for their organisational abilities. Frequently it is left to this person to organise blood tests and follow up meetings. In instances when we have operated solely through the veterinary surgeon the organisation and completion of the paper work has frequently been found wanting. Incorrect forms have been used and frequently important background information has not been supplied. Other agencies involved in the use of metabolic profiles frequently lack the essential background for use in interpretation of results. This has largely been the key to the success of the service. If the DHHPS is to operate to maximum efficiency the team must communicate. On some occasions where one member, either veterinary surgeon or feed specialist has dominated or 'gone their own way' the exercise has suffered accordingly. This has most frequently happened when the veterinary surgeon's contribution has been perceived to be inadequate.

However, one of the main benefits of the scheme has undoubtedly been the team approach. On many occasions an excellent understanding has been established between the adviser and veterinary surgeon to the mutual benefit of both parties.

One of the challenges in solving multifactorial disease problems such as mastitis, lameness and infertility is the ability to integrate data from multiple sources. The consequent challenge is on how to elicit change in management 
performance. The DHHPS has facilitated the solving of complex problems by encouraging multidisciplinary participation. Regular team meetings with the use of post discussion reports do help to ensure that goals and targets are set and that proposed changes do take place.

It is essential that at a very early stage in the involvement with the DHHPS that all parties, but in particular the farmer and veterinary surgeon, thoroughly discuss the costs of the DHHPS. This must not only include obvious costs for sampling and laboratory work but also the payment for advice and time spent by the veterinary surgeon at advisory meetings. It is clear from our survey that this discussion frequently does not take place and that fewer than 50 per cent of veterinary surgeons charge for advice.

\section{Health Records}

The monthly recording of health and fertility data has consistently shown fertility, mastitis and lameness to be the main challenges for the dairy industry. When used properly these records provide a focus for setting targets and establishing future goals. Monthly figures provide historical data for comparison with the current on farm situation. Much of the practitioner's time is devoted to the biological aspects of reproductive and other disease and insufficient time is spent having an overall view of the 'big picture'. The evidence is now overwhelming that the production diseases of the modern high yielding cow can only be effectively reduced when management and nutrition are given full consideration in the development of the control programme.

Over the years the regular submission of regular sheet 2 has been a problem for some farmers. Unless this part of the service is functional on an individual farm the total value of the service is diminished. Some farmers consider the short term benefits of blood sampling as the main part of the DHHPS and choose to ignore the benefits of regular disease monitoring. Others will be using DAISY or similar recording service and do not wish to duplicate recording systems. This may be satisfactory as long as the records are available for discussion at post sampling meetings. As farmers are now directly rewarded or penalised for milk quality, SCC, 
TBC or Bactoscan, and milk constituents the benefits of mastitis control and nutritional monitoring can be clearly demonstrated.

The introduction of farm assurance schemes have made it necessary for members to be able to demonstrate that they are keeping health records and also have updated nutritional plans. As a development from the DHHPS over 500 customers of Unigate are sending in regular monthly data. Farmers joining Unigate's White Gold Scheme must be able to produce updated health records on a regular basis. If members comply with the requirements of this service they receive a premium (currently $0.5 \mathrm{p} / \mathrm{litre}$ ) for their milk. It is perhaps regrettable but understandable that it requires a direct financial reward for farmers to start using a recording system. Besides the reward of a higher milk price farmers have the incentive to use the quarterly reports to identify and quantify the health problems on their farms, all of which are costing them money. Farmers are now being forced to quantify the health status of their herds and this should provide a unique opportunity for some veterinary surgeons to become further involved in advising on herd health and productivity.

\section{Metabolic profiles}

Since the introduction of 'The Metabolic Profile' by Payne (1970) the concept has been used in many ways by veterinary surgeons all over the world. When used as an integral part of an investigation of the suitability of a current feeding regime for a given herd the DHHPS has shown the technique to be very successful. The success is dependent on the technique being used as part of a wide ranging investigation using all the background information available. Blood analysis is only one part of the investigative jigsaw, albeit frequently a very important one. Profiles indicate how the feed is being utilised by the animal.

Frequently blood samples are interpreted in isolation and it is then that misleading or erroneous conclusions can be drawn. When used as a trouble shooting exercise samples are often taken as a last resort. Milk yield may have dropped in response to an inadequate feed intake and homeostasis will have restored blood parameters to within the normal range.

Early investigators became frustrated when the blood parameters did not reflect the theoretical balance of the ration. This was precisely missing the whole 
point of the exercise. Blood values tend to reflect the balance between input and output. Input depends so much on all factors affecting dry matter intake and subsequent digestion of nutrients. Blood samples 'ask the cow what they think of the ration'. Over the years computer calculated rations are found to be deficient for a whole variety of reasons previously discussed. Many nutritional advisers naively assume that feed analysis will always be correlated with productivity. The main reason still being that the cows, in question, do not achieve the dry matter intakes on which the whole ration formulation is based! This is where the training of the veterinary surgeon should allow them to make an invaluable contribution to nutritional management.

\section{Energy Balance}

Energy imbalance is by far the most common problem identified on DHHPS farms. Energy deficiency can result in reduction in productivity, numerous metabolic diseases and is now firmly established as making a major contribution to bovine infertility. The use of glucose as an indicator of energy balance was proposed by Payne et al (1970); Parker and Blowey (1976); Hewett 1974). In addition to glucose the DHHPS has promoted the use of BHB (Kelly, 1977) as an indicator of energy status. This parameter is now routinely used by all the government and private laboratories which offer a blood analysis service to veterinary practitioners. NEFA analysis has also been introduced, as a routine parameter and has proved useful particularly as an indicator of metabolic stress close to parturition and in early lactation.

\section{Protein Status}

Protein Status has become more relevant as there has been better understanding of protein requirements and metabolism. The balance between FME and ERDP has been recognised as essential for optimum rumen function and hence production. The recent upsurge of the use of maize silage in the Midlands and Southern England has resulted in many rations being short of ERDP. The evidence of association between excess dietary protein and infertility is equivocal. Probably it is the balance between energy and protein which is important (Staples 1995). 
High blood globulin values have on occasion identified herds with a high incidence of sub clinical or chronic disease. This has helped clarify whether low productivity in a herd was as a result of presence of disease rather than because of nutritional problems.

\section{Mineral Status}

The identification of low magnesium status has been one of the most common findings. The low blood magnesium status in cows before calving has frequently been associated with an increased incidence of milk fever in postparturient cows. Despite considerable publicity to farmers each year hypomagnesaemia continues to occur. Some farmers do find it difficult to ensure an adequate intake of magnesium to each cow on a daily basis.

The majority of dairy cows tested by DHHPS had adequate blood phosphate concentrations. There is evidence that many farmers supply extra phosphate minerals to their cows in the belief that it is closely associated with fertility. Many could save money as most purchased concentrate has a high mineral inclusion!

Trace element analysis has on occasion proved to be valuable. The significance of blood copper concentrations is currently under review (Telfer 1996). Low selenium status is not uncommon in dry cows and heifers. The importance of trace elements, however, must be kept firmly in perspective. Many farmers and possibly some veterinary surgeons believe that the only point of taking blood samples is to identify some trace element deficiency which will prove to be the cause of all the health and fertility problems on the farm! It is much more attractive to purchase a mineral to solve the problems rather than have to review the fundamentals such as management and basic nutrition. There are at the present time a number of agencies promoting trace element deficiency as the answer to many of the farmers problems.

The current trends in dairy cow nutrition to greater reliance on home grown forages, cereals and 'straights' may, indeed, increase the possibility of mineral imbalance. It will still remain as a possible area for investigation only when 
the much more basic and common problems of dry matter intake, energy balance and protein status have been considered.

\section{Dry period}

The DHHPS over the past twenty years has drawn particular attention to the importance of correct dry cow management. Farmers have tended to have the wrong impression of the dry period. Some have regarded it as a non productive period when management and nutrition can be neglected or at least given a low priority. In fact it has proved to be a crucial time for preparation for the next lactation. As well as the requirement for maintenance and pregnancy there is the additional requirement for the replenishment of reserves. The need for additional growth and development during the first two pregnancies must be taken into consideration. It is now acknowledged by many others, Bell (1995), that the transition from late pregnancy to early lactation is the key area which can influence health, productivity and fertility in the following lactation. During this period there is enormous metabolic challenge to the high yielding cow.

Almost every report from the DHHPS has emphasised the importance of dry cow management and the transition into early lactation. This has allowed veterinary surgeons to become involved in the preparation of the cows for parturition rather than simply being called to deal with dystocia and metabolic problems resulting from inappropriate dry cow management. Veterinary surgeons are most frequently assessing cows some weeks calved during their routine fertility visits and very seldom do they see dry cows especially during periods when they are at grass.

\section{Post sampling Meeting}

One of the major advantages of the DHHPS is getting the farmer, his nutritional adviser and his veterinary surgeon to meet together in order to discuss the results of the blood samples in light of all the other information available on the farm. Plans for the future, the setting of targets and goals and the date of the next meeting should all be key agenda items. Hutchison et al. (1998) suggested that some training on the organisation of, and participation in, such meetings might be helpful. Discussing the results by way of a telephone conversation is not nearly so satisfactory as having a meeting. If the veterinary surgeons really takes their 
involvement in preventive medicine seriously they should devote time to making sure such a meeting takes place and that they chair the proceedings. The post sampling discussion form, which is the minute of the meeting, should be completed on the farm and distributed to all interested parties. Farmers are much more likely to be willing to pay for advice when they receive written reports and fully documented records of decisions made and targets set.

The service which has been in operation for some twenty years can operate extremely well to the mutual benefit of all concerned. The success on an individual unit does depend very much on the enthusiasm of all the participants, particularly on the input of the veterinary surgeon involved. The service has been copied by several agencies in the UK. The Dairy Monitoring Scheme (Ward et al., 1996) is almost an exact copy and was started in association with a specialist who worked for many years on the DHHPS. The stated aim of this service is to get the feed adviser along side the veterinary surgeon on the farm. This service does not collect health and production data on a regular monthly basis. Another former feed specialist who had many years experience of the DHHPS runs a nutrition service which uses metabolic profiles (Hughes, 1998). Almost all the major feed firms operating in the UK offer some advisory service incorporating the use of metabolic profiles. Imitation is one of the sincerest forms of flattery!

\section{Education}

The survey of veterinary practitioners who were involved in the DHHPS came to the overwhelming conclusion that their under graduate education did not prepare them for giving nutritional advice on nutrition. Munro (1997) and Orpin and Piggot (1997) made a plea for better preparation of students in their undergraduate courses. In defence several of the veterinary schools do give some practical training in problem solving involving health and production on dairy farms, but perhaps it is not enough!

At the Royal (Dick) School of Veterinary Studies all students participate in a herd health rotation. As part of the programme they visit a farm, assess health and nutrition, take appropriate samples, write a report for the farmer, and have a discussion session with the farmer at the end of the week. 
The Royal Veterinary College has an elective for students interested in large animal medicine. Part of the time on the elective is devoted to cattle nutrition, and assessment of health and productivity. The author contributes to this elective.

Bristol incorporate on farm investigations of health and productivity during one of their final year rotations.

At Glasgow the author covers the DHHPS, and more specifically the use of metabolic profiles in the fourth year lecture course.

Liverpool run a very similar service to the DHHPS and undoubtedly the students will be exposed to these concepts in their undergraduate course.

New technological developments now make it possible to improve the quality of diagnosis, treatment and control of animal diseases and to enhance the quality of animal life. The DHHPS goes some way towards facilitating the maximum the use of the resources available on the farm using a 'whole farm' or holistic approach.

A multidisciplinary approach has many advantages when dealing with issues, which are at the interface of the disciplines of those giving advice. 
REFERENCES 


\section{REFERENCES}

Abe, A., Yamashita, S. and Noma, A. (1989). Clinical Chemistry, 35/4 552-554.

Adams, R.S., Stout, W.L. and Kradel, D.C. (1978). Use and limitations of Profiles in Assessing Health or Nutritional Status of Dairy Herds. Journal of Dairy Science, 61: 1671-1679.

Agricultural and Food Research Council (1990). Technical committee on response to nutrients. Report No 5. Nutritive requirements of ruminant animals: energy Nutrition Abstracts Review Series, B 60, 729 -804.

Agricultural and Food Research Council (1991). Technical committee on responses to nutrients. Report No 6. A reappraisal of the calcium and phosphorus of sheep and cattle. Nutrition Abstracts Review Series, B 61: 573.

Agricultural and Food Research Council (1992). Technical committee on response to nutrients. Report No 9. Nutritive requirements of ruminant animals: protein Nutrition Abstracts Review Series, B 62 787-835.

Agricultural and Food Research Council (1993). Energy and Protein Requirements of Ruminants. Technical committee on responses to ruminants, CAB International Wallingford UK.

Albright, J.L. (1993). Feeding behaviour of dairy cattle. Journal of Dairy Science, 76: $485-498$.

Allen, W.M. (1981). Nutritional diseases associated with grass. Veterinary Annual, 21: 106-103.

Allen, W.M. and Sansom, B.F. (1985). Milk fever and calcium metabolism. Journal of Veterinary Pharmacology \& Therapeutics, 8:19-29.

Andersson, L. and Lundstrom, K. (1983). Ketone bodies and glucose in blood and milk as indicators of energy balance in postparturient dairy cows. Proceedings of the fifth international conference on production diseases in farm animals, Uppsala, Sweden.

Andersson, L., Gustafsson, A.H. and Emanuelson, U. (1991). Effect of hyperketonaemia and feeding on fertility in dairy cows. Theriogenology, 36: 521-536.

Andrews, A.H. (1992). Bovine Medicine. Blackwell Scientific Publications p.221222. 
Andrews, A. H. (1993). The real cost of dairy cattle disease. British Veterinary Journal, 149: 511.

Anon (1976). Report on the Joint Exercise in Animal Health and Productivity. Ministry of Agriculture, Fisheries and Food Agricultural Development and Advisory Service and the British Veterinary Association. (Ministry of Agriculture, Fisheries and Food Publications).

Bailey, E.E. (1961). Saliva secretion and its relation to feeding in cattle. British Journal of Nutrition, 15: 443-451.

Baird, G.D., Hibbit, K.G. and Hunter, G.D. (1968). Biochemical aspects of Bovine Ketosis. Journal of Biochemistry, 107: 683-689.

Baird, G.D. (1982). Primary ketosis in the high yielding cow: clinical and subclinical disorders, treatment, prevention and outlook. Journal of Dairy Science, 65: 1-10.

Barb, C.R. (1999). The brain-pituitary-adipocyte axis: Role of leptin in modulating neuroendocrine function. Journal of Animal Science, 77: 1249-1257.

Barfoot, L.W., Cote, J.F., Stone, J.B. and Wright, P.A. (1971). An economic appraisal of a preventative medicine program for dairy herd health management, Canadian Veterinary Journal, 12: 2-10.

Bartley, E.E., (1976). Bovine saliva: Production and function. Weinberg, M.S. and Sheffner, A.L. (eds). Buffers in Rumen Physiology and Metabolism. Piscataway, N.J. Church and Dwight 61-81.

Barton, B.A., Rosario, A.H., Anderson,G.W. Grindle, B.P., and Carrol, D.J. (1996). Effects of dietary crude protein, breed, parity and health status on the fertility of dairy cows. Journal of Dairy Science, 79: 2225-2236.

Bauman, D.E. and Currie, W.B. (1980). Partitioning of nutrients during pregnancy and lactation: a review of mechanisms involving homeostasis and homeorhesis. Journal of Dairy Science, 63: 1514-1529.

Beauchemin, K.A. (1991). Ingestion and mastication of feed by dairy cattle. Veterinary Clinics of North America: Food Animal Practice, 7: 439-464.

Beede, D.K. (1991). Mineral and water nutrition. Veterinary Clinics of North America: Food Animal Practice. 7: 373-390.

Bell, A.W. (1995). Regulation of organic nutrient metabolism during transition from late pregnancy to early lactation. Journal of Animal Science, 73: 28042819. 
Bergman, E.D. (1973). Glucose metabolism in ruminants as related to hypoglycaemia and ketosis, Cornell Veterinarian, 63: 341-382.

Bertics, S.J., Grummer, R.R., Cadorniga-Valino, C. and Stoddard, E.E. (1992). Effects of prepartum dry matter intake on liver triglyceride concentration and early lactation. Journal of Dairy Science, 75: 1914.

Bines, J.A. (1985). Feeding Systems and food intake by housed dairy cows. Proceedings of the Nutrition Society, 44: 355-362.

Blaxter, K.L. (1979). The limits to animal production. Veterinary Record, 104: 5-9.

Block, E. (1984). Manipulating dietary ions and cations for prepartum dairy cows to reduce incidence of milk fever. Journal of Dairy Science, 67: 2939-2948.

Blood, D.C., Morris, R.S. Williamson, N.B., Cannon, C.M. and Cannon, R.M. (1978). A health programme for commercial dairy herds 1. Objectives and Methods. Australian Veterinary Journal, 54: 207-215.

Blood,D.C. (1979) The veterinarian in planned animal health and production. Canadian Veterinary Journal, 20:341-347.

Blood, D.C., Radostits, O.M. and Henderson, J.A (1983). Veterinary Medicine, ed 6, London, Bailliere Tindall p 974-983.

Blood, D.C., Radostits, O.M. (1989). In Veterinary Medicine, ed. 7 Bailliere and Tindall, pp.1120-1126.

Blowey, R.W. (1972). Metabolic profiles: some aspects of their use and interpretation in the field. In: Veterinary Annual, 13th edition pp.21-30 J. Wright Ltd. Bristol.

Blowey, R.W., Wood, D.W., and Davies, J.R. (1973). A nutritional monitoring system for dairy herds based on blood glucose, urea and albumen levels. Veterinary Record, 92:691-696.

Blowey, R.W. (1975). A practical application of metabolic profiles. Veterinary Record, 97: 324-7.

Blowey, R.W. (1986). An assessment of the economic benefits of a mastitis control scheme. Veterinary Record, 119 551-553.

Blowey, R.W. and Sharp, M.W. (1988). Digital dermatitis in dairy cattle. Veterinary Record, 122:505-508. 
Blowey, R.W. (1992). Milk Quality In: Bovine Medicine. Ed Andrews, A.H. Blackwell Scientific Publications pp.329-334.

Blowey, R.W. (1992). Metabolic profiles In: Bovine Medicine. Ed. Andrews, A.H. Blackwell Scientific Publications pp 601-606.

Blowey, R.W. and Edmondson, P. (1995) Mastitis Control in Dairy Herds. Farming Press Miller Freeman Professionals Ltd Ipswich.

Booth, J.M. (1988). Update on mastitis. Control measures in England and Wales. How have they influenced the incidence and aetiology? British Veterinary Journal, 144: 316-422.

Borsberry, S. and Dobson, H. (1989). Periparturient diseases and their effect on reproductive performance in five dairy herds. Veterinary Record, 124: 217219.

Bourne, J., Donnelly, C.A., Cox, D.R., Gettinby, G., McInerney, J.R., Morrison, I.and Woodroffe, R. (2000). Bovine tuberculosis: towards a future strategy. Veterinary Record, 146: 207-210.

Bowden, D.M. (1971). Non-esterified fatty acids and ketone bodies in blood as indicators of nutritional status in ruminants: a review. Canadian Journal of Animal Science, 51: 1-13.

Brand, A., Noordhuizen, Y.H. and Schukken (1996a) In: Herd Health and Production Management in Dairy Practice. Wageningen Pers pp. 260-262.

Brand, A. Noordhuizen, Y.H. and Schukken (1996b). In: Herd Health and Production Management in Dairy Practice. Wageningen Pers pp.249-253.

Brand, A., Noordhuizen, Y.H. and Schukken (1996c). In: Herd Health and Production Management in Dairy Practice. Wageningen Pers pp.182-183.

Bramley, A.J, and Neave, F.K. (1975). Studies in the control of coliform mastitis in dairy cows. British Veterinary Journal, 131:160-169.

Brinley Morgan, W.J. and Richards, R.A. (1974). The diagnosis, control and eradication of bovine tuberculosis in Great Britain. Veterinary Record, 94 510-517.

Britt, J.H. (1992) Influence of nutrition and weight loss on reproduction and early embryonic death in cattle. Proceedings XV11 World Buiatrics Congress, 2: 143-151. 
Butler, E.J. (1963). The mineral element content of spring grass in relation o the occurrence of grass tetany and hypomagnesaemia in dairy cows. Journal of Agricultural Science, 60:329-340.

Butler, W.R. and Smith, R.D. (1989). Interrelationships Between Energy Balance and Postpartum Reproductive Function in Dairy Cattle. Journal of Dairy Science, 72: 767-783.

Butler, W.R. and Elrod, C.C. (1992). Reproduction in the high yielding dairy cow as related to energy balance and protein intake. Proceedings Eighth International Conference on Production Diseases in Farm Animals 240-252.

Butler, W.R., Cherney, D.J.R. and Elrod, C.C. (1995). Milk urea nitrogen (MUN) analysis: field trial results on conception rates. Proceedings 57th Cornell nutrition conference for feed manufacturers: 89-95.

Butler, W.R., Calman, J. and Beam, S.W. (1996). Plasma and milk urea nitrogen in relation to pregnancy rate in lactating dairy cattle. Journal of Animal Science, 74: no $4858-865$.

Call, J.W., Butcher, J.E. and Shupe, J.L. (1987). Clinical effects of low dietary phosphorus in feed given to lactating dairy cows. American Journal of Veterinary Research, 48: 133-136.

Canfield, R.W., Sniffen, C.J. and Butler, W.R. (1990). Effects of excess degradable protein on post partum reproduction and energy balance in dairy cattle Journal of Dairy Science, 73: 2342.

Campling, R.C. (1975). Systems of grazing management for dairy cattle. Pasture utilisation by the grazing animal. Occasional Symposium No 8 British Grassland, Society

Carstairs, J.A., Morrow, D.A. and Emergy, R.S. (1980). Postpartum reproductive function of dairy cows as influenced by energy and phosphorus status, Journal of Animal Science, 51: 1122-1130.

Caro, J.F., Sinha, M.K.., Kolacznski, J.W., Zhang, P.L. and Considine, R.V. (1996) Leptin: the tale of an obesity gene. Diabetes, 45: 1455-1462

Castle, M.E., MacDaid, E. and Watson, J.N. (1975). The effect of stocking rate and supplementary concentrate feeding on milk production. Journal of British Grassland Society, 28:137-143.

Castle, M.E., and Watkins, P. (1979). Modern Milk Production London and Boston, Faber \& Faber p 248. 
Cermak, J. (1990). Note on Welfare of Dairy Cows with Reference to Spatial and Comfort Aspects of design of cubicles. Proceedings of the VIth International Symposium on Diseases of the Ruminant, Digit pp 85-90 pub BCVA.

Chamberlain, A.T. and Wilkinson, J.M. (1996). Feeding the Dairy Cow, Chalcombe Publications.

Chalupa, W. and Ferguson (1988). The role of dietary fat in productivity and health of dairy cows In application of Nutrition in Dairy Practice, Proceedings of a symposium of the Dairy Production Medicine Group Trenton, N.J. Veterinary Learning Systems, 36-43.

Chalupa,W.and Sniffen,C.J. (1991). Protein and amino acid nutrition of dairy cattle Veterinary Clinics of North America: Food Animal Practice, 7:353-372.

Christensen, L.G. (1998). Possibilities for genetic improvement of disease resistance, functional traits and animal welfare. Acta Agriculture Scandinavica section A Animal Science, No. S29, pp.77-89.

Clarkson, M.J., Downham, D.Y., and Faull, W.B. (1996). Incidence and prevalence of lameness in dairy cattle. Veterinary Record, 138: 563-7.

Coggins, C.R.E. and Field, A.C. (1976). Diurnal variation in the chemical composition of plasma from lactating beef cows on three dietary intakes. Journal of Agricultural Science, 86: 595-602.

Collick, D.W., Ward, W.R. and Dobson, H. (1989). Associations between types of lameness and fertility. Veterinary Record, 125: 103-106.

Cote, J.F. (1963). Herd health practice Canadian Veterinary Journal, 4: 181-184.

Cote, J.F. and Anderson, N.G. (1986). Monitoring performance in dairy health management . Proceedings X1Vth World Buiatrics Congress, 1: 251-259.

Curtis, C.R., Erb, H.N. and Sniffen, C.J. (1983). Association of parturient hypocalcaemia with eight periparturient disorders in Holstein cows. Journal of American Veterinary Association, 183: 559-577.

Curtis,C.R., ERB, H.N., Sniffen, C.J. and Smith, R.D. (1984). Epidemiology of parturient paressis: prediposing factors with emphasis on dry cow feeding and management. Journal of Dairy Science, 67: 817-825.

Dairy Facts \& Figures (1998). National Dairy Council, 5-7 John Princes Street London 
Darwash, A.O., Lamming, G.E. and Wooliams (1999). The potential for identifying heritable endocrine parameters associated with fertility in post-partum dairy cows. Animal Science, 68: 333-347.

Davies, R.C. (1982). Effects of regular formalin footbaths on the incidence of foot lameness in dairy cattle. Veterinary Record, 111: 394.

Davies, T.H. (1976). The evolution of modern dairy cow grazing systems. ADAS Quarterly Review no 22: 275 -282.

DeGraves, F.J. and Fetrow, J. (1993). Economics of mastitis control in Veterinary Clinics of North America: Food Animal Practice: 9, No 3, 421-434.

Dobson, H. and Smith, R.F. (1998). Stress and subfertility. Reproduction in domestic animals, 33: No 3-4 pp.107-111.

Dodd, F.H., and Westgarth, D.R., Neave, F.K. and Kingwell, R.G. (1969). Mastitis -The strategy of control. Journal of Dairy Science, 52: 689-695.

Dohoo, I.R., Martin, S.W., Meek, A.H. and Sandals, W.C. (1983). Disease production and culling in Holstein-Friesian cows. 1 The data Preventive Veterinary Medicine, 1: 321-332.

Dohoo, I.R. and Martin, S.W. (1984). Disease, production and culling in HolsteinFriesian cows. Disease and production as determinants of disease. Preventive Veterinary Medicine, 2: 671-690.

Dulphy, J.P. and Van Os, M., (1996). Control of voluntary intake of precisionchopped silages by ruminants. Reproduction Nutrition Developments, 36: (2) 113-135.

Earle, D.F. (1976). A guide to scoring dairy cow condition. Journal of Agriculture Victoria, 74: 228-231.

Edmondson, P. and Blowey, R. (1998). Record analysis in mastitis investigation. In: Practice, Vol. 20 6: 297-303.

Eicher, R., Liesegang, A., Bouchard, E. and Tremblay, A. (1999). Effect of cowspecific factors and feeding frequency of concentrate on diurnal variations of blood metabolites in dairy cows. American Journal of Veterinary Research, 60: 1493 .

Elsley, F.W.H. (1978). Measures of metabolic activity In: The use of Blood Metabolites in Animal Production. pp.163-166, Occasional publication of British Society of Animal Production No 1. 
Enevoldsen, C., Grohn, Y.T. and Thysen, I. (1991). Sole ulcers in dairy cows: Association with season, cow characteristics, disease and production. Journal of Dairy Science, 74: 1284-1298.

Erb, H.N., Smith, R.D. and Oltenacu, P.A. (1985). Path model of reproductive disorders and performance, milk fever, mastitis, milk yield and culling in Holstein cows. Journal of Dairy Science, 68: 3337-3349.

Erfle, J.D., Fisher, L.J. and Sauer, F.D. (1974). Interrelationships between blood metabolites and an evaluation of their use as a criteria of energy status of cows in early lactation. Canadian Journal of Animal Science, 54: 293-303.

Erskine, R.J. (1991). Nutrition and Mastitis. In: Veterinary Clinics of North America: Food Animal Practice, 9: No 3 551-61.

Erskine, R.J. Eberhart, R.J. and Hutchinson, L.J. (1988). Incidence and types of clinical mastitis in dairy herds with high and low somatic cell counts. Journal of American Veterinary Medical Association, 192: 761-765.

Eskebo, I., Oltenacu, P.A., Vilson, B. and Nilsson, J. (1994). A disease monitoring system for dairy cows. Veterinary Record, 134: 270-273.

Esslemont, R.J. (1994). The operation of herd fertility and health schemes. Cattle Practice The Journal of the BCVA 137-150.

Esslemont, R.J. (1995). Economic appraisal of herd health schemes Veterinary Annual 35:243-280.

Esslemont, R.J. and Ellis, P.R. (1975). The Melbread Dairy Herd Health Recording Scheme, VEERU, University of Reading.

Esslemont, R.J., Stephens, A.J. and Ellis, P.R. (1982). The design of Daisy the dairy information system Proceedings 12th World Conference on Diseases of Cattle, Amsterdam 634-646.

Esslemont, R.J., Bailie, J.H. and Cooper, M.J. (1985). Fertility Management in Dairy Cattle, London, William Collins.

Esslemont, R.J. and Spincer, I. (1993). Report No 2 Daisy The Dairy Information System, University of Reading.

Esslemont, R.J. and Peeler, E.J.(1993). The scope for raising margins in dairy herds by improving fertility and health. British Veterinary Journal, 149: 537. 
Esslemont, R. J. and Kossaibati, M.A. (1996). Incidence of production diseases and other health problems in a group of dairy herds in England. Veterinary Record, 139: 486-490.

Esslemont, R.J. and Kossaibati, M.A. (1997). Culling in 50 dairy herds in England Veterinary Record, 140: 36-37.

Farm Animal Welfare Council (1997). Report on the Welfare of Dairy Cattle, FAWC, Government Buildings Tolworth Surrey.

Farmers Weekly (1995). What silage samples told us April 21-27.

Faull, W.B., Hughes, J.W., Clarkson, M.J., Downham, D.Y., Manson, F.J., Merritt, J.B., Murray, R.D, Russel, W.B., Sutherst, J.E., and Ward, W.R.(1996). Epidemiology of lameness in dairy cattle: the influence of cubicles and indoor and outdoor walking surfaces. Veterinary Record, 139: 130-136.

Ferguson, J.D. and Chalupa, W. (1989). Symposium: Interactions of nutrition and reproduction; Impact of protein nutrition on reproduction in dairy cows. Journal of Dairy Science, 72: 746-766.

Ferguson, J.D. (1991). Nutrition and fertility in dairy cows Veterinary Clinics of North America: Food Animal Practice7 no.2 483-507.

Ferguson, J.D. (1996). Diet production and reproduction in dairy cows. Animal Feed Science Technology, 59: 173-184.

Fisher, L.J., Donnelly, P.E., Hutton, J.B. and Duganzich, D.M. (1975). Relationships between levels of feeding and certain blood metabolites in dairy cows in mid lactation. Journal of Agricultural Science, 84: 29-37.

Fonseca, F.A., Britt, J.H., McDaniel, B.T., Wilk, J.C. and Rakes, A.H. (1983). Reproductive traits of Holsteins and Jerseys. Effects of age, milk yield and clinical abnormalities on involution of the cervix and uterus, ovulation, oestrus cycles, detection of oestrus, conception rates and days open. Journal of Dairy Science, 66: 1128-1147.

Foote, R.E (1996). Dairy cattle reproductive physiology research and managementPast progress and future prospects. Journal of Dairy Science, 79: 980-990.

Forbes, J.M. (1995). Voluntary intake: a limiting factor to production in high yielding dairy cows? British Society of Animal Science Occasional Publication, 19:13-19. 
Francis P.G. (1987). Mastitis control, a review Proceedings British Cattle Veterinary Association, 1986-87 p 83-91.

Fronk, T.J., Schultz, L.H. and Hardie, A.R. (1980). Effect of dry cow over conditioning on subsequent metabolic disorders and performance of dairy cows. Journal of Dairy Science, 63:1080-1090.

Garnsworthy, P.C. (1988). The effect of energy reserves at calving on performance of dairy cows. In: Garnsworthy, P.C. (ed): Nutrition and Lactation in the Dairy Cow. London, Butterworths p 157-170.

Gerloff, B.J. (1988). The Dry Cow - Resting and transitional phase. Veterinary Clinics of North America: Food Animal Practice 4 No 2: 379-390.

Gerloff, B.J. (1991). Implementation of nutritional consultation within a dairy practice. Veterinary Clinics of North America: Food Animal Practice 7: 621628.

Goodger, W. (1987). Dairy comp 305 program. Veterinary Clinics of North America: Food Animal Practice 3: 553-560.

Goodger, W.J. and Ruppanner, R. (1982a). Historical perspective on the development of dairy practice. Journal of American Veterinary Medical Association, 180:1294-1297.

Goodger, W.J. and Ruppanner, R. (1982b). Why the dairy industry does not make better use of veterinarians. Journal of American Veterinary Medical Association, 181: 706-710.

Goodger, W.J. and Kushman, J.E. (1985). Measuring the impact of different veterinary service programmes on dairy herd health and milk production. Preventive Veterinary Medicine, 3: 211-215.

Grant, R.J. and Albright, J.L. (1995). Feeding behaviour and management factors during the transition period in dairy cattle. Journal of Animal Science, 73: 2791-2803.

Greenhalgh, J.F.D., Reid, G.W. and Aitken, J.N. (1967). The effect of grazing intensity on herbage consumption and animal production. Journal of Agricultural Science Cambridge, 69: 219-223.

Greenhalgh, J.F. and Reid, G.W. (1969). The effects of grazing intensity on herbage consumption and animal production. Dairy cows grazed on two intensities on clean or contaminated pasture. Journal of Agricultural Science, Camb. 72: 223-228. 
Greenough, P.. and Vermunt, J.J. (1991). Evaluation of subclinical laminitis in a dairy herd and observations on associated nutritional and management factors. Veterinary Record, 128: 11-17.

Grohn, Y., Lindberg, L.A., Bruss, M.L. and Farver, T.B. (1983). Fatty infiltration of the liver in spontaneously ketotic dairy cows. Journal of Dairy Science, 66: $2320-2328$.

Grohn, Y.T., Erb, H.N., McCulloch, C.E. and Saloniemi, H.S. (1990). Epidemiology of reproductive disorders in dairy cattle: associations among host characteristics, disease and production. Preventive Veterinary Medicine, 8:25-39.

Grummer, R.R. (1993). Etiology of lipid-related metabolic disorders in periparturient dairy cows. Journal of Dairy Science, 76: 3882-3896.

Grummer, R. (1995). Impact of changes in. organic nutrient metabolism on feeding the transition dairy cow. Journal of Animal Science, 73: 2820-2833.

Grunsell, C.S., Penny, R.H.C., Wragg, S.R. and Allcock, J. (1969). The practicability and economics of veterinary preventive medicine. Veterinary Record, 84 :76.

Gunn, J. (1995). The relationship between bovine mastitis and somatic cell counts in dairy herds in Scotland. PhD Thesis. University of Glasgow.

Harrington, B.D. (1979). Preventive Medicine in Dairy Practice 174: 398-400.

Harrison, J. H., Hancock. D.D. and Conrad, H.R. (1984). Vitamin E and selenium for reproduction in the dairy cow. Journal of Dairy Science, 67:123-132.

Harrison, R.O., Ford, S.P. and Young, J. W. (1990). Increased milk production versus reproduction and energy status of high producing cows. Journal of Dairy Science, 73 :2759.

Hedges, V.J, Blowey, R., Packington, A., and Green, L.E., (2000). A longitudinal field trial of the effect of biotin on claw health in dairy cows; trial design, problems and solutions. Proceedings of the $11^{\text {th }}$ International Symposium on Lameness in Ruminants Italy.

Heinrichs, A.J., Buckmaster, D.R. and Lammers,B.P. (1999). Processing, mixing and particle size reduction of forages for dairy cattle. Journal of Animal Science, 77: 180-186. 
Heitzman, R.J., Hibbit, K.G. and Mather, I. (1972). Changes in hormone and metabolite concentrations in the blood of cows during the experimental induction of ketosis. British Veterinary Journal, 128: 347-353.

Henderson, J.A. (1960). The prospect before us. Canadian Veterinary Journal, 1: 39.

Herdt, T.H., Stevens, J.B., Linn, J. and Larson, V. (1981a). Influence of ration composition and Energy Balance on Blood B-Hydroxybutyrate (Ketone) and Plasma Glucose concentrations of Dairy Cows in Early Lactation. American Journal of Veterinary Research, 42: 1177-1180.

Herdt, T.H., Stevens, J.B., Olson, W.G. and Larson, V. (1981b). Blood Concentrations of B hydroxybutyrate in Clinically Normal Holstein-Friesian Herds and in those with a high prevalence of ketosis. American Journal of Veterinary Research, 42: 503-506.

Herdt, T.H. and Stowe, H.D. (1991). Fat soluble vitamin nutrition for dairy cattle. Veterinary Clinics of North American: Food Animal Practice, 7: 391-416.

Hewett, C. (1974). On the causes and effects of variations in the blood profiles of Swedish dairy cattle. Acta veterinary Scandinavia. Supplement 50:1-152.

Hibbit, K.G. (1979). Bovine Ketosis and its prevention. Veterinary Record, 105:1315.

Hidiroglou, M. (1979). Trace element deficiencies and fertility in ruminants. Journal of Dairy Science, 62: 1195-1206.

Higgins, R.J. and Anderson, W.S. (1983). Fat cow syndrome in a British dairy herd. Veterinary Record, 113 461-463.

Hill, A.W., Reid, I.M. and Collins, R.A. (1985). Observations on the influence of the level of liver fat on the outcome of experimental Escherichia coli mastitis in periparturient cows. Veterinary Record, 117: 549.

Hill, W.G., Thompson, R. and Woolliams, J. A. (1990). Proceedings 4th World Congress on Genetics as applied to Livestock Production Vol. XIV. Edinburgh University Press

Hill, W.G., Brotherstone, S. and Visscher, P.M. (1995). Current and future developments in dairy cattle breeding: a research viewpoint. British Society of Animal Science Occasional Publication 19:1-7.

Hillerton, J.E. (1997). Fifty years of UK research to control mastitis leading to the aetiology of mastitis today. Cattle Practice 5: part 3 247-250. 
Hippen, A.R., She, P., Young J.W., Beitz, D.C., Lindberg, G.L., Richardson, L.F. and Tucker, R.W. (1999) Alleviation of fatty liver in dairy cows with 14 day infusions of glucagons. Journal of Dairy Science, 82: 1139-1152.

Holmes, J.H.G. and Lambourne, L.J. (1970). The relation between plasma free fatty acids concentration and the Digestible Energy Intake of Cattle. Research in Veterinary Science, 11: 27-35.

Hoover, W. H. and Miller, T.K. (1991). Rumen digestive physiology and microbial ecology. Veterinary Clinics of North America: Food Animal Practice 7:311327.

Howe, K.S. (1988). The economics of veterinary services. British Veterinary Journal, 144:343-350.

Hughes, G (1998). Practical nutrition for veterinary surgeons. Cattle Practice 6 part 4 357-360.

Hughes, J. (2000). Cows and Cubicles In Practice 22: 231-239.

Hurley, W.L. and Doane, R.M. (1989). Recent Developments in the Roles of Vitamins and Minerals in Reproduction Journal of Dairy Science, 72: 784804.

Huszenicza, G., Haraszti, J., Molnar, L. and Solti, J. (1988). Some metabolic Characteristics of Dairy Cows with Different Post Partum Ovarian Function. Journal of Veterinary Medicine, 35: 506-515.

Hutchison, L.J., Holden, L.A. and Heald, C.W. (1998). Implementing Dairy Farm Consultant Teams. Proceedings of XX World Association of Buiatrics.

Ingraham, R.H., and Kappel, L.C. (1988). Metabolic Profile Testing. Veterinary Clinics of North America: Food Animal Practice Vol 4 No 2 391-411.

Johnson, C.L.(1986). Plane of nutrition. Principles and Practice of feeding dairy cows. NIRD Technical Bulletin No 8.

Johnston, L.A. and Chew, B.P. (1984). Peripartum changes of plasma and milk vitamin A and B carotene among dairy cows with or without mastitis. Journal of Dairy Science, 67: 1832-1840.

Jordan, E.R., and Fourdraine, R.H., (1993). Characterisation of the management practices of the top milk producing herds in the country. Journal of Dairy Science, 76: 3247-3256. 
Jorgensen, N.A. (1988). Impact of forage fibre content on digestion and digesta passage in lactating dairy cows. Journal of Dairy Science, 71:1556-1565.

Kauffman, W. (1976). Influence of the composition of the ration and the feeding frequency on $\mathrm{pH}$ regulation of the rumen and on feed intake in ruminants Livestock Production Science, 3: 103-114.

Kawata, K (1996). Factors influencing uterine involution and resumption of ovarian activity in post partum high-yielding dairy cattle: a review Veterinary Annual, 36: 346-359.

Kelly, J.M. (1977). Changes in serum B Hydroxybutyrate concentrations in dairy cows kept under commercial farm conditions. Veterinary Record, 101: 499502.

Kelly, J.M. (1984). Subclinical ketosis. Veterinary Annual 24th Issue Ed Grunsell pp 85-93.

Kelly J.M. (1988). Magnesium and milk fever In Practice 10: 168-170.

Kelly, J.M. (1997). The use of metabolic profiles in dairy cows. Irish Veterinary Journal, 50: No 8 494-496.

Kelly, J.M. (2000). Nutrition of the Dairy Cow in The Health of Dairy Cattle pp 4988 Blackwell Science Ltd.

Kelly, J.M. and Whitaker, D.A. (1982). A Dairy Herd Health and Productivity Service. Proceedings of the X11th World Congress on Diseases of Cattle 1: 659.

Kelly, J.M., Whitaker, D.A. and Smith, J.E. (1988). A Dairy Herd Health and Productivity Service. British Veterinary Journal, 144: 470-481.

Kelly, J.M., Whitaker, D.A. and Smith, J.E. (1992). The changing pattern of health problems since the introduction of milk quotas. Proceedings of XV11 World Buiatrics Congress, 2 51-56.

Kelly, J.M. and Whitaker, D.A. (2000). A multidisciplinary approach to dairy herd health and productivity management. British Society of Animal Science, Occasional Publication 26: Vol $1209-222$ ISBN 0906562341.

Kolver, E.S and Muller, L.D. (1998). Performance and nutrient intake of high producing Holstein cows consuming pasture or a total mixed ration. Journal of Dairy Science, 81:1403-1411. 
Kossaibati, M.A. and Esslemont, J. (1997). The cost of production diseases in dairy herds in England. Veterinary Journal, 154:41-51.

Kossaibati, M.A., Hovi, M.,and Esslemont, J. (1998). Incidence of clinical mastitis in dairy herds in England. Veterinary Record, 143: 649-653.

Kronfield, D.S., Donoghue, S., Copp, R.L., Stearns, F.M. and Engle, R.H. (1982). The nutritional status of Dairy Cows Indicated by Analysis of Blood. Journal of Dairy Science, 65: 1925-1933.

Krebs, J.R., Anderson, R., Clutton-Brock, T, Morrison, I. Young.D., Donnelly, C.A., Frost, S. and Woodroffe, R. (1997). Bovine Tuberculosis in cattle and badgers, London HMSO.

Lamming, G.E. and Darwash, A.O. (1998). The use of milk progesterone profiles to characterise components of subfertility in milked dairy cows. Animal Production Science, 59:175-190.

Leaver, J.D. (1985). Milk production from grazed temperate grasslands. Journal of Dairy Research, 52:313-334.

Leaver, J.D. (1988). Level and pattern of concentrate allocation to dairy cows. In: Nutrition and lactation in the dairy cow edited by P.C.Garnsworthy pp 315326 London, Butterworths.

Lee, A.J., Twardock, A.R., and BuBar, R.H. (1978). Blood Metabolic Profiles: Their use and Relation to Nutritional Status of Dairy Cows. Journal of Dairy Science, 61: 1652-1670.

Leech, F.B., Vessey, M.P., Macrae, W.D., Lawson, J.R., MacKinnon, D.J. and Morgan, W.J.B. (1964). Brucellosis in the British Dairy Herd. Animal Disease Survey Report. No. 4 H.M.S.O. London.

Leek, B.F. (1983). Clinical diseases of the rumen: a physiologist's view. Veterinary Record, $113: 10-14$.

Leng, R.A. (1965). Ketone metabolism in Normal and Underfed Pregnant Sheep and in pregnancy Toxaemia. Research in Veterinary Science, 6: 433-441.

Lesch, T.E., Troutt, H.F. and Jones, G.M. (1980). Expanding food-animal veterinary services through nutritional consultation. Journal of American Veterinary Medical Association, 176: 734-737. 
Lindsay, D.B. (1978). The effect of feeding pattern and sampling procedure on blood parameters In: The use of blood parameters in animal production pp.101-120 Occasional publication of British Society of Animal Production No 1.

Lissemore, K.D. (1989). The use of computers in dairy health programs: A review. Canadian Veterinary Journal, 30: 631-636.

Little, W. (1974). An effect of the stage of lactation on the concentration of albumin in the serum of dairy cows. Research in Veterinary Science, 17: 193-199.

Little, W.W., Sansom, B.F., Manston, R., and Allen, W.M. (1984). Importance of water for the health and productivity of the dairy cow. Research in Veterinary Science, 37 : 283-289.

Littledike, E.T., Young, J.W. and Beitz, D.C. (1981). Common metabolic diseases of cattle: ketosis, milk fever, grass tetany and downer cow complex. Journal of Dairy Science, 64:1465-1482.

Livesey, C.T. and Fleming, F.L. (1984). Nutritional influences on laminitis, sole ulcer and bruised sole in Friesian cows. Veterinary Record, 114: 510-512.

Lowman, B.G., Scott, N. and Sommerville, S (1973). Condition scoring of cattle. East of Scotland College of Agriculture Bulletin, No 6.

Lucey, S and Rowlands, G.L. (1984). The association between clinical mastitis and milk yield in dairy cows. Animal Production, 39:165-175.

Lucey, S., Rowlands, C.J. and Russel, A.M. (1986). The association between lameness and fertility in dairy cows. Veterinary Record, 118: 628.

McDonald, P., Henderson, A.R. and Heron, S.J.E. (1991). The Biochemistry of Silage, 2nd edn. Marlow, Chalcombe Publicatios.

McDonald, P., Edwards, R.A. , Greenhaugh, J.F. and Morgan, C.A. (1995). In: Animal Nutrition ed 5, Longman Scientific and Technical pp 465-479.

McDowell, L.R. (1996). Feeding minerals to cattle at Pasture. Animal Feed Science and Technology, 60: No. 3, 247-271.

McGuirk, B.J. (1997). The genus MOET breeding programme. Cattle Practice, 5: 263-265.

Manson, F.J. and Leaver, J.D. (1988). The influence of concentrate amount on clinical lameness in dairy cattle. Animal Production Science, 47: 185-190. 
Manson, F. J., and Leaver, J. D. (1989). The effect of concentrate: silage ratio and of hoof trimming on lameness in dairy cattle. Animal Production Science, 48: $15-21$.

Manston, R. and Allen, W.M. (1981). The use of blood chemistry in monitoring the health of farm livestock. British Veterinary Journal, 137: 241-247.

Manston, R., Rowlands, G.J., Little, W. and Collis, K.A. (1981). Variability of the blood composition of dairy cows in relation to the time of day. Journal of Agricultural Science, Cambridge, 96: 593-598.

Markusfield, O. (1987a). Inactive ovaries in high-yielding dairy cows before service: Aetiology and effect on conception. Veterinary Record, 121: 149-153.

Markusfield, O. (1987b). The Periparturient traits in seven high yielding dairy herds. Incidence rates, associated with parity, and interrelationships among traits. Journal of Dairy Science, 70:158-166.

Markusfield, O. (1995). Integrated Herd Health Programmes - The Israeli Experience Jornodas Techincas Y Symposiums "V111 Jornadas Tecnicas sobre el Ganado Bovino".

Markusfield, O., Galon, N. and Ezra, E. (1997). Body condition score, health, yield and fertility in dairy cows. Veterinary Record, 141: 67-72.

Marsh, R. (1978). Effects of mechanical treatment of forages on fermentation in the silo and on the feeding value of silage. New Zealand Journal of Experimental Agriculture, 6:271-278.

Martin, B., Mainland, D.D., Green, M.A., (1982). Virus: A computer programme for herd health and productivity. Veterinary Record, 110: 446-448.

Mather, E.C. and Melancon, J.J. (1981). The periparturient cow: a pivotal entity in dairy production. Journal of Dairy Science, 64: 1422-1430.

Mayer, E., Liebich, H.G., Armitan, R., Hagemeister, H. and Dirksen, G, (1986). Nutritionally induced changes in the ruminal papillae and in their capacity to absorb short-chain fatty acids in high producing cows. Proceedings of the XIV World Congress on Diseases of Cattle, 2 : 806-817.

Mayne, C.S and Thomas, C. (1986). Grazing management systems in Principles and Practice of Feeding Dairy Cows. NIRD Technical Bulletin 8.

Mayne, S. (1995). Implications of genotype x nutrition interactions for efficiency of milk production systems in Breeding and Feeding the high genetic merit cow. Occasional publication No 19 British Society of Animal Science. 
Menahan, L.A., Shultz, L.H.., and Hoehstra (1966). Factors affecting ketogenesis from Butyric acid in the Ruminant. Journal of Dairy Science, 49: 835-845.

Menzies, P.I., Meek, A.H., Stalbaum, B.W. and Etherington, W.G. (1988). An assessment of the utility of microcomputers and dairy herd software for dairy farms and veterinary practices. Canadian Veterinary Journal, 29 : 287-293.

Meuwissen, T. H. E. (1991). Expectation and variation of genetic gain in open and closed nucleus and progeny testing schemes. Animal Production, 53: 133141.

Milian-Suazo, F., Erb, H.N. and Smith, R.D. (1989). Preventive Veterinary Medicine 7: 19.

Milk Marketing Board (1956-57). Report of the Breeding and Production Organisation No 6 p 76.

Milk Marketing Board (1971-72). Report of the Breeding and Production Organisation No 22 p. 121.

Ministry of Agriculture, Fisheries and Food (1965). Animal Health: A Centenary 1865-1965. Her Majesty's Stationery Office, London.

Ministry of Agriculture Fisheries and Food (1975). Energy allowances and Feeding Systems for Ruminants. Technical Bulletin 33 H.M.S.O.

Ministry of Agriculture Fisheries and Food (2000). Tuberculosis home page http://www.maff.gov.uk.animalh/tb/default.htm.

Moller, K. (1978). Planned animal health and production service ( PAHAPS) in New Zealand dairy herds. Bovine Practitioner, 13: 26-30.

Morris, R. S. (1971). Economic aspects of disease control programmes for dairy cattle. Australian Veterinary Journal, 47: 358-363.

Morrow, D.A. (1963). Developing a dairy herd health programme. Veterinary Medicine, 58: 308-312.

Morrow, D.A. (1976). Fat cow syndrome. Journal of Dairy Science, 59: 1625-1629.

Munro, I.B. (1997). Preventive role in cattle production. Veterinary Record, 141: 255.

National Research Council (1989). Nutrient Requirements of Dairy Cattle 6th rev. Ed.Washington DC, National Academy Press. 
Natzke, R.P., Bray, D.R. and Everett, R.W. (1982). Cow preference for free stall surface material. Journal of Dairy Science, 65: 146-153.

Naylor, J.M., and Ralston, S.L. (1991). EDS. In: Large animal Clinical Nutrition by Mosby -Year Book, Inc.

Nebel, R.L. and McGilliard, M.L., (1993). Interactions of High Milk Yield and Reproductive Performance in Dairy Cows. Journal of Dairy Science, 76: 3257-3268.

Nelson, A.J., and Redlus, H.W. (1989). The key role of records in a production medicine practice. Veterinary Clinics of North America: Food Animal Practice, 5: 517-552.

Noordhuizen, J.P.T.M., Buurman, J., Wilbrink, H.J., Dobbelaar, P. (1986). VAMPP: A computer program to support veterinary herd health and production control on dairy farms. Proceedings. of the X1Vth World Congress on Buiatrics, 1: $260-265$.

Nott, S.B., Kauffman, D.E. and Speicher, J.A. (1981). Trends in the management of dairy farms since 1956, Journal of Dairy Science, 64: 1330-1343.

O'Callaghan, D. and Boland, M.P. (1999). Nutritional effects on ovulation, embryo development and the establishment of pregnancy in ruminants. Animal Science, 68:299-314.

O'Connell, J.M., Meaney, W.A. and Giller, P.S.(1991). An evaluation of four cubicle designs using cattle behaviour criteria. Irish Veterinary Journal, 4: 813.

Offer, N.W., Rooke, J.A., Dewhurst, R..J. and Thomas, C. (1993). Rapid assessment of silage fermentation characteristics by electrometric titration. Animal Production, 56: 423.

Oldham, J. D. (1984). Protein-energy relationships in dairy cows. Journal of Dairy Science, 67: 1090-1114.

Oldham, J.D. (1995). Protein requirements and responses: a UK perspective. British Society of Animal Science Occasional Publication 19:21-29.

Oltenacu, P.A., Britt, J.H., Braun, R.K., and Mellenberger, R.W. (1984). Effect of health status on culling and reproductive performance of Holstein cows. Journal of Dairy Science, 67:1783-1792. 
Oltenacu, P.A., Britt, J.H., Braun, R.K., and Mellenberger, R.W. (1984). Effect of health status on culling and reproductive performance of Holstein cows. Journal of Dairy Science, 67:1783-1792.

Orpin, P. and Piggot, I. (1997). Preventive role in cattle production. Veterinary Record, 141: 315 .

Owen, J. B. (1981). Complete diet feeding of dairy cows. In: Recent Developments in ruminant nutrition, edited by Haresign, W. and. Cole, D.J.A pp 312-324 London Butterworths.

Paglia, D.E. and Valentine, W.N. (1967). Clinical Chemistry, 70: 158.

Parker, B.J.N. and Blowey, R.W. (1976). Investigations into the relationship of selected blood components to nutrition and fertility of the dairy cow under commercial farm conditions. Veterinary Record, 96: 394-404.

Payne, J.M., Dew, A.W., Manston, R. and Faulks, M. (1970). The use of metabolic profile test in dairy herds. Veterinary Record, 87: 150-158.

Payne, J M., Rowlands, G.J., and Manston R. (1974). A statistical appraisal of the results of the metabolic profile tests on 191 herds in the B.V.A./A.D.A.S. joint exercise in animal health and productivity. British Veterinary Journal, 130: $30-34$.

Payne, J.M. (1989). Nitrogen or protein metabolism. In: Metabolic and Nutritional Diseases of cattle p 83 Blackwell Scientific Publications.

Peeler, E., Otte, M., and Esslemont, R.J. (1994). Interrelationships of periparturient diseases of dairy cows. Veterinary Record, 134: 129-132.

Phillippo, M., Humphries, W.R, Atkinson, T., Henderson, G.D. and Garthwaite, P.H. (1987). The effect of dietary molybdenum and iron on copper status, puberty, fertility and oestrus cycles in cattle. Journal of Agricultural Science, 109: 321-36.

Peterse, D.J. (1992). Foot lameness in Bovine Medicine, Blackwell Scientific Publications pp.353-363.

Pickard, D.W. (1978). Calcium, Magnesium and phosphorus in lactation and the dry period. In: The use of blood metabolites in animal production pp.49-52 British Society of Animal Production Occasional Publication No 1.

Pickard, D.W. (1986). Minerals and vitamins. In: Principles and Practice of Feeding Dairy Cows. Technical Bulletin No. 8 NIRD Ed. Broster. 
Plymm Forshell (1994). Metabolic profiles in milk. Cattle Practice, 2 part 4525.

Potter, M.J. and Broom, D.M. (1990). Behaviour and Welfare Aspects of Cattle Lameness in Relation to Building Design. Proceedings of the VI International Symposium on Diseases of the Ruminant Digit pp 80-84 Pub BCVA.

Pryce (1998). Profitable Lifetime Index (PLI) Farmers Weekly Dec 31.

Pryce, J.E., Esslemont, R.J., Thomson, R., Veerkamp, R.F., Kossaibati, M.A. (1998). Estimation of genetic parameters using health, fertility and production data from a management recording system for dairy cattle. Animal Science, 66 no Pt3 pp.577-584.

Rabiee, A.R., Lean, I.J., Gooden, J.M. and Miller, B.G. (1999). Relationships among metabolites influencing ovarian function in the dairy cow. Journal of Dairy Science, 82: 39-44.

Radloff, H. D., Schultz, L. H., Hoekstra, W.G. (1966). Relationship of Plasma Free Fatty Acids to Other Blood Components in Ruminants Under Various Physiological Conditions. Journal of Dairy Science, 49: 177-182.

Radostits, O.M. and Blood, D.C. (1985). Herd health: A textbook of health and production management of agricultural animals. W.B Saunders Company.

Radostits, O. M. (1986). Bovine herd health programmes - State of the art and science. Proceedings of the X111th World Congress on Buiatrics, 1: 233-250.

Radostits, O.M., Leslie, K.E., and Fetrow. J., (1994). In: Herd Health: Food Animal Production, W.B. Saunders Company.

Rakes, A. H. and Davenport, D.G. (1971). Responses of dairy cows to two systems of distributing annual concentrates over the lactation cycle. Journal of Dairy Science, 54: 1300-1304.

Randox International Quality Assessment Scheme General Clinical Chemistry. Randox Laboratories Ltd. Ardmore, Diamond Road, Crumlin, Co. Antrim.

Reid, I. and Roberts, J. (1982). Fatty liver in dairy cows. In Practice, 4: 164-169.

Reid, I., Rowlands, G.J., Dew, A.M., Collins, R.A., Roberts, C. J., Manston, R. (1983). The relationship between post-parturient fatty liver and blood composition in dairy cows. Journal of Agricultural Science, 1012: 473-480. 
Reinhardt, T.A., Horst ,R.L., Goff, J.P. (1988). Calcium, phosphorus and magnesium homeostasis in ruminants. Veterinary Clinics of North America: Farm Animal Practice 4 pp.331-350.

Reynolds, C.K. and Beever, D.E. (1995). Energy requirements and responses: a UK perspective. British Society of Animal Science Occasional Publication 19: $31-41$.

Risco, C.A., Drost, M., Thatcher, W.W., Savio, J. and Thatcher, M.J. (1994). Effects of calving related disorders on prostaglandin, calcium, ovarian activity and uterine involution in postpartum dairy cows. Theriogenology, 42: 183-203.

Roberts, C.J., Reid, I.M., Dew, S.M., Stark, A.J., Baird, G.D., Collins, R.A. and Mather, D (1978). The effects of underfeeding for six months during pregnancy and lactation on blood constituents, milk yields and body weight of dairy cows. Journal of Agricultural Science Cambridge, 90: 383-395.

Ropstad, E. (1988). Constituents of blood and milk in relation to fertility, nutrition and metabolic status in dairy cows. Thesis Norwegian College of Veterinary Medicine, Oslo.

Ropstad, E., Larsen, H.J. and Refsdal, A.O. (1989). Immune function in dairy cows related to energy balance and metabolic status in early lactation. Acta Veterinaria, Scandinavica, 30: 209-219.

Rowlands, G.J. (1978). Changes in concentration of serum albumin in dairy cow at calving and their possible significance in relation to milk yield and fertility during lactation. In Blood Profiles in Animal Production Occasional Publication of British Society of Animal Production No 1 Ed. D. Lister.

Rowlands, G.J. (1980). A review of variations in the concentrations of metabolites in the blood of beef and dairy cattle associated with physiology, nutrition and disease with particular reference to the interpretation of metabolic profiles. World Review of nutrition and dietetics, 35:172-235.

Rowlands, G.J., Russell, A.M., Williams, L.A., (1983). Effects of season, herd size, management system, and veterinary practice on the lameness incidence in dairy cattle. Veterinary Record, 113: 441.

Rowlands, G.J., Lucey, S. and Russell, A. M. (1986). Susceptibility to disease in the dairy cow and its relationship with occurrences of other diseases in the current or preceding lactation. Preventive Veterinary Medicine, 4: 223-234.

Ruckebusch, Y., Phaneuf, L.P., and Dunlop, R. (1991). Physiology of Small and Large animals. Philadelphia, B. C. Decker. 
Ruckebusch, Y., Phaneuf, L.P., and Dunlop, R. (1991). Physiology of Small and Large animals. Philadelphia, B. C. Decker.

Russel, A.J.F., Doney, J.M. and Reid, R.L., (1967). The use of biochemical parameters in controlling nutritional state in the pregnant ewes, and the effect of underfeeding on lamb birth-weight. Journal of Agricultural Science, Cambridge, 68: 351-358.

Russel, A.J.F., Peart, J.N., Eadie, J., MacDonald, A.J. and White, I.R. (1979). The effect of energy intake during late pregnancy on the production from two genotypes of suckler cow. Animal Production, 28: 309-327.

Russel, A.J.F. and Wright, I.A. (1983). The use of blood metabolites in the determination of energy status in beef cows. Animal Production, 37: 335343.

Russell, A.M., Rowlands, G.J., Shaw, S.R and Weaver, A.D. (1982). Survey of lameness in British dairy cattle. Veterinary Record, $111: 155-160$.

Russell, A.M. and Rowlands, G.J. (1983). Cosreel: Computerised recording system for herd health information management. Veterinary Record, 112:189-193.

Schnurrenberger, P.R. (1979). Defining preventive medicine in veterinary practice. J. American Veterinary Medical Association, 174: 373-380.

Schmidt, G.H., Smith, T.R. (1986). The use of dairy improvement testing programs by dairy farmers. Journal of Dairy Science, 69: 3156-3164.

Schwalm, J.W., Waterman, R., Shook, G.E. and Schultz, L.H. (1971). Blood metabolite interrelationships and changes in mammary gland metabolism during subclinical ketosis. Journal of Dairy Science, 55:58-64.

Scottish Farm Buildings Investigation Unit (1985). Annual Farm Building Cost Guide $S F B I$, Aberdeen.

Scott, P.R. (1982). Fat metabolism in the high yielding dairy cow and its relationships to production disease. MPhil Thesis University of Edinburgh.

Seegers, H., Beaudeau, F., Fourichon, C. and Bareille, N. (1998(. Reasons for culling in French cows. Preventive. Medicine, 36: 257-271.

Siegel, M and Treu (1982). American Association of Clinical Chemistry.

Shanks, R.D., Freeman, A.E. and Dikinson, F.N. (1981). Postpartum distribution of costs and disorders of health. Journal of Dairy ScienceI, 64: 683-688. 
Shultz, L.H. (1971). Management and nutritional aspects of ketosis. Journal of Dairy Science, 54: 962-973.

Slyter, L.L. (1976). Influence of acidosis on rumen function. Journal of Animal Science, 43: 910-929.

Smith, K.L., Harrison, J.H., Hancock, D.D., Todhunter, D.A. and Conrad, H.R. (1984). Effect of vitamin E and selenium supplementation on incidence of clinical mastitis and duration of clinical symptoms. Journal of Dairy Science, 67: $1293-1300$.

Somner, H. (1975). Preventive medicine in dairy cows. Veterinary Medical Review 1: 42-63.

Sprecher, D.J., Hostetler, D.E., and Kaneene, J.B. (1997). A lameness scoring system that uses posture and gait to predict dairy cattle reproductive performance Theriogenology, 47: No 6 pp 1179-1187.

Staples, C.R., Thatcher, W.W., Burke, J.M. (1995). Influences of dietary energy, fat, and protein on reproductive performance of lactating dairy cows. Proceedings 1Xth International Conference on Production Diseases in Farm Animals 204-221.

Stephens, A.J., Esslemont, R.J. and Ellis, P. (1982). Daisy in veterinary practice. Planned animal health and production services and small computers. Veterinary Annual, 22: 6-17.

Studer, V.A., Grummer, R.R. and Bertics, S.J. (1993). Effect of prepartum propylene glycol on periparturient fatty liver in dairy cows. Journal of Dairy Science, 76: 2931-2939.

Suttle, N.F. (1986). Problems in the diagnosis and anticipation of trace element deficiencies in grazing livestock Veterinary Record, 119: 148-152.

Suttle, N.F. (1993). Overestimation of copper deficiency Veterinary Record, 1:123124.

Sutton J.D., (1986). Milk Composition. In: Principles and Practice of Feeding Dairy Cows pp.203-218 NIRD Technical Bulletin No 8.

Sutton, J.D., Hart, I.C., Morant, S. V., Schuller, E. and Simmonds, A.D. (1988). Feeding frequency for lactating cows: diurnal patterns of hormones and metabolites in peripheral blood in relation to milk-fat concentration. British Journal of Nutrition, 60:265-274. 
Swann, M. (1975). Report of the Committee of Enquiry into the Veterinary Profession. H.M.S.O. London.

Swanson, L.V., (1989). Discussion - interaction of nutrition and reproduction. Journal of Dairy Science, 72: 805-814.

Targowski, S.P. (1983). Role of immune factors in protection of the mammary gland. Journal of Dairy Science, 1781-1789.

Telfer, S.B. (1996). The use of caeruloplasmin activities and plasma copper concentrations as indicators of copper status in cattle. Proceedings of the $X ! X$ Buiatrics Conference, Vol 2 pp 402-404.

Thompson, J.R., Pollack, E.J. and Pelissier, C.L (1983). Inter-relationships of parturition problems, production of subsequent lactation, reproduction and age at first calving. Journal of Dairy Science, 66:1119-1127.

Thrusfield, M. (1986). Veterinary Epidemiology page 8 Pub Butterworths.

Toussaint-Raven, E. (1973). Lameness in cattle and foot care. Netherlands Journal of Veterinary Science, 5: 105-111.

Treacher, R. J. (1978). Dietary protein levels and blood composition in dairy cattle. In The Use of Blood Metabolites in Animal Production p133 Occasional Publication of British Society of Animal Production, No 1.

Trevaskis, L.M. and Fulkerson, W.J. (1999). The relationships between various animal and management factors and milk urea and its association with reproductive performance of dairy cows grazing pasture. Livestock Production Science, 57: No3 pp 255-265.

Trinder, N., Woodhouse, C. D. and Renton, C. P. (1969). The effect of Vitamin E and selenium on the incidence of retained placentae in dairy cows. Veterinary Record, 83: 550-553.

Udomprasert, P. and Williamson, N.B. (1990). The Dairy Champ program: a computerised recording system for dairy herds. Veterinary Record, 127: 256262.

Vaillancourt, J.P., Martineau, G., Morrow, M., Marsh, W. and Robinson, A (1991). Construction of questionnaires and their use in Veterinary Medicine, Proceedings Society for Veterinary Epidemiology and Preventive Medicine, 94-106. 
VanDrop, T.E., Dekkers, D.C.M., Martin, S.W. and Noordhuizen, J.P.T.M. (1998). Genetic parameters of health disorders, and relationships with 305 day milk yield and conformation traits of registered Holstein cows. Journal of Dairy Science. 81: No 8 pp 2264-2270.

Van Saun, R. J. (1991). Dry cow nutrition. Veterinary Clinics of North America: Food Animal Practice, 7:599-620.

Van Soest, P.J., Mertens, D.R. and Deinum, B. (1978). Preharvest factors influencing the quality of conserved forage. Journal of Animal Science, 47: 7112-720.

Vazquez-Anon, M., Bertics, S., Luck, M. and Grummer, R.R. (1994). Peripartum liver triglyceride and plasma metabolites in dairy cows. Journal of Dairy Science, 77: 1521.

Veenhuizen, J.J., Drackley, J.K., Richard, M.J., Sanderson, T.P., Miller, D.L. and Young, J.W. (1991). Metabolic changes in blood and liver during the development and the treatment of experimental fatty liver and ketosis in cows. Journal of Dairy Science, 74: 4238.

Veerkamp, R.F., Simm, G. and Oldham, J.D. (1995). Genotype by environmental interactions: experiences from Langhill. British Society of Animal Science Occasional publication 19:59-66.

Ward, W.R., Murray, R.D., White, A.R. and Rees, E.M. (1995). The use of blood biochemistry for determining the nutritional status of dairy cows. In Recent Advances in Animal Nutrition. Nottingham University Press Ed Garnsworthy, P.C. and Cole, D.J.A. pp 29-51.

Ward, W.R., Murray, A.R., White, A.R. and Rees, E.M. (1996). Blood biochemistry and nutrition of dairy cows. Proceedings World Buiatrics Congress Vol 2pp 348-352.

Wassell, T.R. (1993). An Investigation into the factors affecting the adoption of Dairy Herd Health Schemes by Veterinary Surgeons and Dairy Farmers. $P h D$ Thesis University of Brighton.

Wassell, T.R. (1995). A blue print for the Implementation of a Dairy Herd Health Scheme Bovine Practioner, 29. 
Wassell, T.R. and Esslemont, R.J. (1992). Survey of the operation of dairy herd health schemes by veterinary practices in the United Kingdom. Veterinary Record, 130: 260-263.

Weaver, L.D. (1987). Effects of nutrition on reproduction in dairy cows. Veterinary Clinics of North America: Food Animal Practice No: 513-532.

Webster, J. (1993). Understanding the Dairy Cow ch 6 p.161. Blackwell Scientific Publications.

Webster, J (1995). Welfare considerations in the future selection and management strategies Breeding and feeding the High Genetic Dairy Cow Occasional Publication No 19. British Society of Animal Science.

Wentink, G.H., Rutten, V.P.M.G., and Whensing, T.H. (1996). Nutrition, metabolic disease and immunity in dairy cows Proceedings X1X World Buiatrics Congress 337-339.

West, H.J. (1989). Liver function in dairy cows in late pregnancy and early, lactation. Research in Veterinary Science, 46:231-237.

West, H. J. (1990). Effect on liver function of acetonaemia and the fat cow syndrome in cattle. Research in Veterinary Science, 48: 221-227.

Whitaker, D.A. (1978). A fertility control programme in dairy cows in New South Wales. British Veterinary Journal, 136: 214-221.

Whitaker, D.A. (1998). Are links between between blood urea and fertility in cattle a diversion from reality? Cattle Practice, 6: 399-403.

Whitaker, D.A. (1999). Trace Elements - The real role in dairy cow fertility. Cattle Practice 7 part 3 pp 239-241.

Whitaker, D.A. (2000). Use and interpretation of metabolic profiles in Health of Dairy Cattle. Blackwell Science Ltd.

Whitaker, D.A., and Kelly, J.M. (1982). Incidence of clinical and subclinical hypomagnesaemia in dairy cows in England and Wales. Veterinary Record, 110: $450-451$.

Whitaker, D.A., Kelly, J.M., and Smith, E.J., (1983). Incidence of lameness in dairy cows. Veterinary Record, 113: 60-62. 
Whitaker, D.A., Kelly, J.M. and Smith, E.J., (1983). Sub-clinical ketosis and serum beta-hydroxybutyrate levels in dairy cattle. British Veterinary Journal, 139: 462-463.

Whitaker, D.A., da Rosa, G.O., Smith, E., and Kelly, J.M. (1993). Some effects of nutrition and management on the fertility of dairy cattle. Veterinary Record, 133: 61-64.

Whitaker, D.A., Kelly, J.M. and Smith, S. (2000). Disposal and disease rates in 340 British dairy herds. Veterinary Record, 146:363-367.

Wildman, E.E., Jones, G.M. and Wagner, P.E. (1982). A dairy cow body condition scoring system and its relationship to selected production characteristics. Journal of Dairy Science, 65: 494: 501.

Wilesmith, J.W., Francis, P.G. and Wilson, C.D. (1986). Incidence of clinical mastitis in a cohort of British dairy herds, Veterinary Record, 118: 199-204.

Wilkinson, J.M. (1988). Silage UK 6th ed. Chalcombe Publications, Marlow Bottom, Bucks, pp 1-185.

Wilkinson, J.M. and Stark, B.A. (1992). Silage in Western Europe Chalcombe Publications.

Williams, L.A., Rowlands, G.L. and Russell, A.M. (1986). Effect of wet weather on lameness in dairy cattle. Veterinary Record, 118: 259-264.

Williamson, N.B. (1986). The use of Computerised Recording Systems in Dairy Health and Management Programs. Proceedings of the XIIIth World Congress on Buiatrics, Dublin 593-600.

Wilson, C.D. and Kingwell, R.D. (1975). International Dairy Federation, Annual Bulletin, Document 85 p 422.

Wise, J. (1987). US market for food animal veterinary services. Journal of Veterinary Medicine Association, 190: 1530-1533.

Wood, P.D.P. (1980). A note on the lactation curves of some high yielding British Friesian cows. Animal Production, 30: 299-302.

Young, G.B., Lee, G.J., Waddington, D., Sales, D.I., Bradley, J.S. and Spooner, R.L. (1983). Culling and wastage in dairy cows in East Anglia. Veterinary Record, 113: 107. 


\section{Appendices}




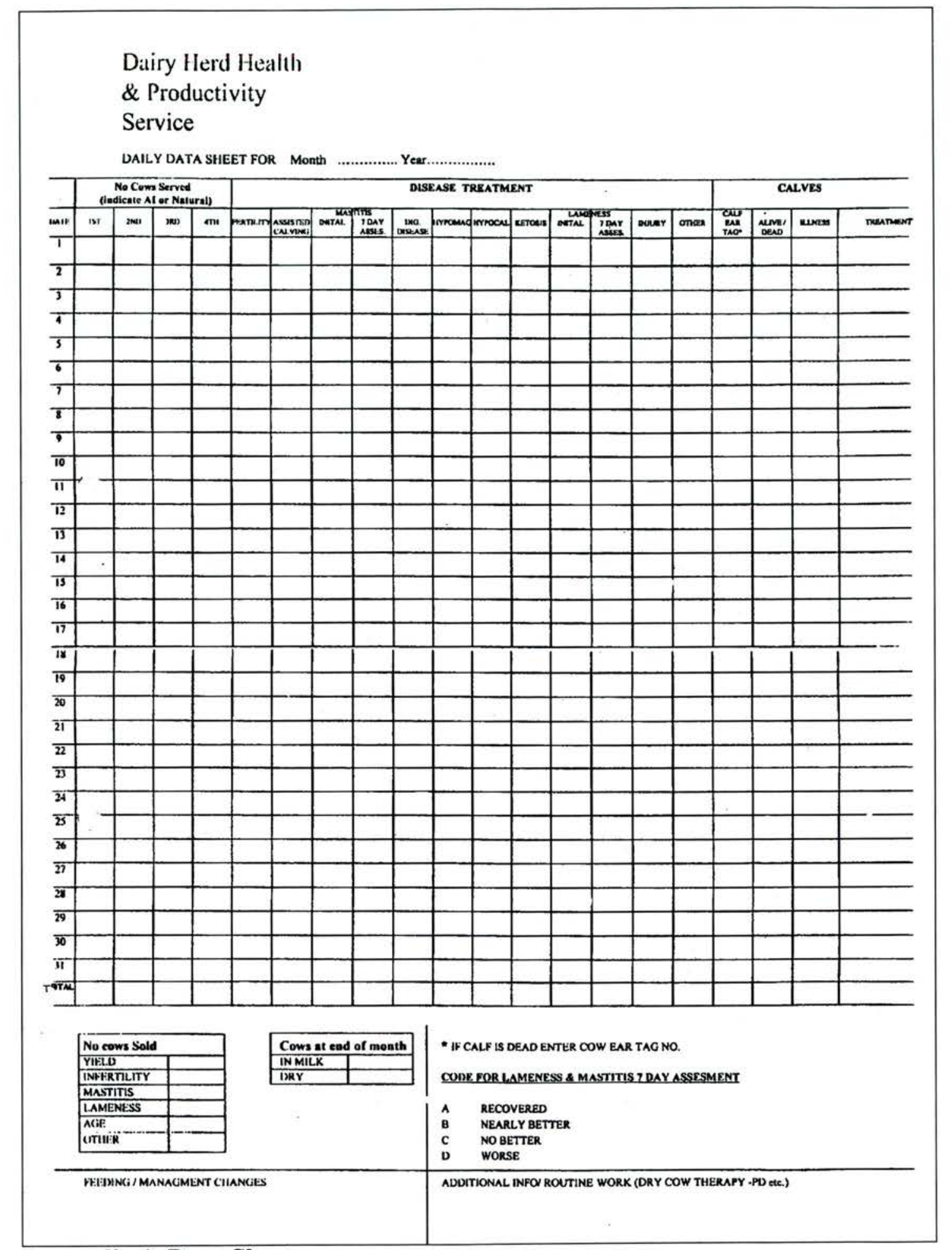

Appendix 1 Barn Sheet 


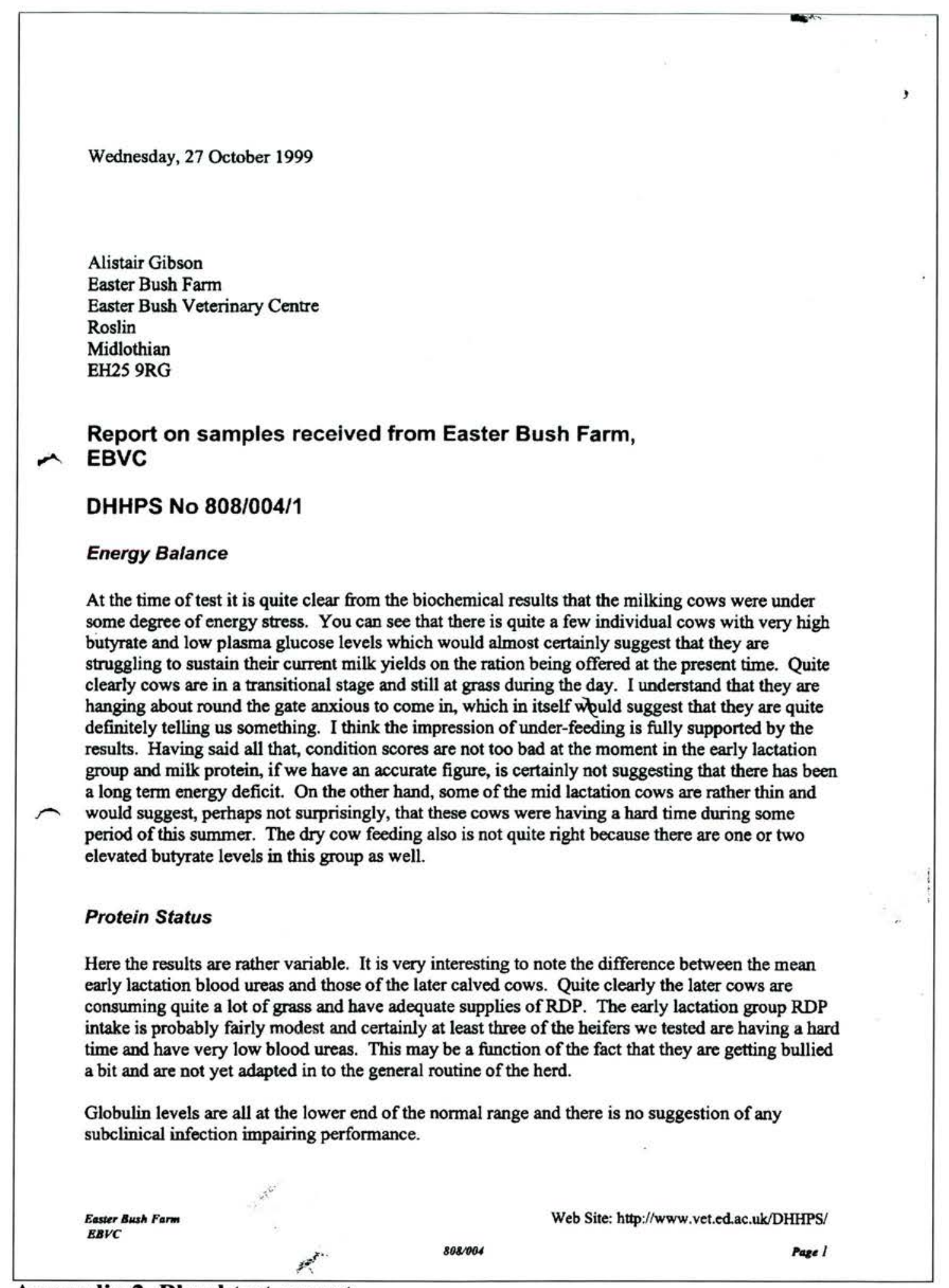

Appendix 2 Blood test report 


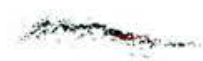

\section{Mineral Status}

Magnesium levels are again variable with one or two borderline results. Again, I think low magnesium in one or two individual cows is a function of reduced DM intake rather than the fact that the magnesium content of the diet is inadequate. Phosphate levels are all satisfactory.

On this occasion we have looked at the trace elements and perhaps it is not surprising to see a few low coppers creeping in again. I do not think coppers are sufficiently low to merit further copper supplementation, but it is interesting to note that the mid lactation group who are probably relying a fair bit on the grass at the present time, do have a low mean copper concentration. One or two dry cows are also low in copper. Glutathione peroxidase levels are all within the normal range and this would suggest that selenium intake is satisfactory.

\section{Conclusion}

This has been an interesting test and the main points coming from it are:

1. Milking cows are all currently short of energy and need to have more feed as soon as possible. I would have thought going on to the winter diet would be the most sensible way ahead.

2. Dry cow preparation again does not look to be satisfactory at the moment.

3. Clear evidence from blood urea nitrogens that the heifers are finding it difficult to adapt to the routine of the herd and are certainly not attaining satisfactory DM intakes at the present time.

4. Copper levels are not drastically low but should be monitored carefully at subsequent tests.

It would be invaluable to do another test in perhaps three or four weeks when cows are fully established on their winter diet.

Kind regards.

Yours sincerely

JM Kelly MRCVS

Copies: $\quad$ Colin Penny LAPTU

Donald Lawson 


\section{Relevant}

Publications 
Reprinted from The Veterinary ReCord, December 17, 1977

\title{
Changes in serum B hydroxybutyrate concentrations in dairy cows kept under commercial farm conditions
}

\author{
J. M. KELly, bvms, Mrcvs, Department of Animal Health, Royal (Dick) School of Veterinary Studies, Veterinary Field \\ Station, Easter Bush, Roslin, Midlothian
}

Veterinary Record (1977). 101. 499-502

$\beta$ hydroxybutyrate (BHB) serum concentrations were measured at regular intervals throughout a lactation in groups of animals from three commercial dairy herds. The period of study covered all the major seasonal management changes. BHB levels changed significantly only when the dietary intake of the cows was altered either in quantity or quality. The changes in concentrations of serum BHB were of particular interest during the two graxing seasons when the deterionting quality of the pasture was reflected in significantly higher concentrations. It is considered that serum BHB concentrations are worthy of further investigation as a parameter for inclusion in preventive medicine monitoring schemes for commercial dairy herds.

As milk yields from dairy cows increase the search for new and accurate criteria for assessing the optimum nutrient intake for dairy cattle under commercial farm conditions becomes more urgent. Not only must the diet be capable of permitting the cow to achieve optimum yields but it must be adequate in quality and quantity and sufficiently well balanced in order to preserve the animal's health.

In recent years many practitioners have used the metabolic profile (Payne 1970) or the modified system introduced by Blowey (1973) as an aid to monitoring the nutritional status of dairy cattle. Both these tests use blood or plasma glucose as the sole parameter for assessing energy status. Kronfield (1972) and Parker (1976) are, however, among the many workers to observe that there is not always a constant relationship between blood glucose concentrations and energy balance.

Other biochemical indices which have been used to asses the adequacy of energy intake in ruminants include plasma non-esterified fatty acid (NEFA), ketone, cholesterol and triglyceride concentrations. Earlier experiments, mainly on sheep, using some of these parameters are reviewed by Bowden
(1971). Russel and others (1967) and Foot and others (1973) reported the use of plasma ketone concentrations to assess energy deficits in ewes in late pregnancy.

As a result of these reports an initial study was made of serum $\beta$ hydroxybutyrate (BHB) concentrations in dairy cattle. BHB is the ketone body which is present in the greatest quantity in the blood of normal, well fed animals, Menahan (1967). Most previous reports of BHB levels in dairy cows, Robertson (1953), Heitzman (1972), Erfle (1974) and Fisher (1975) have been on experimental animals and cover only a restricted period of lactation. In this study groups of cows from well managed commercial farms were sampled throughout a lactation covering all the major seasonal management changes.

\section{Materials and methods}

Eight cows, calving within an interval of one week of each other during December 1974, from each of three commercial dairy herds, (A, B and C) were sampled at seven day intervals from three weeks before calving and for the first six weeks of lactation and then at 14-day intervals from January until August 1975. A separate group from herd A and two separate groups from herd B were examined at weekly intervals from September 1975 until May 1976 to cover periods of nutritional change in autumn and winter.

All samples were obtained from the jugular vein and on each occasion the visit was made at the same time in relation to the morning concentrate feed. Blood samples were collected into evacuated tubes, one containing an oxalate fluoride mixture and the other no additive. Samples were taken to the laboratory without delay and plasma glucose estimations were made on the same day. Sera were separated and frozen.

The samples were analysed for plasma glucose, serum albumin, total protein, globulin, non-esterified fatty acids (NEFA), calcium, magnesium and inorganic phosphate using standard methods (Parker 1976). Serum BHB concentrations 
TABLE 1 : Diets during periods of winter feeding

\begin{tabular}{|c|c|c|}
\hline Group & Ration & $\begin{array}{l}\text { ME Ef Ration } \\
\text { as Percentage of Requirement: }\end{array}$ \\
\hline $\begin{array}{l}\text { Herd A } \\
\text { Group 1 } \\
\text { Group } 2\end{array}$ & $\begin{array}{l}\text { Silege, hay, } 4 \text { lbs beriey } \\
+16 \text { per cent protein concentrate } \\
\text { Silege, hay, } 4 \text { lbs barley } \\
+16 \text { per cent protein concentrate }\end{array}$ & $\begin{array}{l}100 \text { to } 105 \text { per cent } \\
92 \text { to } 95 \text { per cent }\end{array}$ \\
\hline $\begin{array}{l}\text { Herd B } \\
\text { Group 1 }\end{array}$ & $\begin{array}{l}\text { Silage + brewer's grains. } 4 \text { lbs } \\
\text { berioy }+16 \text { per cent protein } \\
\text { concentrate }\end{array}$ & 100 to 105 per cent \\
\hline Group 2 & $\begin{array}{l}\text { Autumn grass then kale } \\
\text { changing to silege }+8 \text { Ibs barley } \\
+18 \text { per cent protein concentrate } \\
\text { Silege }+ \text { brewers grains }+8 \text { lbs } \\
\text { barley }+18 \text { per cent protein } \\
\text { concentrate }\end{array}$ & $\begin{array}{l}85 \text { to } 90 \text { per cent } \\
\text { increasing to } 100 \text { per cent } \\
100 \text { to } 105 \text { per cant }\end{array}$ \\
\hline $\begin{array}{l}\text { Herd C } \\
\text { Group 1 }\end{array}$ & $\begin{array}{l}\text { Silege + beet puip + } 18 \text { per cent } \\
\text { protein concentrate }\end{array}$ & 85 to 95 per cent \\
\hline
\end{tabular}

TABLE 2: Herd A Group 1 sampled weekly between January to August 1975. Elghe cows mean values and standerd deviations

\begin{tabular}{|c|c|c|c|}
\hline $\begin{array}{l}\text { Teast } \\
\text { No }\end{array}$ & $\begin{array}{l}\text { Event prior } \\
\text { to sampling }\end{array}$ & $\begin{array}{l}\text { Plasma Glucose } \\
\text { mg per } 100 \mathrm{ml}\end{array}$ & $\begin{array}{l}\text { Sorum BHB } \\
\text { me per } 100 \mathrm{ml}\end{array}$ \\
\hline $\begin{array}{l}1 \\
2 \\
2 \text { to } 4 \\
4 \\
4 \text { to } 14 \\
14 \\
15 \\
16 \\
17 \\
17 \text { to } 22 \\
23\end{array}$ & $\begin{array}{l}\text { Pre-calving } \\
\text { Colving } \\
\text { No change } \\
\text { No change } \\
\text { No diet change } \\
\text { No change } \\
\text { Barley stopped } \\
\text { Grass (cold and wet) } \\
\text { Grass (warm and dry) } \\
\text { Grass } \\
\text { Grass deteriorating }\end{array}$ & $\begin{array}{l}64 \cdot 7 \pm 4 \cdot 61 \\
70 \cdot 5 \pm 9 \cdot 12 \\
N S O \\
61 \cdot 4 \pm 4 \cdot 61 \\
N S D \\
63 \cdot 7 \text { to } 2 \cdot 89 \\
62 \cdot 3 \pm 4 \cdot 27 \\
58 \cdot 1 \pm 6 \cdot 09 \\
58 \cdot 8 \pm 6 \cdot 03 \\
N S D \\
58 \cdot 1 \pm 7 \cdot 1\end{array}$ & $\begin{array}{l}4.8 \pm 0.62 \\
4.7 \pm 0.86 \\
\text { NSD } \\
4 \cdot 6 \pm 0.65 \\
\text { NSD } \\
4.1 \pm 0.51 \\
5.9 \pm 1.61 . \\
7 \cdot 2 \pm 2.3 \\
4.4 \pm 0.9 \\
\text { NSD } \\
7.0 \pm 1.01 . *\end{array}$ \\
\hline
\end{tabular}

NSD $-\mathrm{No}$ significant difference comparing two successive tests.
$-\mathrm{PO}<-05 \quad 0<<001$

were estimated using the manual method of Williamson (1962). During the second year of the project estimation were carried out by the manual method and by the automated method of Zivin (1973). The cows were weighed when sampled using a weighing-crate and Weighband (Dalton Supplies).

Details of ration were collected on each visit and al variations in quantity and quality were noted. The roughage component of the diet was analysed at regular intervals and automatic concentrate feeders were calibrated weekly.

Each part of the ration fed to cows in herd $\mathbf{A}$ was weighed before feeding and all rejected food reweighed, during the period when cows were housed. The metabolisable energ (ME) concentrations of the dietary components were calculated. Estimated ME intakes were then expressed as a percentage of the ME requirements according to breed, body weight, milk yield and quality, and stage of lactation (Technical Bulletin 33).

Milk yield was recorded on day of sampling or as near to that day as was possible. All herds were run on a commercial basis but had good standards of management, nutrition and record keeping. No attempt was made to alter nutrition according to results.

\section{Results}

The mean serum BHB concentrations in the groups of cows from the three herds ranged from 3 to $9.9 \mathrm{mg}$ per 100 $\mathrm{ml}$. Individual cow concentrations ranged from $2 \cdot 4$ to $27 \cdot 4$ $\mathrm{mg}$ per $100 \mathrm{ml}$

Herd A group 1.-Plasma glucose concentrations ranged from $58.1 \mathrm{mg}$ per $100 \mathrm{ml}$ when cows were at grass to $70.5 \mathrm{mg}$ per $100 \mathrm{ml}$ immediately after calving (Table 2). Differences between successive samplings were not significant because of the wide variation. Mean serum BHB concentrations ranged from 4.1 per $100 \mathrm{ml}$ to $7.2 \mathrm{mg}$ per $100 \mathrm{ml}$ after cows had been turned out to grass when weather was cold and wet. During the first weeks of the study there was no significant change in
TABLE 3: Herd A Group 2 sampled weokly between September to December 1975. Eight cows (recently calved) mean and standord deviation

\begin{tabular}{|c|c|c|c|}
\hline $\begin{array}{l}\text { Teat } \\
\text { No }\end{array}$ & $\begin{array}{l}\text { Event prior } \\
\text { to sampling }\end{array}$ & $\begin{array}{l}\text { Plasms Glucose } \\
\mathrm{mg} \text { per } 100 \mathrm{ml}\end{array}$ & $\begin{array}{l}\text { Sorum ВHB } \\
\mathrm{mg} \text { per } 100 \mathrm{ml}\end{array}$ \\
\hline $\begin{array}{l}1 \\
2 \\
3 \text { to } 7 \\
8 \\
9 \\
10 \\
11 \\
11 \text { to } 18 \\
16\end{array}$ & $\begin{array}{l}\text { Cows at grasa } \\
\text { Barley cut } \\
\text { No changeg } \\
\text { Cows inside } \\
\text { Hay increased by } 3 \mathrm{~kg} \\
\text { Hay cut by } 3 \mathrm{~kg} \\
\text { Hey increased by } 2 \mathrm{~kg} \\
\text { No diet changs } \\
\text { Change to low yialding }\end{array}$ & $\begin{array}{l}55 \cdot 7 \pm 3.36 \\
56 \cdot 9 \pm 7 \cdot 37 \\
\text { NSD } \\
59 \cdot 8 \pm 6.3 \\
62.7 \pm \pm 4.4 \\
66 \cdot 9 \pm 5.2 \\
64.5 \pm 5.5 \\
\text { NSD }\end{array}$ & $\begin{array}{l}7.0 \pm 0.92 \\
9.9 \pm 1.70 \\
\text { NSD } \\
8.5 \pm 1.53 \\
6.6 \pm 1.020 \\
8.4 \pm 1.03^{\circ} \\
6.4 \pm 0.960 \\
\text { NSD }\end{array}$ \\
\hline & & $58 \cdot 8 \pm 9 \cdot 5$ & $9 \cdot 7 \pm 1 \cdot 2^{900}$ \\
\hline
\end{tabular}

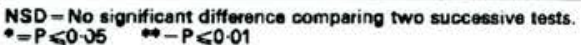

TABLE 4: Herd B Group 1 samplod weakly batween January to August 1975. Eight cowe mean values and etandard deviation

\begin{tabular}{|c|c|c|c|}
\hline $\begin{array}{l}\text { Teat } \\
\text { No }\end{array}$ & $\begin{array}{l}\text { Event prior } \\
\text { to sampling }\end{array}$ & $\begin{array}{l}\text { Plasma Glucose } \\
\mathrm{mg} \text { per } 100 \mathrm{ml}\end{array}$ & $\begin{array}{l}\text { Sorum ВнВ } \\
\text { me por } 100 \mathrm{~m}\end{array}$ \\
\hline $\begin{array}{l}1 \\
2 \\
3 \\
3 \text { to } 8 \\
8 \\
9 \\
10 \\
11 \\
11 \text { to } 13 \\
14\end{array}$ & $\begin{array}{l}\text { Pre-calving } \\
\text { Calving } \\
\text { No change } \\
\text { No change } \\
\text { No change } \\
\text { Berley cur } \\
\text { Grass (cold and wet) } \\
\text { Grass (warm weather) } \\
\text { Grass } \\
\text { Grass deteriorating }\end{array}$ & $\begin{array}{l}68 \cdot 9 \pm 12 \cdot 14 \\
69 \cdot 6 \pm 8 \cdot 91 \\
69 \cdot 1 \pm 7 \cdot 69 \\
N S D \\
64 \cdot 4 \pm 5 \cdot 61 \\
63.9 \pm 6 \cdot 25 \\
66 \cdot 3 \pm 7 \cdot 34 \\
65 \cdot 0 \pm 6 \cdot 21 \\
N S D \\
66 \cdot 6 \pm 4 \cdot 8 \cdot 6\end{array}$ & $\begin{array}{l}5.2 \pm 1.04 \\
6.1 \pm 1.81 \\
5.1 \pm 1.34 \\
N S D \\
4.1 \pm 0.94 \\
5.7 \pm 0.81 . \\
5.8 \pm 1.67 \\
3.0 \pm 0.37 \\
N S D \\
6.5 \pm 1.6 * 0\end{array}$ \\
\hline
\end{tabular}

BHB concentrations until mid-day barley was stopped and then concentrations rose. After cows were at grass and weather conditions improved serum BHB concentrations fell significantly only to rise again very significantly when grass deteriorated in the late summer.

Herd A group 2.-Plasma glucose concentrations ranged from $55.7 \mathrm{mg}$ per $100 \mathrm{ml}$ when cows were on grass in late autumn to $66.9 \mathrm{mg}$ per $100 \mathrm{ml}$ when established on winter feed (Table 3). Differences between successive samplings were not significant. Serum BHB concentrations ranged from $\mathbf{9 . 9}$ $\mathrm{mg}$ per $100 \mathrm{ml}$ at grass in autumn to $6.4 \mathrm{mg}$ per $100 \mathrm{ml}$ when on winter ration. When barley, which was fed to supplement autumn grass, ran out BHB concentrations rose significantly. Concentrations fell significantly when cows were housed and then rose and fell as part of hay ration was cut and then increased. Concentrations then remained steady until cows were transferred to a low yielding group of cows after one hundred days of lactation when BHB concentrations again increased significantly.

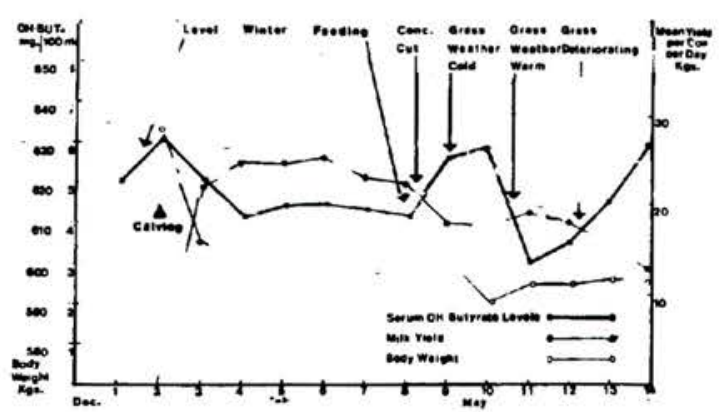

FIG. 1: Changes in mean BHB serum concentrations in cows from Herd B, group 1 throughout the lactation and the relationship between these concentrations and mean milk yield and body weight shanges. 
TABLE 5: Herd B Group 2 sampled weekiy between September 1975 to March 1976. Twelve cows mean values and standard deviation

\begin{tabular}{|c|c|c|c|}
\hline $\begin{array}{l}\text { Test } \\
\text { No }\end{array}$ & $\begin{array}{l}\text { Event prior } \\
\text { to sampling }\end{array}$ & $\begin{array}{l}\text { Plasme Glucose } \\
\mathrm{mg} \text { per } 100 \mathrm{ml}\end{array}$ & $\begin{array}{l}\text { Serum BHB } \\
\text { mg per } 100 \mathrm{ml}\end{array}$ \\
\hline $\begin{array}{l}1 \\
2 \\
3 \\
4 \\
5\end{array}$ & $\begin{array}{l}\text { Pro-calving at grass } \\
\text { Calving } \\
\text { Hay introduced } \\
\text { Brewer's grains and berley } \\
\text { Changed concentrate } \\
\text { (cows scouring) }\end{array}$ & $\begin{array}{l}52 \cdot 6 \pm 15 \cdot 0 \\
61 \cdot 18 \pm 15 \cdot 7 \\
54 \cdot 0 \pm 6 \cdot 9 \\
52 \cdot 4 \pm 4 \cdot 3 \\
58 \cdot 6 \pm 4 \cdot 96\end{array}$ & $\begin{array}{l}6 \cdot 9 \pm 1.9 \\
7.8 \pm 1.17 \\
6 \cdot 1 \pm 1.00 \% \\
7 \cdot 6 \pm 1.00 \% \\
8.1 \pm 1.21\end{array}$ \\
\hline $\begin{array}{l}6 \\
6 \text { to } 18\end{array}$ & $\begin{array}{l}\text { Silage started } \\
\text { No change in diet }\end{array}$ & $\begin{array}{l}57 \cdot 1 \pm 4 \cdot 41 \\
\text { NSD }\end{array}$ & $\begin{array}{l}5.2 \pm 1.08 * * \\
\text { NSD }\end{array}$ \\
\hline
\end{tabular}

NSD - No significant difference comparing two successive tests
$-\rightarrow P<0.05$

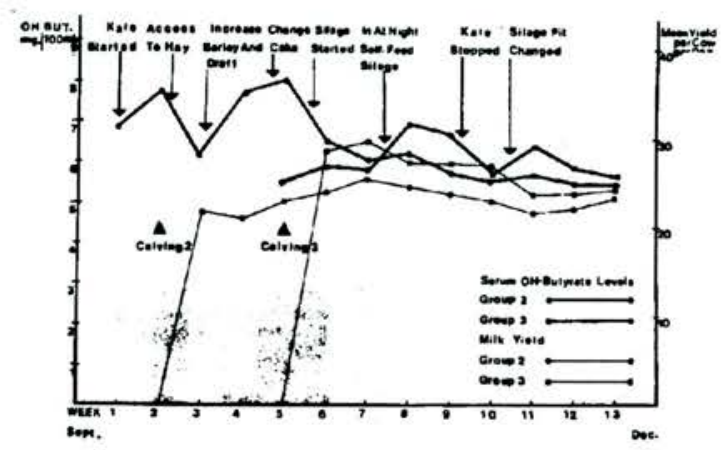

FIG. 2: Relationship between BHB serum concentration of Herd $B$, groups 2 and 3 cows and their respective mean milk yields.

Herd B, group 1.-Plasma glucose concentration ranged from $68.9 \mathrm{mg}$ per $100 \mathrm{ml}$ just before calving to $55.6 \mathrm{mg}$ per $100 \mathrm{ml}$ on grass in late summer. Changes in plasma glucose concentrations between two tests as grass deteriorated were significant (Table 4).

Sera BHB concentrations ranged from $3.0 \mathrm{mg}$ per $100 \mathrm{ml}$ on good grass to $6.5 \mathrm{mg}$ per $100 \mathrm{ml}$ when grass was deteriorating. No significant changes in sera BHB concentrations occurred until just before turning out to grass when barley was cut. BHB concentrations again dropped significantly where grazing conditions were good and rose again as grazing conditions deteriorated.

Herd B, group 2.-Plasma glucose concentrations ranged from between $52.5 \mathrm{mg}$ per $100 \mathrm{ml}$ when cows were on autumn grass to $61.2 \mathrm{mg}$ per $100 \mathrm{ml}$ at calving. None of the differences between successive tests were significant (Table 5).

BHB serum concentrations ranged from $5.2 \mathrm{mg}$ per $100 \mathrm{ml}$ when cows were on winter feed to $8.1 \mathrm{mg}$ per $100 \mathrm{ml}$ when cows were scouring. When hay was introduced to cows on autumn grass BHB concentrations fell significantly. The introduction of brewers' grains and barley to diet followed soon after by a change to a higher energy concentrate produced increased BHB concentrations which fell again when silage was started and a full winter feeding regime was under way.

Herd B, group 3.-These cows calved five weeks later than group 2 cows and were not subjected to any major dietary changes during the first few weeks of lactation. Management changes such as staying indoors at night and change of silage pit produced changes in BHB concentrations but these were not significant. Over a period of 20 weeks the mean serum BHB concentrations did not change significantly from a concentration $5.4 \mathrm{mg}$ per $100 \mathrm{ml}$.

Herd C.-Cows in this group were potentially very high yielders but the group system of feeding employed restricted maximum energy intakes of some of the cows. Plasma glucose concentrations ranged from $53.9 \mathrm{mg}$ per $100 \mathrm{ml}$ when on deteriorating grazing conditions to $61.8 \mathrm{mg}$ per $100 \mathrm{ml}$
TABLE 6: Herd C sampled once every two weeks between January and August 1975. Eight (high yielding) cows mean values and standard doviation

\begin{tabular}{|c|c|c|c|}
\hline $\begin{array}{l}\text { Tost } \\
\text { No }\end{array}$ & $\begin{array}{l}\text { Event prior } \\
\text { to sampling }\end{array}$ & $\begin{array}{l}\text { Plasma Glucose } \\
\mathrm{mg} \text { per } 100 \mathrm{ml}\end{array}$ & $\begin{array}{l}\text { Serum 8HB } \\
\mathrm{mg} \text { per } 100 \mathrm{ml}\end{array}$ \\
\hline $\begin{array}{l}1 \\
2 \text { to } 5 \\
5 \\
5 \text { to } 7 \\
8 \\
9 \\
9 \text { to } 13 \\
13 \\
14\end{array}$ & $\begin{array}{l}\text { Calving } \\
\text { Two clinical cases ketosis } \\
\text { No change } \\
\text { Grass (weather cold) } \\
\text { Grass (weather warm) } \\
\text { No change } \\
\text { Grass deteriorating } \\
\text { Extra concentrate fed }\end{array}$ & $\begin{array}{l}59 \cdot 1 \pm 7 \cdot 51 \\
N S D \\
61 \cdot 8 \pm 6 \cdot 7 \\
N S D \\
59 \cdot 9 \pm 7 \cdot 7 \\
58 \cdot 2 \pm 3 \cdot 8 \\
N S D \\
53 \cdot 9 \pm 2 \cdot 1 \cdot 6 \\
56 \cdot 2 \pm 4 \cdot 5\end{array}$ & $\begin{array}{l}7 \cdot 6 \pm 3 \cdot 84 \\
\text { NSD } \\
9 \cdot 0 \pm 4 \cdot 32 \\
\text { NSD } \\
7 \cdot 2 \pm 1 \cdot 81 \\
3 \cdot 3 \pm 0 \cdot 90^{\circ .} \\
\text { NSD } \\
6 \cdot 1 \pm 1 \cdot 90^{\circ} \\
4 \cdot 1 \pm 0.90^{\circ}\end{array}$ \\
\hline
\end{tabular}

NSD-No significant difference comparing two successive tests.

$\rightarrow \rightarrow P_{50.05} \rightarrow-P<0.01$

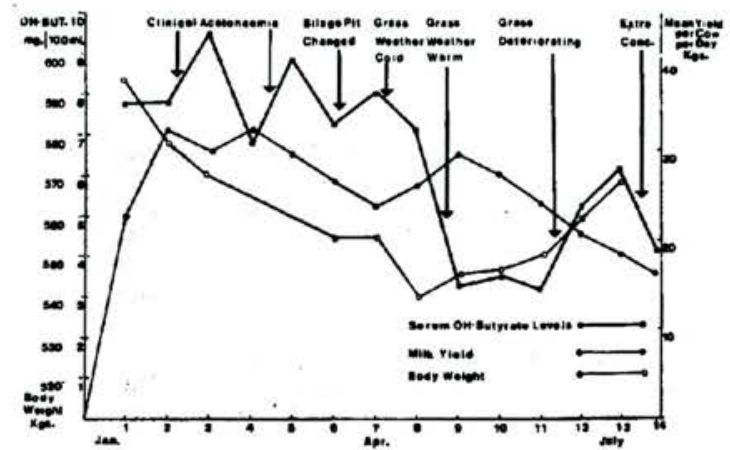

FIG 3: Changes in mean BHB serum concentrations in cows from Herd $\mathbf{C}$ throughout the lactation and the relationship between these concentrations and the mean milk yield and body weight changes.

after calving (Table 6). Significant differences were found between two tests at grass' when grazing conditions were changing.

Sera BHB concentrations ranged from $3.3 \mathrm{mg}$ per $100 \mathrm{ml}$ on good grass to $9.0 \mathrm{mg}$ per $100 \mathrm{ml}$ when two cows were clinically ketotic. Levels remained relatively high during the winter period and did not become significantly lower until grazing conditions became favourable. Serum BHB concentrations again rose as grass deteriorated and fell again as extra concentrate was fed to compensate for lower nutritive value of the grass.

\section{Discussion}

Serum BHB concentrations closely followed dietary fluctuations in all groups of cows, not only in the first few weeks of lactation, the period normally associated with high ketone concentrations, but throughout the entire lactation and dry period. When the quality and quantity of the ration remained constant, other than to adjust amount of concentrate fed according to yield, there were no significant fluctuations in BHB concentrations covering periods of up to five months. When dietary changes were made gradually, eg, when cows were given time to adjust to higher fodder intakes in late lactation, no significant fluctuations in BHB concentrations were recorded. However, when changes in diet were made suddenly or where food of a different quality was substituted for part of the ration significant fluctuations were found in BHB concentrations.

BHB serum concentrations from animals at grass were of particular interest. In the first year of the study all three herds showed the same pattern throughout the grazing season. During the first two weeks at grass conditions were cold and wet and restricted the cows' grazing activity and grass intake. Raised BHB concentrations were found at this time. As cows adjusted to optimum grazing condition BHB concentrations fell very significantly and rose again as 
the grass deteriorated during the dry summer months. Cows sampled during the second grazing season (1976) showed the same fluctuations.

In this investigation plasma glucose concentrations did not follow changes in food intake as closely as serum BHB concentrations. However, in cows where high concentrations of BHB (10 to $40 \mathrm{mg}$ per $100 \mathrm{ml}$ ) were found, eg, in clinical cases of ketosis, glucose levels were useful as an additional indicator of the severity of the conditions, ie, plasma glucose concentrations were of value in cases of gross rather than marginal dietary deficit.

Mean plasma NEFA concentrations were generally low (below $300 \mu$ Eq per litre) in well fed cows but considerable differences, which could not be accounted for on a nutritional basis, were sometimes found between successive tests. These fluctuations in concentrations were most frequent during the grazing season and may have been due to excitement or changes of management routine (Holmes and Lambourne 1970).

This study gives further support to advice given on ketosis prevention by Baird (1974). High quality roughage and husbandry methods which allow maximum feed intakes were necessary to control serum BHB concentrations in the first weeks of lactation. Cows fed pre partum on a controlled rising plane of nutrition with no constituent changes in ration can maintain very steady concentrations of serum BHB after parturition, attain peak yields and still lose an acceptable amount of bodyweight.

Groups of cows sampled in this study were on a good plane of nutrition and much more extreme values have been found (mean values 15 to $25 \mathrm{mg}$ per $100 \mathrm{ml}$ ) in cows from herds which had health and production problems.

This preliminary study indicates that BHB concentrations should be further investigated to establish their potential as a parameter in preventive medicine monitoring schemes fo. commercial dairy herds.

Acknowledgements.-I wish to thank Professor G. S. Ferguson, Department of Animal Health, Royal (Dick) School of Veterinary Studies and Dr A. Russel, Hill Farming Research Organisation for their help and encouragement with this work; Dr G. R. Scott of the Centre of Tropical Veterinary Medicine for his help in preparation of manuscript; and $\mathrm{Mr}$ A. Dowell and the laboratory staff of the Department of Animal Health for carrying out blood analysis and the farmers and farm staff for their co-operation throughout. Financial support was received from Spillers Farm Feeds Ltd.

\section{REFERENCES}

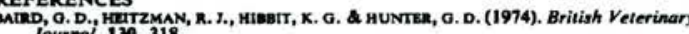
mower, na. w., woop, D. w. \& DAvis, J. R. (1973). Vetertinary Record. 92.691. Bow' Eury, J.' D., Fister, L. J. \& suUE, P. D. (1974). Canadian Journal of Animal Science.

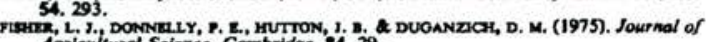

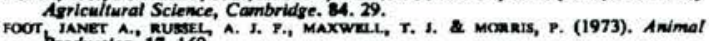

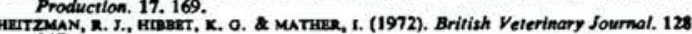
34. OLMs, 1. н. O. \& uMmounNa, L. 1. (1970). Research in Veterinary Sclence. 11.27 AchULTZ, L. .. \& Hoexsma, w. O. (1960). Jourmal of Dairy Sclence.

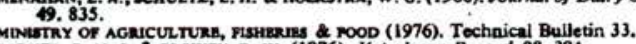
PARKER, A. N. J. \& BLOWE, , R. W. (1976). Veterinary Record. 98. 394.

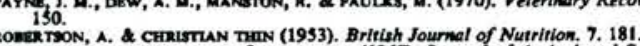
Ussal, A. J. $F$. DONEY, 68. 351 Lumson, D. K., MELLNOYY, JANE \& KRes, H. A. (1962). Biachemistry Journal. 82. 90.
ZiviN, J. A. S surk, J. F. (1973). Analytical Blachemistry. 52.456. 


\title{
A DAIRY HERD HEALTH AND PRODUCTIVITY SERVICE
}

\author{
J. M. KELLY, D. A. WHITAKER and E. JILL SMITH \\ Department of Veterinary Clinical Studies, Veterinary Field Station, Easter Bush, Roshin, \\ Midlothian EH25 9RG
}

\section{SUMMARY}

A Dairy Herd Health and Productivity Service (DHHPS), involving each year some 244 large dairy herds and 127 veterinary practices in the UK has been in operation for the past 10 years. It provides the dairy farmer with a framework for cooperation between his own veterinary practitioner, the specialist nutritional adviser and the laboratory based veterinary surgeon. The scheme, by combining techniques such as computerized data recording and pre-planned blood analysis, provides regular information on disease occurrence, adequacy of nutrition and management in relation to productivity and economic performance. It affords the opportunity for the veterinary practitioner to lead a multi-disciplinary team advising on the health, nutrition and management on progressive dairy farms, and to demonstrate to their clients the full potential of good, active veterinary involvement.

\section{INTRODUCTION}

During the past 20 years the UK dairy industry has undergone many changes. Among the more dramatic has been the marked increase in milk production from individual cows, whereas the number of dairy herds in the country has decreased sharply and the size of herds has increased accordingly. As a result there is almost the same number of cows producing much more milk on a smaller number of more intensively farmed units.

With changes in husbandry the pattern of disease has also altered. The major infectious diseases, e.g. tuberculosis, brucellosis, are under control or are at least susceptible to control measures and their economic importance has been superseded by production diseases such as infertility, mastitis and lameness. The causes of these diseases are multi-factorial and their control is likely to involve a multi-disciplinary approach.

The veterinary practitioner is normally present on dairy farms more frequently than any other agricultural adviser and should be in the strongest position to initiate and lead a team approach to improving health and maintaining optimum productivity. Many practitioners, however, were so involved with tuberculosis and brucellosis eradication 
schemes that they lost the opportunity of establishing routine health programmes and have been content with only a 'fire brigade' type of approach. Many have diversified and expanded their interest in companion animals. Some, who feel that their education did not prepare them for this advisory role, consider themselves vulnerable on matters of nutrition and productivity. For whatever reason, the development of herd health and productivity programmes in the UK has been relatively slow.

A lead towards the promotion of preventive medicine was taken by the Mid West Veterinary Association, who investigated the advantages to the farmer of this approach (Grunsell et al, 1969). This report stimulated the development of the Joint Exercise in Animal Health and Productivity (Jointex, 1976), which demonstrated some of the benefits of joint advice by veterinary surgeons and agricultural advisers. The Swan Committee of Enquiry into the veterinary profession in the UK (Swan, 1975) recommended the continuance and expansion of Jointex. Mainly because of the costs of administration those recommendations have not been followed.

There has, however, been considerable progresss in the development of computerized livestock recording systems, which greatly facilitate the monitoring of fertility (DAISY, Esselmont, Stephens \& Ellis, 1982) and disease (COSREEL, Russell \& Rowlands, 1983 and VIRUS, Martin, Mawland \& Green, 1982).

It has also become obvious that nutrition, as well as infection, plays an important role in animal health. Payne et al (1970) and Blowey, Wood \& Davies (1973) showed how blood analysis could assist in the nutritional monitoring of dairy cows.

A herd health and productivity scheme must be capable of providing regular coordinated measurements of disease occurrence, overall health status, of adequacy of nutrition and management, productivity and economic performance and of comparing the results of these measurements with the levels obtained by other dairy farms using similar management techniques. It was with these principles in mind that the Dairy Herd Health and Productivity Service (DHHPS), described in this paper, was established. It gives the veterinary practitioner the initiative in leading a multi-disciplinary team, which can identify trends and plan, where necessary, coordinated remedial action. The service combines techniques such as computerized data recording with blood analysis on a regular preplanned basis.

\section{MATERIALS AND METHODS}

The DHHPS depends on the close cooperation between farmer, his veterinary surgeon, nutritional adviser and veterinary consultant.

\section{Choice of farm}

It is considered that a herd size of 70 is the minimum for cost/benefit from this type of exercise. The farmer must be progressive and willing to keep some well defined but minimal records, use his veterinary surgeon regularly, and be prepared to use the information produced constructively. The farmer is asked to sign an agreement to pay for membership of the service and to pay his veterinary surgeon for blood sampling, sample tubes, and discussion time. When agreement has been reached a data Sheet 1 is prepared, giving basic background information on the herd relating to management, husbandry and productivity. 


\section{Veterinary surgeon}

The veterinary practitioner must be prepared to be actively and positively involved. He must participate in the planning of tests and selection of cows, carry out blood tests and above all must lead the post-sampling discussion meetings.

\section{Nutritional adviser}

The nutritional adviser must have an interest in cooperation with the veterinary profession and must be prepared to participate in planning the timing of tests, condition scoring, weighing of cows and attending discussion meetings.

\section{Record keeping}

A data Sheet (Fig. 1) relating to feed input, health and fertility and general herd assessment is completed each month. A copy is left on the farm and further copies are sent to the veterinary surgeon, to the nutritional adviser and to the DHHPS unit in Edinburgh where data is entered into a DEC PDP11 mini-computer with a floppy-disk storage system. The monthly information is used to generate a quarterly and annual report which summarizes and compares culling rates, disease incidence and fertility efficiency.

\section{Blood sampling}

Blood samples are taken from representative cows at pre-planned stages throughout the year. Normally up to four blood tests are done in each herd each year. Up to 17 cows are tested on each occasion, seven early lactation, five mid-lactation and five dry. It is essential that cows sampled are truly representative of the animals in their groups. Cows with known health problems should not be included. Timing of tests is dependent on calving pattern, but peak sampling times are 2-3 weeks after turnout, i.e. May or June, during the autumn grazing period and after the start of the winter feed regimen. A test under optimal grazing conditions is particularly useful in herds which have newly joined the service, as results may provide a baseline for comparison with those obtained at subsequent tests. At the same time as samples are taken a data Sheet 3 (Fig. 2) is completed, and is sent with samples to the laboratory. Data concerning each individual cow are entered into the computer.

Samples are analysed on an automated system for $\beta$-hydroxybutyrate, plasma glucose, albumin, urea, globulin, magnesium and inorganic phosphate using standard methods (Kelly, 1977). Biochemical results are printed on a report form (Fig. 3) alongside theoretical nutritional inputs and requirements and the cow data considered essential for meaningful interpretation.

Cow data. These are taken from Sheet 3 which accompanies the blood samples.

Blood results. These are automatically entered into the computer via a link from the auto-analyser.

\section{Feed data}

This section uses the information provided on Sheet 3 (and so depends on its accuracy) to look initially at the theory of the diet. It can be extremely useful, particularly when assessing the economic use of forage.

Fed total DM. This is the sum of the fed concentrate dry matter (Fed Conc DM) in kilogrammes (kg) and the fed forage dry matter (Fed F'age DM) according to the figures given on Sheet 3 . 


\section{Dairy Herd Health \& Productivity Service}

SHEET 2

DATA INPUT FOR MONTH OF

10

FAPAERA

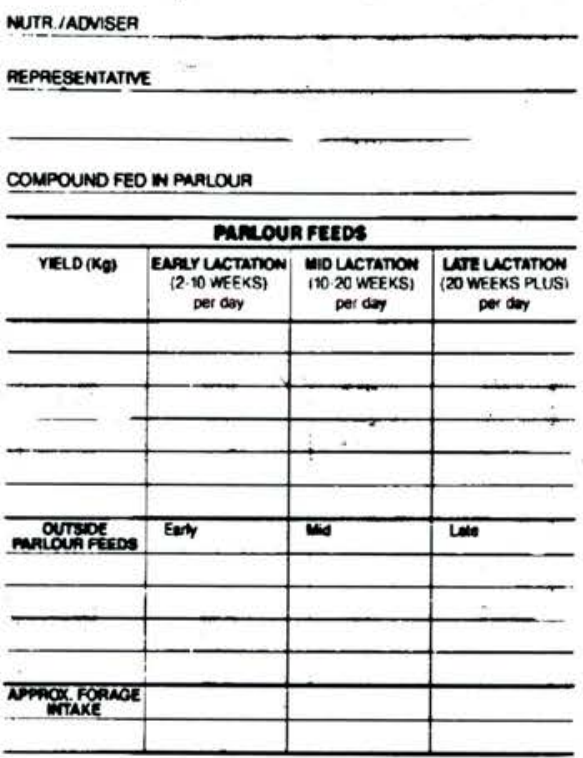

HERO

ASSESSMENT

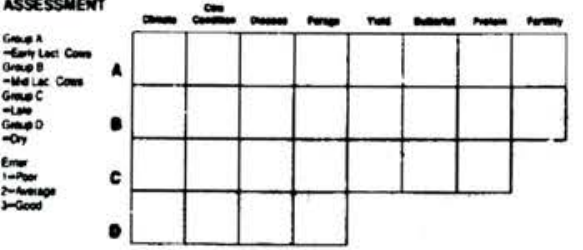

II Additionel Minereis Supplied, Indicate Hethod \& Type

commente

Fig. 1.
Code Na.

\section{Number of Cows in Milk inct, Hellore on End of wonth \\ Number of Cows Dry at End at month}

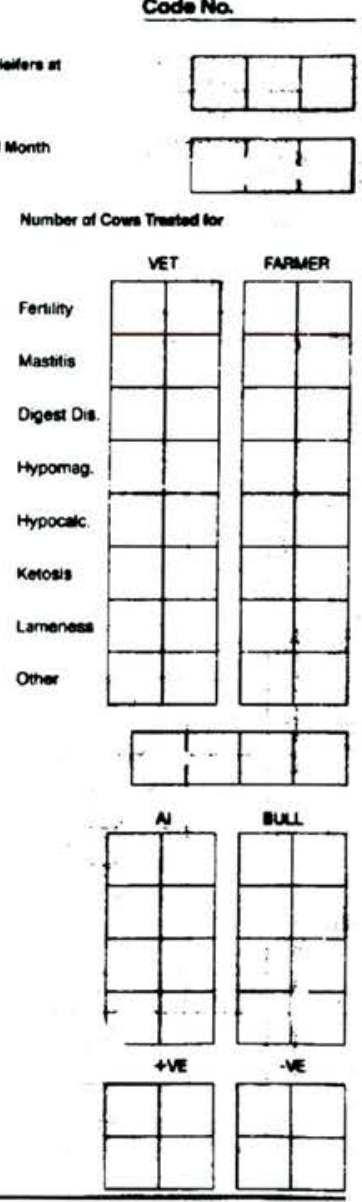

Number of Cows Sold

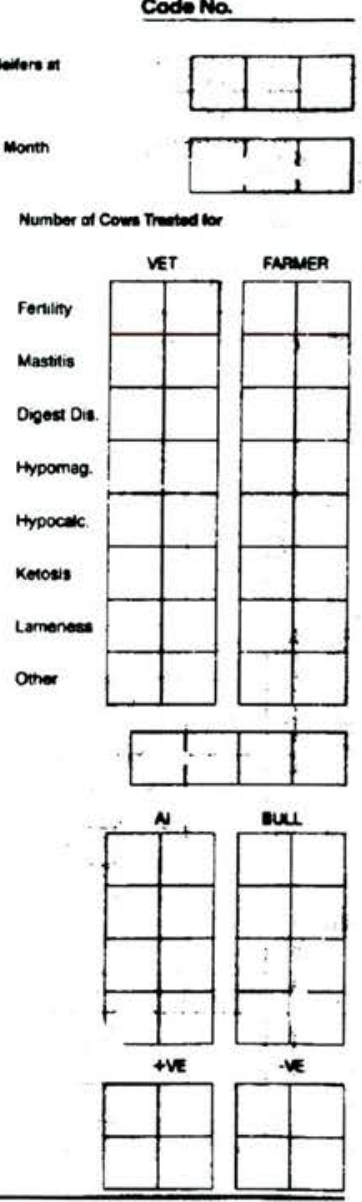

Number of Com trented ion

soceuneof
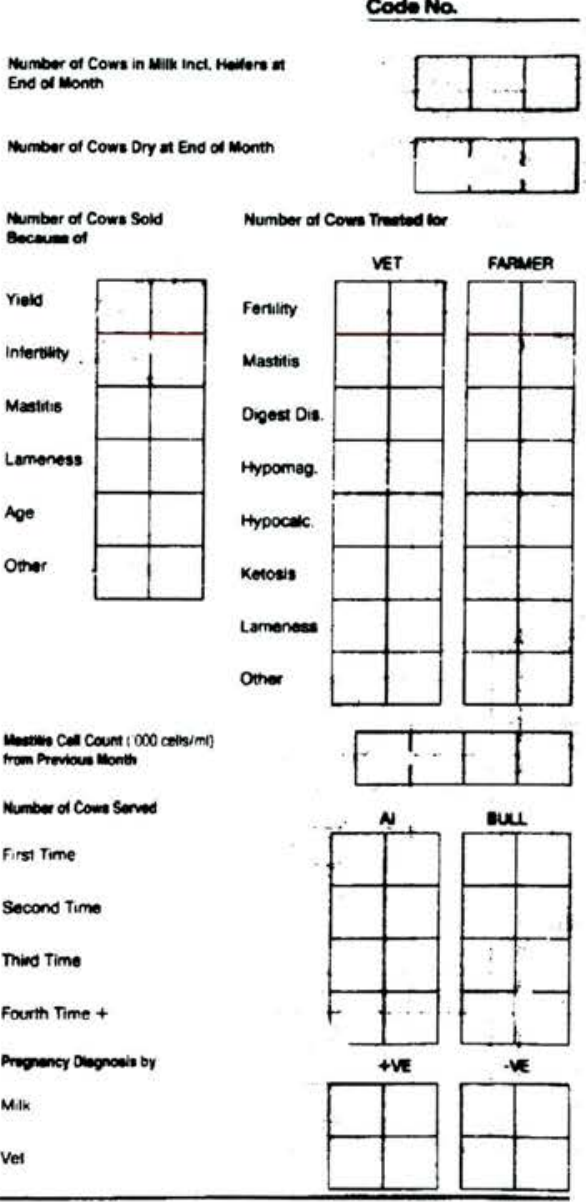

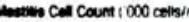
trom Previous Honth

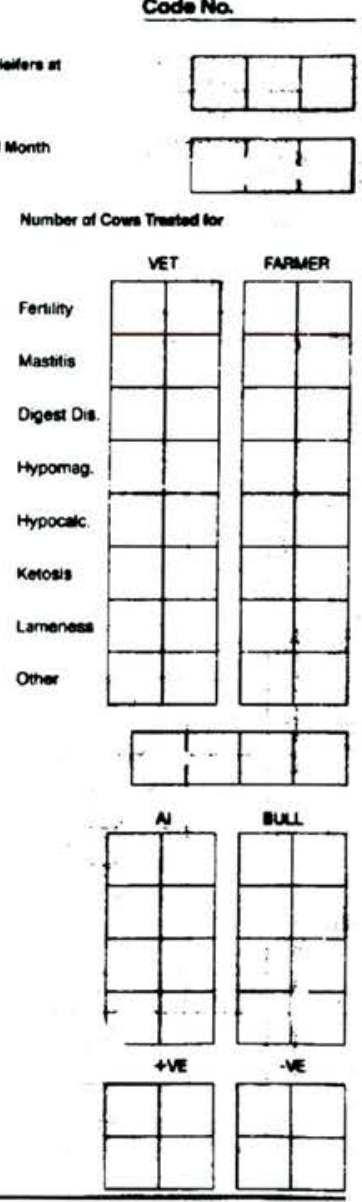

Arogrency dognowia by

Milk

Vet

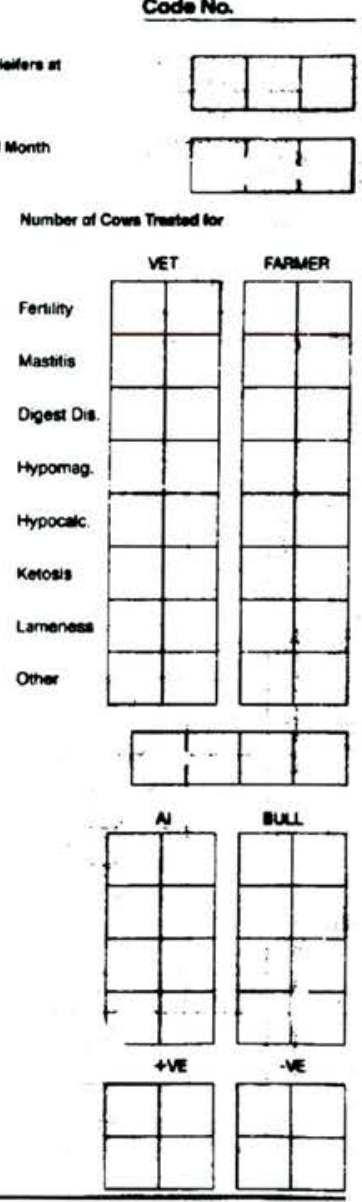

First Time

Second Time

Thind Time

Fourth Time + 
BRITISH VETERINARY JOURNAL, 144, 5

\section{Dairy Herd Health \& Productivity Service}

\section{SHEET 3}

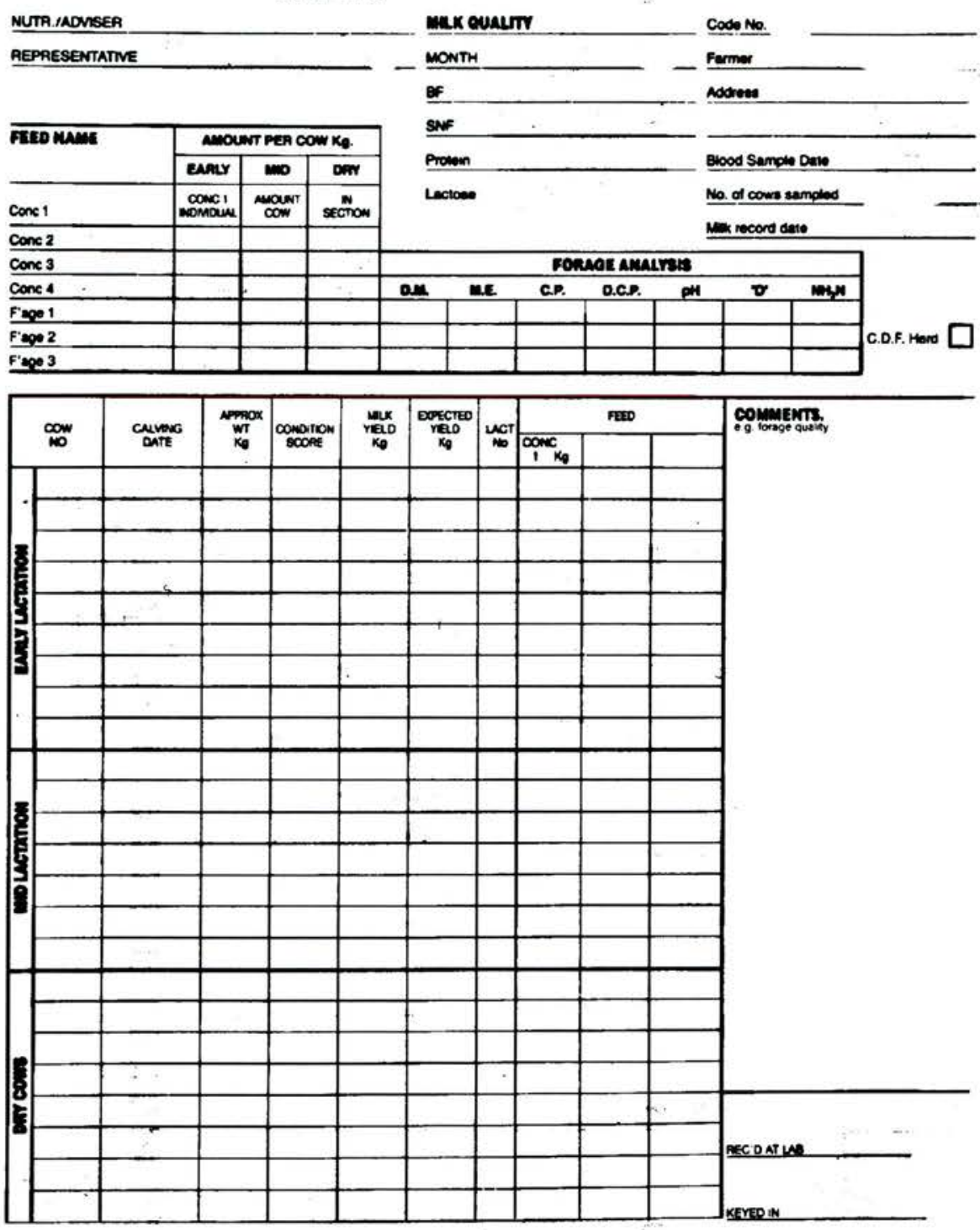

Fig. 2. 


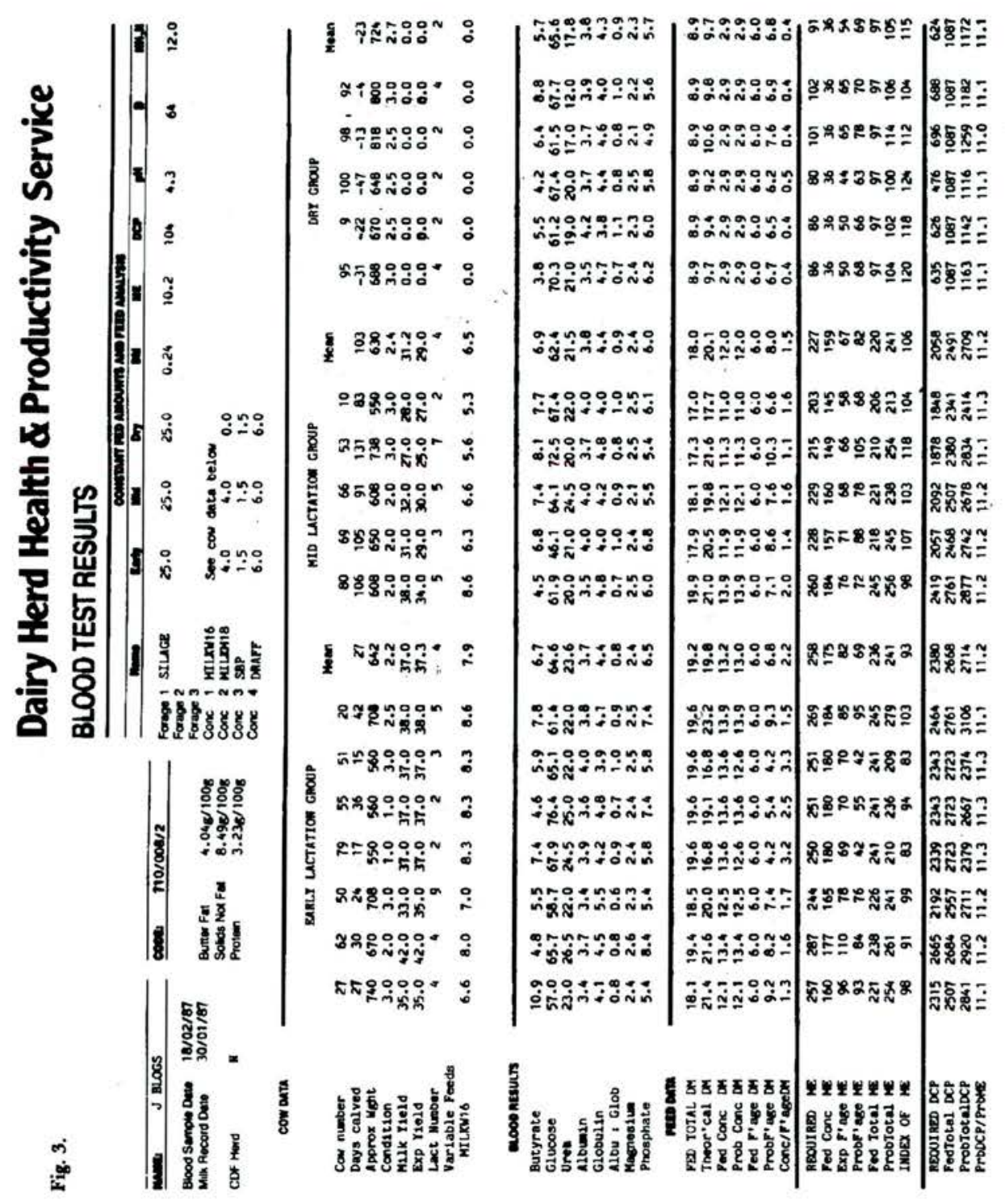


Theor'cal DM. This is the theoretical dry matter intake (TDMI) calculated from the individual body weight in $\mathrm{kg}$ and fat-corrected milk yield in $\mathbf{~ k g}$.

$$
\text { TDMI }-(0 \cdot 022 \times W t)+(0 \cdot 2 \times(\text { yield } \times \text { BF } \% / 4 \cdot 0))
$$

(from Ministry of Agriculture, Fisheries and Food, 1975, with adjustment for highyielding cows).

Up to 15 days calved, this is reduced automatically by the computer by $15 \%$ (2-3 kg). The reduction is itself reduced progressively to nothing at 42 days calved, by which time animals should have achieved maximum dry matter intake.

In the absence of an established dry matter intake (DMI) equation for dry cows the following equation was devised:

$$
\mathrm{DMI}-(0 \cdot 0114 \times \mathrm{Wt})+1 \cdot 857
$$

Between 0 and 7 days pre-calving this is reduced by $10 \%$, between 8 and 14 days by $5 \%$. A further $5 \%$ reduction is made with cows of condition score greater than $3 \cdot 5$.

Fed Conc DM. This is the sum of the dry matter of cake, concentrates etc. taken from Sheet 3. Analyses are stored in the computer memory.

Prob Conc DM. The computer assumes that at least $25 \%$ of the TDMI will always be forage. If concentrate feeding is very high, TDMI limits may then be exceeded and all concentrates may not be eaten. Prob Conc DM is the consequent theoretical reduction in intake down to $75 \%$ of TDMI under those circumstances. Otherwise it is the same as the Fed Conc DM.

Fed F'age DM. This the total dry matter of forages fed according to Sheet 3 information.

Prob F'age DM. Ths is the TDMI minus the Prob Conc DM, so it is never less than $25 \%$ of TDMI but it is often different to the Fed F'age DM.

Conc/F'age DM. This is calculated using the Fed Conc DM and the Prob F'age DM.

Required ME. This is the metabolizable energy (ME) in megajoules (MJ) each cow requires.

$$
\text { For maintenance }-8 \cdot 3+(0 \cdot 091 \times \text { weight in } \mathbf{k g}) \mathrm{MJ}
$$

$$
\text { for pregnancy }-1 \cdot 13 \times 2 \cdot 718^{0.0106 t} \mathrm{MJ} \text {; }
$$

where $\boldsymbol{t}-280$ minus days to calving;

for $1 \mathrm{~kg}$ of milk-1.694[(0.386 $\times \mathrm{BF} \%)+(0 \cdot 205 \times \mathrm{SNF} \%)-0 \cdot 236 \mathrm{MJ}]$

SNF-protein $\%+$ lactose $\%+0 \cdot 9$

No allowances are made for weight change (Ministry of Agriculture, Fisheries and Food, 1975).

Fed Conc ME. This is calculated from the Fed Conc DM and ME values of concentrates fed.

Exp F'age ME. This is the Required ME minus the Fed Conc ME. It is therefore a function of rationing levels of concentrates, not TDMI or forage intakes. Exp F'age ME 
shows what energy the planners are assuming cows are getting from forages. It is a very useful calculation for both nutritional and economic reasons.

Prob F'age ME. This is calculated from the ME value of the forages and the Prob F'age DM.

Fed Total ME. This is the sum of the Fed Conc ME and the fed forage ME. The latter is not printed out but is the Fed F'age DM times the ME value of the forages.

Prob Total ME. This is the sum of the Prob F'age ME and the probable concentrate ME. The latter is also not printed out but is calculated from the Prob Conc DM and ME values of the concentrates.

Index of $M E$. This is [(Prob Total ME)/(Required ME) $] \times 100$.

This is the theoretical intake of energy as a percentage of requirement. It depends on the TDMI. In early lactation it may be between 95 and $100 \%$ to acknowledge some weight loss. In mid-lactation it should be over $100 \%$.

Required DCP etc. This is calculated knowing body weight, milk yield and quality using tables published by the Scottish Agricultural Colleges (1978).

Fed Total DCP. This is the sum of the fed concentrate DCP and the fed forage DCP.

Probable Total DCP. This is the sum of the probable concentrate DCP and the probable forage DCP.

The report (Fig. 3) is sent to the practitioner involved with an accompanying letter of interpretation from the laboratory-based veterinary surgeon. The onus is then on the practitioner to call a meeting on the farm involved to discuss the results of the test. Decisions can then be made to make appropriate management or nutritional changes, which may be necessary when findings are assessed in conjunction with current health, productivity and profitability of the herd. All members of the service have their herds fully costed and this information is available at discussion meetings. Results of these discussions are summarized in writing and this record of the meeting is distributed to all concerned.

Newletters are published by the DHHPS and discussion groups and refresher courses are held to further understanding of and involvement in the use of preventive medicine schemes in dairy herds.

\section{RESULTS AND DISCUSSION}

\begin{tabular}{lcc} 
Membership & Average herd size & Average milk yield/cow \\
\hline Current no. of herds & 146 & 5961 litres \\
\hline 220 & & \\
\hline
\end{tabular}

The average membership of the service during the past 3 years has been 244 of the larger dairy units with above average productivity. Currently 127 veterinary practices, throughout the UK, are involved.

\section{Quarterly Herd Health Report}

The information obtained from the monthly data Sheet 2 is summarized in the Quarterly Herd Health Report (Fig. 4). 


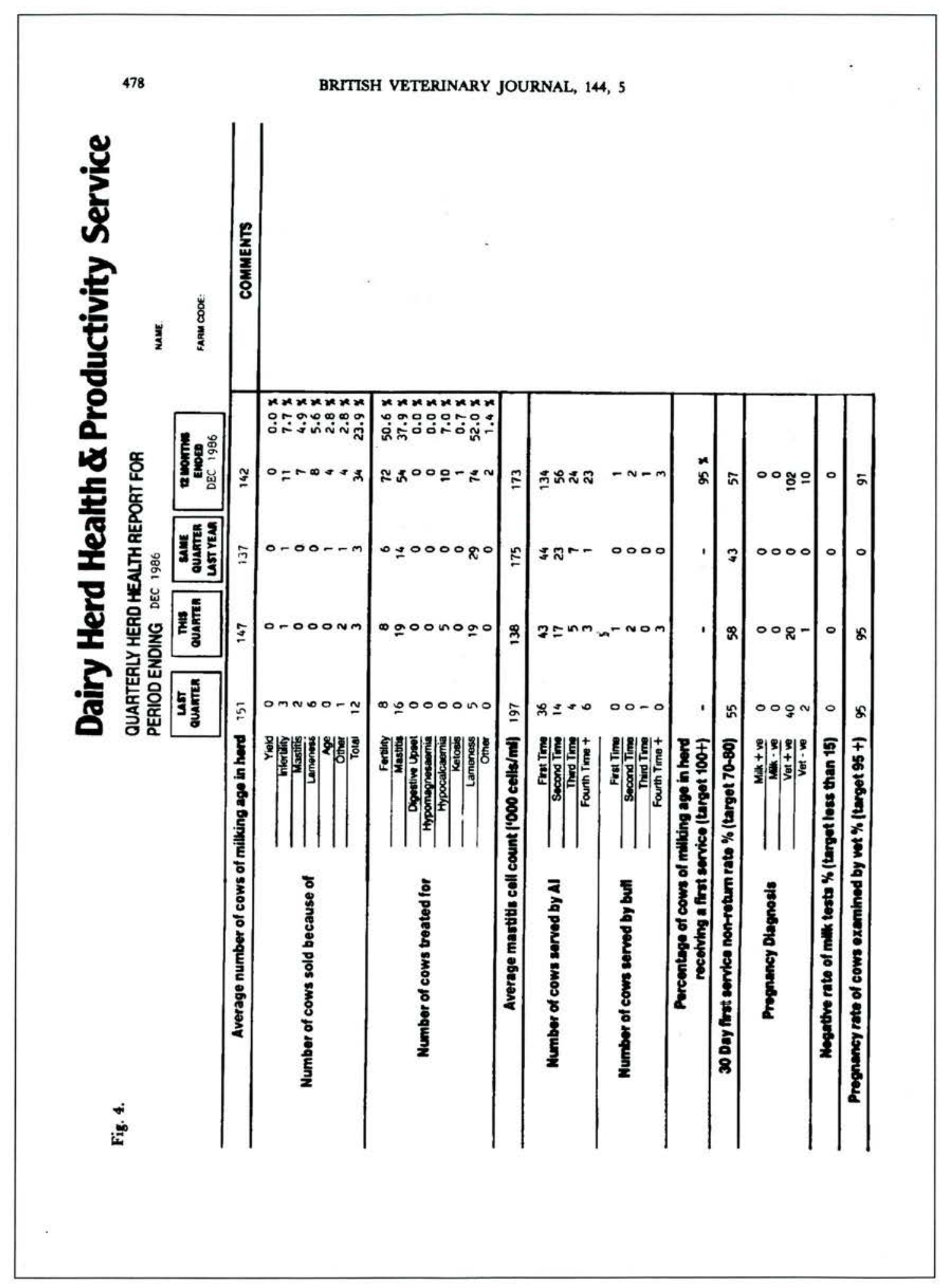


Cull rate. The overall target is less than $20 \%$ per annum. The average rates for infertility, mastitis and lameness should each be below $6 \%$.

Treatment rate. Trends from previous quarter and differences from the same quarter last year are important. Levels found on other farms provide useful targets or comparisons.

Number of cows served. This section is used to set targets for the number of first services and overall services which are necessary to maintain calving index and calving pattern.

Percentage of cows of milking age receiving a first service within a 12-month period. This index is a useful guide to the average calving to first service interval and reflects management policy and heat detection efficiency.

30-Day first service non-retum rate $\%$. This is not a conception rate, which is always lower. If the non-return rate is low conception rates will be low. If the non-return rate is high conception rates may be good or returns to service may be being missed.

Negative rate of milk tests. If the rate is over the target (15\%) conception rates may be low and if samples have been taken at 24 days after service, then returns to service are being missed.

Pregnancy rate of cows examined by vet. Not many herds achieve the target of $95 \%$. Lower figures are chiefly a consequence of failure to detect returns to service.

This report does not attempt to provide an exhaustive analysis of herd fertility or disease, nor is it intended to replace other fertility programmes which may be in operation. It does, however, highlight trends which would benefit from specific veterinary intervention and provides invaluable background information for use when interpreting results of blood profiles.

The information gathered on a monthly basis is limited, but it has been found to be near to the maximum that one can expect to obtain from a large number of farms on a regular basis. Unless the information is seen to be used in a meaningful manner, which is readily understood, then the monthly flow of data will soon cease.

\section{Blood sampling}

The successful use of blood sampling of dairy cows for biochemical analysis depends on selecting the correct cows, timing the tests correctly and interpreting the results in light of all the relevant background information relating to cow health and productivity. Early lactation cows are best sampled between 2 and 6 weeks calved. If sampled earlier, biochemical results relate to disturbances at calving. If sampled later, cows have often adapted to deficiencies in the diet by dropping body weight or milk yield. Dry cows should preferably be sampled between 1 and 3 weeks before calving.

\section{Blood sample report form (Fig. 3)}

By displaying blood results alongside the information of milk yield, body weight and condition score, stage of lactation, and detailed theoretical nutritional input, it is possible to make much more meaningful interpretation of biochemical results. On occasion the results demonstrate the balance or imbalance which is suggested by the nutritional and productivity data, e.g. low theoretical index of ME being supported by biochemical evidence of high $\beta$-hydroxybutyrate levels and low plasma glucose concentrations. On many tests, however, unsatisfactory blood results do not equate with theoretical calculations and it is then that subsequent investigation, observation and discussion suggest possible overestimations of what the animal is, in fact, eating and utilizing. For example, 
there may be overestimation of the quality or intake of autumn grass or of silage; rumenal imbalance, or too high concentrate: forage ratio. These are common reasons why theoretical nutritional inputs do not achieve optimum productivity.

Blood sampling frequently identifies low blood concentrations of magnesium and is the best way of identifying potential metabolic problems before they become manifest clinically.

The average number of blood tests per annum is 2.6 for each farm in the DHHPS. Generally, as the scheme becomes well established on a farm, blood sampling will be less frequent unless problems occur, when much more frequent sampling, i.e. five or six tests, may be carried out to identify and eliminate unsatisfactory nutritional or managemental factors.

The DHHPS has highlighted the necessity for full consultation on the farm to discuss blood sample results and reports so that the correct perspective can be maintained and practical solutions identified. The blood tests themselves are frequently catalysts to much wider ranging discussion and involvement of veterinary surgeons. Completed discussion forms, which are a written record of decisions taken or advice given at the meeting held to discuss blood test results, are received following $45 \%$ of tests.

Herds which have withdrawn from the DHHPS have remained members for an average of 28 months. However, herds which regularly returned Sheet 2 data and used written discussion forms remained members for an average of 36 months. Farmers who became actively involved with the service, especially with respect to discussion of results and who are given positive advice in relation to herd health and productivity, remain members for a longer period of time. Of those leaving the service, only $16 \%$ gave the reason as lack of interest; the majority withdrew for commercial reasons, e.g. farm sold, change of farm policy as a result of quota. Comparatively few stated veterinary costs as sole reason for withdrawal, but this is clearly an important consideration, especially if clear advice on health and productivity is not forthcoming.

Optimum productivity is synonymous with good health and in the present times of acute financial pressure for the dairy farmer, the role of the veterinary surgeon must be to assist in the maintenance of the profitability of unit. Profit margins are being reduced and, if reasonable income cannot be sustained, then neither dairy farming nor its dependent large animal veterinary practices will survive in their present form. Veterinary surgeons should have an important role to play in an industry where survival may depend on efficiency. Some farmers will have to be convinced of this, and membership of a service, such as DHHPS, has enabled some veterinary surgeons to demonstrate to their clients the full potential of good, active veterinary involvement. The service is now in its eleventh year and continues to attract membership from among the larger dairy herds. It may be of greater value as farmers strive to maintain profitability within quota.

\section{ACKNOWLEDGEMENT}

The authors wish to acknowledge the cooperation received from farmers and veterinary surgeons who participate in the service and Dalgety Agriculture from whom we receive financial and technical support. 


\section{REFERENCES}

BLOWEY, R. W., WoOD, D. W. \& DAvtes, J. R. (1973). Veterinary Record 92, 691.

Esselmont, R. J., Stephens, A. J. \& Ellus, P. R. (1982). Proceedings of 12 th World Conference on Diseases of Cattle, Amsterdam, p. 670.

Grunsell, C. S., Penny, R. H. C., WragG, S. R. \& Allock, J. (1969). Veterinary Record 84, 26.

JoINTEX (1976). Veterinary Record 98, 349.

KELLY, J. M. (1977). Veterinary Record 101, 499.

Martin, B., Mawland, D. D. \& Grekn, M. A. (1982). Velerinary Record 110, 446

Ministry OF Agriculture, Fisheries AND FOOD (1975). Energy Allowances and Feeding Syslems for Ruminants. Technical Bulletin, No. 33 London: HMSO.

Payne, J. M., Dew, A. M., Manston, R. \& Faulks, M. (1970). Veterinary Record 87, 170.

Russell, A. M. \& Rowlands, G. J. (1983). Veterinary Record 112, 189.

Sootrish Agricultural Colleges (SAC) (1978). Nutrient Allowances for Cattle and Sheep. SAC Publication No. 29.

Swan, M. (1975). Report of the Committee of Enquiry into the Veterinary Profession. London: HMSO.

(Acompled for publication 25 November 1987) 


\title{
Multidisciplinary approach to dairy herd health and productivity management
}

\section{J. M. Kelly and D. A. Whitaker (2000) British Society of Animal Science}

Occasional Publication 26: Vol 1 209-222 (ISBN 0906562341)

Royal (Dick) School of Veterinary Studies, Easter Bush Veterinary Centre, Roslin, Midlothian EH25 $9 R G, U K$

\begin{abstract}
There is concern that the substantial increases in production in dairy herds that can be achieved will bring greater health and fertility problems. Despite considerable advancements in the understanding of the biology of reproduction and its control, fertility apparently continues to decline. As many factors, including health and nutrition, influence reproductive performance it is generally agreed that a multidisciplinary approach is necessary if improvement in fertility is to be achieved. Herd health schemes have evolved to improve health, fertility, productivity and profitability but the uptake of such schemes in the UK has been low. The veterinary input to many farms is at best routine fertility visits, confined to examination of the reproductive tract, and at worst occasional emergency calls. The Dairy Herd Health and Productivity Service (DHHPS) provides the opportunity for veterinary surgeons to lead a multidisciplinary team which can monitor health, fertility and production and can plan, when necessary, remedial action. Over a period of twenty years it has continued to identify infertility, mastitis and lameness as the main reasons for the involuntary disposal of dairy cows, although on some farms BSE has been a major factor. The trend in the last few years has been for an increase in culling for reasons of disease rather than for age or yield. The average disease rates have remained high with over 100 treatments per 100 cows each year for conditions which may directly or indirectly influence reproduction. Blood profiling and condition scoring demonstrated that at least a third of the cows sampled were mobilising excessive fat during transition from the dry period to early lactation. Improving both health and nutrition, before and after calving, would greatly improve reproductive performance in many herds. A team approach, with farmers, veterinarians, nutritionists and other advisors working together with well defined goals and objectives, is necessary if progress is to be made in improving reproductive performance. High yield can not always be the excuse for poor fertility.
\end{abstract}

\section{Introduction}

Herd health and reproduction have been ranked as top priorities for improving the future productivity and profitability of dairy enterprises. There are a multitude of genetic, disease, nutritional, management, and physiological issues that can dramatically alter reproductive performance. As problems associated with health and reproduction usually have multiple causes they require an integrated multidisciplinary approach to problem solving. It is essential that all those involved in 
influencing and making key decisions work as a team. Many veterinary surgeons who claim to offer a herd health service are in fact only making a routine fertility visit. Much of the veterinary practitioner's time is devoted to the biological aspects of reproduction and insufficient time is spent having an overall view of the 'big picture'. The evidence is now overwhelming that production diseases of the modern high yielding cow can only be effectively reduced when management and nutrition are given full consideration in the development of a control programme. On many farms the detailed work of rectal examination, scanning or hormone administration will be performed by the veterinary surgeon in isolation from advice being given on nutrition and management by other advisors. Large dairy farms require an integrated approach to herd management, but farmers have not looked on veterinary surgeons for production -orientated management advice. The veterinary surgeon will normally have no vested interest when giving advice about nutrition, design of new facilities or other general management issues. Thus by perceiving the veterinary surgeon only as a clinician the opportunity for an integrated, unbiased team approach is often missed. On the other hand many veterinary surgeons consider that their undergraduate education did not equip them to advise on nutrition and this requires in many cases a restructuring of the emphasis of part of the veterinary curriculum to include courses on herd health management, nutrition and economics.

The main aim of this paper is to emphasise some of the main issues influencing optimum reproduction on a herd basis and to illustrate a multidisciplinary approach to herd health and productivity management.

\section{Fertility management}

As genetic merit for production rises, studies from large populations suggest that fertility and some aspects of health are deteriorating (Pryce et al., 1998; Darwash et al., 1999). This apparent decline in fertility is occurring at a time when there have been outstanding advancements in the understanding of the biology of reproduction and its control. A deterioration in fertility appears to be taking place despite the considerable effort and resource devoted to it. It may be that the demands for lactation exceed the ability of the cow to achieve a state of metabolic equilibrium necessary for optimal reproduction (Bauman and Currie, 1980). In the UK, reduction in fertility cannot be entirely attributed to high yields. Although individual herds in the UK are achieving yields comparable to those in the US, where some states are averaging $9000 \mathrm{~kg}$ per cow per lactation with individual herds producing $>14,000 \mathrm{~kg}$ per cow (Chase, 1993), the average yield in 1997 for recorded Holstein/Friesian herds in England and Wales was 6,760 kg/yr (Dairy Facts and Figures, 1998). It is also important to note that much of the research data base on cow nutrition and fertility was derived from herds achieving relatively modest production, or extrapolated from work on beef cattle or sheep. 


\section{Factors which may affect fertility}

1 Periparturient problems such as dystocia, retained placenta or uterine infection

2 Ovarian dysfunction

3 Oestrus detection and subsequent cow management

4 Quality of semen or embryo and skill of operator in timing and application

5 Body condition change and physiological adjustment during the transition from dry to early lactation

6 Milk production and its effect on metabolism, typically characterised by negative energy balance

7 Production disease such as hypocalcaemia, hypomagnesaemia, acidosis, ketosis, mastitis or lameness

8 Nutrition, including forage quality and factors influencing dry matter intake

9 Housing with particular reference to cow comfort and welfare

The literature on many of these issues is voluminous. Many conferences and symposia are devoted to these topics and yet progress continues to disappoint. Researchers from diverse disciplines have been involved. Frequently communication between the ruminant nutritionist, the reproductive physiologist and the veterinarian is limited. 'The amazingly complex lactating cow is studied compartmentally rather than holistically' (Staples et al., 1998). Unfortunately much specialist knowledge is imparted to the farmer in a fragmented manner. Farmers tend to become confused by apparently contradictory advice often perceived to be supplied with a commercial bias.

\section{Herd health schemes}

Radostits et al. (1994) reviewed the progress that has occurred in the last twenty years in the development of production- orientated animal health, veterinary services for animal production units. There is broad agreement among veterinary surgeons, researchers and farmers regarding the components of a herd health scheme. Practising veterinary surgeons may make regular scheduled visits to herds in a health management programme to examine animals and records for evidence of subclinical disease and impaired productivity and to assess fertility. Health, fertility and production data can be analysed with assistance of a computer. The herd owner and veterinary surgeon should agree targets of performance. When a shortfall occurs, the reasons for failure may be determined using the help of specialist agricultural advisors. All components of the dairy farm, interrelate. Relationships have been established between health, fertility, nutrition, production and profitability. There are limitations in dealing with any one of these factors in isolation.

The evolution of ultrasound equipment, the refinement of rapid hormone assays and the availability of prostaglandins, progestagens and GnRH have facilitated the management of reproduction. The development of microcomputer technology has led to the development of many programmes for the dairy industry (Lissemore, 1989). Among the better known examples are DAISY (Esslemont et al., 1982); VAMPP (Noordhuizen et al., 1986), Dairy comp 305 (Goodger, 1987) and Dairy CHAMP 
(Udomprasert and Williamson, 1990). There is, however, a requirement for veterinarians to make better use of the information generated. A computer will not transform a poorly conceived herd health scheme into a successful one. The success of any herd health programme will depend almost entirely on the interaction between the veterinary surgeon and the farmer acting on and reacting to information.

Wassell and Esslemont (1992) gave a rather depressing view of the uptake of herd health schemes in the UK. A survey of 566 veterinary practices with dairy farms as clients revealed that only 15 per cent of herds were involved in routine visits and the remaining 85 per cent relied on non-routine or fire-brigade work as their only contact with a veterinarian, despite the fact that the majority of practices were very positive about the benefits of running health schemes.

Esslemont (1995) suggests that the situation is much better in the US. Brand et al. (1996a) provide a blue- print for veterinary surgeons to implement a consulting service for farm management. Studer (1998) concluded that as more research has shown that the additional needs of the high-producing cows may be a factor limiting reproduction, bovine practitioners have become more involved with dairy cow nutrition. Because of a better understanding of the dynamics of energy in the dairy cow and its effect on reproduction, fertility examinations now include nutrition monitoring and body condition scoring.

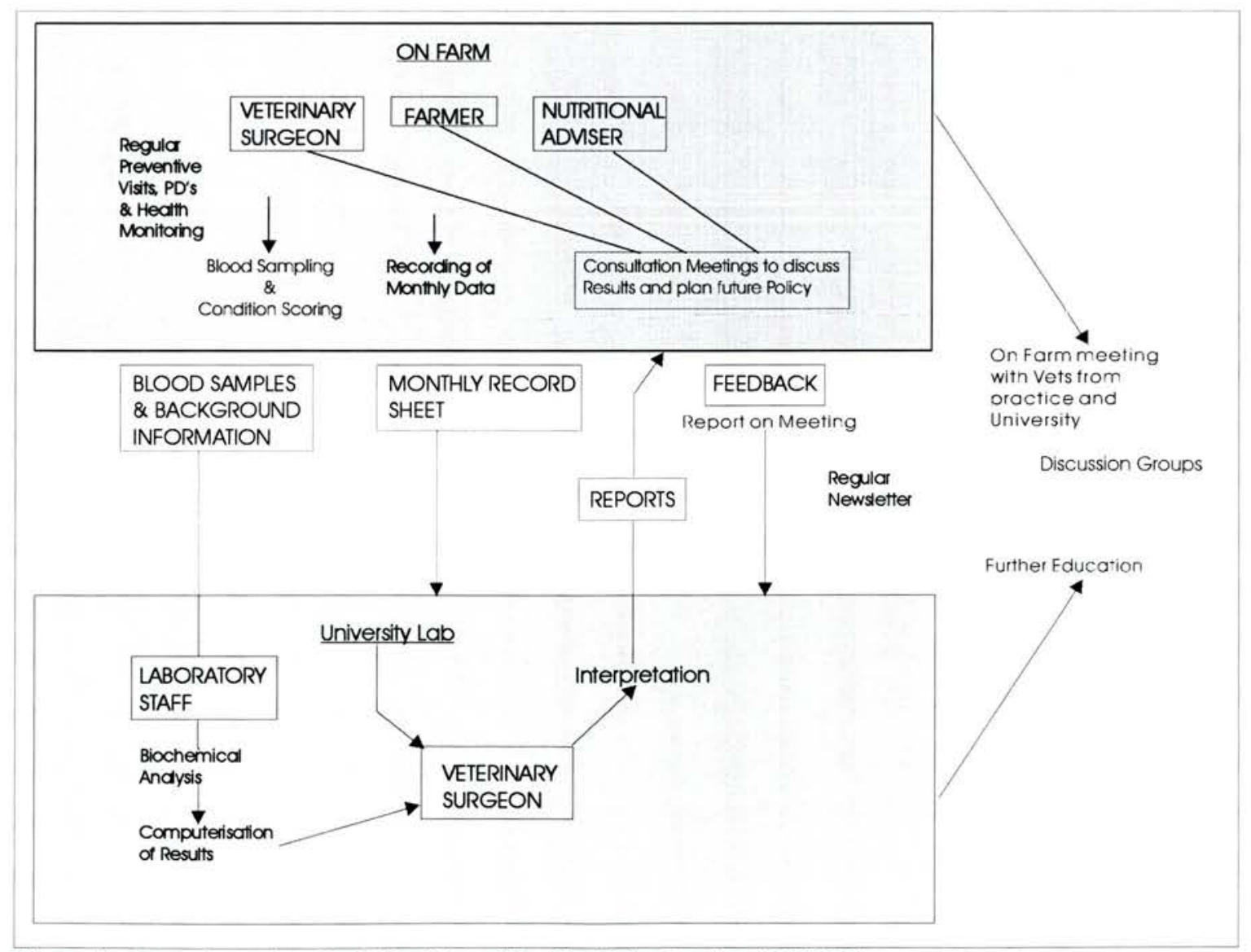

Figure 1: How the Dairy Herd Health and Productivity Service (DHHPS) operates 
A herd health and productivity service must be capable of providing regular co-ordinated measurements of disease occurrence, overall health status, adequacy of nutrition and management, productivity and economic performance and of comparing the results of these measurements with targets. It was with these principles in mind that the Dairy Herd Health and Productivity Service (DHHPS) (Figure 1), Kelly et al. (1988), was established to help the veterinary practitioner take the initiative in leading a multidisciplinary team which can identify trends and plan, where necessary, coordinated remedial action. This service which has been in operation for over twenty years has involved over 250 veterinary practices and some 1000 of the larger dairy herds throughout the UK. Herds joined this service because of their interest in nutritional monitoring and disease recording.

Data presented are from herds that supplied full monthly information for the previous 13 months. Average number of farms providing data each year from 1980-1998 was 70 (range 41-137). Average herd size was 130 (range 50-500) and average annual milk yield of 6400litres (range 4200-9500) .

Table 1: Overall percentage cows culled and primary percentage reason for culling in DHHPS herds (1980-1998)

\begin{tabular}{|c|r|r|r|r|r|r|r|r|r|r|}
\hline YEAR & $\mathbf{1 9 8 0}$ & $\mathbf{1 9 8 2}$ & $\mathbf{1 9 8 4}$ & $\mathbf{1 9 8 6}$ & $\mathbf{1 9 8 8}$ & $\mathbf{1 9 9 0}$ & $\mathbf{1 9 9 2}$ & $\mathbf{1 9 9 4}$ & $\mathbf{1 9 9 6}$ & $\mathbf{1 9 9 8}$ \\
\hline Cull rate & $\mathbf{2 0 . 8}$ & $\mathbf{1 9 . 9}$ & $\mathbf{2 5 . 0}$ & $\mathbf{2 0 . 5}$ & $\mathbf{2 1 . 9}$ & $\mathbf{2 1 . 1}$ & $\mathbf{2 3 . 6}$ & $\mathbf{2 4 . 5}$ & $\mathbf{2 9 . 0}$ & $\mathbf{2 3 . 4}$ \\
\hline Age & 12.5 & 11.0 & 8.8 & 9.8 & 11.9 & 11.4 & 9.7 & 12.3 & 14.1 & 10.7 \\
\hline Low milk yield & 20.5 & 15.1 & 14.4 & 16.1 & 12.8 & 13.2 & 10.2 & 11.8 & 12.4 & 8.5 \\
\hline Voluntary culls & $\mathbf{3 3 . 0}$ & $\mathbf{2 6 . 1}$ & $\mathbf{2 3 . 2}$ & $\mathbf{2 5 . 9}$ & $\mathbf{2 4 . 7}$ & $\mathbf{2 4 . 6}$ & 19.9 & $\mathbf{2 4 . 1}$ & $\mathbf{2 6 . 6}$ & $\mathbf{1 9 . 2}$ \\
\hline Infertility & 25.5 & 30.7 & 35.6 & 32.2 & 28.3 & 26.6 & 28.0 & 24.5 & 24.8 & 26.1 \\
\hline Mastitis & 16.0 & 17.6 & 13.2 & 11.2 & 11.4 & 13.3 & 11.9 & 14.3 & 15.5 & 14.1 \\
\hline Lameness & 4.3 & 5.0 & 5.6 & 5.8 & 5.9 & 6.6 & 5.5 & 6.1 & 6.9 & 6.8 \\
\hline Other & 21.2 & 20.6 & 22.4 & 24.9 & 29.7 & 28.9 & 34.7 & 31.0 & 26.2 & 33.8 \\
\hline Involuntary culls & $\mathbf{6 7 . 0}$ & $\mathbf{7 3 . 9}$ & $\mathbf{7 6 . 8}$ & $\mathbf{7 4 . 1}$ & $\mathbf{7 5 . 3}$ & $\mathbf{7 5 . 4}$ & $\mathbf{8 0 . 1}$ & $\mathbf{7 5 . 9}$ & $\mathbf{7 3 . 4}$ & $\mathbf{8 0 . 8}$ \\
\hline
\end{tabular}

Cull rates (Table 1) from individual farms can be influenced by many variables such as milk quota, bovine spongiform encephalopathy (BSE) and the price of cull cows. However all surveys investigating the rate of culling in dairy herds suggest that fertility, mastitis and lameness continue to be the main reasons for involuntary culling (Kelly and Whitaker 1982; Kelly et al., 1992; Esslemont and Kossaibati 1997; Seegers et al., 1998). In order to take full advantage of the economic benefits of high genetic merit the farmer would ideally replace around 18 per cent of the herd annually, having culled, on a voluntary basis because yield or age (Esslemont and Kossaibati, 1997). In practice DHHPS figures would suggest that around 23 per cent will be disposed of each year. The rate of voluntary culling (for age and yield ) has fallen over the years from 33 per cent to 19 per cent of total culls. All surveys identify infertility as the main reason for involuntary culling. DHHPS reported a 
range (24.5 to 35.6 per cent) of cows culled for that reason and Esslemont and Kossaibati (1997) 36.5 per cent. Seegers et al. (1998) in a study of French Holstein cows found that reproductive disorders accounted for 28.5 per cent of reasons for culling. The importance of good reproductive health programmes is therefore emphasised.

Table 2: Disease rates/100 cows ( 1980 - 1998)

\begin{tabular}{|c|r|r|r|r|r|r|r|r|r|r|}
\hline YEAR & \multicolumn{1}{|c|}{1980} & $\mathbf{1 9 8 2}$ & $\mathbf{1 9 8 4}$ & $\mathbf{1 9 8 6}$ & $\mathbf{1 9 8 8}$ & $\mathbf{1 9 9 0}$ & $\mathbf{1 9 9 2}$ & $\mathbf{1 9 9 4}$ & $\mathbf{1 9 9 6}$ & $\mathbf{1 9 9 8}$ \\
\hline Fertility & 27.5 & 30.7 & 25.2 & 28.4 & 28.9 & 28.9 & 30.0 & 36.0 & 44.4 & 43.2 \\
\hline Mastitis & 46.0 & 39.5 & 29.9 & 30.5 & 31.7 & 28.7 & 30.9 & 33.3 & 33.5 & 39.9 \\
\hline Lameness & 24.6 & 23.4 & 22.5 & 26.6 & 26.8 & 29.6 & 34.1 & 37.3 & 32.1 & 26.5 \\
\hline Hypocalcaemia & 10.5 & 6.0 & 5.2 & 7.8 & 7.7 & 6.1 & 6.1 & 6.9 & 5.2 & 5.8 \\
\hline Digestive Disorder & 2.3 & 1.6 & 1.2 & 1.1 & 0.9 & 0.9 & 1.3 & 1.0 & 0.9 & 2.0 \\
\hline Ketosis & 1.3 & 1.2 & 1.1 & 1.3 & 1.5 & 0.9 & 1.1 & 0.6 & 0.5 & 0.7 \\
\hline Other & 14.6 & 9.1 & 6.8 & 5.6 & 5.7 & 5.3 & 5.9 & 14.6 & 4.4 & 3.8 \\
\hline
\end{tabular}

\section{Disease rates}

\section{Fertility}

The physiological, metabolic and pathological events which occur in early lactation are crucial in influencing the subsequent reproductive performance of dairy cow. DHHPS records (Table 2) show a range of between 25.2 to 44.4 fertility treatments per 100 cows are given each year. Rates on individual farms will depend to some extent on the awareness and expertise of the herdsman and the use made of the veterinary surgeon for post- partum checks and treatments. Francosand Myer (1988) reported that in high-producing dairy herds the average incidence of primary post-partum reproductive disorders was 50.4 per cent: this included negative pregnancy diagnosis and repeat breeders. Fonseca et al. (1983) suggested that clinical abnormalities post-partum are more important than age or milk yield in their effects on reproductive performance. Among post-partum disorders, retained placenta and endometritis, in particular, had detrimental effects on fertility indices (Markusfeld, 1987; Borsberry and Dobson, 1989; Nakoa et al., 1992).

\section{Mastitis}

The clinical mastitis rate for DHHPS members over the past 18 years has fluctuated between 28 and 46 cases per 100 cows (Table 2). It has not changed very much over this period although the mean bulk milk somatic cell count has fallen from 414,800 to $139,000 / \mathrm{ml}$ milk between 1980 and 1998 . Kossaibati et al. (1998) reported 43.4 quarter-cases per 100 cows, with 1.6 per affected cow. They also suggest that little progress had been made in the last decade in reducing clinical mastitis. Although there may not be a direct association between mastitis and reproductive performance they 
may be part of a complex resulting from other conditions such as parturient paresis (Curtis et al., 1985).

\section{Lameness}

Over the period that the DHHPS has been in operation the lameness rate has varied from 22.5 (Whitaker et al., 1983a) to 37.3 cases per 100 cows. This is very similar to the 24 cases per 100 cows reported by Esslemont and Kossaibati (1996). Clarkson et al, (1996) reported an annual incidence of 54.6 new cases per 100 cows with a prevalence of 20.6. This survey used locomotion scores (Manson and Leaver, 1988), as a measurement of prevalence. In all such reports there was a wide variation between farms. Lucey et al. (1986); Collick et al. (1989); Sprecher et al. (1997) showed that lameness was associated with increased calving to first service and calving to conception intervals. Lameness before service increased the risk of oestrus not being observed (Peeler et al., 1994). It is suggested that lameness might affect reproductive performance by physically inhibiting a cow from exhibiting oestrus and by reducing food intake and hence compromising energy status. Stressinduced reductions of fertility may be mediated by effects at pituitary and hypothalamic levels to reduce LH drive of follicular growth and oestradiol production (Dobson and Smith, 1998).

\section{Hypocalcaemia (milk fever)}

The DHHPS range has been from 5.2 to 10.5 cases per 100 cows each year (Table 2). Borsberry and Dobson (1989) and Esslemont and Kossaibati (1996) reported an incidence of 9.4 and 7.7 cases per 100 cows respectively. There is a considerable body of literature which indicates that hypocalcaemia is a risk factor for several reproductive disorders including dystocia, uterine prolapse, retained placenta and metritis (Grohn et al., 1990). Risco et al (1994) reported that milk fever resulted in a delay in first ovulation and uterine involution.

\section{Digestive disorders}

The rate is not high (Table 2). This category includes acidosis and displaced abomasum. Acidosis was not found to be a risk for any reproductive disorder (Grohn et al., 1990). Digestive diseases will, however, reduce dry matter intake. Curtis et al. (1985) found that nutrition indirectly affected reproductive disorders through metabolic problems such as milk fever and left displaced abomasum.

\section{Ketosis}

DHHPS recorded a range from 0.3 to 1.5 clinical cases per year, similar to Curtis et al. (1985) and Borsberry and Dobson (1989). Clinical ketosis was associated with silent heat, cystic ovary and other infertility (Grohn et al., 1990). One clinical case of ketosis in an early lactation group will normally indicate that all the other cows in the group at a similar stage of lactation are struggling to sustain energy balance. Metabolic disease has been associated with cystic ovarian disease (Andersson et al., 
1991), anoestrous (Huszenicza et al.,1988) and reduced immunity (Ropstad et al., 1989). Prevention of periparturient and metabolic disease are important components of nutritional and fertility relationships (Ferguson, 1996).

The DHHPS data suggest that an average dairy herd of 100 cows is going to have more than 100 treatments per annum for conditions which may directly or indirectly influence subsequent reproductive performance. Some cows will have more than one disease because of the relationship between the periparturient disorders.

\section{The interaction of nutrition and fertility}

O'Callaghan and Boland (1999) reviewed nutritional effects on ovulation, embryo development and the establishment of pregnancy in ruminants. The detrimental effects of prolonged negative energy balance on reproductive performance are apparent (Butler and Smith, 1989; Canfield et al., 1990; Harrison et al., 1990; Nebel and McGilliard, 1993; Ferguson, 1996). Grummer (1995) emphasised the importance of the transition period from 3 weeks before calving to 3 weeks after calving. Pregnancy, decreased feed intake during late gestation, lactogenesis and parturition can have considerable effects on metabolism. Pre-partum feed intake is positively correlated to post-partum feed intake which is in turn related to energy status. Energy management from late gestation through the post-partum period may have significant effects on reproductive function (Ferguson, 1996).

From the point of view of monitoring herd health and fertility it has been important to seek relevant indicators of nutritional status.

\section{Calculated energy balance}

In the postpartum dairy cow, Butler et al. (1981) found a correlation between calving to first ovulation interval and the mean energy balance during the first 20 days. Energy balance also affects the numbers of follicles per cow and the pattern of follicular distribution (Lucy et al., (1991). Calculation of energy balance requires precise knowledge of inputs and requirements for maintenance and production. Accurate input calculations necessitate individually controlled feeding and detailed feed evaluation. Cow requirements will vary according to genotype and environment. This information is unlikely to be available on most commercial units.

\section{Milk yield and quality}

Milk production, both volume and constituents, butterfat and protein, give an indication of nutritional status (Sutton, 1986). The modern high yielding cow has been selected to maintain milk yield in spite of inadequate food intake by mobilising her body resources (Bauman and Currie, 1980). When milk yield and protein content finally fall the animal may have been in negative energy balance for some time. 


\section{Body condition score}

Changes in body condition score (BCS) correlate with cumulative negative energy balance and reflect total negative energy deficit. Body condition score (Lowman et al., 1973; Wildman et al., 1982) gives a useful, if historical, indication of longer term energy balance. Factors such as excess body fat that reduce intake of feed may increase the magnitude or incidence of negative energy balance (Garnsworthy and Topps, 1982). In most studies cows that lose greater amounts of body condition from calving until breeding have lower conception rates (Ferguson, 1996). Suriyasathaporn et al. (1998) indicated that loss in body condition and actual condition scores before conception or first insemination, or both, can be used as a prognosis for days open and days to first insemination in dairy herds.

In 1998 DHHPS found that in 353 herd tests, 58 per cent of the herds had a body condition score difference between dry and early lactation groups of $>0.5$, and 20 per cent $>1.0$.

\section{Blood metabolites}

Homeorhetic controls ensure body tissue, primarily adipose stores, will be mobilised to support milk production because of insufficient intake of nutrients (Bauman and Currie, 1980). This results in mobilisation of body reserves leading to hypoglycaemia and an increase in free fatty acids and ketone bodies in circulation. As energy balance is influenced by a large number of conflicting factors it is perhaps not surprising that no single marker has been shown to reflect energy status under all circumstances.

Metabolic profiles have been developed since 1970 to predict energy and other nutrient intakes by using some of these biochemical indices (Payne et al., 1970), and have been appraised under field conditions (Parker and Blowey, 1976; Kelly, 1977; Lee et al., 1978; Kronfeld et al., 1982; Ward, et al., 1995). Opinions on the value of metabolic profiles are equivocal. Abnormalities in blood composition are the result of failure in a complex biochemical interplay and the cause and effect relationships are seldom simple. The homeostatic control mechanisms within the animal, and the complex factors governing rumen function and microbial flow which affect the availability of the nutrients in the diet, may mean that direct relationships between the concentrations of blood and dietary components are sometimes unlikely. For these reasons, in practice, it is much more valuable to use blood chemistry together with nutritional assessment than if one or other is used in isolation (Manston and Allen, 1981)

\section{Energy balance}

\section{Glucose}

Although glucose was initially used as the sole predictor of energy status (Payne et al., 1970; and Parker and Blowey, 1976) the correlation is by no means precise. Plasma glucose concentrations 
remain relatively stable during the prepartum transition period, increase dramatically at calving and then decrease immediately postpartum (Vazquez-Anon et al., 1994). Low glucose results are likely to be significant but normal results may not necessarily reflect a positive energy balance. Low concentrations of plasma glucose have been associated with decreased reproductive efficiency (Harrison et al., 1990) and ovarian energy supply (Rabiee et al., 1999).

In the period 1992-98, DHHPS found that 28.5 per cent of 19,434 cows sampled between 5-42 days calved were below $3 \mathrm{mmol} / \mathrm{litre}$. Ward et al. (1995) reported that a quarter of cows calved less that 42 days had low glucose results.

\section{Beta-hydroxy butyrate (BHB)}

Beta-hydroxybutyrate (BHB) is the ketone body which is present in the greatest quantity in the blood of the normal well fed ruminant. When animals are under energy stress plasma ketones rise due to incomplete oxidation of non- esterified fatty acids. There is a close correlation between the two main ketone bodies, BHB and acetoacetate, and the concentration of BHB approximates to that of the total ketone bodies (Grohn, et al., 1983). The disadvantage of its use as a metabolic marker is the fact that as well as being produced by the liver there is also BHB production in the rumen wall (Menahan, 1966). This may account for prandial variations (Manston, et al., 1981). Kelly (1977) found that BHB concentrations did reflect changes in dietary energy intake. Russel et al. (1979) in trials with suckler cows found BHB concentrations in late pregnancy were closely and inversely related to energy intake. Herdt (1981) concluded that plasma glucose and BHB were not accurate indicators of energy balance but conceded that BHB might be used as an indicator of the relative glucogenic potential of dairy rations and that this metabolite could be used to adjust factors in the ration which influence glucose availability. Grohn et al. (1983) established cut-off points for BHB in dairy cows - healthy below $1 \mathrm{mmol} / \mathrm{l}$, mildly ketotic $1-3$ and severely ketotic over 3 , agreeing with normal range (Whitaker et al. 1983b). Plasma ketone concentrations mirror hepatic triglyceride concentrations and may increase during the post-partum period (Veenhuizen et al., 1991).

From 1992-98, DHHPS found $34.3 \%$ of 9,235 dry cows, sampled $0-14$ days before calving and 28 per cent of 20,502 cows between 5-40 days post calving, had raised BHB results. Ward et al. (1995) also found one third cows in post partum groups had raised BHB blood concentrations.

\section{Non- esterified fatty acids (NEFAs)}

Mobilisation of body reserves during periods of negative energy balance results in an increase in blood concentration of NEFA. This parameter would appear to be most useful during the transition phase from late pregnancy to early lactation (Huszenicza et al., 1988; Whitaker et al., 1993). Gerloff 
(1988) advocated reducing stress, maximising quality roughage intake and avoidance of body condition loss as being important in avoiding high plasma NEFA concentrations associated with fatty liver. Dry matter intake around calving was highly correlated to plasma NEFA (Grummer, 1995). Studer et al. (1993) found pre-partum plasma glucose, NEFA and BHB were closely correlated with liver triglyceride at day 1 post-partum. Nutritional strategies to minimise the elevation in plasma NEFA prior to calving results in lower liver triglyceride at calving with a reduction in susceptibility to ketosis. Harrison et al. (1990) found that both BHB and NEFA were correlated negatively with energy balance and suggested that they may provide general indications of overall energy status.

Using the optimum range of $<0.4 \mathrm{mmol} /$ litre for cows at the end of pregnancy and $<0.7$ for milking cows, (Whitaker et al., 1993) DHHPS found that between 1992-98, 30.6 per cent of 9,235 dry cows, and 21.9 per cent of 20,502 early lactation cows sampled had elevated NEFA results.

In monitoring the transition period from pre to post-partum a combination of NEFA, BHB and plasma glucose have been found useful in the practical 'on farm' situation. Comparison with cows calved $>100$ days makes interpretation of results more reliable.

\section{Indicators of protein status}

\section{Urea}

Lee et al. (1978) confirmed the relationship between protein intake and blood urea. Blood urea may also reflect the protein/energy balance of the ration and elevated blood urea concentration may occur as a result of insufficient energy in the diet to allow the rumen microbes to utilise all the rumendegradable protein available. O'Callaghan and Boland (1999) suggested that there was strong evidence in the literature to associate high dietary crude protein with decreased pregnancy rates in lactating cows (Ferguson and Chalupa, 1989; Canfield et al., 1990; Butler et al., 1996). They proposed that the mechanism affecting the reproductive process may be primarily operating at the level of the oocyte. Staples et al. (1995) suggested that elevated intakes of protein may exert its effect through increased energy costs to the animal. Whitaker (1998) concluded that the evidence of causal links between high blood urea and poor fertility was equivocal. Barton et al. (1996) found that a high crude protein diet only influenced fertility when cows also had post-parturient health problems. When cows were sampled on the day of insemination Trevaskis and Fulkerson (1999) found no evidence that high milk urea was associated with poor reproductive performance in dairy cows grazing pasture.

DHHPS found that 25 per cent of 20,554 cows from 5-42 days post partum had blood urea nitrogen (BUN)concentrations above $3.3 \mathrm{mmol} / 1$ which Butler et al. (1996) quoted as associated with decreased pregnancy rates. 


\section{Trace elements}

Controlled trial evidence is generally not available proving that trace element imbalance affects the fertility of dairy cows (Whitaker 1999). The exceptions are high dietary molybdenum (Phillippo et al., 1987) and selenium. Increased dietary selenium and Vitamin $\mathrm{E}$ has been reported as being beneficial in lowering the incidence of retained placenta and improving immune status (Trinder $e t$ al., 1969; Hurley and Doane, 1989). DHHPS, using GSH-Px as an indicator of selenium status, found newly calved heifers more commonly have low results, probably reflecting a low dietary selenium intake during the last third of pregnancy. DHHPS found 16.3 per cent of 1,206 heifers and 4.9 per cent of 6,998 cows had low GSH-Px results. Deficiencies of copper, manganese, iodine and cobalt have been associated with poor fertility but much of the evidence is anecdotal.

In summary, metabolic profiling may assist in identifying possible nutritional imbalances, but is only likely to be effective when it is carried out as part of a full, systematic investigation of the nutritional status of the herd. Interpreting blood results without full use of background information can be unrewarding and even misleading. Blood sampling should not be looked on as a 'quick fix'. There can be no substitute for observing cows feeding and resting, and assessing their general welfare and environment. Social dominance and competition for food can markedly influence dry matter intake (Grant and Albright, 1995). Important basic procedures such as examination of the faeces may give invaluable information regarding the balance of a diet (Brand et al., 1996b). Water is an essential nutrient although it is frequently overlooked (Beede, 1991). Cows will commonly drink after milking and many cows will be prevented from doing this by being immediately confined to an AI stall for several hours!

By far the most common nutritional cause of reproductive inefficiency is likely to be energy imbalance. Less common and less fully evaluated would be protein/energy imbalance which may be caused by excessive protein in the diet. Trace element and vitamin deficiencies would be much further down the list, but in practice, because their involvement is not clearly understood, they are often considered, erroneously, at farm level to be the sole solution to the complex problem of unsatisfactory reproductive performance.

\section{Conclusions}

Periparturient health and nutrition play an important part in reproductive performance. Undoubtedly there will be an interaction between nutrition and health status and calving to conception interval. In the majority of herds in UK and Ireland health and nutritional management will have a much greater influence on fertility than high yield. Post- parturient health problems are extremely common and may directly or indirectly influence reproductive performance. Nutritional management often focuses entirely on production requirements. It is apparent that nutrition plays not just a preventive but a dynamic role in metabolic and infectious disease. Many routine veterinary fertility visits still tend to concentrate on the biological aspects of fertility control. These visits are, however, a good starting point for the establishment of a more holistic health scheme. 
The period of transition between late pregnancy and early lactation presents an enormous metabolic challenge to the high yielding cow. Failure to respond adequately can result in a series of post-partum health problems many of which may compromise future reproductive performance. Evidence supports the concept of the late gestation period being a critical component in preparation for lactation. Post-partum energy supply appears to be essential for optimal reproductive function, and is dependent on the health, management, nutrition and change in body condition score over the transition period from three weeks pre-partum to three weeks post partum. The difference between cows in negative energy balance is more likely to be related to how much they can eat than how much milk they give. It may be more desirable to select animals which depend less on mobilised tissue and more on extra dry matter intake to supply energy for milk production. More research on factors controlling dry matter intake in early lactation is required. Dietary management assessment, condition scoring and blood profiling can have an important part to play in fulfilling the objective of minimising fat mobilisation and negative energy balance at this critical stage. This is equally, if not more important, than post calving examination of the reproductive tract in achieving satisfactory fertility. Veterinarians, nutritionists and research workers must recognise the interrelationship of metabolic changes at parturition, and health and fertility.

Research in reproduction must be translated to the producer in practical terms that can be related to enhanced performance and profitability. To be successful any fertility or health scheme must have clear objectives and well defined goals or targets. There must be regular progress reviews and reports. A herd health programme should encompass issues such as disease prevention as well as fertility, nutrition, production management and welfare. A multidisciplinary approach has many advantages especially when dealing with these issues, which are at the interface of the disciplines of those giving the advice. Farmers will have to be convinced of the value of such an approach. The assumption that biological targets are equal to economic targets should not always be made! Only by having a well defined, practical, on farm approach can scientific knowledge relating to reproductive performance be put into practice.

\section{Acknowledgements}

The authors acknowledge the cooperation received from farmers and veterinary surgeons who participate in the DHHPS and Dalgety Agriculture for financial and technical support. Thanks are due to Sandra Smith and Cathy Bertram for assistance in data processing and preparation of reports and Alex Dowell for his technical expertise in the laboratory.

\section{References}

Andersson, L., Gustafsson, A.H. and Emanuelson, U. 1991. Effect of hyperketonaemia and feeding on fertility in dairy cows. Theriogenology, 36: 521-536. 
Barton, B.A., Rosario, A.H., Anderson, G.W. Grindle, B.P., and Carrol, D.J. 1996. Effects of dietary crude protein, breed, parity and health status on the fertility of dairy cows. Journal of Dairy Science 79: 2225-2236.

Bauman, D.E. and Currie, W.B. 1980. Partitioning of nutrients during pregnancy and lactation: a review of mechanisms involving homeostasis and homeorhesis. Journal of Dairy Science. 63: $1514-1529$.

Beede, D.K. 1991. Mineral and water nutrition. Veterinary Clinics North America: Food Animal Practice 7: 373-390.

Borsberry, S. and Dobson, H. 1989. Periparturient diseases and their effect on reproductive performance in five dairy herds. Veterinary Record. 124: 217-219.

Brand, A. Noordhuizen, Y.H. and Schukken 1996a in Herd Health and Production Management in Dairy Practice Wageningen Pers.

Brand, A. Noordhuizen, Y.H. and Schukken 1996b in Herd Health and Production Management in Dairy Practice Wageningen Pers pp 249-253

Butler, W.R., Everett, R.W. and Coppock, C.E., 1981 The relationships between energy balance, milk production and ovulation in postpartum Holstein cows. Journal of Animal Science 53: 742-748

Butler, W.R. and Smith, R.D. 1989. Interrelationships between energy balance and postpartum reproductive function in dairy cattle. Journal of Dairy Science 72: 767-783.

Butler, W.R., Calman, J. and Beam, S.W. 1996. Plasma and milk urea nitrogen in relation to pregnancy rate in lactating dairy cattle. Journal of Animal Science 74: no 4858 -865.

Canfield, R.W., Sniffen, C.J. and Butler, W.R. 1990. Effects of excess degradable protein on post partum reproduction and energy balance in dairy cattle. Journal of Dairy Science 73: 23422349.

Chase, L.E. 1993 Developing nutrition programs for high producing dairy herds. Journal of Dairy Science 76: 3287-3293.

Clarkson, M.J., Downham, D.Y., Faull, W.B. Hughes, J.W., Manson, F.J., Merritt, J.B., Murray, R.D., Russell, W.B., Sutherst, J.E., and Ward, W.R. 1996. Incidence and prevalence of lameness in dairy cattle. Veterinary Record 138: 563-7.

Collick, D.W., Ward, W.R. and Dobson, H. 1989. Associations between types of lameness and fertility. Veterinary Record 125: 103-106.

Curtis, C.R., Hollis, N., Erb, H.N., Sniffen, C.J., Smith, R.D. and Kronfield, D.S. 1985 Path analysis of dry period nutrition, post partum metabolic and reproductive disorders and mastitis in Holstein cows Journal of Dairy Science 68: 2347-2360

Dairy Facts \& Figures. 1998. National Dairy Council, 5-7 John Princes Street London

Darwash, A.O., Lamming, G.E. and Woolliams. 1999. The potential for identifying heritable endocrine parameters associated with fertility in post-partum dairy cows. Animal Science 68: 333-347.

Dobson, H. and Smith, R.F. 1998. Stress and subfertility. Reproduction in Domestic Animals 33: No 3-4 pp 107-111. 
Esslemont, R.J., Stephens, A.J. and Ellis, P.R. 1982. The design of DAISY the dairy information system. Proceedings 12th World Conference of. Diseases of Cattle, Amsterdam 634-646.

Esslemont, R.J. 1995. Economic appraisal of herd health schemes. Veterinary Annual 35: 243-280.

Esslemont, R. J. and Kossaibati, M.A. 1996. Incidence of production diseases and other health problems in a group of dairy herds in England. Veterinary Record. 139: 486-490.

Esslemont, R.J. and Kossaibati, M.A. 1997. Culling in 50 dairy herds in England. Veterinary Record. 140: 36-37.

Ferguson, J.D. and Chalupa, W. 1989. Symposium: Interactions of nutrition and reproduction; Impact of protein nutrition on reproduction in dairy cows. Journal of Dairy Science 72: 746-766.

Ferguson, J.D. 1996. Diet, production and reproduction in dairy cows. Animal Feed Science Technology 59: 173-184.

Fonseca, F.A., Britt, J.H., McDaniel, B.T., Wilk, J.C. and Rakes, A.H. 1983. Reproductive traits of Holsteins and Jerseys. Effects of age, milk yield and clinical abnormalities on involution of the cervix and uterus, ovulation, oestrus cycles, detection of oestrus, conception rates and days open. Journal of Dairy Science. 66: 1128-1147

Franco, G. and Myer, E. 1988. Analysis of fertility indices of cows with extended postpartum anoestrus and other reproductive disorders compared to normal cows. Theriogenology 29: 99- 412 .

Garnsworthy, P.C. and Topps, J.H. 1982. The effects of body condition at calving, food intake and performance in early lactation on blood composition of dairy cows given complete diets. Animal Production 35: 121-125.

Gerloff, B.J. 1988. The dry cow - resting and transitional phase. In: Veterinary Clinics of North America: Food Animal Practice 4: 379-390.

Goodger, W. 1987. Dairy comp 305 program. Veterinary Clinics of North America: Food Animal Practice 3: 553-560.

Grant, R.J. and Albright, J.L. 1995. Feeding behaviour and management factors during the transition period in dairy cattle. Journal of Animal Science 73: 2791-2803.

Grohn, Y., Lindberg, L.A., Bruss, M.L. and Farver, T.B. 1983. Fatty infiltration of the liver in spontaneously ketotic dairy cows. Journal of Dairy Science 66: 2320-2328.

Grohn, Y.T., Erb, H.N., McCulloch, C.E. and Saloniemi, H.S. 1990. Epidemiology of reproductive disorders in dairy cattle: associations among host characteristics, disease and production. Preventive Veterinary Medicine 8:25-39.

Grummer, R. 1995. Impact of changes in organic nutrient metabolism on feeding the transition dairy cow. Journal of Animal Science 73: 2820-2833.

Harrison, R.O., Ford, S.P., Young, J.W., Conley,A.J. and Freeman, A.E. 1990. Increased milk production versus reproduction and energy status of high producing cows. Journal of Dairy Science. 73 :2749-2758. 
Herdt, T.H., Stevens, J.B., Linn, J. and Larson, V. 1981. Influence of ration composition and energy balance on blood B-hydroxybutyrate (ketone) and plasma glucose concentrations of dairy cows in early lactation. American Journal of Veterinary Research 42: 1177-1180.

Hurley, W.L. and Doane, R.M. 1989. Recent developments in the roles of vitamins and minerals in reproduction. Journal of Dairy Science 72: 784-804.

Huszenicza, G., Haraszti, J., Molnar, L. and Solti, J. 1988. Some metabolic characteristics of dairy cows with different postpartum ovarian function. Journal Veterinary Medicine 35: 506-515.

Kelly, J.M. 1977. Changes in serum B Hydroxybutyrate concentrations in dairy cows kept under commercial farm conditions. Veterinary Record. 101: 499-502.

Kelly, J.M. and Whitaker, D.A. 1982. A Dairy Herd Health and Productivity Service. Proceedings of the XII ${ }^{\text {th }}$ World Congress on Diseases of Cattle 1: 659-663.

Kelly, J.M., Whitaker, D.A. and Smith, J.E. 1988. A Dairy Herd Health and Productivity Service. British Veterinary Journal. 144: 470-481.

Kelly, J.M., Whitaker, D.A. and Smith, J.E. 1992. The changing pattern of health problems since the introduction of milk quotas. Proceedings XV11 World Buiatrics Congress 2 51-56.

Kossaibati, M.A., Hovi, M. and Esslemont, R.J. 1998. Incidence of clinical mastitis in dairy herds in England. Veterinary Record 143: 649-653.

Kronfeld, D.S., Donoghue, S., Copp, R.L., Stearns, F. M. and Engle, R.H. 1982. The nutritional status of dairy cows indicated by analysis of blood. Journal of Dairy Science 65: 1925-1933.

Lee, A.J., Twardock, A.R. and BuBar, R.H. 1978. Blood metabolic profiles: Their use and relation to nutritional status of dairy cows. Journal of Dairy Science . 61: 1652-1670.

Lissemore, K.D. 1989. The use of computers in dairy health programs: A review. Canadian Veterinary Journal 30: 631-636.

Lowman, B. G., Scott, N. and Sommerville, S 1973. Condition scoring of cattle. East of Scotland College of Agriculture Bulletin, No 6.

Lucey, S., Rowlands, C.J. and Russel, A.M. 1986. The association between lameness and fertility in dairy cows Veterinary Record 118: 628-631

Lucy, M.C., Staples, C.R., Michel, F.M. and Thatcher, W.W. 1991. Energy balance and size and number of ovarian follicles detected by ultra sonography in early postpartum cows. Journal of Dairy Science 74: 473-482.

Manson, F.J. and Leaver, J.D. 1988 The influence of concentrate amount on clinical lameness in dairy cattle Animal Production 47: 185-190

Manston, R. and Allen, W. M. 1981. The use of blood chemistry in monitoring the health of farm livestock. British Veterinary Journal. 137: 241-247.

Manston, R. , Rowlands, G. J. , Little, W. and Collis, K. A. 1981. Variability of the blood composition of dairy cows in relation to the time of day. Journal Agricultural Science. Cambridge 96: 593-598. 
Markusfeld, O. 1987. The periparturient traits in seven high yielding dairy herds. Incidence rates, associated with parity, and interrelationships among traits. Journal of Dairy Science. ,70:158-166.

Menahan, L.A., Shultz, L.H. and Hoehstra,W.G. 1966. Factors affecting ketogenesis from butyric acid in the ruminant. Journal of Dairy Science. 49: 835-845.

Nakoa, T., Moriyoshi, M. and Kawata, K. 1992. The effect of postpartum ovarian dysfunction and endometritis on subsequent reproductive performance in high and medium producing dairy cows. Theriogenology 37: 341-349.

Nebel, R.L. and McGilliard, M.L. 1993. Interactions of high milk yield and reproductive performance in dairy cows. Journal of Dairy Science 76: 32573268.

Noordhuizen, J.P.T.M., Buurman, J., Wilbrink, H.J. and Dobbelaar, P. 1986. VAMPP: A computer program to support veterinary herd health and production control on dairy farms. Proceedings of the $X 1 V^{\text {th }}$ World Congress on Buiatrics, 1: $260-265$.

O'Callaghan, D. and Boland, M.P. 1999. Nutritional effects on ovulation, embryo development and the establishment of pregnancy in ruminants. Animal Science 68: 299-314.

Parker, B.J.N. and Blowey, R.W. 1976. Investigations into the relationship of selected blood components to nutrition and fertility of the dairy cow under commercial farm conditions. Veterinary Record. 96: 394-404.

Payne, J.M. , Dew, A.W. , Manston, R. and Faulks, M. 1970. The use of metabolic profile test in dairy herds. Veterinary Record 87: 150-158.

Peeler, E.J. Otte, M.J. and Esslemont, R.J. 1994. Interrelationships of periparturient diseases of dairy cows. Veterinary Record 134 : 129-132.

Phillippo, M., Humphries, W.R, Atkinson, T., Henderson, G.D. and Garthwaite, P.H. 1987. The effect of dietary molybdenum and iron on copper status, puberty, fertility and oestrus cycles in cattle. Journal of Agricultural Science Cambridge 109: 321-36.

Pryce, J.E., Esslemont, R.J., Thomson, R., Veerkamp, R.F. and Kossaibati, M.A. 1998. Estimation of genetic parameters using health, fertility and production data from a management recording system for dairy cattle. Animal Science 66: Part 3 pp 577-584.

Rabiee, A.R., Lean, I.J., Gooden, J.M. and Miller, B.G. 1999. Relationships among metabolites influencing ovarian function in the dairy cow. Journal of Dairy Science. 82: 39-44.

Radostits, O. M. Leslie, K.E. and Fetrow, J. 1994 in Herd health: Food Animal Production Medicine 2nd edition W.B Saunders Company pp 1-24.

Risco, C.A., Drost, M., Thatcher, W.W., Savio, J. and Thatcher, M.J. 1994. Effects of calving related disorders on prostaglandin, calcium, ovarian activity and uterine involution in postpartum dairy cows. Theriogenology 42: 183-203.

Ropstad, E., Larsen, H.J. and Refsdal, A.O. 1989. Immune function in dairy cows related to energy balance and metabolic status in early lactation. Acta Veterinaria. Scandinavica. 30: 209-219. 
Russel, A.J.F., Peart, J.N., Eadie, J., Macdonald, A.J. and White, I.R. 1979. The effect of energy intake during late pregnancy on the production from two genotypes of suckler cow. Animal Production. 28: 309-327.

Seegers, H., Beaudeau, F., Fourichon, C. and Bareille, N. 1998. Reasons for culling in French cows. Preventive. Medicine. 36: 257-271.

Sprecher, D.J., Hostetler, D.E., and Kaneene, J.B. 1997. A lameness scoring system that uses posture and gait to predict dairy cattle reproductive performance. Theriogenology 47: No 6 pp 1179-1187.

Staples, C.R., Burke, J.M. and Thatcher, W.W. 1998. Influence of supplemental fats on reproductive tissues and performance of lactating cows. Journal of Dairy Science 81: 856871.

Staples, C.R., Thatcher, W.W. and Burke, J.M. 1995. Influences of dietary energy, fat, and protein on reproductive performance of lactating dairy cows. Proceedings $1 X^{\text {th }}$ International Conference on Production Diseases in Farm Animals 204-221.

Studer, E. 1998. A veterinary perspective of on-farm evaluation of nutrition and reproduction. Journal of Dairy Science 81: 872-876.

Studer, V.A., Grummer, R.R. and Bertics, S.J. 1993. Effect of prepartum propylene glycol on periparturient fatty liver in dairy cows. Journal of Dairy Science 76: 2931-2939.

Suriyasathaporn, W., Nielen, M., Dieleman, S.J., Brand, A., Noordhuizen-Stassen, E,N., and Schukken, Y.H. 1998. A Cox proportional-hazards model with time-dependent covariates to evaluate the relationship between body condition score and the risks of first insemination and pregnancy in a high producing dairy herd Preventive Veterinary Medicine 37:159-172

Sutton J.D. 1986 Milk Composition. In Principles and Practice of Feeding Dairy Cows NIRD Technical Bulletin No 8. pp 203-218

Trevaskis, L.M. and Fulkerson, W.J. 1999. The relationships between various animal and management factors and milk urea and its association with reproductive performance of dairy cows grazing pasture. Livestock Production Science 57: No 3 pp 255-265.

Trinder, N., Woodhouse, C.D. and Renton, C.P. 1969. The effect of Vitamin E and selenium on the incidence of retained placentae in dairy cows. Veterinary Record 85: 550-553.

Udomprasert, P. and Williamson, N.B. 1990 A computerized recording system for dairy herds. Veterinary Record 127: 256-262

Vazquez-Anon, M. , Bertics, S., Luck, M. and Grummer, R.R. 1994. Peripartum liver triglyceride and plasma metabolites in dairy cows. Journal Dairy Science 77: 1521-1528.

Veenhuizen, J.J., Drackley, J.K., Richard, M.J., Sanderson, T.P., Miller, D.L. and Young, J.W. 1991. Metabolic changes in blood and liver during the development and the treatment of experimental fatty liver and ketosis in cows. Journal Dairy Science. 74: 4238-4253.

Ward, W.R., Murray, R.D., White, A.R. and Rees, E.M. 1995. The use of blood biochemistry for determining the nutritional status of dairy cows. In Recent Advances in Animal Nutrition Nottingham University Press Ed Garnsworthy, P.C. and Cole, D.J.A. pp 29-51 
Wassell, T.R. and Esselmont, R.J. 1992. Survey of the operation of dairy herd health schemes by veterinary practices in the United Kingdom. Veterinary Record. $130: 260-263$.

Whitaker, D.A., Kelly, J.M. and Smith, E.J. 1983a. Incidence of lameness in dairy cows. Veterinary Record $113:$ 60-62.

Whitaker, D.A., Kelly, J.M. and Smith, E.J. 1983b. Sub-clinical ketosis and serum betahydroxybutyrate levels in dairy cattle. British Veterinary Journal 139: 462-463.

Whitaker, D.A., da Rosa, G.O., Smith, E. and Kelly, J.M. 1993. Some effects of nutrition and management on the fertility of dairy cattle. Veterinary Record 133: 61-64.

Whitaker, D.A. 1998. Are links between blood urea and fertility in cattle a diversion from reality? Cattle Practice 6: part 4 pp 399-403.

Whitaker, D.A. 1999 Trace elements-The real role in dairy cow fertility. Cattle Practice 7: part 3 pp 239-242.

Wildman, E.E., Jones, G.M. and Wagner, P.E. 1982. A dairy cow -body condition scoring system and its relationship to selected production characteristics. Journal of Dairy Science. 65: 494: 501 